Florida International University FIU Digital Commons

6-24-2015

\title{
Writers' Club: The Effect of Extra Writing on Fourth-Grade, Hispanic Students' Writing, and Their Attitude Towards Writing
}

Helen F A Barnes

hbarn001@fiu.edu

DOI: $10.25148 /$ etd.FIDC000117

Follow this and additional works at: https://digitalcommons.fiu.edu/etd

Part of the Curriculum and Instruction Commons

\section{Recommended Citation}

Barnes, Helen F A, "Writers' Club: The Effect of Extra Writing on Fourth-Grade, Hispanic Students' Writing, and Their Attitude Towards Writing" (2015). FIU Electronic Theses and Dissertations. 2183.

https://digitalcommons.fiu.edu/etd/2183 


\title{
FLORIDA INTERNATIONAL UNIVERSITY \\ Miami, Florida
}

\section{WRITERS' CLUB: THE EFFECT OF EXTRA WRITING ON FOURTH-GRADE, HISPANIC STUDENTS' WRITING, AND THEIR ATTITUDE TOWARDS WRITING}

\author{
A dissertation submitted in partial fulfillment of the \\ requirements for the degree of \\ DOCTOR OF EDUCATION \\ in \\ CURRICULUM AND INSTRUCTION
}

by

Helen Felicity Angela Barnes 
To: Dean Delia C. Garcia

College of Education

This dissertation, written by Helen Felicity Angela Barnes, and entitled Writers' Club: The Effect of Extra Writing on Fourth-Grade, Hispanic Students' Writing, and their Attitude towards Writing, having been approved in respect to style and intellectual content, is referred to you for judgment.

We have read this dissertation and recommend that it be approved.

Leonard B. Bliss

Erskine Dottin

Lynne D. Miller

Joyce C. Fine, Major Professor

Date of Defense: June 24, 2015

The dissertation of Helen Felicity Angela Barnes is approved.

Dean Delia C. Garcia

College of Education

Dean Lakshmi N. Reddi

University Graduate School

Florida International University, 2015 
(C) Copyright 2015 by Helen Felicity Angela Barnes

All rights reserved. 


\section{DEDICATION}

I dedicate this dissertation to my husband, Stephen Barnes, without whose constant, loving, support, and patience it would never have been achieved; and to my children, Helen and William, who have willed me through the process. I further dedicate it to my parents George and Helen Collier, who have encouraged me, and finally, to my maternal grandmother, Audrey Hopkins, who, to this day, I can feel tapping me on the knee, and hear saying, "Education is what is important." 


\section{ACKNOWLEDGMENTS}

My thanks go to my committee for their guidance and support. Dr. Joyce Fine, my advisor through my journey to my Masters, and my major professor through my doctorate. Over the years, you have become not just my academic guide and mentor but my friend and advocate. Whenever I faced what I thought of as insurmountable obstacles, you talked me down off the cliff and set me back on the right path. Without your support I doubt I would have achieved this, my dream. Dr. Lynne Miller, for your time and invaluable feedback, you have been a sounding board for my ideas and led me to clearer thinking. Dr. Leonard Bliss, you opened my mind to a foreign area of study. Your classes, encouragement, and insistence that I achieve all that I can have instilled in me a thorough enjoyment in exploring the quantitative analysis of data, that I believed was beyond me. Without your backing it would not have been possible. Dr. Erskine Dottin, since 2003, when I took Social, Historical and Philosophical Foundations of Education, I have been the recipient of your support and many hugs, that have been much appreciated.

I would also like to thank Dr. Linda Bliss for your expertise and highly-valued feedback. 


\begin{abstract}
OF THE DISSERTATION
WRITERS' CLUB: THE EFFECT OF EXTRA WRITING ON FOURTH-GRADE, HISPANIC STUDENTS' WRITING, AND THEIR ATTITUDE TOWARDS WRITING
\end{abstract}

by

Helen Felicity Angela Barnes

Florida International University, 2015

Miami, Florida

Professor Joyce C. Fine, Major Professor

Nationally, as well as at state and local level, 75\% of students in Grades 4, 8 and 12 have been determined to be writing at the basic or below basic level. In 2012, the standards were made more stringent for the incorporation of details and adherence to customary English conventions. After that, students' writing scores plummeted. Hispanic students scored more poorly than their White counterparts. Earlier studies indicated that students' attitude towards writing becomes less positive as they progress through the grades. The purpose of the study was to examine the effect of extra writing on 60 fourth-grade, Hispanic students' writing, and their attitude towards writing through participation in a Writers' Club versus an At Home Writing Group or a group with no extra writing.

The study followed a quasi-experimental, pretest-posttest, non-equivalent group design. The groups were the Writers' Club $(n=22)$, the At Home Writing Group $(n=18$ and no extra writing $(n=20)$. All students received regular writing instruction and homework. The Writers' Club met 24 times for 30 minutes each meeting, over an 8-week period. Pretest and posttest writing samples were evaluated using Spandel's 
Teacher Six-Point Writing Guide and attitude towards writing was evaluated using Kear, Coffman, McKenna, and Ambrosio's Writing Attitude Survey.

A univariate analysis of covariate was conducted on the pretest and posttest writing samples and responses to the Writing Attitude Survey protocol. The independent variable was group membership, the dependent variable was the posttest scores and the covariate was the pretest scores. The writing samples were examined for three conditions: incorporation of details (ideas), adherence to the conventions of customary English and overall writing skill.

The results of the current study showed no significant difference in fourth-grade, Hispanic students' writing or their attitude towards writing based on group membership. The conclusions of the study are that the results were potentially compromised by a variety of limitations and that it may have been conducted over too short a period for positive effects to be seen. The conclusion is that further research is warranted with adjustments to the setting and the timeframe. 


\section{TABLE OF CONTENTS}

CHAPTER

PAGE

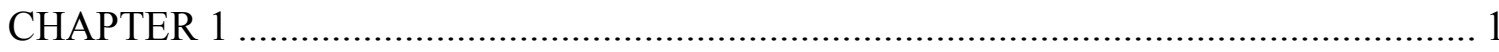

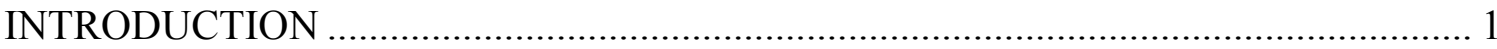

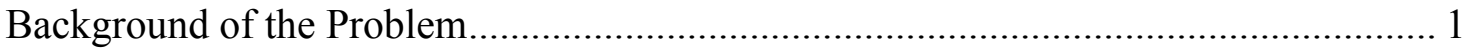

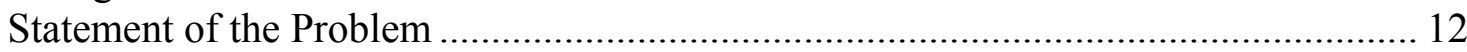

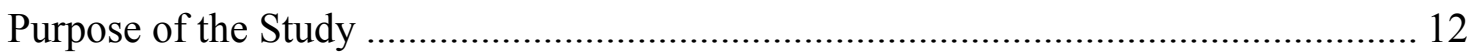

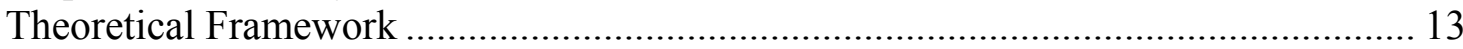

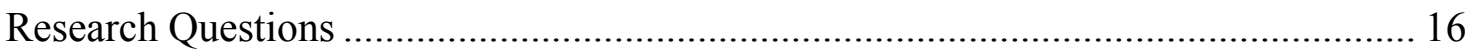

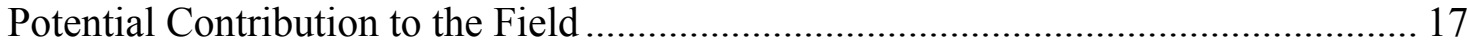

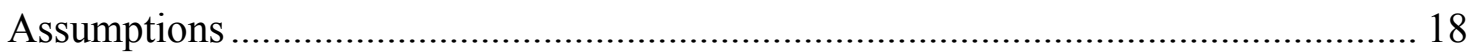

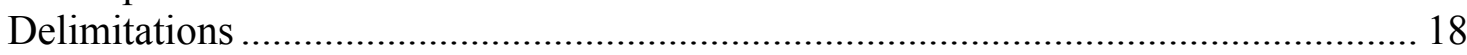

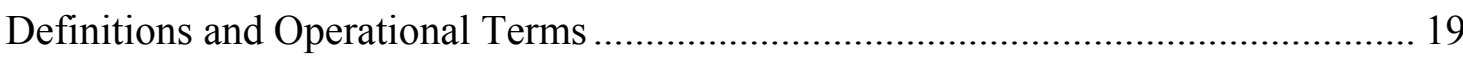

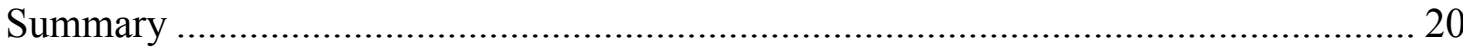

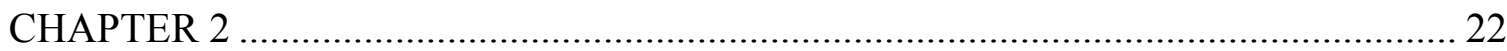

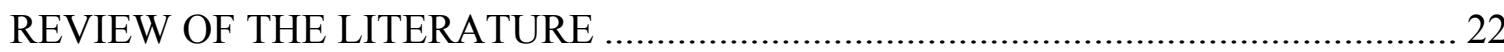

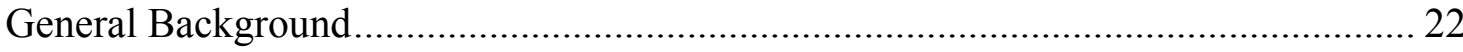

State of Students' Current Writing Proficiency ......................................................... 23

Standards - Common Core State Standards and Florida State Standards...................... 25

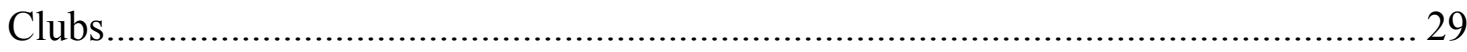

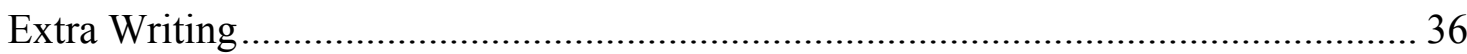

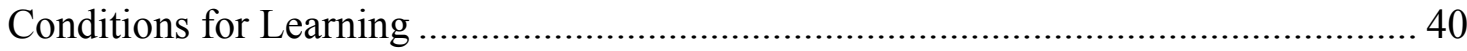

6 Trait Writing for Assessment and Instruction ......................................................... 46

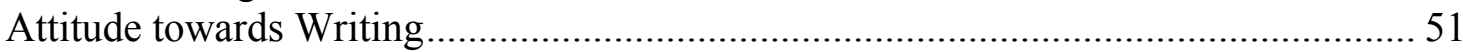

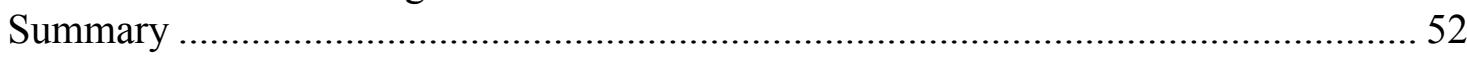

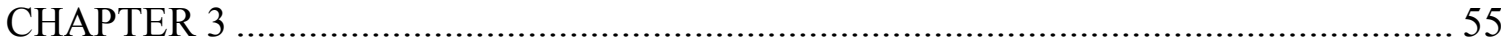

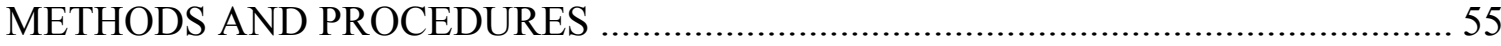

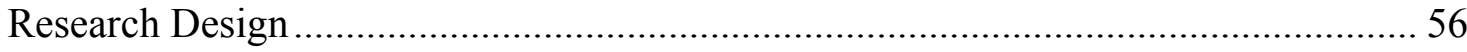

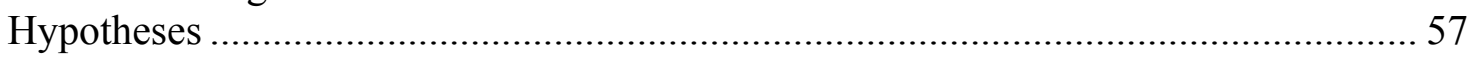

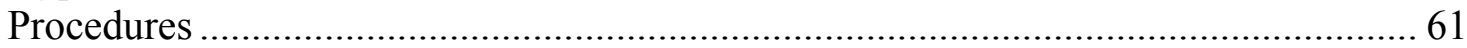

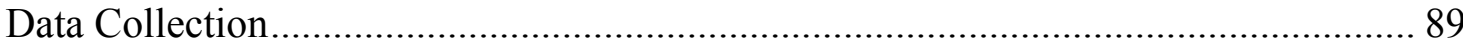

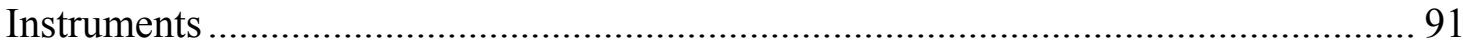

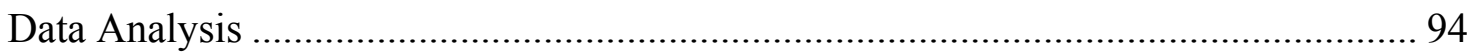

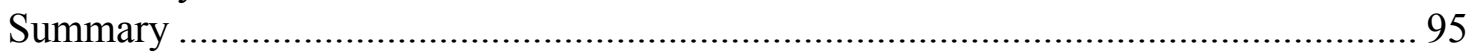

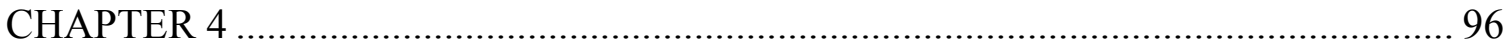

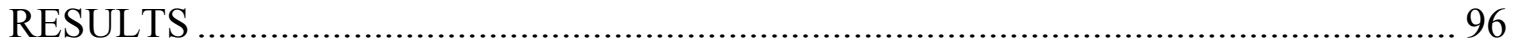

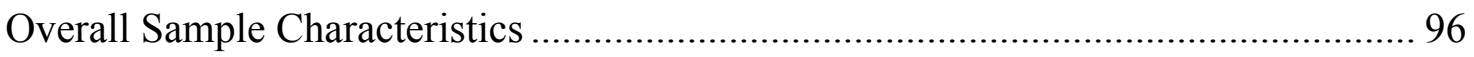

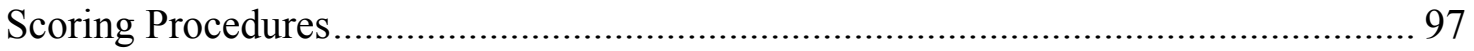

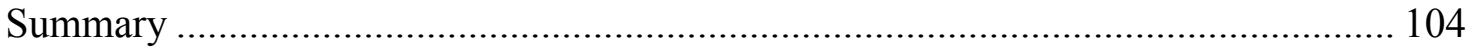




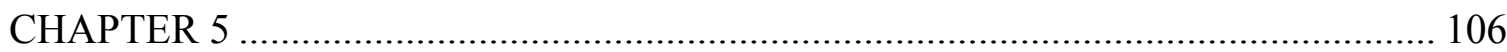

CONCLUSIONS, IMPLICATIONS AND DISCUSSION ...................................... 106

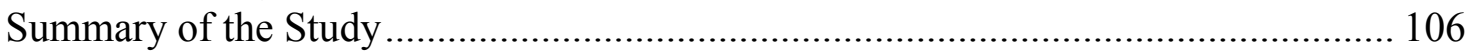

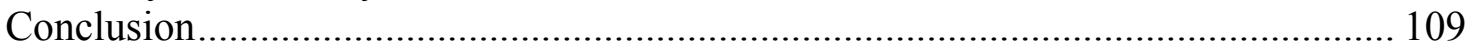

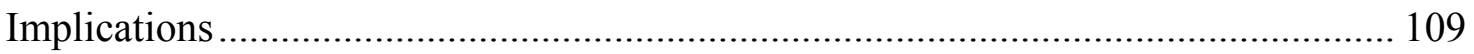

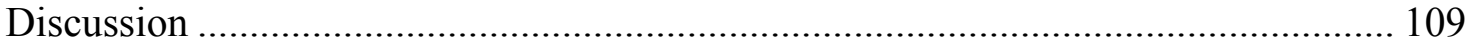

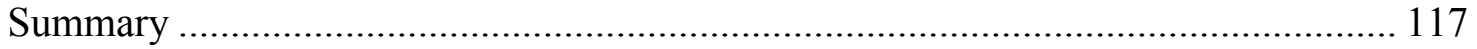

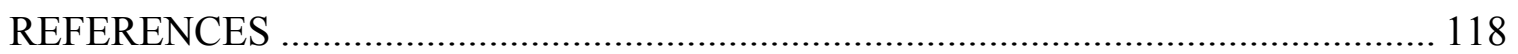

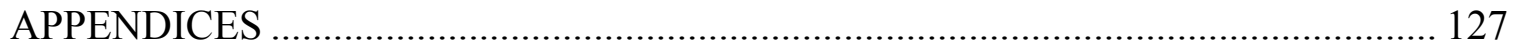

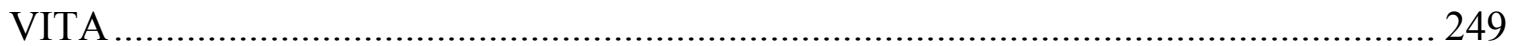




\section{LIST OF TABLES}

TABLE

PAGE

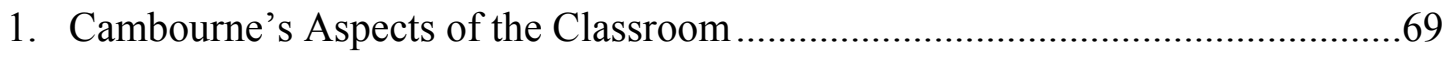

2. Cambourne's Conditions for Learning '......................................................... 76

3. At Home Writing Group Activities - Week1 ................................................. 81

4. At Home Writing Group Activities - Week 2 ................................................ 81

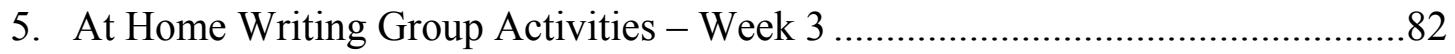

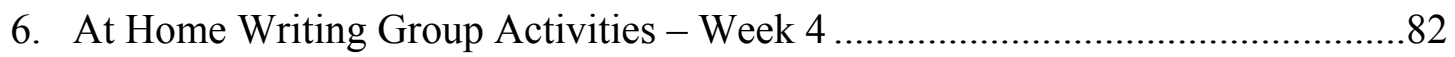

7. At Home Writing Group Activities - Week 5 .............................................. 83

8. At Home Writing Group Activities - Week 6 .............................................. 83

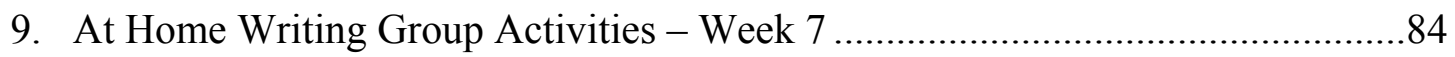

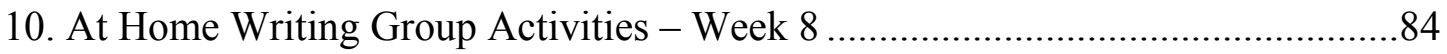

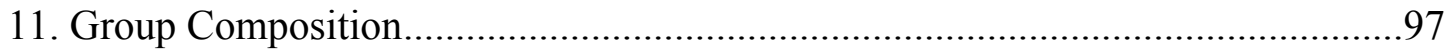

12. Overall Writing Posttest Mean Scores Adjusted by Pretest Scores .......................99

13. Ideas Posttest Mean Scores Adjusted by Pretest Scores....................................101

14. Conventions Posttest Mean Scores Adjusted by Pretest Scores .........................102

15. Writing Attitude Survey Posttest Mean Scores Adjusted by Pretest Scores .......104 


\section{CHAPTER 1}

\section{INTRODUCTION}

In 2002, the College Board instituted the National Commission on Writing (NCW) to spotlight the importance of writing in school, college and career. One of the goals of the commission was to keep writing in the public eye. Since then, the need to write proficiently has become even more important and requires multiple modes, means, genres, and registers (Partnership for $21^{\text {st }}$ Century Skills, 2011). The newly instituted Common Core State Standards (CCSS) identified writing as an essential skill and made it a priority for schools (National Governors Association Center for Best Practices, Council of Chief State School Officers, 2010).

\section{Background of the Problem}

\section{The Importance of Writing}

Studies conducted of both business communities and government agencies have indicated the importance of writing skills (Beaufort, 2008; Conboy, 2008; Tiersma, 2008). Writing has become an essential criterion for a professional career and is also vital to clerical and support workers (National Commission on Writing, 2005). At the inception of a job application, a poorly written resume, curriculum vitae or application letter is likely to severely impede the applicant's chances of employment (National Commission on Writing, 2005; Graham, Harris, \& Olinghouse, 2007). College and career writing are often discipline specific. For instance, the way in that historians, engineers, lawyers or scientists write differs (Beaufort, 2008). 
To be successful in college or higher education, strong writing skills are essential (Graham, Harris, \& Hebert, 2011; Peha, n.d.), especially the ability to read and write expository text (Montelongo \& Hernandez, 2007). College level writing requires a command of academic language, the ability to structure a paper appropriately, focus on a point, and demonstrate awareness of the intended audience (Bezbatchenko, n.d.). College level activities may include writing summaries of a reading, using writing to react to a reading and, frequently, using writing to analyze a reading, to state a thesis and to present an argument. At the college level, writing is used as the prime means to evaluate the internalization of content (Peha, n.d.). Williams and McEnerney (n.d.) noted that the role of writing at the college level is different from that of the role of writing at the secondary school level.

Newell (2006) argued that at the secondary school level, students are writing both to learn and to be evaluated. Much of the writing done at the secondary school level requires only minimal composing. However, the benefit of essay writing is that it "makes more demands on the writer than does answering study questions or fill in the blank exercises" (Newell, 2006, p. 238). He also argued that students at the secondary level need to be more proficient at writing across the curriculum following a variety of styles or text types, and employing a number of genres (Newell, 2006).

Writing is probably the most direct, simplest and most effective (both in terms of cost and time) method for students to demonstrate the internalization of content area material (Graham, Harris \& Olinghouse, 2007; Peha, n.d.). Not only is writing a significant means for evaluating learning, learning takes place as the result of writing (Harrison, 1983; Langer \& Applebee, 1987; Newell, 2006). It is through writing that 
understanding grows and is clarified (Bazerman et al., 2005; Newell, 2006); thus, writing is an upward spiral of growth in learning and, as such, it is a lifelong pursuit.

Strong writing skills support success in secondary school, college, and career. These writing skills need to build on a secure foundation that is constructed at the elementary level, where writing skills become gradually more complex and sophisticated (National Governors Association Center for Best Practices, Council of Chief State School Officers, 2010). Students naturally communicate by writing. They learn to write as they learn to read; writing may even precede reading (Graves, 1994; Tompkins, 2008). The youngest students believe in themselves as writers and enter school ready and willing to write (Graves, 1983). However, as students advance through the grades, their attitude towards writing gradually becomes less positive (Kear, Coffman, McKenna, \& Ambrosio, 2000; Knudsen, 1991, 1992, 1993), even in the lower grades writing may be regarded as a school chore (McCarry \& Greenwood, 2009). Taking advantage of students' initially positive stance and supporting and strengthening it is essential if the needs of students in the $21^{\text {st }}$ Century are to be met.

\section{Levels of Writing Proficiency}

The recently instituted Common Core State Standards introduced more rigorous standards for writing, making it a priority for schools, teachers and students (National Governors Association Center for Best Practices, Council of Chief State School Officers, 2010).

In 2011, the writing skills of students in Grades 8 and 12 were assessed, nationally. Students in Grade 4 were assessed in 1998 and 2002. The National Assessment of Educational Progress (NAEPb), in The Nation's Report Card - Writing 
2011, identified "about one-quarter of students perform at the Proficient level in writing". "The NAEP Proficient level represents solid academic performance for each grade assessed. Students performing at this level have clearly demonstrated the ability to accomplish the communicative purpose for writing" (National Center for Education Statistics, 2012b, p.1, italics in original). Approximately $75 \%$ of students performed at a basic or below basic level. The NAEP basic level denoted "partial mastery of the prerequisite knowledge and skills that are fundamental for proficient work at each grade" (National Center for Education Statistics, 2012b, p.2). Achievement levels have remained static, or close to static, for 17 years. This national research demonstrates the critical nature of this problem and the need for a change in practice.

At the state level, in Florida, the research mirrors the problem encountered at the national level. However, the assessment of students' writing skills, in Florida, is complicated because there have been many changes in the standards for writing and in the methods of assessment.

In 2000, the name of the writing portion of the Florida Comprehensive Assessment Test (FCAT) was changed to FCAT Writing. Students, in a single, 45 minute, session, were required to respond to an assigned topic. In 2006, a multiple choice section was added to the assessment, and it was renamed FCAT Writing+. The test was administered in two sessions and the scores were combined to result in the student's achievement score. In 2009, the multiple choice portion was discontinued, and the name of the test reverted to FCAT Writing. Up to this point, the students' writing was evaluated by two raters and half the students responded to one type of prompt (narrative or expository at fourth grade) and other half responded to the alternative type. 
In 2010 and 2011, only one rater was used to assess the writing samples, that precluded half points resulting when the two raters' points were combined and divided; all the students in a given grade level were asked to respond to the same type of prompt. In 2010 and 2011, the prompts were narrative and expository respectively. The writing samples were scored on a continuum from 1 to 6 , with 1 being the lowest and 6 being the highest. From 2001 to 2011, there had been a steady improvement in the number of fourth-grade students achieving a score of 4 or above, statewide. In 2001, $40 \%$ of students achieved at this level. By 2011, that score was achieved by $81 \%$ of students. Care must be taken when including the scores for 2010 and 2011 (FDOE, 2005-2013c), owing to the turmoil that resulted from the grading of the essays and the type of prompt. Nevertheless, a steady trend of improvement in the numbers of fourth-grade students achieving an average score of 4 statewide was evident. In 2012, that average score plummeted to 3.25 for fourth-grade students (Geisinger, Romjild, \& Chin, 2012), with only $26 \%$ of students achieving a score of 4 or above.

The Buros Center for Testing was commissioned to examine what prompted the dramatic drop in scores for 2012. They discounted the possibility that the essay prompt was more difficult than previous prompts and that student writing skills declined from one year to the next. The other hypotheses were that the more rigorous standards affected the scores and that the "anchor, training and validity papers were assigned scores that were somewhat lower than what they would have been under the previous writing standards, and the operational scoring of the student essays duplicated this more stringent essay scoring" (Geisinger et al., 2012, p. 15). Geisinger et al. (2012) were prepared to make an "educated guess" (p.16) as to why the scores dropped so dramatically. They 
suggested that the scorers implemented appropriate scoring based on the changed criteria and that the standard of student writing did not change but, owing to the more stringent requirements, the students achieved lower scores. The more rigorous requirements demanded the inclusion of more and better details (ideas) and compliance with the conventions of customary English. For the purpose of this study, the aspects of conventions of customary English focused on were the inclusion of appropriate capitalization and sentence endings; together with the use of commas, apostrophes and quotation marks. The use of transitional phrases and paragraphing were also addressed as part of the adherence to conventions of customary English. Geisinger et al. (2012) stated that, "only time will tell if instruction improves student performance across the state, but there is evidence in the literature that higher standards do lead to higher performance" ( $p$. 17). This is, students may reach higher standards if they receive instruction in the areas included in the more stringent standards, conventions and the incorporation of details (ideas).

In 2013, there were more changes to the Florida writing assessment procedures. There was another name change; to FCAT 2.0 Writing. The time allocation was increased from 45 minutes to 60 minutes. Unlike 2010, 2011 and 2012 when students responded to a single prompt, fourth-grade students were asked to respond to a narrative, expository or persuasive prompt. The more stringent 2012 standards remained in place. Each student paper was graded by two raters. Of fourth-grade students, $37 \%$ achieved a score of 4 or above (FDOE, 2005-2013c). Although these scores appear to be considerably better than those for 2012, the increased time allocation cannot be discounted. With more time, the inclusion of more detail was possible, and there was more time for editing to improve 
conventions of writing. Further research is needed to investigate interventions to improve students' skills regarding conventions and the incorporation of details (ideas), if their writing is to achieve the level required by the more rigorous standards.

At a local level, students' scores within the Miami-Dade Public School District closely reflect those of both the nation and the state. In 2013, with an increase of $33 \%$ in the time allocated, a score of 4 or above was achieved by $37 \%$ of students.

\section{Hispanic Students' Writing}

Up to this point, scores have been reported for all students. The following is a breakdown of those scores taken from the Florida Department of Education (2005-2013b) website to examine the differences that exist between the scores of White and Hispanic students within the Miami-Dade Public School District. In 2011, prior to the dramatic drop in scores, the overall percentage of students achieving a score of 4 or above was $80 \%$. Broken down, $87 \%$ of White students and $80 \%$ of Hispanic students achieved a writing score of 4 or above. In 2012, when the more stringent standards were introduced, the overall percentage of students achieving a score of 4 or above fell precipitously to $26 \%$. Broken down, $40 \%$ of White students and $27 \%$ of Hispanic students achieved a writing score of 4 or above. In 2013, the overall percentage of students achieving a score of 4 or above was $37 \%$. Broken down, $52 \%$ of White students and $38 \%$ of Hispanic students achieved a writing score of 4 or above. Within the Miami-Dade Public School District, there is a considerable disparity between the scores of White students and their Hispanic counterparts, indicating a gap in student achievement in writing along racial/ethnic lines. The difference suggests the need for quality instruction is greater for 
Hispanic students than it is for White students. Thus conducting the research within the Hispanic community is justified.

\section{Attitude towards Writing}

One of the factors affecting writing performance is the attitude towards writing (Williams, 2012). In addition to examining the effect of participation in Writer's Club on fourth-grade Hispanic students' writing achievement, this study examined the effect on students' attitude towards writing. Attitude towards writing is based on two perspectives. The first is the premise that those students with a positive attitude are more likely to choose to write and to spend time writing (Graham, Berninger \& Fan, 2007). The second perspective is that students' experiences when engaging with writing influenced their development of positive or negative attitudes towards writing (Kear et al., 2000). In addition to these two perspectives, there have been studies that have found that students' attitude towards writing becomes less positive as they progress through the grades (Knudsen, 1991, 1992, 1993). Despite searches in the following databases ERIC, ProQuest dissertations \& theses, Latin-American Newsstand, and PsychINFO, no relevant articles were found relating to Hispanic/ Latino fourth-grade students' attitude to writing using keywords: fourth-grade, Hispanic, Latino, writing, and attitude, in a variety of combinations. Assessing the students' attitude before participating in the Writers' Club provided data regarding the attitude the students held towards writing and potentially their willingness to participate in writing activities. Conducting the assessment of their attitudes towards writing after participation provided data related to the effect on writing attitudes of engaging in extra writing activities. 
Being knowledgeable about students' attitude concerning writing has the potential to benefit writing instructional practices (Kear et al., 2000). Students' positive attitude towards writing becomes less positive as they progress through the grades (Kear et al., 2000, Knudsen, 1991, 1992, 1993). Barnard (2002) found that relinquishing the teachercentered model of instruction in favor of a writing workshop resulted in greater enjoyment of writing, together with the benefit of feedback from multiple sources. He reported that participation in the writing workshop built on students' sociocentricity and, with its reduced focus on teacher-centeredness, encouraged a more positive attitude towards writing. These data about enhancing the understanding of ways to maintain or improve positive attitudes within a writing workshop is valuable because it supports the concept of conducting a Writers' Club, incorporating a somewhat casual, more social setting, with a guide to provide support.

\section{The Social Nature of Learning}

Humans are essentially social beings interacting with one another within the structure of relationships (Schultz \& Fecho, 2000). Learning is social in nature, it occurs within the context of an environment where scaffolding by a more experienced other and collaboration with peers takes place and is dependent upon interaction (Vygotsky, 1978). Students at fourth-grade (9-10 years old) are social beings. They are no longer the egocentric beings they were previously, and their peers are influential in their thinking and growth (Elsenbroich \& Gilbert, 2014). Engaging in writing under the aegis of a club builds on students' natural belief in themselves as writers (Graves, 1983) and plugs into their burgeoning social development. Participation in a club, by its very nature, incorporates close interaction between members (Poleck, 2010). 
The current study adopted the concept of "club" capitalizing on students' sociocentricity and made the creation of text, or writing, the central element. Kong and Fitch (2002) found that though students were somewhat resistant to participating in a book club at the outset they grew to enjoy it and became "experts" (Kong \& Fitch, 2002, p. 353) at conducting literary conversations. Kong and Fitch (2002) posited that there was the potential that students may be somewhat resistant to the writers' club initially. However, as they engaged in activities related to developing their writing skills and became more comfortable expressing themselves in this register they were likely to enjoy the experience.

Participation in the Writers' Club had the potential to facilitate fourth-grade students' participation in writing activities and encourage positive attitudes towards writing. Providing a setting with a club-like atmosphere removed writing from the more formal setting of the classroom. In the more relaxed atmosphere of a club, with the provision of positive experiences with writing, students' writing skills and attitude towards writing had the potential to be bolstered.

\section{Interventions}

According to Graham and Perin's (2007) meta-analysis of the writing intervention literature, a number of interventions to improve students' writing have been implemented. They identified 11 interventions with averaged effect sizes ranging from 0.82 to -0.32 . These interventions included strategy instruction, summarization, peer assistance, setting product goals, word processing and sentence combining, all of which had averaged effect sizes of 0.5 and above. The other interventions had lower effect sizes. Grammar instruction was the only intervention to have a negative effect size. One 
intervention that Graham \& Perin (2007) addressed was extra writing. However, their conclusions regarding this oft recommended strategy was that they could not draw any reliable or meaningful conclusions because of the "small number of [reported] effect sizes and the diversity of procedures for providing extra writing, and variety in control conditions" (Graham \& Perin, 2007, p. 464). To improve students' writing skills, increasing the amount of writing students do was a prime recommendation of the National Commission on Writing, 2003.

Providing extra writing through participation in a Writers' Club or an At Home Writing Group offered the opportunity to examine the effect of extra writing under two conditions. The first in a social setting with the support of an experienced other, in the form of the researcher, the second in an at home setting. The Writers' Club setting built upon students' predisposition to be social and The At Home Writers' Group enmeshed writing in the home environment. The Writers' Club had the potential to be a promising setting to provide writing instruction, building on students' sociocentricity. Incorporating book clubs as an intervention has been effective in improving reading skills (Raphael, 2001; Raphael, Florio-Ruane, \& George, 2001; Raphael \& McMahon, 1994). Participation in a writers' club, as an intervention, has been minimally addressed.

McCarry \& Greenwood (2009) were influenced by the book club ideas to enhance reading but wanted to turn the focus to writing. They conducted a 2-year study involving a Writers' Lunch Club beginning with nine students in first grade. The students wrote in journals and met every couple of weeks to share their writing. Improvements in their students writing were observed, but there were some shortfalls in the study. The time frame of the meetings was not explained. Also, the number of students was small and 
they were young (in first grade) at the beginning of the project. Most importantly, whilst McCarry \& Greenwood (2009) reported that the students' writing, and perceptions' of writing had improved, there were no supporting data or analysis provided to support this. The current study was conducted with 60 students, 22 of whom were in the Writers' Club, 18 of whom were in the At Home Writing Group and 20 of whom received no extra writing. The students in the current study were older and likely had more writing experience than those in McCarry \& Greenwood's (2009) study. In the current study, the students' writing and attitude towards writing were examined pre- and post the intervention.

\section{Statement of the Problem}

The problem investigated by this study is three-fold. Firstly, a high percentage of fourth-grade students have demonstrated less than proficient writing skills that may hinder their progress through school, college and into the workforce. This is particularly true of Hispanic students. Secondly, the writing standards have become more stringent, requiring the inclusion of more details (ideas) and conformity to the conventions of customary English. Thirdly, students' attitude towards writing has been found to become less positive as they progress through the grades, impacting their willingness to engage in writing.

\section{Purpose of the Study}

The purpose of this intervention study was to examine the effect of extra writing in a Writers' Club on fourth-grade, Hispanic students' writing, specifically the incorporation of details and the use of customary English conventions, and their attitude towards writing (the student's self-perception of his/her attitude towards writing). 
Several questions drove the conceptualization of the procedures used in the study. Various outcomes were examined. Comparisons were conducted, between the writing skills and attitude towards writing of students who were involved in the Writers' Club with those of students exposed to an enhanced at home writing program, the At Home Writing Group, and to students who received no extra writing. All the students were exposed to regular classroom writing instruction and homework.

This research was contributed to the knowledge base regarding the effectiveness of extra writing. It offers suggestions to teachers who are trying to devise ways to improve students' writing to meet the new writing standards and the higher expectations of the current writing test. It may benefit future students participate in a writer's club.

\section{Theoretical Framework}

The study was conducted from a sociocultural perspective. The theoretical framework relied on the concept that learning takes place in social settings. Cognitive growth and internalization of concepts is a communal activity. Students must make knowledge their own within the dynamic of a group sharing membership of a society or culture (Bruner, 1986; Vygotsky, 1978). Piaget proposed that students' cognitive development goes through a number of stages; in the early years students are egocentric, but they gradually become sociocentric and interaction with peers gains in importance, to some extent supplanting the influence of authority figures that existed prior to this stage. The transition from egocentricity to sociocentricity is developmental, taking place from about the age of seven (Elsenbroich \& Gilbert, 2014).

Based on Vygotsky's (1997) theory, the zone of proximal development "is the distance between actual developmental level as determined by independent problem 
solving and the level of potential development as determined through problem solving under adult guidance or in collaboration with more capable peers" (Vygotsky, 1997, p. 33). He posited that language learning activates a number of internal processes that operate only when the child is working in conjunction with peers or with adult guidance. Thus, it was reasonable to hypothesize that participation in a writers' club with peers and the guidance of a capable adult would lead to improvement in writing.

Based on this theoretical framework, the current study followed a writers' club format. Students participated in writing experiences in a safe, relaxed, social setting. There were opportunities for working alone, in pairs, in small groups and whole group situations. Collaboration and cooperation were encouraged and facilitated. The atmosphere of the Writers' Club was less formal than that of the classroom. The students self-regulated, with guidance, developing the rules of their club, selecting topics for writing and determining how and with whom to progress their projects. The researcher provided structure, instruction and scaffolding; building a learning community where students were immersed in writing, expected to be responsible and encouraged to take risks to further their growth in writing.

Brufee's (1984) theory of collaborative learning was influential to the study. Bruffee maintained that thought, internal conversation, is born out of the social conversation and that writing is "internalized conversation re-externalized" (Bruffee, 1984, p. 641). He argued that when students help each other their work improved; not only the person being helped benefitted, but the helper also learned from the act of helping. Engaging in conversation in a learning community provided enrichment for all participants regardless of the role they took. He encouraged teachers to encourage 
students to "engage in conversation among themselves" (Bruffee, 1984, p. 642), contriving to ensure that those conversations are as "similar in as many ways as possible to the way in which we would like them eventually to ...write" (Bruffee, 1984, p. 642). Teachers are often reluctant to surrender their position of authority that hinders authentic discussion between students. It is important for teachers also to position themselves as a member of the community. Whilst it may be necessary for teachers to assume the role of guide in any given circumstance, it is important for them to relinquish that role as quickly as possible and return to the position of the peer. It is insufficient to put students together with no guidance or preparation. Creating a collaborative learning setting "requires us to create and maintain a demanding academic environment that makes collaboration ... a genuine part of students' [writing] development” (Bruffee, 1984, p. 652).

Finally, Cambourne's theory of learning was also foundational to the study. Cambourne (2000) argued that the setting was important, that it consisted of three main elements - the physical space, the human behaviors that take place within the physical space and the programs or routines and events that take place within the physical space. He also maintained that certain conditions need to be present in order for learning to take place (Cambourne, 1995). Cambourne's $(1995,2001)$ conditions include immersion where students are provided with a plethora of experiences with text, demonstration where experienced others model the process of writing particularly making visible the underlying components of creating text. Both of these conditions affect and are affected by engagement. Engagement includes both the teacher and the student. The teacher demonstrates engagement by consistently making explicit the importance of becoming proficient writers in a manner that is relevant to the students (Cambourne, 2001). 
Learners become engaged when they perceive themselves as potential doers of the demonstrations they observe. Engagement is initiated when students make connections with demonstrations, appreciate that what is demonstrated will have an impact on their lives, and trust that they can participate in mimicking the demonstrations without fear of "physical or psychological hurt if their attempts are not fully correct" (Cambourne, 1995, p. 187). Cambourne (2001) identified that the teacher would also have expectations that the student would become a good writer and take responsibility for his/her own growth and decision making. Cambourne (2001) identified three further conditions

approximation, use, and response. Approximation relates to the teacher communicating that "having a go" (p. 415) is critical to learning, and "that mistakes are our friends in that they help us adjust and refine our knowledge" (p. 415). Use involves many opportunities to apply the skills being developed, and response involves thoughtful, relevant, nonthreatening, targeted feedback provided by more capable others. Cambourne's theory of learning is foundational to the development of the Writers' Club to enhance fourth-grade, Hispanic students' writing skills.

\section{Research Questions}

- What effect does participation in a writers' club have on fourth-grade, Hispanic students' writing?

- What effect does participation in a writers' club have on fourth-grade, Hispanic students' incorporation of ideas in their writing?

- What effect does participation in a writers' club have on fourth-grade, Hispanic students' adherence to the appropriate conventions of customary English? 
- What effect does participation in a writers' club have on fourth-grade, Hispanic students' attitude towards writing?

\section{Potential Contribution to the Field}

The need for improvement in writing has been well documented over at least two decades (National Assessment of Academic Progress, 1998, 2002, 2007, 2011). Since writing is such a critical skill for school (Common Core State Standards, 2010; Newell, 2006), college (Bezbatchenko, n.d.; Peha, n.d.; Williams \& McEnery, n.d.) and career (Graham, Harris, \& Olinghouse, 2007; National Commission on Writing, 2005), examining ways and means for improving the standard of writing and enriching the writing experience are imperative. Conducting the study in the Miami-Dade School District had the potential to provide insight into the ways and means for improving writing skills not only in the Miami-Dade area but both statewide and nationwide. Miami-Dade is the fourth largest school district in the country (NCES, 2006) and the students' performance in writing not only reflects the state's proficiency levels it also mirrors the national proficiency levels. The results of the study had the potential contribute to the body of knowledge regarding methods of instruction in writing for fourth-grade students, particularly Hispanic students, and potentially for other age groups and ethnicities. In addition, the data were intended to help to fill the gap in the knowledge base, specifically identified by Graham and Perin (2007) as needing further research, regarding the value of extra writing. There is evidence that reading skills can be enhanced by participation in a book club. By extension, it was reasonable to believe that writing skills could be augmented by participation in a writing club. In addition, with research indicating that attitude towards writing declines as students advance 
through the grades (Kear et al., 2000, Knudsen, 1991, 1992, 1993), examining if participation in a writing club creates an environment that supports a positive attitude had the potential to be valuable.

\section{Assumptions}

In designing this study it was assumed that fourth-grade, Hispanic students in this study had a knowledge base regarding writing upon which to build. Additionally, it was assumed that they would collaborate with each other and be supportive and kind to each other. Furthermore it was assumed that fourth-grade, Hispanic students in this study responded honestly to the survey questions.

\section{Delimitations}

Fourth-grade, Hispanic students have performed poorly on writing assessments therefore the participants were limited to fourth-grade students attending a Miami-Dade public school in a predominantly Hispanic neighborhood. Nevertheless, in order for students to be able to access the benefits of participation in the Writers' Club, the participants were limited to students with a minimum English proficiency of Level 3 English for Speakers of Other Languages (ESOL). Owing to scheduling, the Writers' Club was limited to three meetings per week, each lasting for 30 minutes, during the school day. As it is a widely used and appropriate analytical instrument for assessing writing, Spandel's (2013) Teacher Six-Point Writing Guide was selected to evaluate the students' writing samples. In similar vein, since it was specifically designed for grades 112, the Writing Attitude Survey developed by Kear, Coffman, McKenna, and Ambrosio (2000) was used to evaluate the students' attitude towards writing. 


\section{Definitions and Operational Terms}

Adolescent. Students in Grades 4-12 (Graham \& Perin, 2007), aged between 9 and 18 are considered to be adolescent.

Attitude. A "psychological state(s) acquired over a period of time as a result of our experiences" (McLeod, 1991). Attitudes are influential in the way people respond to certain circumstances or activities. It is not the response but the inclination to respond in a particular manner. Attitudes may be accompanied by an emotional response but they are not the emotions themselves, though "revisions of attitude may result in revisions of emotional experience related to writing" (Musgrove, 1998/1999). Attitude towards writing was measured using the Writing Attitude Survey (Kear et al., 2000)

Club. A group of people who gather together to pursue a common interest "small, collaborative group[s] whose purpose is to enhance literacy" (Polleck, 2010, p. $51)$.

Conditions. "particular states of being (doing, behaving, creating), as well as being a set of indispensable circumstances that co-occur and are synergistic in the sense that they both affect and are affected by each other." (Cambourne, 1995, p. 184).

Evaluation. The examination of student work to place a value on it based on a pre-determined rubric without the intent to assign a grade but with the intent to establish a standard. This term was used in preference over assessment because assessment carries the connotation of grading or testing (Spandel, 2013).

Extra Writing. Writing activities or experiences in addition to those regularly scheduled as part of the curriculum. The students in the Writers' Club and the At Home 
Writing Group engaged in an additional 90 minutes of writing activities or experiences beyond their regularly scheduled curriculum.

Genre. Written text that has a specific style following accepted patterns, syntax, and conventions including, but not limited to, narrative or expository/informational covering persuasive, compare and contrast, problem and solution, sequence, description, procedural or transactional.

Teacher Six-Point Writing Guide. An analytical assessment tool developed by Vikki Spandel (2013) that can be used to evaluate student writing aligning with the 6Trait model. The 6 Traits are specifically: ideas, organization, voice, word choice sentence structure and conventions/presentation.

Text type. The format writing takes including, but not limited to, letters, essays, brochures, cards, media articles, reports, poems, plays, biographies, instructions, blogs, emails, etc. The text types addressed in the current study were letters and essays.

Writing sample. A piece of writing produced by a student that provides evidence of his/her writing skill. It may be gathered under timed or non-timed conditions. It may be in response to an on-demand writing prompt or written spontaneously.

\section{Summary}

In this chapter the background to the study was provided. It covered, first, the importance of writing in respect to the workforce, college, and school; second, the levels of writing proficiency based on national and Florida assessment; third the comparison of results for White and Hispanic students; finally attitudes towards writing, the social nature of learning and interventions were explained. The theoretical framework underpinning the study as coming from a socio-cultural perspective was addressed. The 
chapter also included the purpose of the study, the research questions, the potential contributions to the field, the assumptions, the delimitations, and definitions and operational terms. 


\section{CHAPTER 2}

\section{REVIEW OF THE LITERATURE}

\section{General Background}

In 2012, according to the National Center for Education Statistics (NCESa) over $70 \%$ of U.S. students in Grades 8 and 12 were writing at a basic or below basic level. In 2002, when students in Grade 4 were last assessed nationally, only $28 \%$ were performing proficiently (NCES, 2012). The position in Florida mirrors that of the nation. Within Miami-Dade County Public Schools (M-DCPS) the situation is very similar. The percentage of Hispanic students performing at or below the basic level is considerable higher than that of their White counterparts.

Book clubs have been found to be successful at improving reading skills (Raphael, 2001; Raphael, Florio-Ruane, \& George, 2001; Raphael \& McMahon, 1994). Building on the success of book clubs, developing an intervention in the form of a writing club had the potential to support students' growth in writing.

In 2003, the National Commission on Writing made the recommendation that students should double the amount of time they spent writing. In their meta-analysis of writing instruction provided to adolescent students, Graham \& Perin (2007) found a number of interventions to be effective, and specifically identified extra writing as being highly recommended, but concluded that there were insufficient studies to support this contention. This study contributed to the knowledge base regarding the effectiveness of extra writing as an intervention and incorporated it in the Writers' Club and the At Home Writing Group for comparison against no extra writing. All students participated in regular classroom instruction and homework. 
Students' attitude towards writing has been found to become less positive as they progress through the grades (Knudson, 1991, 1992, 1993). Even younger students think that writing is a school chore (McCarry \& Greenwood, 2009). Since attitude is influential in engagement, examining if providing writing experiences through an alternative means, during a Writers' Club, is influential on attitude was valuable.

The Common Core State Standards place a greater focus on writing, regarding it as an essential skill (National Governors Association Center for Best Practices, Council of Chief State School Officers, 2010). The Florida Standards are closely aligned with the CCSS.

Using Spandel's (2013) Teacher Six-Point Writing Guide as the evaluation instrument is in line with best practice in writing assessment. Smith (2003) concluded that the "6 Trait method is a reliable reference to guide a writer through the demanding task of writing well" (Smith, 2003, p. 5) as well as being an effective tool for teachers to assess writing.

Students' attitude towards writing will be assessed using Kear, Coffman, McKenna, and Ambrosio's (2000) Writing Attitude Survey, that was designed especially for use with K-12 students.

\section{State of Students' Current Writing Proficiency}

The National Assessment for Educational Progress (NAEPb) collects and reports on students' academic performance periodically, both at national and state levels. According to the Nations Report Card - Writing 2011, only 27\% of students in Grades 8 and 12 performed at or above the proficient level, in writing. The other $73 \%$ performed at the basic level or below. According to the NAEP, a larger percentage of Hispanic 
students scored at the basic or below basic level; $86 \%$ of students in Grade 8 and $89 \%$ of students in Grade 12. Partial mastery implies inappropriate preparedness for college and the workforce. The percentages have remained constant over the past 17 years, dating back to the 1998 assessment, indicating that a chronic problem exists.

In 2002, when fourth-grade students were last assessed, $28 \%$ of them were performing at or above the proficient level (Persky, Daane \& Jin, 2003). Florida's fourth-grade students performed better than the national average with $33 \%$ of them achieving proficient or advanced scores. Nevertheless, $67 \%$ of students were performing at the basic or below basic level, cause for concern. Of Florida's Hispanic students $83 \%$ were performing at the basic or below basic level. Based on the trends over time of students in Grades 8 and 12, writing skills have remained, to all intents and purposes, static. It is unlikely that students in Grade 4 are scoring much higher than they were in 2002. The 2012 Florida Comprehensive Assessment Test - Writing results indicted a precipitous fall in the percentage of students achieving a score of 4 or above. The average score fell to 3.25. Alberto Carvalho (2012), the M-DCPS Superintendent of Schools, posited that the "decline in writing scores is exacerbated in Miami-Dade County given the disproportionate number of English Language Learners (ELL) served in our schools" the majority of these are Hispanic. If the problem is to be addressed effectively, strategies need to be infused into instruction during the earlier grades to develop proficient writing skills, that is why this study examined the effect of participation in a writers' club on the writing skills of fourth-grade, Hispanic students.

Providing quality writing instruction presents challenges; Read and Landon-Hays (2013) found that teachers believed that following the traditional model of assigning a 
writing task and providing limited feedback, employing a whole class fix-up technique, was not effective. Instead, the participants in Read and Landon-Hays' (2013) study agreed that ideally teachers should be able to provide an environment where individual feedback would be possible. They also agreed that instruction should focus on process rather than the product, with writing being revised based on personal teacher feedback. To build upon these findings, the current study focused on the provision of an environment, in the form of the Writers' Club, conducive to the provision of individual feedback. The participants were encouraged to select their topics and were supported while they worked through the process of pre-writing, revising, editing and producing a final publishable copy. As part of the Writers' Club, individual feedback was provided during brief one-to-one conferences during the club meetings, and using written feedback in individual students' notebooks.

Bearing in mind that the expectations indicated by standards are currently in flux it is relevant to explore the current state of the standards.

\section{Standards - Common Core State Standards and Florida State Standards}

Two consortia, the Partnership for Assessment or Readiness for College and Careers (PARCC) and the SMARTER Balanced Assessment Consortium (SBAC), were charged with the task of developing two sets of assessments from that states could choose (Long, 2011). Florida was a governing state in the PARCC consortia. The current assessments are not aligned with the CCSS (Porter, McMaken, Hwang, \& Yang, 2011). The assessments that are under construction will focus more on formative assessment than has previously been the case (Hain, 2011) but summative assessment (high stakes testing) will continue to be undertaken. Formative assessment provides information that 
supports teachers in their instructional plans and is ongoing. The Writers' Club provided the ideal opportunity to conduct formative assessment of students' development and progress.

The CCSS were adopted by Florida's State Board of Education in 2010 and will be in full effect, as revised, in the academic year 2014-2015 (Florida Department of Education [FDOE], 2005-2013d). The goal of the CCSS is to provide clear standards that will ensure that all students graduate from high school prepared to enter college or the work force (Hain, 2011), regardless of demography (FDOE, 2005-2013d). The standards are designed to indicate what students are expected to be able to do (skills) rather than what they should know (content) or how they should be taught (pedagogy) (Gardner \& Powell, 2013; Porter et al., 2011). Other authorities would argue that the standards cover not only what students should be able to do but also what they ought to know (Fin \& Petrilli, 2010). The assessments to align with the CCSS and/or the Florida Standards are still being developed.

Porter, McMaken, Hwang and Yang (2011) conducted a study comparing current state standards with CCSS. According to Porter et al.'s (2011) results the CCSS are fast becoming national standards with only a handful of states refraining from participating. The CCSS initiative "developed these standards as a state-led effort to establish consensus on expectations for student knowledge and skills that should be developed in Grades K-12" (Porter et al., 2011, p 103). Porter et al. (2011) found that there was a substantial difference in content between state standards and the CCSS even when the states were aggregated, so the adoption of the CCSS will represent considerable change. Current materials are not aligned with the CCSS, and it will take time to build curriculum 
materials that are. The major downside of this study, when related to the current study, is that data for Florida were intermittent.

Carmichael, Martino, Porter-Magee and Wilson (2010) conducted a similar study. Again it was determined that the CCSS were better than most state standards but equal to or weaker than those of some states. Carmichael et al. (2010) graded the CCSS and each state's standards. The CCSS earned a B+; Florida earned a B and fell into the "too close to call" (p. 14) group of states, or a state with standards equivalent to the CCSS.

The CCSS English and Language Arts standards were determined to be "particularly strong when it comes to providing useful and explicit guidance about the quality and complexity of reading and writing that should be expected of students each year, including providing annotated samples of student writing." (p. 8). The study identified a list of problems with the state standards. Only "vague expectations for student writing" will be addressed here. Many of the current writing standards are so vague as to be essentially meaningless (Carmichael et al., 2010). Carmichael et al. (2010) argued that students need to gain mastery of multiple genres. They are critical of many states that do not prioritize what genres should be addressed when. Carmichael et al. (2010) emphasized that whilst narrative writing is appropriate in the early grades and that more complex genres should be introduced progressively, it is rarely stated in state standards that narrative writing should take a less prominent role as students advance up the grades.

The National Governors Association Center for Best Practices (NGA), Council of Chief State School Officers (CCSSO) (2010) highlighted the importance of writing logical arguments including evidence and supported this being taught at the elementary 
level. Both short and more extended projects were focused upon in the writing standards. The CCSS requirements for students in Grade 4 are more rigorous and detailed than Florida's Sunshine State Standards. The CCSS detail expectations for writing types, following a process approach, editing for conventions and incorporating technology for the presentation of final products. Furthermore, they identify expectations regarding the research of written projects and incorporate the need to write over both short and longer periods of time (NGA, CSSO, 2010).

There has been considerable controversy over the adoption of the CCSS in Florida. Ninety-eight different amendments were considered by the Florida legislature. The majority of these related to the mathematic standards with one major exception for writing - the inclusion of cursive writing (McGrory, 2013). In February, 2014, the Florida State Board of Education approved changes to the CCSS. Overall, the writing standards were unchanged. However, within the strand "language standards", a provision for cursive writing was included, and a minor change was made to the wording of the academic language standard. The revised CCSS will be referred to as the Florida Standards, and to reflect this the alpha-numeric coding of the Florida Standards has been changed to Language Arts Florida Standards (LAFS) from the Language Arts Common Core (LACC) (FDOE, 2005-2013a).

The organization of the Writers' Club will enable students to "Write routinely over extended time frames (time for research, reflection, and revision) and shorter time frames (a single sitting or a day or two)" (CCSS.ELA-Literacy.W.4.10/LAFS.4.W.4.10). During the Writers' Club “With guidance and support from peers and adults, [students will be encouraged to] develop and strengthen writing as needed by planning, revising, 
and editing” (CCSS.ELA-Literacy.W.4.5/LAFS.4.W.2.5). The Writers' Club will facilitate students to "Produce clear and coherent writing in that the development and organization are appropriate to task, purpose, and audience" (CCSS.ELALiteracy.W.4.4/LAFS.4.W.2.4). (Common Core State Standards Initiative, 2014a; FDOE, 2005-2013a). The alphanumeric codes for CCSS and The Florida Standards are both included since the wording for both is identical. In addition, to a focus on the above mentioned standards, there will be a focus on the development of improved skills in regards to the use of the conventions of customary English and the inclusion of more and better details (ideas), this is to address specifically the more stringent scoring criteria that were introduced to the FCAT in 2012 (Geisinger, Romhild \& Chin, 2012). This study examined the effect of extra writing employing two treatment conditions; participation in a Writers' Club and participation in an At Home Writing Group. Participation in the Writers' Club encompassed the aspects of writing mentioned above while the At Home Writing Group were provided with a range of activities for the students to engage in without specific instruction. The study examined how extra writing may facilitate fourthgrade, Hispanic students' growth in writing, particularly in the areas of conventions and including details (ideas), together with their attitude towards writing.

\section{Clubs}

Taking part in a book club has been the focus of Taffy Raphael's work for more than two decades. Her initial Book Club program (Raphael \& McMahon, 1994) incorporated a writing element, but the focus was reading. When Book Club Plus came out (Raphael, Florio-Ruane, \& George, 2001) the program had become more sophisticated, and was designed to "promote all students' learning and incorporate skills 
and strategies associated with reading acquisition and critical thinking required for living in and contributing to a democratic society" (p. 161). The writing component had been expanded, but the focus was still the engagement and response to text rather than the creation of students' text. The club atmosphere promoted student participation, engagement, and enhanced students' social nature. The present study built upon this, already strong, foundation and examined the effect of participation in a Writers' Club on fourth-grade, Hispanic students' writing and attitude towards writing. The current study extended the book club concept and examined its effect on writing and attitudes towards writing.

Taffy Raphael instituted the concept of the book club as an alternative framework for reading instruction, the writing element primarily emphasized the maintenance of reading logs, writing in response to what had been read, and taking notes linking text to text connections. (Raphael \& McMahon, 1994). Raphael and McMahon's (1994) primary focus was reading. The goal was to encourage authentic discussions surrounding books addressing the norms of a traditional classroom, where the emphasis was on individual work and taking turns, rather than engaging in discussion where the thrust and parry of excited conversation could flourish. Building upon these goals, during the Writers' Club meetings students will be encouraged to engage in discussion related to writing.

Raphael and McMahon (1994) found that students' literacy development benefited, and the students' scores on standardized tests were as high as those of students who had experienced a more traditional method of instruction. The benefit afforded to the students in the Book Club program was that they had considerably higher recall of the 
texts they had read the previous year than did their counterparts who had experienced tradition instruction. The students in Raphael and McMahon's (1994) study were fourth graders, like those of the current study. However, although it was called Book Club, the experience took place in a regular classroom setting, during class time. Extending the book club concept to an extra writing time activity, the Writers' Club will provide an environment on school premises but not during regular literacy instruction class time. Book Club focused on primarily improving reading skills whereas the current study's objective is to improve writing skills.

In 2001, Raphael et al. addressed the advances in the program in Book Club Plus: A conceptual framework to organize literacy instruction. Book Club Plus was designed to "promote students' learning and incorporate skills and strategies associated with reading acquisition and critical thinking required for living in and contributing to a democratic society.” (Raphael et al., 2001, p. 161) Again the focus was reading rather than writing. The impact of Book Club qualitatively examined how it was implemented in one third-grade classroom and impacted the literacy development of three students, a struggling reader, an unenthusiastic reader and a successful reader. The concept of the club was limited in that it involved only three students, and it was conducted in the regular classroom setting. The present study involved membership in a club, comprised of 22 fourth-grade, Hispanic students. Raphael et al. (2001) employed qualitative methods. The current study followed a quantitative design, examining the significance of participation in the Writers' Club on fourth-grade, Hispanic students' writing and their attitude towards writing. 
Polleck (2010) extended participation in a book club to somewhat older adolescents. She argued that engagement in "small collaborative groups whose purpose is to enhance literacy and personal and social growth" (p. 51) provided a safe space for self-discovery. Her argument was at the foundation of the current study. However, unlike the current study, her study focused exclusively on reading rather than writing. She argued that participation in a book club provided a venue for those who have a love of reading to enhance their experience and that struggling or reluctant readers exposed to relevant texts also experienced growth. Similarly, participation in the Writers' Club offered the already enthusiastic writers opportunities to grow their skills and those students less fervent about writing, an opportunity to develop competence. Polleck (2010) also highlighted the importance of self-selection of text, the choice was elemental in improving both reading and the motivation to read for reluctant readers. Many aspects of Polleck's (2010) study were reflected in the current study. The concept of small groups providing support to each other through collaboration was at the center of the Writers' Club. Again, as with Polleck's (2010), self-selection was crucial though it related to topics to write about rather than texts to read. Polleck's (2010) study, examining the effect of participation in a book club, resulted in the enhancement of both literacy and personal growth.

Heller's (2006) qualitative study was conducted in a Title 1 elementary school in a Midwestern U.S. state. Her participants comprised four, first-grade girls. Heller used information books, and each student maintained a book club journal including drawing and/or written responses. The book club was held three days a week during the normal literacy time slot in a mobile classroom away from the regular classroom. This came 
close to the current study in that the club was held three days a week and was conducted in a separate setting from the regular classroom but the membership was much smaller, at a lower grade level, and was conducted during regular literacy time thus providing an alternative method of instruction rather than extra time on task. The objectives of the book club were to "listen to and read nonfiction in order to learn new information: to talk, write and draw in response to nonfiction books; to enjoy sharing books with friends." (Heller, 2006, p. 361). The book club followed a clearly outlined format. The dialogue between the students and teacher was encouraged. Elements of Heller's (2006) work were used in the current study. The encouragement to use dialogue and maintain a journal was incorporated, as was meeting three times per week, in the Writers' Club. However the current study was a Writers' Club designed to facilitate growth in writing specifically, rather than a Book club designed to broaden an appreciation of reading. Additionally, in the current study the Writers' Club was conducted with a much larger number of students, 22, and they were older, in fourth grade. Also the Book Club was conducted during the regular literacy time slot, and the Writers' Club was a pull-out activity. Finally, the analysis of the data followed a different design. It was quantitative.

McCarry \& Greenwood (2009) built on the book club idea. McCarry, a firstgrade teacher, wanted to get her first-grade students to engage fully in writing. She had observed that students regarded writing as a chore and she wanted to "find a way to ignite interest in the writing process and energize the children to write" (McCarry \& Greenwood, 2009, p. 38). McCarry modeled that she was a writer too. The researcher in the current study followed McCarry's lead and maintained her own journal. She wrote and shared alongside the members of the Writers' Club. She provided an example of 
what a writer did and model texts for the students. McCarry made the club strictly voluntary and arranged that they would meet a couple of times each month to share writing during lunchtime, and she provided food. The current study had volunteer participants, but meetings were held three times per week rendering participation more intense. Food was not a feature of the current study.

In McCarry and Greenwood's (2009) study, initially, the membership consisted of nine, first-grade students all of whom were strong writers. McCarry encouraged less adept writers to join, and gradually membership grew. The current study started with a membership of 22 students with no potential for adding students once the study had started. Because of the design of the study, adding members would compromise the results. In McCarry and Greenwood's (2009) study, individual improvement was observed qualitatively. The current study followed a pretest-posttest design. Student essays were evaluated using Spandel's (2013) Teacher Six-Point Writing Guide before and after participation, to provide quantitative results and examine the significance of participation in the Writers' Club as against participation in the At Home Writing Group or participation in the group with no extra writing. At the end of the first year, McCarry reflected that reluctant writers had become more enthusiastic and that the children who had attended the Writers' Lunch Club showed "remarkable improvement" (p. 40). She observed that the children no longer regarded writing as a chore but as an important part of everyday life. She also noted that they attended more to writing conventions, incorporated voice and had a sense of audience. McCarry extended the Writers' Lunch Club into a second and third year. During the second year Greenwood noted that all but one of the original members had re-joined and that the membership had increased to such 
an extent that a "second lunch bunch" (p.40) had to be created. Greenwood observed that he saw "children proud of their work" (p.40). The children's endorsement of the Writers' Lunch Club came in their writing, they wrote that they particularly liked sharing their work. These findings indicate that the students' attitude towards writing was positively affected by participating in the club but it offered no significance, due to the design of the study.

In summary, the concept of the club has been explored in a variety of ways using a variety of methodologies to enhance reading skills. These clubs have been successful, not only in enhancing reading skills, but also in the retention of those skills (Raphael and McMahon, 1994). Students who are of mixed ability levels (Raphael et al., 2001) and both those who are already keen readers and those who are less enthusiastic (Polleck, 2010), have benefited from participation in a book club and the appreciation of informational text (Heller, 2006) has been enhanced.

Building upon studies relating to literacy development through participation in a Book Club, McCarry and Greenwood (2009) developed the Writers' Lunch Club. It is upon that study that the current study directly builds, incorporating some similar features. Both clubs are voluntary, and incorporate personal journals. The Writers' Club will take place in addition to literacy class time, but during school time rather than during lunch time. The current study extended the earlier study in a variety of ways: The Writers' Lunch Club met only twice a month for a year whereas the Writers' Club will meet three times per week for 8 weeks or a total of 24 meetings. The number of meetings will be similar, but the current Writers' Club was more intense, with the increased frequency. The Writers' Lunch Club targeted first-grade students though they continued as they 
progressed through the grades. The current study will be directed at fourth-grade, Hispanic students. The Writers' Lunch Club membership, initially, numbered nine and all were strong writers whereas the Writers' Club membership included 22 students who were of mixed ability. The Writers' Lunch Club was evaluated qualitatively, relying on observation of students' writing progress as exemplified by their writing samples, whereas the Writers' Club was statistically analyzed using pretest and posttest writing samples garnered before and after the intervention. Finally, the Writers' Club membership will be Hispanic, whereas the race/ethnicity of members of the Writers" Lunch Club was not a focus, or was not mentioned.

Although attitude toward writing was not directly addressed in McCarry and Greenwood's (2009) study, it was implied. McCarry stated at the beginning of the study that "children ... viewed writing as a school chore" (p.38), at the end of the first year of the study "the writing club children saw writing no longer as a chore but rather as a significant daily activity" (p.40). Furthermore, Greenwood noted that all but one of the students who participated in the Writers' Lunch Club the first year joined up to participate the second year, providing circumstantial evidence that their attitudes towards writing had improved. These implications made it advisable to examine attitude towards writing both before and after participation in the Writers' Club more formally.

\section{Extra Writing}

The National Commission on Writing (2003) called for students' time spent writing to be at least doubled. It stated that "writing is how students connect the dots in their knowledge" (National Commission on Writing, 2003, p. 3) and argued that writing instruction and practice were both short-changed in the classroom. One of the 
recommendations was that "more out-of-school time should be used to encourage writing” (p.3). Whilst in the current study the Writers' Club did not use out-of-school time, neither did it take up already designated literacy instruction time. The provision of extra writing time was created by modifying the regular school schedule to incorporate one and half hours of extra writing time during the school week. The activities were designed to be developmentally appropriate, following another of the Commission's recommendations, including needed instruction. "Writing is a complex intellectual activity that requires students to stretch their minds, sharpen their analytical capabilities, and make valid and accurate distinctions" (National Commission on Writing, 2003). As such, providing students with the necessary skills instruction is critical to their success. It is through writing that learning is consolidated. Writing is not limited to being a method for evaluation. It actually supports understanding of content. The National Commission addressed the findings of the NAEP 1998, identifying that those standards "establish a very high threshold" (p.16), but highlighted that students were unable to "produce writing at the high levels of skill, maturity, and sophistication required in a complex, modern economy" (p.16). Students were able to provide some supporting details, and their conventions were "not an utter disaster" (p. 17). The findings of the commission resulted in the strong recommendation that writing time be doubled and that more writing time be encouraged during the school day. This study provided students with the opportunity to be part of a Writers' Club, during the school day. The activities supported the students in improving their use of writing conventions and incorporating details (ideas). The At Home Writing Group engaged in a variety of writing activities out-of-school. The Commission's observation that "just 15 minutes of writing four nights per week would 
add 33\% to the amount of time the average elementary student spends writing" (p. 28) was exceeded. The students spent one and half hours per week on extra writing tasks and were encouraged to have parents and other family members get involved.

During the late 1970s and early 1980s, Barak Rosenshine conducted studies into the effect of academically engaged minutes, or "time-on-task", on students' learning. His findings indicated that being on task was the most important factor predicting learning gains (Datta, 1982). Datta (1982) defined "off-task" as activities not directly concerned with learning, such as opening books, and "on-task" activities as direct engagement with content. During the Writers' Club, efforts were made to keep "of-tasks" to a minimum and to capitalize on opportunities for 'on-task" activities. Berliner \& Rosenshine (1976) examined teaching methods and their effect on knowledge acquisition. They found that, even if the overall achievement was equivalent, other factors such as "efficiency, motivation and attitude may differ greatly" (p. 12). When these factors are taken into account, it was observed that different teaching methods may be more or less successful. Participation in the Writers' Club was designed to activate these factors, particularly attitude and motivation. In their report, they referred to Doty's (1967) study that determined that when instruction incorporated a discussion element, and social needs were met there was a greater likelihood of success. This was an integral aspect of the Writers' Club. They concluded that, when direct instruction was provided, "learning takes place in a convivial academic atmosphere" (p. 16). One of the principal goals of their study was to determine the academic learning time; when students were participating in on-task behaviors; engaged and giving their attention to the activity at hand. Even slight increases in academic learning time resulted in higher gains. Another 
factor with positive results was academically focused feedback. This was further supported in Rosenshine's (1981) study where he examined, How time is spent in elementary classrooms. In this later study, he examined academically engaged minutes of $2^{\text {nd }}$ and $5^{\text {th }}$-grade students. He found that there is a positive correlation between academic engagement and achievement, but that it was difficult to see how more time could be found for academic engagement. Providing a Writers' Club could be a means for providing the extra time needed for higher gains in writing skills. He also reiterated the importance of substantive interaction (explanations, questions, answers and feedback), that as has been stated earlier, was a component of the Writers' Club.

Lavy (2009) conducted an international study of the effect of extra time on achievement. He included data referring to math, science and reading. For the purposes of this review, his results about reading are those that will be addressed. He did not directly refer to writing. His findings indicated that extra time is causal, "positive and highly significant" (p.2). He argued that an increase of as little as one extra hour of instruction, per week, in each of the subjects resulted in a raise in test scores. He further pointed out, "the effect was larger for girls, for pupils from low socioeconomic families and for immigrants" (p.4). In the current study, there were fewer girls than boys but all students qualified for free or subsidized lunches and all were Hispanic, except one who was Asian. The estimated effects were less for reading than for math and science, nevertheless they were positive and large. The greatest effect was felt when the instructional time was increased from less than 2 hours to between 2 and 3 hours per week. 
Farbman \& Kaplan (2005), in their report on extended-time school, concluded that more time learning results in higher student achievement. The study was carried out in Massachusetts from 2003-2005. There were five distinct conditions for learning to be boosted: more time on task, greater breadth and depth of curriculum, more opportunities for planning and professional development, extended experiential and enriched learning activities and stronger adult-child relationships. Per se, it is not the extra time but how it is used that results in academic gains. Seven schools were profiled, six in Massachusetts and one in New York. Farbman \& Kaplan (2005) concluded that the positive effects of more time were evident in all the schools. They particularly mentioned that the extra time allowed "teachers to cover material in greater depth" (p.35) and that "longer class times and individualized sessions enable teachers to consistently tailor their teaching to students' individual learning needs" (p.35). The Writers' Club was able to do these things, though the school day was not extended.

In summary, extra time on task supports gains in learning. Despite this Graham \& Perin, (2007) were unable to find conclusive evidence of the benefits of extra time on writing.

\section{Conditions for Learning}

Foundational to the Writers' Club is the literature relating to Cambourne's (1995, 2000, 2001) conditions of learning. Cambourne (1995) identified the tension between the challenges of learning in the school setting when compared to the ease of learning out of the school setting. He determined that this was the result of a pedagogy, relying on specific scope and sequence for learning. This involved learning step by step, with mastery of step one being required before the introduction of step two. It involved 
endless drill and practice. This is still seen in the form of repetitive responses to prompts being the norm in writing classes, especially at the fourth-grade level. Cambourne (1995) determined that oral language acquisition was a highly complex skill that is learned rapidly, without distress and is almost universally successful. He examined the conditions under which language was learned and concluded that the following were necessary: immersion, demonstration, engagement, expectations, responsibility, approximation, employment and response. He then sought the assistance of other teachers to explore these conditions as they might relate to literacy learning. The result of his inquiry was that engagement is the key, all the other conditions go for nothing and learning will not result, if students do not engage. Also, it was found that there were four processes that needed to take place for learning to be internalized: transformation, discussion/reflection, application and evaluation. Cambourne's (1995) conditions were taken as constructs and applied specifically to the development of extra writing in the Writers' Club. These conditions were applied to this study in the following manner: Immersion means the state of being steeped in stimuli. Students need to be immersed in both model texts and writing experiences. Model texts were read aloud during some meetings and made available every meeting for students to study. Writing time constituted a large proportion of the meeting time (from 10-20 minutes out of 30).

Demonstration means experiencing multifaceted exposure to text. Model texts, as stated above, provided demonstrations of how texts are constructed and used. Practical demonstrations of how to construct and use text were provided, meeting by meeting, covering needed skill experiences. 
Engagement means intentional active participation. Students engaged in contributing to ideas and made suggestions as practical demonstrations took place during the meetings. Students were supported in the development of their perception of themselves as capable doers of that which was demonstrated and encouraged to experiment. Their attempts were valued. The students used their journals to emulate both the practical demonstrations and the model texts. They had opportunities to share their process and products one-to-one, with a small group, and with the whole group. When revising sentences, that failed to follow the correct conventions of customary English, students engaged with each other and the researcher-guide to orally make corrections. They then wrote the corrected version of the sentence(s) in their journals. Students were provided with graphic organizers to gather details (ideas) for their writing and were offered opportunities to discuss their thinking with each other and with the researcher-guide. Students had ample time to produce and share their independent work. Expectations mean messages for success communicated by significant others. The students were made aware of the high expectations that the researcher-guide held of their likelihood of success. The researcher-guide fostered open relationships between herself and the students and between the students and each other, to facilitate them in their understanding of what is expected of them. The students' confidence in themselves was fostered through non-threatening support and constructive feedback within group meetings, individual conferences and personal feedback via their journals. At the end of each conference, the students were encouraged to identify what their goals were and over what period they intended to achieve them. 
Responsibility means making decisions and choices about learning. The students were encouraged to demonstrate responsibility when they developed the rules of the club, to facilitate the routines and to clarify expected behaviors while participating in the club. The rules recognized the common goals of the club and set parameters for appropriate behavior. Students were enfranchised regarding what to do, through opportunities to express verbally what they intend to work on and what targets they wished to set for themselves during individual conferences. Once these goals are identified, students made a note of them in their journals and set time frames for achievement. The researcherguide checked up with students using conferences to clarify progress towards goals.

Approximation means measured steps towards learning goals. Errors were accepted, examined and regarded as an approximation rather than inadequacy. Support was given to facilitate each student's growth based on his/her demonstrated needs. It was important for the students to observe the researcher-guide making purposeful mistakes and correcting them, demonstrating that our mistakes help us to progress and that they are not debilitating.

Use means opportunities to practice. Students were given time to practice what they were learning within their own writing. They were encouraged to talk through what they were doing and how they planned to proceed during discussion sessions and writing time.

Response means meaningful response from significant others in regards to goals. Students were provided with feedback during group sharing sessions, peer discussion and one-to-one conferences with the researcher-guide. In addition the researcher-guide provided individual feedback through comments made in the students' journals. During 
early meetings of the club, constructive criticism was demonstrated. Such constructive criticism was given in a non-threatening manner, pertinent to their writing, in manageable quantities and as suggestion to be considered.

In his later work, Cambourne (2000) identified three further elements that he regarded as pivotal to learning: the physical space, the behaviors that took place within the physical space and the routines that typically occurred within the physical space. The physical space included print availability in the form of books, magazines and other texts, the furniture, the display space and other resources. The behaviors involved the human component within the setting. While the inanimate content of the space was expected to remain constant, Cambourne (2000) identified it was the human component that resulted in the processes for learning being instigated through a "wide range of interactions both with one another and with the physical paraphernalia there" (Cambourne, 2000, p. 513). Through his observations of classrooms, he determined that teachers manipulate the conditions. One of the most important things teachers manipulate is the discourse of the environment. This involved creating an atmosphere that manifests itself in a consensus of opinion that literacy is critical. This is achieved consciously by the teacher. The routines covered the teachers' expectations. Routines include such things as having a positive attitude towards learning, seeking and accepting advice willingly, understanding the need for preparedness when going public and applying knowledge. Also, the routines involved such things as feedback.

Physical space means location and environment. Writers' Club meetings took place in a familiar setting; a media center was used. The physical space was within the library. There were some tables, accommodating 6, 4, or 2 students. There were some 
single-person tables. There was a rug on the floor and students were permitted to work at the tables or on the floor. In a section of the meeting space, there were some computers that were available for students to use. A portable crate containing materials for use during Writers' Club, including pencils, the students' journals and a selection of books, was available.

Behaviors within the space mean conduct and actions. During the early meetings of the club, the students with input from the researcher-guide, developed the rules for the Writer's Club. These rules dictated appropriate behaviors and outlined the expectations of members during meetings. The rules were open to revision by majority vote, if any behaviors were found to be unacceptable by members of the group. The students had access to a small bell that anyone could ring to make any announcement. The bell was most often rung by students to remind their classmates to work more quietly to allow everyone to concentrate.

Routines within the space mean learning activities within the timeframe. Instruction followed a routine that included taking attendance, conventions experiences, discussion of an appropriate topic, and writing time, that included conferences. Meetings concluded with tidy-up time. This provided students with a stable framework within which to work. Lesson plans were developed with routines clearly stated; these included concept development steps: explain, demonstrate, guide, practice, and apply.

In his further work, Cambourne (2001) addressed the attempt to turn theory into practice. He developed "a framework for turning theory of learning into classroom reading instruction" (Cambourne, 2001, p. 415). He took each condition, identified what the condition meant and explored possible strategies that could be employed to 
implement the identified condition. The Writers' Club built upon this framework to develop strategies that could be implemented within the Writers' Club environment to facilitate growth in writing.

\section{Trait Writing for Assessment and Instruction}

To support effective writing instruction, in the 1980s the 6 Trait model was

developed. It used the analytical approach to assessing writing, focusing on traits. It was developed in response to the need of teachers for a reliable tool, closely aligned with effective writing instruction (Culham, 2003; Kozlow \& Bellamy, 2004; Northwest Regional Education Laboratory, 2004). Prior to the development of the 6 Trait writing model, writing samples were largely assessed in a holistic manner, assigning an overall score for any given piece. Based on earlier research (Diederich, 1974; Murray, 1982; Purves, 1992), some characteristics of effective writing have been identified. The characteristics align well with process writing: pre-writing, drafting, revising and editing (Emig, 1971, Applebee, 1986). According to Spandel (2013), the 6 Traits were developed by the Analytical Writing Assessment Development Committee; a 17 member group of teachers, all of whom were volunteers, teaching grades three through 12 in the Beaverton, Oregon School District. These teachers perceived a need to improve writing assessment as one element in improving the teaching of writing. In its initial stages, the teachers identified characteristics they regarded as representative of good writing. The traits were developed, and scales established ranging from beginning skills to excellent skills. Initially, six traits were identified, and one further trait was added relating to presentation, in 1999. 
Both Culham (2003) and Spandel (2013) refer to the traits as ideas, voice, organization, sentence fluency, word choice, and conventions. Culham (2003) separates the +1 into an individual trait - presentation and Spandel (2013) enmeshes it with conventions. Either way, it is not an element of the actual writing but rather provides the window dressing for publication. The $6+1$ Trait Writing is not a writing curriculum (Coe, Hanita, Nishioka, \& Smiley, 2004; Culham, 2003; Spandel, 2013). It is a model that complements writing instruction, providing guidance about what to look for in a writing sample and a means of assessing it. The specific traits used in the rubric were arrived at after weeks of work, reading student writing samples and sorting them into "high, middle and beginning levels and documenting ...reasons for ranking them" (Spandel, 2013, p. 431). Beaverton then conducted a field test of the identified traits. Approximately 5,000 student writing samples, 1,250 from each of the following grades: three, five, eight and 11, were examined using the assessment. Today, this is the most common analytic model used to judge how well students write (Calfee \& Miller, 2007). Spandel's (2013) most up to date iteration, the Teacher Six-Point Writing Guide, is a 6-point scale with each aspect (ideas, organization, voice, word choice, sentence structure and conventions/presentation) having five items presented on a continuum. Scales range from 1 to 6 with 1 indicating minimal command of the specific trait and 6 indicating advanced skills. Spandel's Teacher Six-Point Writing Guide is an informal assessment. Whilst a prepared rubric is used, the outcome is at least partially dependent on the assessor's individual interpretation of any given writing sample and of the assessment. The Teacher Six-Point Writing Guide is the instrument that was used in the current study to evaluate the students' writing samples. 
There have been many studies that employed the $6+1$ Trait as the treatment to improve writing skills, including the rubric for evaluation purposes (Arter, Spandel, Culham and Pollard, 1994; Kozlow and Belamy, 2004; Andrade, Buff, Terry, Erano and Paolino, 2009)

Arter, et al. (1994) conducted a study under the aegis of Northwest Regional Education Laboratory (NWREL) included six fifth-grade classrooms with 67 students in the treatment group and 65 in the control group. The researchers argued that the six trait model presented the best available means for making the judgments of whether writing had improved.

Andrade, et al. (2009) conducted a study to examine how the use of rubrics could improve sixth, seventh and eighth-grade student writing. They developed two rubrics; one oriented towards sixth-grade students and one oriented towards eighth-grade students. The rubrics were designed using the $6+1$ Trait as a model and targeting the New York State standards for English/Language Arts. The rubrics were used for selfassessment, peer assessment, and teacher assessment with the objective of encouraging self-reflection or providing peer or teacher feedback. Andrade et al. (2009) addressed validity and reliability directly. Validity was determined by the rubrics' alignment with the New York Standards and further supported by an informal poll of the students. All concerns were addressed and they reported "students told us that they understood and valued the rubrics" (Andrade et al., 2009, p. 7). They also stated that, "teachers' classroom observations of peers and self-assessment sessions confirmed the students' claims" (Andrade et al., 2009, p. 8). Reliability focused on inter-rater reliability, they examined how closely each of the raters rated two essays. They found that scores tended 
to be close but did not strive for perfection. Minor changes in the wording of the rubrics resulted. No data for psychometric analysis of the rubrics was given.

Andrade et al. (2009) reported that, within the course of the study, the researchers found that the students' writing, when using the rubrics, improved. However, when they wrote under practice test conditions they did not transfer their skills to that setting. Two adjustments were made. Firstly the researchers developed an acronym to "jog" the students' memories when writing. Secondly, one of the teachers added extrinsic rewards for improvement in writing to provide motivation and challenge. It was not clear whether all the teachers did this. Andrade et al.'s (2009) findings were based on scores for the ELA tests conducted in 2006 and 2007, by grade level and sub group. The sub groups were: African American students, special needs students and economically disadvantaged students. They found that all but two of the categories of students (overall seventh-grade students and African American seventh-grade students) percentages achieving a score of 3 or 4 improved. Grades six and eight improved by $7 \%$ and $15 \%$ respectively overall. The most impressive improvements were for economically deprived students who improved $20 \%$ for both grades six and eight. The seventh-grade scores showed fewer gains. This may have been the result of the design of the test in seventh grade that did not ask for an extended writing response. No psychometric tests of significance were reported. Thought was given to using the rubrics, or modified forms thereof, developed in Andrade et al.'s (2009) study, but some considerations supported the use of Spandel's (2013) Teacher Six-Point Writing Guide. Andrade et al.'s (2009) rubrics were developed for sixth and eighth grade; the current study participants were in fourth grade. Their rubric was adjusted from the $6+1$ Trait Rubric to encompass New York State standards. 
The current study was carried out in Florida. No psychometric data were provided to support their rubrics as being more reliable or valid than the $6+1$ Trait Rubric, and their rubrics were used in a single study whereas the $6+1$ Trait is widely disseminated throughout the U. S.

Coe et al. (2012) conducted another study examining the impact of the $6+1$ Trait writing model on fifth-grade writing achievement. They collected data for their clustered-randomized experimental study from 74 Oregon schools -54 during academic year 2008/2009 and 20 during academic year 2009/2010. They concluded that improvements in three of the six traits were significant - organization, voice, and word choice. The mean scores for the treatment group were higher than the control group for the other three traits - ideas, sentence structure and conventions but not significant. The Coe et al. (2012) study offered insight into the effectiveness of a $6+1$ Trait model of instruction including the use of the assessment. The current study did not follow the $6+1$ Trait model, only used Spandel's (2013) Teacher Six-Point Writing Guide for assessment of student writing for the pretest and posttest. Furthermore, the Coe et al. (2012) study examined the effect on fifth-grade students, and the current study examined what effect participation in Writers' Club had on fourth-grade, Hispanic students' writing.

Spandel's (2013) Teacher Six-Point Writing Guide lends itself to formative assessment, providing both teachers and students with the language of writing. This can be used to encourage students to reflect on their own, and each other's, writing rather than depending solely on the teacher for feedback (Andrade et al., 2009). The 6+1 Trait writing model was designed to help teachers teach and assess student writing. The materials of the program are designed to "build teacher understanding ... and teacher 
knowledge of the characteristics of quality writing ... and to provide formative assessment feedback to students" (Kozlow \& Bellamy, 2004, p. 4 and 5).

The $6+1$ Trait model and its assessment rubric are widely disseminated throughout the U.S. and other countries (Kozlow \& Bellamy, 2004; Coe et al., 2012). For the purpose of this study, the $6+1$ Trait Writing Instruction was not the model of instruction. Spandel's (2013) Teacher Six-Point Writing Guide was used to evaluate student writing.

\section{Attitude towards Writing}

One of the factors affecting writing performance is the attitude towards writing (Williams, 2012). So, the effect of the Writers' Club on students' attitude towards writing was also examined. This was based on two perspectives. The first was the premise that those students with a positive attitude are more likely to choose to write and to spend time writing (Graham, Berninger \& Fan, 2007). The second perspective was that students' experiences when engaging with writing influence their development of positive or negative attitudes towards writing (Kear et al., 2000).

There have also been studies that have found that students' attitude towards writing becomes less positive as they progress through the grades (Knudsen, 1991, 1992, 1993). Despite searches in the following databases ERIC, ProQuest dissertations \& theses, Latin-American Newsstand, and PsychINFO, no relevant articles were found relating to Hispanic/ Latino fourth-grade students' attitude to writing using keywords: fourth-grade, Hispanic, Latino, writing, and attitude, in a variety of combinations. Assessing the students' attitude before they participated in Writers' Club provided data regarding the attitude the students hold towards writing and potentially their willingness 
to participate in writing activities. Conducting the assessment of their attitudes towards writing after participation provided data for related to their writing attitudes after engaging in writing activities.

Being knowledgeable about students' attitude concerning writing can potentially benefit writing instructional practices (Kear et al., 2000). Students' positive attitude to writing becomes less positive as they progress through the grades (Kear et al., 2000, Knudsen, 1991, 1992, 1993). Barnard (2002) found that relinquishing the teachercentered model of instruction in favor of a writing workshop, together with the benefit of feedback from multiple sources, resulted in greater enjoyment of writing. Participation in Writers' Club had the potential to build on students' sociocentricity and, with its reduced focus on teacher-centeredness, encourage a more positive attitude towards writing. Gathering data to enhance the understanding of ways to maintain or improve positive attitudes was valuable. Finally, given the lack of evidence regarding the attitude Hispanic students hold towards writing this study presented a base line regarding their attitude towards writing.

\section{Summary}

Based on national assessments, overall, only $25 \%$ of students write at a proficient or advanced level according to NAEP. Hispanic students perform less well than their White counterparts, with approximately $13 \%$ writing proficiently. When Floridian students' scores are examined their results are commensurate with the national results. There is very little difference in the percentages between M-DCPS and the state. During the 2012 FCAT assessment there was a significant drop in the average scores in MDCPS possibly attributable to the disproportionate number of Hispanic students in the district, 
many of whom are English language learners. The aforementioned percentages have remained static for 17 years. It is important for students to write proficiently if they are to be successful in college and career.

The introduction of the CCSS has placed a greater focus on writing. The Florida Standards closely reflect the CCSS. The degree of rigor for writing has been increased, particularly regarding the adherence to the conventions of customary English and the inclusion of details (ideas).

Providing instruction under the aegis of clubs has shown some success, according to a number of studies (Heller, 2006; McCarry \& Greenwood, 2009; Polleck, 2010; Raphael, Florio-Ruane, \& George, 2001; Raphael \& McMahon, 1994). Reading clubs have been shown to be beneficial to reading enhancement. Extending the concept of the club to writing, McCarry and Greenwood (2009) conducted a qualitative study with a Writers' Lunch Club. Their study was the foundation of the proposed study.

Spandel's (2013) 6 Trait writing assessment, as epitomized in her Teacher SixPoint Writing Guide, has been determined to be in line with best practice. This is the instrument that was used to evaluate students' writing in the current study. It is ideally designed to provide scores for overall writing skills, the adherence to the conventions of customary English, and the inclusion of details (ideas) that were statistically analyzed for significance.

Students' attitude towards writing becomes less positive as they progress through the grades (Knudson, 1991, 1992, 1993). Since attitude towards writing is instrumental in students' willingness to engage in writing and the attention they give to their work the 
current study examined the effect of participation in a Writers' Club on students' attitude towards writing.

The Writing Attitude Survey that was used to analyze students' attitude towards writing was developed by Kear et al. (2000). It was specifically designed for use with students between $\mathrm{K}-12$. 


\section{CHAPTER 3}

\section{METHODS AND PROCEDURES}

The focus of the current study was to examine the effect of participation in Writers' Club on fourth-grade, Hispanic students' writing; particularly as it related to their incorporation of details (ideas) and their adherence to the conventions of customary English as well as their overall writing skill. Also, their attitude toward writing was examined. Sixty, fourth-grade, Hispanic students provided a writing sample and completed a writing attitude survey prior to participating in one of three writing conditions: Writers' Club, At Home Writing Group and a group with no extra writing. After the intervention, they provided a second writing sample and completed the writing attitude survey a second time. Forty, fourth-grade, Hispanic students participated in one

of the two treatment conditions. Twenty-two, fourth-grade, Hispanic students participated in Writers' Club that lasted for 24, 30-minute, meetings over an 8-week period. The meetings included a variety of writing activities designed to facilitate growth in overall writing. The activities were designed to facilitate the inclusion of details (ideas) and conformity to conventions of English. Eighteen, fourth-grade, Hispanic students participated in the At Home Writing Group. This ran concurrently with the Writers' Club. Students spent 90 minutes per week engaged in a variety of writing activities at home. A comparison group of 20 fourth-grade, Hispanic students participated in a group with no extra writing. All students received regular writing instruction and homework

This chapter presents the research design including the general and specific research hypotheses. This is followed by the procedures of the study. Details are provided regarding participant recruitment, teachers' contribution, the Writers' Club, the 
At Home Writing Group, the group with no extra writing, and the evaluators' contribution. Data collection includes the administration of the pretest and posttest writing samples, the administration of the pretest and posttest Writing Attitude Survey and support for the use of the instruments. The chapter concludes with data analysis.

\section{Research Design}

This intervention study followed a quasi-experimental, pretest-posttest, nonequivalent group design. It examined the effect of extra writing using two treatment conditions: participation in a Writers' Club or participation in an At Home Writing Group on fourth-grade, Hispanic students' writing. Based on national, statewide and local assessment of students' writing skills, approximately $75 \%$ of students write below a basic level (National Center for Education Statistics, 2012a; Pretsky, Daane, \& Jin, 2003). In Florida, there was a considerable drop in the writing scores in 2012 (Geisinger et al, 2012) and the standards relating to the inclusion of details (ideas) and adherence to the conventions of customary English were made more stringent (Geisinger et al., 2012; FDOE, 2005-2013d). Thus the current study focused on overall writing development, the incorporation of details (ideas) and the command of the conventions of customary English. In addition, students' attitude to writing becomes less positive as they progress through the grades (Kear et al, 2000; Knudsen, 1991, 1992, 1993) and no research on fourth-grade Hispanic students' attitude to writing was found. Thus the students' attitude to writing was examined. The goal was to answer the research questions:

- What effect does participation in a writers' club have on fourth-grade, Hispanic students' overall writing? 
- What effect does participation in a writers' club have on fourth-grade, Hispanic students' incorporation of ideas in their writing?

- What effect does participation in a writers' club have on fourth-grade, Hispanic students' use of appropriate conventions of customary English?

- What effect does participation in a writers' club have on fourth-grade, Hispanic students' attitude towards writing?

\section{Hypotheses}

\section{General Research Hypothesis One.}

Hypothesis 1: There is a relationship between participation in a writers' club and the overall writing of fourth-grade, Hispanic students.

\section{Specific research hypothesis 1.}

Fourth-grade, Hispanic students who participate in the Writers' Club will achieve significantly higher mean scores for their overall writing than students who participate in the At Home Writing Group or who are in the No Extra Writing group, when their writing samples are evaluated using Spandel's (2013) Teacher Six-Point Writing Guide and controlled for pretest scores.

\section{Subordinate hypotheses for $\mathbf{H}_{1}$.}

Members of the Writers' Club will achieve significantly higher mean scores for their overall writing than students who participate in the At Home Writers Group, when their writing samples are evaluated using Spandel's (2013) Teacher Six-Point Writing Guide and controlled for pretest scores.

Members of the Writers' Club will achieve significantly higher mean scores for their overall writing than students who are in the No Extra Writing group, when their 
writing samples are evaluated using Spandel's (2013) Teacher Six-Point Writing Guide and controlled for pretest scores.

Members of the At Home Writing Group will achieve significantly higher mean scores for their overall writing than students who are in the No Extra Writing group, when their writing samples are evaluated using Spandel's (2013) Teacher Six-Point Writing Guide and controlled for pretest scores.

\section{General Research Hypothesis Two.}

Hypothesis 2: There is a relationship between participation in a writers' club and the ability to incorporate details (ideas) in the writing of fourth-grade, Hispanic students.

\section{Specific research hypothesis 2 .}

Fourth-grade, Hispanic students who participate in the Writers' Club will achieve significantly higher mean scores for their incorporation of details (ideas) in their writing than students who participate in the At Home Writing Group or who are in the No Extra Writing group, when their writing samples are evaluated using Spandel's (2013) Teacher Six-Point Writing Guide and controlled for pretest scores.

\section{Subordinate hypotheses for $\mathrm{H}_{2}$.}

Members of the Writers' Club will achieve significantly higher mean scores for their incorporation of details (ideas) in their writing than students who participate in the At Home Writers Group, when their writing samples are evaluated using Spandel's (2013) Teacher Six-Point Writing Guide and controlled for pretest scores.

Members of the Writers' Club will achieve significantly higher mean scores for their incorporation of details (ideas) in their writing than students who are in the No Extra 
Writing group, when their writing samples are evaluated using Spandel's (2013) Teacher Six-Point Writing Guide and controlled for pretest scores.

Members of the At Home Writing Group will achieve significantly higher mean scores for their incorporation of details (ideas) in their writing than students who are in the No Extra Writing group, when their writing samples are evaluated using Spandel's (2013) Teacher Six-Point Writing Guide and controlled for pretest scores.

\section{General Research Hypothesis Three.}

Hypothesis 3: There is a relationship between participation in a writers' club and the ability to adhere to the conventions of customary English in the writing of fourth-grade, Hispanic students.

\section{Specific research hypothesis 3.}

Fourth-grade, Hispanic students who participate in the Writers' Club will achieve significantly higher mean scores for their ability to adhere to the conventions of customary English in in their writing than students who participate in the At Home Writing Group or who are in the No Extra Writing group, when their writing samples are evaluated using Spandel's (2013) Teacher Six-Point Writing Guide and controlled for pretest scores.

\section{Subordinate hypotheses for $\mathrm{H}_{3}$.}

Members of the Writers' Club will achieve significantly higher mean scores for their ability to adhere to the conventions of customary English in their writing than students who participate in the At Home Writers Group, when their writing samples are evaluated using Spandel's (2013) Teacher Six-Point Writing Guide and controlled for pretest scores. 
Members of the Writers' Club will achieve significantly higher mean scores for their incorporation of details (ideas) in their writing than students who are in the No Extra Writing group, when their writing samples are evaluated using Spandel's (2013) Teacher Six-Point Writing Guide and controlled for pretest scores.

Members of the At Home Writing Group will achieve significantly higher mean scores for their ability to adhere to the conventions of customary English in their writing than students who are in the No Extra Writing group, when their writing samples are evaluated using Spandel's (2013) Teacher Six-Point Writing Guide and controlled for pretest scores.

\section{General Research Hypothesis Four.}

Hypothesis 4: There is a relationship between participation in a writers' club and attitude towards writing of fourth-grade, Hispanic students.

\section{Specific research hypothesis 4 .}

Fourth-grade, Hispanic students who participate in the Writers' Club will achieve significantly higher mean scores for their responses to the Writing Attitude Survey than students who participate in the At Home Writing Group or who are in the No Extra Writing group, when controlled for pretest scores.

\section{Subordinate hypotheses for $\mathbf{H}_{4}$.}

Members of the Writers' Club will achieve significantly higher mean scores for their responses to the Writing Attitude Survey than students who participate in the At Home Writing Group, when controlled for pretest scores. 
Members of the Writers' Club will achieve significantly higher mean scores for their responses to the Writing Attitude Survey than students who are in the No Extra Writing group, when controlled for pretest scores.

Members of the At Home Writing Group will achieve significantly higher mean scores for their responses to the Writing Attitude Survey than students who are in the No Extra Writing group, when controlled for pretest scores.

\section{Procedures}

\section{Participant Recruitment}

Fourth-grade students attending a Miami-Dade County Public School were recruited to participate in the study. The students in fourth grade were offered the opportunity to participate. Students with ESOL levels 1 and 2 status were excluded because these students were deemed to lack sufficient command of English to benefit from the intervention. All the students in the study were identified as Hispanic. All the students in the study qualified for free or reduced lunches. All the students in the study fell within the expected age band for fourth grade (age nine at September 1, 2014). Of the 60 students in the study, 39 were boys and 21 were girls.

Once the appropriate approvals had been obtained, the researcher met with the principal to discuss the recruitment of participants, the appropriate way of addressing the logistics of setting up the study and to arrange meetings with the teachers, students and parents. Owing to the impending holidays, the principal suggested that the Parent Information Letter and Consent Form be distributed by the teachers immediately. Two copies were sent out, on consecutive days, at the end of November. The proposal was for the students to join an after-school writers' club, during the Spring Term. Each meeting 
would last for 90 minutes and take place three times per week for an 8 -week period. The responses were very poor. Parents were unwilling for their students to participate most citing previous commitments and/or transport difficulties. The principal of the school was still anxious for the study to go ahead.

A meeting with the fourth grade teachers was convened, with the principal present. The agenda (Appendix B) covered an introduction to the researcher, an explanation of the three conditions: Writers' Club, At Home Writing Group and No Extra Writing group; the teachers' involvement and any questions. During this meeting, it was decided that Writers' Club could be conducted during school time, if adjustments to the daily schedule were made. The meetings would have to be reduced to 30 minutes each, but would still take place three times a week. The teachers were asked for their best recommendations for timing, and a schedule was established. The Parent Information Letter and Consent Form required only minor revisions. The new letter outlined the study. The conditions were explained: the Writers' Club meetings would take place during school hours and last for 30 minutes each. To distinguish them from the original letters, the new letters were printed on yellow paper. The teachers handled the distribution and collection of the revised Parent Information Letter and Consent Form (Appendix C). The teachers indicated that they preferred the researcher to administer the Writing Attitude Survey. The time for the researcher to visit the school to talk to the students was arranged. Amendments to the IRB approval were sought and approved. The researcher visited each of the school's fourth-grade classrooms. The meeting with the students followed an agenda (Appendix D). What was involved in the study was explained to the students, including an outline of the various groups and what each 
entailed. The students were told that the first treatment group would consist of 25 fourthgrade students who would participate in Writers' Club. The club would meet three times per week for 30 minutes.

The second treatment group would consist of another 25 fourth-grade students who would participate in the At Home Writing Group. Each student in the At Home Writing Group would be provided with a folder of writing activities to be completed at home. The folders would be distributed and collected on the same day each week. There would be a writing log within the folder that should be filled out by the student and initialed by a parent to verify the accuracy of the information on the form.

The remaining fourth-grade students would receive no extra writing. All students would receive regular classroom instruction and homework. The study would last for an 8-week period during the spring semester.

The students were asked to think about each of the groups and decide which they would like to belong to. They were informed that all the groups were equally important and that they could choose not to participate at all. Student assent forms (Appendix E) were passed out during this meeting. The students decided which group they wanted to belong to and signed the forms. Discussion was held regarding dropping out and joining late.

During the researcher's visit to the first classroom, one student wanted to know if he could change his mind before the Writers' Club started and what would happen if he decided he didn't want to participate. The researcher explained that he could change his mind prior to the club starting and switch to another group if he wanted to. It was explained that he could drop out of his chosen group at any time but if the study had 
already started he would not be able to switch groups. This was explained to each of the classes.

The students were told to discuss their participation with their parents. They were also advised that their participation was dependent on the researcher receiving their parents' consent, they were provided with an additional Parent Information Letter and Consent Form (Appendix C) and reminded that the form that needed to be completed was the yellow one. The students were told that their parents would also be invited to a special meeting, so they could be informed about the project. Each student was given an announcement, in English and Spanish, to give to their parents, inviting them to the meeting.

All fourth-grade students' parents and teachers were invited to attend a meeting at the school, where a full explanation of the study was given, following the agenda (Appendix F). Consent forms (Appendix C) were obtained from the parents who wished their children to participate in the study.

Parents were offered the opportunity to select which condition they would prefer for their child. Two parents indicated a preference different from that of their children. One set of parents indicated that they did not want their child to participate in any way at all. That student's writing samples and Writing Attitude Surveys were eliminated from the data. Another mother indicated that she preferred her child to participate in a different group from the one indicated by the child. This was discussed with the child. She was offered the choice of belonging to the group selected by her mother or joining the No Extra Writing group. She decided that she would join the group her mother had 
given permission for her to join. The due date for receipt of parent consent letters was set one week after the explanatory meeting and before the Writers' Club began.

Students were accepted into the different conditions based on indicated preferences. Of the 69 students in the fourth grade, six did not qualify because of their ESOL status, one student's parents declined to have their child participate, one student was unable to produce a pretest writing sample, and one student completed a pretest writing sample but left the school prior to the intervention starting. None of the students was eliminated from the group they selected based on over-subscription. Twenty-two students joined Writers' Club, 18 students joined the At Home Writing Group and 20 students participated in the group with no extra writing. All students received regular writing instruction and homework.

\section{Teachers' Contribution}

The fourth-grade teachers were asked to collect two writing samples from the students. The first sample was collected prior to the intervention, the pretest, and the second sample was collected after the intervention, the posttest. The teachers made arrangements for the researcher to visit the classroom before and after the intervention to administer the Writing Attitude Survey. The teachers arranged a schedule for the researcher to visit the classrooms on a weekly basis to deliver and collect the At Home Writing Group's folders. The teachers dispersed and collected the At Home Writing Group folders to the students and communicated with the researcher regarding folders handed in late and students' absences. 


\section{Activities and Materials}

The writing activities developed for use by the students in the Writers' Club were designed to target the adherence to the conventions of customary English and the inclusion of details (ideas) in writing. The adherence to conventions of customary English were primarily addressed through unpunctuated sentences being written on the white-board. These were then discussed by the students, initially with the help of the researcher-guide. As the students became progressively more adept at correcting the sentences the researcher-guide relinquished her role of authority figure and took on the role of observer, while the students discussed the sentence and decided what to do. This was done to be in line with the theoretical framework of the study. Brufee (1984) encouraged teachers to relinquish the role of authority and return to that of peer. $\mathrm{He}$ further argued that when students help each other their work improved. Cambourne (2001) argued that engagement is a critical element in learning. It is initiated when students make connections with demonstrations and perceive themselves a capable doers of what was demonstrated. As a result, as soon as the students demonstrated confidence in their ability to correct the sentences the researcher-guide encouraged them to do so. This also aligns will with Cambourne's (2001) position regarding responsibility. Students need to take responsibility for their own growth (See Appendix G, Lesson Plans and Reflections).

The students were provided with a plethora of texts. The inclusion of details (ideas) was addressed through the two primary text types incorporated in the Writers' Club. The students first wrote letters and then essays. The letters were based on the text Goldilocks and the Three Bears and involved taking a stance and writing to another 
character in the book. The students were encouraged to go beyond the text and develop the details of their letters using their own ideas. This was in line with Cambourne's $(1995,2001)$ conditions of immersion, responsibility and engagement. They had been provided with a demonstration and were expected to take responsibility for their decision making regarding what to include (see Lesson Plans Appendix G).

When the Writers' Club members moved on to write essays there was an overall content area. This was Florida because this is in line with the expectations for students in Grade 4. This topic was refined to the Everglades. The students were allowed to choose what they wanted to write about within this overarching topic. They were provided with graphic organizers and instructed in how to use them. They were also taught how to conduct research using model texts to gather details to add to their essays. The gradual steps the students made towards their final products were conducted under many of Cambourne's conditions of learning (See Appendix G, Lesson Plans and Reflections), but in particular, use, approximation, engagement,

At all times the researcher-guide communicated her expectations, that the students would be successful at whatever they were engaged with (Cambourne, 2001).

Similarly, the materials provided to the At Home Writers' Group were selected with care. To target adherence to the conventions of customary English, each week the students had an activity related to an aspect of conventions. These activities included things like word building, sentence building, connectives etc. To target the inclusion of details (ideas), there were activities which encouraged creativity. These addressed informational writing through report writing, writing a news article or making a family 
encyclopedia and narrative writing through a variety of prompts beginning "Imagine you are a ...."

Each week, the At Home Writers' Group had a Free Choice activity allowing the participants to take responsibility for their growth. It also allowed them to follow their personal interest, rather than being dictated to by the prompt. Nevertheless, there were a variety of prompts to encourage those who might have been experiencing "writers' block", but which encouraged the inclusion of details.

\section{Writers' Club}

The Writers' Club took place three days per week, for 24 sessions, over an eightweek period. Each Writers' Club meeting lasted for 30 minutes. The meetings took place on consecutive days, in the early afternoon, immediately after lunch. The researcher-guide supervised the Writers' Club meetings. There were other school personnel on the premises but not involved in the Writers' Club. Students came to the club, after being dismissed by their teachers 5 minutes before the starting time of the meetings.

Careful consideration was given to the setting in which the Writers' Club took place. Cambourne (2000) identified the importance of the setting. He cited three components that he referred to as "aspects of the classroom" (p. 512) that contribute to student internalization of content. He argued that the "physical paraphernalia" (p. 512), the "human behaviors" (p. 513) and the "programs (routines and events)" (p. 514) are all elemental to the learning process. These aspects of learning together with what they mean and how they were implemented in the Writers' Club are outlined in Table 1, below. 
Table 1

Cambourne's Aspects of the Classroom

\begin{tabular}{|c|c|c|}
\hline Aspect & $\begin{array}{l}\text { Meaning of } \\
\text { Cambourne's } \\
\text { Aspect (2000) }\end{array}$ & $\begin{array}{l}\text { How "aspects of the classroom" (p. 512) were incorporated into the } \\
\text { Writers' Club }\end{array}$ \\
\hline $\begin{array}{l}\text { Physical } \\
\text { Space }\end{array}$ & $\begin{array}{l}\text { Location and } \\
\text { environment - } \\
\text { the "inanimate } \\
\text { paraphernalia" } \\
\text { (p. 512) present } \\
\text { in the setting }\end{array}$ & $\begin{array}{l}\text { The Writers' Club meetings took place in a familiar setting, within the } \\
\text { library. On three sides of the work space were filled book-shelves. } \\
\text { Books related to the topics being covered by the Writers' Club, were } \\
\text { also provided by the researcher-guide. Furniture was arranged to } \\
\text { encourage student interaction. There was a single table which seated six } \\
\text { or eight students, other tables seated two or four students. There were } \\
\text { some individual tables. There was a rug on the floor. Students were } \\
\text { permitted to work at the tables or on the floor. There were a number of } \\
\text { computers, for students to use. The students had individualized, lined, } \\
\text { composition books and personal pencils to work with. There was lined, } \\
\text { loose-leaf paper available. As the Writers' Cub moved into the essay } \\
\text { writing portion there were a variety of graphic organizers available. } \\
\text { There was a Smart board and a white board available. The lighting } \\
\text { enabled all students to see and work with ease, and the temperature was } \\
\text { comfortable. }\end{array}$ \\
\hline $\begin{array}{l}\text { Human } \\
\text { Behaviors }\end{array}$ & $\begin{array}{l}\text { "Human } \\
\text { components" (p. } \\
513) \text { - conduct } \\
\text { and actions } \\
\text { within the space }\end{array}$ & $\begin{array}{l}\text { The human components consisted of the researcher-guide and } 22 \\
\text { students. The researcher-guide promoted a pro-writing, pro-reading } \\
\text { atmosphere, and encouraged the students to be authors of their own } \\
\text { success. She endeavored to engender a sense of student power. This } \\
\text { was done through providing the students with opportunities to determine } \\
\text { how the Club operated, and allowing them choices regarding what they } \\
\text { wanted to write. As an example, during the early meetings of the club } \\
\text { the students, with input from the researcher/guide developed the } \\
\text { Writer's Club rules. An example of choice regarding what to write, the } \\
\text { students decided which character they wished to represent in their letter } \\
\text { writing and to whom they were writing. The researcher-guide } \\
\text { deliberately encouraged the students' to believe in themselves as writers, } \\
\text { and to value their work. The researcher-guide focused on open } \\
\text { questions: How can you best express that point of view? What do you } \\
\text { mean by that? She also recapped what had been addressed and } \\
\text { summarized experiences during discussion. }\end{array}$ \\
\hline $\begin{array}{l}\text { Routines } \\
\text { and } \\
\text { Events }\end{array}$ & $\begin{array}{l}\text { Programs within } \\
\text { the setting - } \\
\text { "microprograms" } \\
\text { and } \\
\text { "macroprograms" } \\
\text { (p. 514) }\end{array}$ & $\begin{array}{l}\text { Instruction followed a regular routine (microprograms) - conventions } \\
\text { experiences, discussion of an appropriate topic, writing time which } \\
\text { included conferences. This provided students with a stable framework } \\
\text { within which to work. Behind this planning lay the researcher-guide's } \\
\text { expectations (macropograms). Her goals for the students included } \\
\text { having or developing a positive attitude towards writing, including many } \\
\text { details in written work, following the conventions of customary English, } \\
\text { conduct research through sustained reading from a variety of sources, } \\
\text { begin prepared to seek advice, be able to make decisions with regard to } \\
\text { writing, accepting errors as a natural part of the learning process, } \\
\text { making positive attempts to edit, being prepared for publication, etc. }\end{array}$ \\
\hline
\end{tabular}


Familiarization with the setting took place during the first two meetings. The tables were set up by the researcher-guide to provide the students with choices about where and with whom to sit. The students were informed that the tables might be moved or reorganized based upon the needs of the group at any given time. The first two meetings set the stage for the start of the Writers' Club proper and included an introduction, providing the students with supplies, and establishing club rules and behaviors. Building upon Cambourne's theory of learning regarding space and the behaviors therein, together with responsibility, appropriate behavior for the group was discussed, and rules established. The students discussed and developed the "rules", and a poster was created to be clearly displayed at each meeting. The rules held a degree of flexibility, if the group members decided that they did not fulfill the needs of the club they could be changed by majority vote. This did not happen. The students were encouraged to be attentive and to wait to ask questions or make comments. Following Cambourne's recommendations, the routine that would be followed during the meetings was explained.

During meetings, focused guidance was provided regarding various conventions (e.g. the use of capital letters, sentence endings and transitions followed by commas), brainstorming ideas, and deciding on an appropriate organizational format. Further guidance was provided on the selection of the most effective words, the structuring of sentences and the incorporation of voice. The process approach to writing was incorporated in the mini-lessons including drafting, revising, editing and publishing. This was done in whole group sessions at the beginning of the meeting. The follow-up was done in small group sessions or individually, based on student need. The goal of the 
project was to target including a main idea, supported by details, and the use of the conventions of customary English. This can be evidenced through many genres: narrative, informational (cause and effect, compare and contrast, persuasive, opinion, etc.) and text types (letters, essays, poems, posters, advertisements, etc.). Students were also guided to consider audience during their writing.

During the third meeting, the students were asked to punctuate a basic sentence and to write a brief paragraph. This work was examined by the researcher-guide to establish some of the areas that needed to be addressed in future meetings. They were informal assessments designed to guide instruction.

The subsequent club meetings followed routines. They opened with discussion. This covered either an unpunctuated sentence that was written on the board, or what needed to be addressed in written work. When the meeting opened with an unpunctuated sentence, discussion ensued and the corrected version was written in their notebooks. Next, there was an introduction or review of a text type and a mini-lesson, as appropriate. On occasion, prior to the students participating in writing time there was a State of the Class (Calkins, 1994; Temple, Ogle, Crawford \& Freppon, 2011) session, where the students shared where they were in their writing. Everyone wrote during writing time; students selected whether to work alone, with a partner or in a small group. When time allowed, the researcher-guide wrote in her writing book.

Once the students were engaged in an appropriate activity, the researcher-guide moved about the classroom, providing support and conferencing with students individually. The student conference most often took the form of a one-to-one interaction with the researcher-guide to address specific writing skills. On occasion, the conference 
might involve a small group of students facing similar challenges. Conferences were instigated by either the student or the researcher-guide. The student could postpone a researcher-guide instigated conference. At the end of writing time, the students tidied up.

Opportunities were provided for the students to share their work. The students participated in a whole group sharing time. Prior to this, they engaged in a session where "how to be an audience" was discussed. The students were introduced to the concept of providing constructive feedback: how to phrase what they want to say so it would not be hurtful but would be helpful to the writer.

After each meeting of Writers' Club, the researcher-guide wrote reflections, elaborating on the procedures that took place during the meeting (See Appendix G). Notes were taken regarding how well the timeframe was adhered to and if any circumstances arose that required deviation from the planned activities for the meeting. Notes were also taken regarding individual students' progress, concerns, successes, and challenges. These observations resulted in revisions to the plans for the following meeting, and revisions were carefully noted (Appendix G).

The students wrote on topics of their choice. The text types that were included were letters and essays. Letters were the focus of the club during the meetings up to meeting seven, after that essays were the focus.

The letter writing focused on expressing a point of view, incorporating details (ideas) and following conventions of customary English. The researcher-guide read Goldilocks and the Three Bears by Vera Southgate (Appendix H, Book 1) aloud to the students. They were encouraged to take a position; that of Goldilocks or one of the three bears, and write to one of the other characters expressing their feelings regarding what 
had happened in the story. They were guided to consider the recipient and include ideas from the text. Furthermore, they were encouraged to elaborate based on their experience or by thinking of consequences of the actions and to add details accordingly. For example, one student took the role of Baby Bear and expressed how he had been looking forward to his breakfast of porridge and was frustrated to find it had been eaten. He went on to say, Mama Bear had to cook a different breakfast that was less to his taste. Another student took the role of Papa Bear, writing to Goldilocks to express his annoyance. He so enmeshed himself in the character that he referred to "my wife" and "my son" in his letter and demanded an apology for them both.

The students were exposed to the correct format for a letter, including how to punctuate addresses, salutations, and closing phrases. They had to create addresses for themselves and their recipient; this challenged their imaginations regarding what would be appropriate and realistic. Some students chose to work alone, and others chose to work with a friend. Most either chose to work with a friend who was taking the same stance, or with a friend who was taking the role of the character to whom they were writing. They discussed what to say and how to say it. The discussions were lively and interesting. Initially, they needed guidance to extend their ideas beyond those in the book. Once the concept had been discussed, and they appreciated that they could do this, they did it. All the students wrote rough drafts before creating a final copy. They received oral feedback from their peers and both oral and written feedback from the researcher-guide. The letter writing was completed with a read aloud by the students, sharing their letters and receiving oral peer and researcher-guide feedback on the final iteration (Meeting 8, Appendix G). 
Meeting 9 opened the essay writing portion. The researcher-guide introduced the Everglades as the umbrella area of study. This was selected keeping in mind that fourthgrade students focus on a study of Florida. The Everglades is a unique ecosystem of great importance to life in Florida, especially South Florida. First, to whet their appetites an informational picture book (Appendix H, Book 8) was shown to the students. It covered multiple aspects of the Everglades and generated many observations and comments. Then, to demonstrate informational text and to take a particular aspect of the Everglades wildlife, Manatees by Patricia A. Fink (Appendix H, Book 9) was read aloud. The reading of this text was conducted over two meetings. At the conclusion of the reading, the students were asked to discuss the format of informational text. They were then advised that they would be able to choose a topic they would like to research and write about, based on the Everglades. The researcher-guide provided a plethora of books for the students to browse through (Appendix $\mathrm{H}$ ) and use for research.

Once the students had selected a topic they wished to write about, they conducted research. Most students chose one of the books provided by the researcher-guide as a starting point. A selection of graphic organizers, sourced from Florida Center for Reading Research (C.015.SS1, C.015.SS2, C.015.223, C.015.SS4, C017.SS1, C.07.SS2, C.017.SS3, C.017.SS4, C.018.SS1, C.018.SS2, and C.018.SS3), were provided. Explanations of how to use the graphic organizers were provided. The instruction was given regarding how to take notes from the text, whether it be books, magazines or web sources. The students were given opportunities to use the school's computers during Writers' Club meetings, to conduct research. They were also encouraged to continue with their research out of the meetings. The students selected an appealing graphic 
organizer, or created one in their notebooks, and using a variety of sources wrote notes. Once they reached a point where they believed they had sufficient information to begin writing, they wrote rough drafts. The rough drafts were shared with peers and received oral feedback. At a minimum, the researcher-guide provided written feedback every third meeting, oral feedback was given during conferences and in general terms on an as need basis.

Students were able to use computers for their writing or pencil and paper; they were encouraged to take notes by hand before moving to working on the computer. All the students chose to write their final products in their notebooks. Students were encouraged, as part of the concept of belonging to a club, to discuss their progress with peers, providing or seeking guidance, support or an audience, at their discretion. The work related to the Everglades was an extended writing project over many sessions, as had been the letter writing experience. The sharing time for the Everglades project took place during Meeting 17.

Meeting 18 was playful. The students played "quick write" games. They did a One Minute Write, where they had to write down as many random words as they could against the timer and then do it again to see if they could improve their score. It was stressed that the only competition was against oneself. What others achieved was irrelevant. They were then asked to think quickly of a topic they knew a lot about and were asked to write for 10 minutes on that topic; it could be anything. At the end of the meeting the students were asked to think of a topic they would like to write about during the next meeting, over a short time frame. During meeting 19, they had an 18-minute window to write about the topic they had thought about, and 10 minutes to share it. 
Meeting 20 focused on the upcoming writing assessment. Strategies were discussed, and encouragement given, after the conventions exercise had been completed.

The final two meetings were focused on an essay written over a short time frame. The students were offered graphic organizers if they wanted to use them. A topic of My Best Friend was suggested but not mandated. Sharing time was allocated at the end of the last meeting before the posttest took place. The lesson plans for all the meetings can be found in Appendix G.

Cambourne's $(1995,2001)$ Conditions for Learning were paramount in all the meetings. What these are, what is meant by them and how they were incorporated in the Writers Club can be seen in Table 2

\section{Table 2}

Cambourne's Conditions for Learning

\begin{tabular}{lll}
\hline Condition & $\begin{array}{l}\text { Meaning of } \\
\text { Conditions for } \\
\text { Learning (1995, } \\
\text { 2001) }\end{array}$ & $\begin{array}{l}\text { How the "Conditions for Learning" were incorporated into the } \\
\text { Writers' Club. }\end{array}$ \\
\hline Immersion & $\begin{array}{l}\text { The state of } \\
\text { being steeped in } \\
\text { both aural and } \\
\text { visual stimuli }\end{array}$ & $\begin{array}{l}\text { Periodically, the researcher-guide conducted a read-aloud. Many } \\
\text { model texts were made available for students to study. Students } \\
\text { engaged in sustained silent reading to conduct research, and used a } \\
\text { variety of sources. Writing time constituted a large proportion of } \\
\text { the meeting time (from 10-20 minutes). }\end{array}$ \\
Demonstration & $\begin{array}{l}\text { Experiencing } \\
\text { multifaceted } \\
\text { exposure to text }\end{array}$ & $\begin{array}{l}\text { Model texts provided demonstrations of how texts are constructed } \\
\text { and used. Practical demonstrations, by the researcher-guide, of how } \\
\text { to construct and use text were provided meeting by meeting } \\
\text { covering needed skill experiences. The researcher-guide conducted } \\
\text { write-alouds to demonstrate the use of appropriate conventions. She } \\
\text { also wrote in view of the students, and read what she had written } \\
\text { aloud to them, commenting on her thinking as she went along. Joint } \\
\text { development of graphic organizers was done with the whole group } \\
\text { to demonstrate the inclusion of details (ideas), and how } \\
\text { informational text is constructed. }\end{array}$ \\
& &
\end{tabular}




\begin{tabular}{|c|c|c|}
\hline Condition & $\begin{array}{l}\text { Meaning of } \\
\text { Conditions for } \\
\text { Learning (1995, } \\
2001)\end{array}$ & $\begin{array}{l}\text { How the "Conditions for Learning" were incorporated into the } \\
\text { Writers' Club. }\end{array}$ \\
\hline Engagement & $\begin{array}{l}\text { Intentional, } \\
\text { attentive, active } \\
\text { participation by } \\
\text { both the teacher } \\
\text { and students. }\end{array}$ & $\begin{array}{l}\text { The researcher-guide communicated the importance of becoming a } \\
\text { skillful writer. Students contributed ideas, and made suggestions, as } \\
\text { practical demonstrations. Students were supported in their } \\
\text { perception of themselves a capable doers of that which was } \\
\text { demonstrated, and encouraged to experiment. Their attempts were } \\
\text { valued. The students used their journals to emulate both the practical } \\
\text { demonstrations and the model texts. They had opportunities to share } \\
\text { their process and products one-to-one, with a small group, and with } \\
\text { the whole group. When revising sentences which failed to follow } \\
\text { conventions of customary English students engaged with each other } \\
\text { and the researcher-guide to make corrections. Students were } \\
\text { provided with graphic organizers to gather details (ideas) for their } \\
\text { writing and were offered opportunities to discuss their thinking with } \\
\text { each other and with the researcher/guide. Students had time to } \\
\text { produce their independent work and share it. }\end{array}$ \\
\hline Expectations & $\begin{array}{l}\text { Messages for } \\
\text { success } \\
\text { communicated } \\
\text { by significant } \\
\text { others. The } \\
\text { teacher holds } \\
\text { the conviction } \\
\text { that all students } \\
\text { will become } \\
\text { good writers }\end{array}$ & $\begin{array}{l}\text { The students were made aware of the high expectations that the } \\
\text { researcher-guide held of their likelihood of success. Explicit } \\
\text { instruction was provided, demonstrating what "good" writer do. } \\
\text { The researcher-guide promoted open relationship between herself } \\
\text { and the students, as well as between the students and each other. } \\
\text { The students' confidence in themselves was fostered through non- } \\
\text { threatening support and constructive feedback within group } \\
\text { meetings and individual conferences. The researcher-guide } \\
\text { encouraged mixed ability flexible grouping that avoided negative } \\
\text { expectations. }\end{array}$ \\
\hline Responsibility & $\begin{array}{l}\text { Encouraging } \\
\text { students to make } \\
\text { decisions and } \\
\text { choices about } \\
\text { learning, }\end{array}$ & $\begin{array}{l}\text { The researcher-guide engaged the students in taking responsibility } \\
\text { for the development of the rules of the club, to clarify expected } \\
\text { behaviors while participating in the club. The rules recognized the } \\
\text { common goals of the club, and set parameters for appropriate } \\
\text { behavior. Students were enfranchised regarding what to do through } \\
\text { opportunities to express verbally what they intend to work on, and } \\
\text { what targets they wish to set for themselves during individual } \\
\text { conferences. The researcher-guide checked up with students by } \\
\text { means of conferences to clarify progress towards goals. Students } \\
\text { were encouraged by open ended questions regarding how to } \\
\text { progress through their writing to reflect on to take responsibility for } \\
\text { their learning. Students were expected to justify their position } \\
\text { wherever possible. }\end{array}$ \\
\hline Approximation & $\begin{array}{l}\text { Mistakes are our } \\
\text { friends" (p. } \\
415 \text { ), failed } \\
\text { attempts should } \\
\text { be viewed } \\
\text { positively. }\end{array}$ & $\begin{array}{l}\text { Errors were accepted, examine and regarded as approximation rather } \\
\text { than inadequacy, as measured steps towards goals. Support was } \\
\text { given to facilitate each child's growth, based on his/her } \\
\text { demonstrated needs. It was important that students observed the } \\
\text { researcher-guide making purposeful mistakes and correcting them, } \\
\text { demonstrating that our mistakes help us to progress and that they are } \\
\text { not debilitating. } \\
\text { (continued) }\end{array}$ \\
\hline
\end{tabular}




\begin{tabular}{lll}
\hline Condition & $\begin{array}{l}\text { Meaning of } \\
\text { Conditions for } \\
\text { Learning (1995, } \\
\text { 2001) }\end{array}$ & $\begin{array}{l}\text { How the "Conditions for Learning" were incorporated into the } \\
\text { Writers' Club. }\end{array}$ \\
\hline Use & $\begin{array}{l}\text { Opportunities to } \\
\text { practice writing } \\
\text { in authentic } \\
\text { ways. }\end{array}$ & $\begin{array}{l}\text { Students were given time to practice what they were learning within } \\
\text { their own writing. They were encouraged to talk through what they } \\
\text { were doing, and how they planned to proceed during discussion } \\
\text { sessions and writing time. They were provided with opportunities to } \\
\text { engage in writing to solve specific problems, and address specific } \\
\text { purposes. }\end{array}$ \\
Response & $\begin{array}{l}\text { Meaningful } \\
\text { response from } \\
\text { significant } \\
\text { others in regards } \\
\text { to goals and } \\
\text { how to achieve } \\
\text { them. }\end{array}$ & $\begin{array}{l}\text { Students were provided with feedback in sharing sessions, during } \\
\text { one-to-one conferences with the researcher-guide, and by means of } \\
\text { their notebooks, at least once a week. During early meetings of the } \\
\text { club, constructive criticism was demonstrated. Students were } \\
\text { exposed to positive feedback. Such constructive criticism was given } \\
\text { in a non-threatening manner, pertinent to their writing, in } \\
\text { manageable quantities, and as suggestions to be considered. }\end{array}$ \\
\hline
\end{tabular}

To demonstrate what Cambourne's Conditions for Learning looked like during the Writers' Club, the following is an excerpt taken from the researcher-guide's reflection on a randomly selected meeting (Meeting 21, see Appendix G).

Eight students arrived promptly for the meeting. I told them we would focus on the use of quotation marks and that they could write down the sentences and see if they could punctuate them while we awaited the other students (Approximation, Use). Gradually, the others trickled in. As each group appeared they became more rowdy. They all wrote down the sentences that were:

Quotation marks indicate speech. Jensi said, "Good morning, Ms. Helen." "It is hot, today." said Leo.

Then we addressed a very difficult sentence: "Maikel," said Vanessa, "is going to the zoo." The punctuation is critical. Revise it, and it changes who is going to the zoo. Maikel said, "Vanessa is going to the zoo." (Demonstration). The students were intrigued by this sentence (Approximation). We discussed it and various volunteers 
began to read the two different punctuations expressively, all but one of the students understood what was happening (Engagement, Immersion, Use). I was able to demonstrate how important punctuation is. One student, JA, said, "Now I get why it is so important." This exercise took up the bulk of the meeting. One student, NL, indicated he was finished so I allowed him to return to class. I attempted to ask them how the writing test had gone on Monday, but someone called out, "Can't we just write.” So I said, "Yes," and for the final five to ten minutes of the meeting they wrote about whatever they wished (Engagement, Immersion; Responsibility).

Conferences: $\quad$ Four students (JB, FC, AN and JD) had 1 minute conferences with (Expectations; me saying that they couldn't think of anything, I told each of them Response) $\quad$ if they started with, "Today, I got out of bed and ..." they would be able to get started. They all did; three of the four students wrote about something completely different once they put their pencils to the paper.

Time was quickly up. I told them their writing would be their ticket out the door. The students each brought their books, open at their work, for me to see. Some had written quite prolifically, considering the impromptu nature of the task. They placed their books in the box and deposited their pencils in the jar, before leaving (Responsibility, Routines).

Each meeting was different but all the meetings incorporated some, if not all of Cambourne's Conditions for Learning, in some form. His Aspects of the Classroom were most often identified during the early meetings. However, those conditions regarding physical space, behaviors within the space and routines and events therein were in evidence during all the meetings. 


\section{The At Home Writing Group}

The At Home Writing Group consisted of 18 students. Each week all students were provided with a colored folder containing a writing log (Appendix I), seven different writing activities and five loose-leaf sheets of paper. The writing log had to be completed by the student to indicate that activities had been completed and, how long the activities had been worked on each day. Parents were asked to sign off on the logs, by initialing the appropriate column, confirming that the student worked for the time specified. The students were informed that they could do any or all of the activities, as time permitted, and that they could repeat or retain activities from one week to the next if they wished. They were expected to give equivalent time to these activities as the Writers' Club students gave to attending meetings; 90 minutes per week. The time could be broken up as the student desired.

Some of the writing activities were sourced from a variety of Internet-based sites offering free access to educational materials, others were developed by the researcherguide. Tables 3-10 provide details regarding the activities that were provided to the At Home Writing Group week by week. 
Table 3

At Home Writing Group Activities - Week 1

\begin{tabular}{|c|c|c|}
\hline Item & Title & Source \\
\hline 1 & Word Building & $\begin{array}{c}\text { Retrieved from } \\
\text { http://www.greatschools.org/worksheets-activities/6602-building- }\end{array}$ \\
\hline 2 & $\begin{array}{c}\text { Making an } \\
\text { Illustrated } \\
\text { Vocabulary Book }\end{array}$ & $\begin{array}{c}\stackrel{\text { words }}{\text { Retrieved from }} \\
\text { http://www.education.com/activity/article/Vocabulary_Book_fourt } \\
\mathrm{h} /\end{array}$ \\
\hline 3 & $\begin{array}{l}\text { Write a Simile } \\
\text { Poem ... Starring } \\
\text { Your Pet }\end{array}$ & $\begin{array}{c}\text { Retrieved from } \\
\text { http://www.education.com/activity/article/pet-similies-poem/ }\end{array}$ \\
\hline 4 & Fast Fact Finding & $\begin{array}{l}\text { Retrieved from } \\
\text { http://www.greatschools.org/worksheets-activities/6663-finding- }\end{array}$ \\
\hline 5 & $\begin{array}{l}\text { Dr. Martin Luther } \\
\text { King, Jr }\end{array}$ & Developed by Researcher (Appendix J) \\
\hline 6 & $\mathrm{Me}$ & Developed by Researcher (Appendix J) \\
\hline 7 & Free Choice & Developed by Researcher (Appendix J) \\
\hline
\end{tabular}

Table 4

At Home Writing Group Activities - Week 2

\begin{tabular}{|c|c|c|}
\hline Item & Title & Source \\
\hline 1 & Connectives & $\begin{array}{c}\text { Retrieved from } \\
\text { http://www.greatschools.org/worksheets-activities/6675- }\end{array}$ \\
\hline 2 & $\begin{array}{l}\text { Note Taking } \\
\text { Exercise }\end{array}$ & $\begin{array}{c}\frac{\text { connectives.gs }}{\text { Retrieved from }} \\
\text { http:/www.education.com/activity/article/Take Notes middle/ }\end{array}$ \\
\hline 3 & $\begin{array}{l}\text { Write Jump Rope } \\
\text { Rhymes }\end{array}$ & $\begin{array}{l}\text { Retrieved from } \\
\text { http://www.education.com/activity/article/jump-rope-rhymes/ }\end{array}$ \\
\hline 4 & $\begin{array}{l}\text { Following } \\
\text { Instructions } \\
\text { Reporting }\end{array}$ & $\begin{array}{c}\text { Retrieved from } \\
\underline{\text { http://www.greatschools.org/worksheets-activities/6664- }} \\
\text { following-instructions.gs }\end{array}$ \\
\hline 5 & $\begin{array}{l}\text { Imagine you are a } \\
\text { Scientist }\end{array}$ & Developed by the Researcher (Appendix J) \\
\hline 6 & $\begin{array}{l}\text { Compare and } \\
\text { Contrast }\end{array}$ & Developed by the Researcher (Appendix J) \\
\hline 7 & Free Choice & Developed by the Researcher (Appendix J) \\
\hline
\end{tabular}


Table 5

At Home Writing Group Activities - Week 3

\begin{tabular}{|c|c|c|}
\hline Item & Title & Source \\
\hline 1 & Conjunctions & $\begin{array}{c}\text { Retrieved from } \\
\text { http://www.greatschools.org/worksheets-activities/6566- }\end{array}$ \\
\hline 2 & $\begin{array}{l}\text { Personalized } \\
\text { recipe Book }\end{array}$ & $\begin{array}{c}\frac{\text { conjunctions.gs }}{\text { Retrieved from }} \\
\text { http://www.education.com/activity/article/recipe-book/ }\end{array}$ \\
\hline 3 & Write a Haiku & $\begin{array}{l}\text { Retrieved from } \\
\text { http://www.gigglepoetry.com/poetryclass/Haiku.html }\end{array}$ \\
\hline 4 & $\begin{array}{l}\text { Guess What? A } \\
\text { writing Game }\end{array}$ & $\begin{array}{c}\text { Retrieved from } \\
\text { http://www.education.com/activity/article/guess_what_writing_ga } \\
\text { me fourth// }\end{array}$ \\
\hline 5 & Holidays & Developed by the Researcher (Appendix J) \\
\hline 6 & $\begin{array}{l}\text { Imagine you are } \\
\text { the Lead Singer in } \\
\text { a Music Band }\end{array}$ & Developed by the Researcher (Appendix J) \\
\hline 7 & Free Choice & Developed by the Researcher (Appendix J) \\
\hline
\end{tabular}

Table 6

At Home Writing Group Activities - Week 4

\begin{tabular}{|c|c|c|}
\hline Item & Title & Source \\
\hline 1 & Sentence Building & $\begin{array}{c}\text { Retrieved from } \\
\text { http://www.greatschools.org/worksheets-activities/6660- }\end{array}$ \\
\hline 2 & Reported Speech & $\begin{array}{c}\frac{\text { compound-sentences.gs }}{\text { Retrieved from }} \\
\frac{\text { http://www.greatschools.org/worksheets-activities/6667-rewriting- }}{\text { a-dialogue-removing-quotes }}\end{array}$ \\
\hline 3 & The Daily News & $\begin{array}{c}\text { Retrieved from } \\
\text { http://www.education.com/activity/article/Daily_News_fourth/ }\end{array}$ \\
\hline 4 & $\begin{array}{l}\text { How to Write a } \\
\text { Scary Story }\end{array}$ & $\begin{array}{c}\text { Retrieved from } \\
\text { http://www.education.com/activity/article/write_a_spooky_story_f } \\
\text { ourth/ }\end{array}$ \\
\hline 5 & $\begin{array}{l}\text { Living } \\
\text { Underwater }\end{array}$ & $\begin{array}{l}\text { Retrieved from } \\
\frac{\text { http://www.education.com/files/241001_241100/241034/creative- }}{\text { writing-prompt-03.pdf }}\end{array}$ \\
\hline 6 & $\begin{array}{l}\text { Sample } \\
\text { Cinquains, }\end{array}$ & $\begin{array}{c}\text { Retrieved from } \\
\text { http://www.readwritethink.org/files/resources/lesson_images/lesso } \\
\text { n43016-1.PDF }\end{array}$ \\
\hline & $\begin{array}{l}\text { Cinquain Graphic } \\
\text { Organizer, } \\
\text { Cinquains } \\
\text { Reflections }\end{array}$ & $\begin{array}{l}\text { http://www.readwritethink.org/files/resources/lesson_images/lesso } \\
\frac{\text { n43/RWT016-2.PDF }}{\text { http://www.readwritethink.org/files/resources/lesson_images/lesso }} \\
\text { n51/cinqreflection.pdf }\end{array}$ \\
\hline 7 & Free Choice & Developed by the Researcher (Appendix J) \\
\hline
\end{tabular}


Table 7

At Home Writing Group Activities - Week 5

\begin{tabular}{|c|c|c|}
\hline Item & Title & Source \\
\hline 1 & $\begin{array}{l}\text { Paragraphs and } \\
\text { Punctuation }\end{array}$ & $\begin{array}{c}\text { Retrieved from } \\
\frac{\text { http://www.greatschools.org/worksheets-activities/6665- }}{\text { punctuating-a-paragraph.gs }}\end{array}$ \\
\hline 2 & $\begin{array}{l}\text { Make a Family } \\
\text { Encyclopedia }\end{array}$ & $\begin{array}{c}\text { Retrieved from } \\
\text { http://www.education.com/activity/article/make_a_family_encyclo } \\
\text { pedia/ }\end{array}$ \\
\hline 3 & $\begin{array}{l}\text { Writing an } \\
\text { Acrostic Report }\end{array}$ & Developed by the Researcher (Appendix J) \\
\hline 4 & Couplet Poem & $\begin{array}{c}\text { Retrieved from } \\
\text { http://www.education.com/activity/article/couplet-poem/ }\end{array}$ \\
\hline 5 & $\begin{array}{l}\text { Write a Nutsy } \\
\text { News Story } \\
\text { President }\end{array}$ & $\begin{array}{c}\text { Retrieved from } \\
\text { http://www.education.com/pdf/write-nutsy-news/ } \\
\text { Developed by the Researcher (Appendix J) }\end{array}$ \\
\hline 7 & Free Choice & Developed by the Researcher (Appendix J) \\
\hline
\end{tabular}

Table 8

At Home Writing Group Activities - Week 6

\begin{tabular}{|c|c|c|}
\hline Item & Title & Source \\
\hline 1 & Prepositions & $\begin{array}{c}\text { Retrieved from } \\
\text { http://www.greatschools.org/worksheets-activities/6606- } \\
\text { prepositions-2.gs }\end{array}$ \\
\hline 2 & Dream Journal & $\begin{array}{c}\text { Retrieved from } \\
\mathrm{http}: / / \mathrm{www} . \text { education.com/activity/article/dream-journal/ }\end{array}$ \\
\hline 3 & $\begin{array}{c}\text { Make a Fun } \\
\text { Brochure }\end{array}$ & $\begin{array}{c}\text { Retrieved from } \\
\text { http://www.education.com/activity/article/make_a_fun_brochure_f } \\
\text { ourth/ }\end{array}$ \\
\hline 4 & Bio-poem & Developed by the Researcher (Appendix J) \\
\hline 5 & Important topic & Developed by the Researcher (Appendix J) \\
\hline 6 & No Electricity & Developed by the Researcher (Appendix J) \\
\hline 7 & Free Choice & Developed by the Researcher (Appendix J) \\
\hline
\end{tabular}


Table 9

At Home Writing Group Activities - Week 7

\begin{tabular}{|c|c|c|}
\hline Item & Title & Source \\
\hline 1 & $\begin{array}{l}\text { Colons, Semi- } \\
\text { colons and dashes }\end{array}$ & $\begin{array}{l}\text { Retrieved from } \\
\underline{\text { http://www.greatschools.org/worksheets-activities/6674-colons- }} \\
\text { semicolons-and-dashes.gs }\end{array}$ \\
\hline 2 & Be a Detail Artist & $\begin{array}{l}\text { Retrieved from } \\
\text { http://www.education.com/activity/article/Detail_Artist_fourth }\end{array}$ \\
\hline 3 & $\begin{array}{l}\text { Win the Pangram } \\
\text { Competition }\end{array}$ & $\begin{array}{l}\text { Retrieved from } \\
\text { http://www.education.com/activity/article/win-pangram- } \\
\text { competition/ }\end{array}$ \\
\hline 4 & Create a Lipogram & $\begin{array}{c}\text { Retrieved from } \\
\mathrm{http}: / / \text { www.education.com/activity/article/create-lipogram/ }\end{array}$ \\
\hline 5 & Special Powers & Developed by Researcher (Appendix J) \\
\hline 6 & $\begin{array}{l}\text { The Parts of a } \\
\text { Letter, } \\
\text { Write a Letter }\end{array}$ & $\begin{array}{l}\text { Retrieved from } \\
\text { https://www.teachervision.com/writing/printable/45999.html }\end{array}$ \\
\hline 7 & Free Choice & Developed by Researcher (Appendix J) \\
\hline
\end{tabular}

Table 10

At Home Writing Group Activities - Week 8

\begin{tabular}{|c|c|c|}
\hline Item & Title & Source \\
\hline 1 & Clauses & $\begin{array}{c}\text { Retrieved from } \\
\text { http://www.greatschools.org/worksheets-activities/6611-clauses- } \\
\text { parts-of-a-sentence.gs }\end{array}$ \\
\hline 2 & Pantoum Poem & $\begin{array}{l}\text { Retrieved from } \\
\mathrm{http}: / / \mathrm{www} . \text { education.com/activity/article/pantoum-poem/ }\end{array}$ \\
\hline 3 & Skeltonic Verse & $\begin{array}{c}\text { Retrieved from } \\
\mathrm{http}: / / \mathrm{www} . \text { education.com/activity/article/skeltonic-verse/ }\end{array}$ \\
\hline 4 & My Birthday & Developed by Researcher (Appendix J) \\
\hline 5 & No Phone & Developed by Researcher (Appendix J) \\
\hline 6 & $\begin{array}{l}\text { Imagine You're } \\
\text { the Lead Singer in } \\
\text { a Music Band }\end{array}$ & Developed by Researcher (Appendix J) \\
\hline 7 & Free Choice & Developed by Researcher (Appendix J) \\
\hline
\end{tabular}


Free Choice was included every week, and could be repeated multiple times, at the students' discretion.

\section{No Extra Writing Group}

The remaining students in fourth grade formed the No Extra Writing group. They received regular classroom instruction without additional activities.

\section{Summary}

The students participating in the Writers' Club and the At Home Writing Group engaged in extra writing but under different conditions. All the students received regular classroom instruction and homework. Those eligible students who did not participate in the Writers' Club participated in either the At Home Writing Group or the No Extra Writing group and acted as the comparison groups examining the value of extra writing via Writers' Club.

\section{Evaluators' Training and Contribution}

Independent evaluators were sought from relevant doctoral and masters programs at a South Florida university. Twelve individuals were offered the opportunity to be evaluators, six accepted. The independent evaluators participated in a 1-day workshop to explain the study. Each evaluator was provided with a folder containing a copy of the PowerPoint presentation (Appendix K), each of the writing samples used for the workshop and sufficient Teacher Six-Point Writing Guides to use with them. The researcher introduced the study to the independent evaluators. They were informed that the study would be conducted over eight weeks and that they would be required to evaluate some samples of students' writing gathered at the beginning and end of the study. Once the introduction was completed, a PowerPoint presentation was made, 
focusing on evaluating intermediate students' writing samples using the 6 Traits. Each trait was explained with examples taken from Spandel's (2013) text. Spandel's (2013) Teacher Six-Point Writing Guide (p. 13) was introduced and explained in detail, including a demonstration of how the continuum in the 6-point scale for each trait worked. The evaluators were provided with examples of students' writing, taken from Spandel's (2013) text. These are pre-scored in the text.

The PowerPoint presentation was interspersed with exercises in the evaluation of writing samples. After the initial introduction to the 6 traits (Appendix K, Slide 2) the evaluators were given two writing samples to examine without any instruction, The Redwoods (Spandel, 2013, p. 8) and Mouse Alert (Spandel, 2013, p. 10). They were asked to evaluate them, without a rubric, just using the terms for the six traits. They examined the samples independently, first. Then, they discussed what they had focused on for their evaluation. Lastly, they responded to focusing questions related to the two samples (Appendix K, Slides 4 and 5).

The evaluators were provided with a copy of Spandel's (2013) Teacher Six-Point Writing Guide (p. 13) and asked to examine it focusing on the 6 Traits - Ideas, Organization, Voice, Word Choice, Sentence Fluency and Conventions-Presentation separated into columns. The evaluators were instructed that each trait was to be examined in isolation. Instruction followed regarding Ideas (Appendix K, Slides 6-9), then the evaluators were provided with two new writing samples, The Baseball (Spandel, 2013, p. 73) and Making Decisions (Spandel, 2013, p. 71). They were instructed to examine the Ideas section of the rubric. The continuum was explained. There are six levels of proficiency from 1 , indicating minimal writing skill, to 6 , indicating advanced 
writing skill. Each level contains five attributes related to the overall trait being examined (in this case, Ideas), these the evaluators were asked to mark a, b, c, d, e, for each level. It was explained that the writing sample should be evaluated for each attribute on the scale from one to six, first a, then b, etc. The result would be one level circled for each attribute. From this a score, out of six, could be derived for the trait; total up all five scores and divide by five. If an evaluator was unable to decide squarely on a level for an attribute they were advised to circle the two adjacent levels closest to their evaluation and then divide the whole by six to arrive at a score for the trait under consideration.

After both writing samples, The Baseball (Spandel, 2013, p. 73) and Making Decisions (Spandel, 2013, p. 71), had been evaluated for Ideas, and each evaluator had generated a score for the trait, all the evaluators shared their scores. Discussion ensued. Finally, the researcher shared the score recommended by Spandel (2013), taken from the text. The researcher-guide explained that the goal was not to score the sample the same as Spandel (2013) had scored it, that was for guidance, but for the evaluators to learn to score equivalent to each other to provide inter-rater reliability. The next trait to be examined was Conventions (Appendix K, Slides 11-15); the evaluation process followed the same procedure as Ideas. These two traits were given prominence owing to their importance to the research questions of the study; though all the traits were covered thoroughly. Each of the other traits was taken individually, following the same procedure until the evaluators had examined the two writing samples, The Baseball (Spandel, 2013, p. 73) and Making Decisions (Spandel, 2013, p. 71), for all six traits. 
Once the PowerPoint presentation was completed, the evaluators gradually worked their way through each of the additional writing samples, A Strange Visitor (Spandel, 2013, p. 176), Computing Batting Averages (Spandel, 2013, p. 111), Going Veggie (Spandel, 2013, p. 76), Japan (Spandel, 2013, p. 235), Some Cartoons are Violent (Spandel, 2013, p. 104) and Zeena and the Marshmellows (Spandel, 2013, p. 138). They worked first independently to score the writing samples; then they were paired or grouped to discuss what had influenced their thinking. The evaluators were given time to discuss the writing samples and, based on their collaboration with peers, either changed their scores or retained them. Once they believe they had finished their scoring, the scores that Spandel (2013) determined as being appropriate for any given writing sample were provided, and discrepancies were discussed.

Finally, when the researcher determined that the evaluators had examined sufficient student writing samples to be evaluating similarly, they were given two student writing samples Gorillas (Spandel, 2013, p. 275) and Marco Polo (Spandel, 2013, p. 208), that they had not previously seen to evaluate without reference to their colleagues. These two writing samples were submitted to the researcher for analysis, to determine interrater reliability.

The independent evaluators examined and scored both the pretest and the posttest writing samples submitted by the participants, returning them to the researcher for analysis. The students' writing samples were evenly distributed between the independent evaluators, resulting in each evaluator examining either eight or nine samples each for the pretest and the posttest. 


\section{Data Collection}

\section{Administration of the Pretest and Posttest Writing Samples}

The researcher delivered an appropriate number of writing sample materials to each classroom. The students were asked to write an essay for 45 minutes, during regular class time. The topic was My Family (Appendix L). The wording of the topic was developed with the advice of the school principal and the researcher's major professor. Each student was provided with the prompt and a double-sided sheet of specially lined paper. The first writing sample was collected prior to the start of the intervention and constituted the pretest. The teachers were provided with instructions for test administration to keep the conditions as similar as possible for all the students (Appendix M). They were told they could provide the students with extra paper if it were needed. The teachers collected the writing samples for onward transmission to the researcher. This process was repeated at the end of the intervention. This constituted the posttest. The wording on the teachers' instructions was unchanged from pretest to posttest, except identifying that the assessment was either the pretest or the posttest.

The writing samples were given to the researcher who removed all identifying marks, creating a blind assessment. Writing assessment is improved when the assessors do not know who wrote the paper (Graham, Harris, \& Hebert, 2011). The researcher made copies of all the writing samples. The copies were randomly transmitted to each of the independent evaluators, together with sufficient Spandel's Teacher Six-Point Writing Guides. The researcher kept the originals in her possession. Each student writing sample was identified by a four digit number. How the four digit number could be decoded to identify the student was known only to the researcher. Scores for all the fourth-grade 
students' writing samples were obtained; one for each trait, but most importantly for ideas (details) and conventions, and an overall score for each writing sample was calculated. Both the writing sample copy and the evaluation rubric were collected by the researcher from the independent evaluators.

\section{Administration of the Writing Attitude Survey}

The teachers arranged a convenient time for the researcher to visit their classrooms to conduct the pretest Writing Attitude Survey and repeat the process for the posttest. The researcher provided each student with a copy of the Writing Attitude Survey (Kear et al. 2000, pp16-21), this included a sheet showing the "Garfield" pictures enlarged (Appendix N) with clearly written explanation of what each expression represented.

Prior to the administration of the survey, the researcher went over the pictures and the wording. The students were told to think about each question and circle the expression that best showed what their feelings were, not what Garfield might feel. The researcher read each question aloud, to control for any reading difficulties within the group. The students were allowed time to think about the question and circle the appropriate expression. Each question was identified by its number. When all the questions on a single page were completed the researcher instructed the students to turn over and locate the next numbered question before reading it. Once all the questions had been answered, the researcher asked the students to return to the first page. With each page, the researcher asked the students to ensure that each question had only one answer

circled, and then she asked the students to count the number of circles on each page: one for each question. As each page was turned, the students checked that they had 
responded to each question and confirmed this with the researcher. Once the administration of the Writing Attitude Survey was completed, the researcher collected all the surveys, quickly checking that all the questions had a circled answer. In this manner, the researcher ensured that all questions were answered. This was the pretest. After the intervention was completed, the process was repeated, as the posttest.

The scoring of the Writing Attitude Survey followed a Likert scale format. Each question elicited a response along a 4-point scale from very happy to very sad, using Garfield expressions. A very happy expression received a score of four points, a somewhat happy expression received a score of three points, a somewhat sad expression received a score of two points and a very sad expression received a score of one point. The points for all the items were added, to result in an overall attitude score. Both the pretest and the posttest were scored by the researcher.

All fourth-grade students were included in the collection of the writing sample and the administration of the survey, even those who would not be eligible to participate, so as to make them feel comfortable. This was done at the suggestion of the school principal. Once the data were collected the researcher removed the samples that were not eligible.

\section{Instruments}

\section{Teacher Six-Point Writing Guide}

The students' writing samples were evaluated using Spandel's (2013) Teacher Six-Point Writing Guide, details of its use are provided in Evaluator Contribution. This is a formative assessment allowing for "evaluation of instructional progress in relation to proficiency standards ... data provide the opportunity for feedback, ... and can be used to 
inform whether the instruction worked" (Black \& Dylan as cited by Kumar \& Eyck, 2008, p. 4). The 6 Trait model is the most commonly used analytic writing model (Cafree \& Miller, 2007). It is widely distributed throughout the U.S. and its elements align well with most states' standards (Coe et al., 2012; Kozlow \& Bellamy, 2004). It correlates well with the holistic assessment used by the College Board (Coe et al., 2012) but examines the individual characteristic that go together to create an effective written product (Culham, 2003; Diederich, 1974; Murray, 1982; Purves, 1992; Spandel, 2013). The National Writing Project uses the Analytic Writing Continuum that was based on the 6+1 Trait Writing model and provided data supporting inter-rater reliability over a period of years together with test-retest reliability and a close correlation between the analytic writing assessment and the holistic assessment (National Writing Project, 2012). As evidence for inter-rater reliability, "At each scoring event, at least $15 \%$ of papers are randomly selected to be read by two independent raters. Over the past eight years, interrater reliability rates have ranged from 89 to 93 percent across attributes" (National Writing Project, 2012, p. 2). To evidence test-retest reliability the consistency of the standards of the Analytic Writing Continuum was monitored between 2008 and 2011 (See Figure 1), 500 papers were scored by two independent raters. "For each attribute, the frequency distributions of scores from multiple years of scoring were plotted on a single coordinate plane (i.e., all resemble the holistic graph below)" (National Writing Project, 2012, p. 2). 


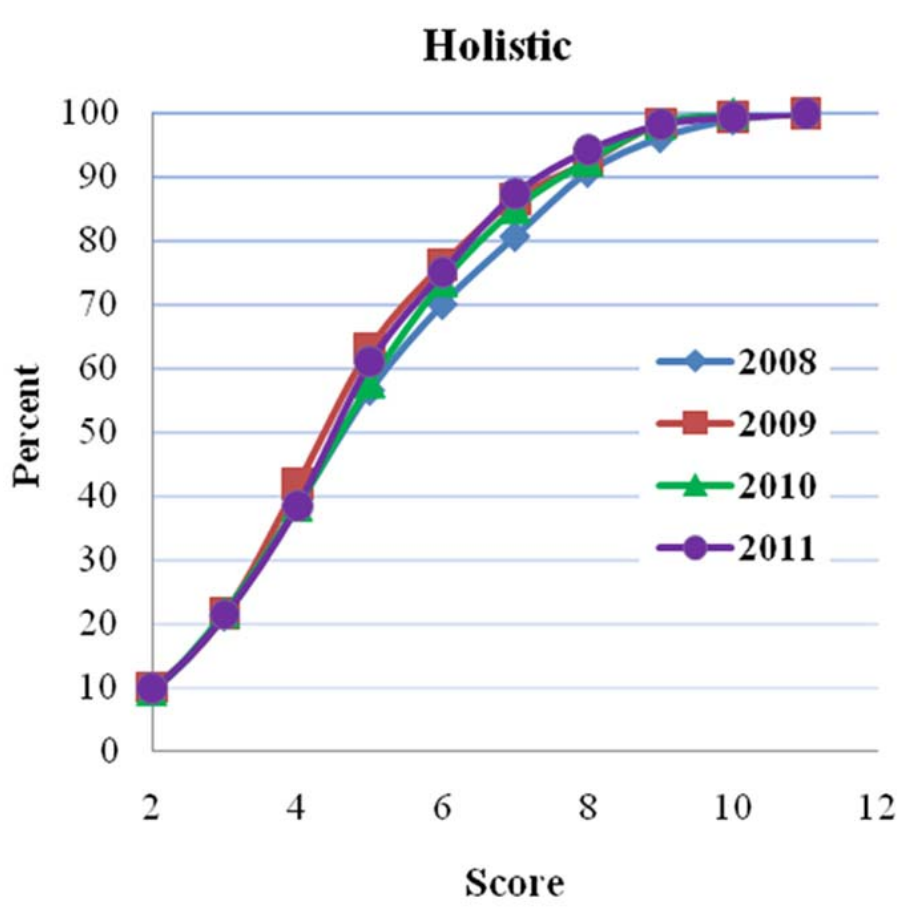

Cumulative Relative

Frequency distributions of

Holistic scores across all grade

levels ( $N=498), 2008-2011$.

Two raters' scores are

summed to produce a scale

ranging from 2-12. The

curves lie nearly directly on

top of one another, indicating

exceptional scale consistency

... across time (National

Writing Project, 2012, p. 2)

Figure 1. Holistic Scores Across all Grade Levels - 2008-2011

Reliability is improved if training is given to the assessors on how to score the writing samples (Graham et al., 2011), this was conducted as part of the study, during the professional development workshop. Another method for improving reliability is to provide evaluators with examples of points on the scale (Graham et al., 2011). During the professional development, the independent evaluators were exposed to a range of examples, addressing traits separately and in combination. Independent evaluators scored the example papers and discussed their differences to improve inter-rater reliability, these are also strategies for improving reliability according to Graham et al. (2011).

The students' attitude was examined using the Writing Attitude Survey developed by Kear, Coffman, McKenna and Ambrosio (2000). This scale was developed 
specifically for Grades 1-12. It followed an attractive format and was designed to be appropriate for group administration within a short period. The research to develop the instrument initially included 54 items that after five separate analyses resulted in 28 items that were identified as being highly reliable. The resultant instrument was administered to over 1500 U.S. students and the reliability and evidence of validity were based on this national sample. The Cronbach's Alpha was calculated at each grade level, and the coefficients ranged from .85 to .93 , the Cronbach's Alpha for the grade being targeted (fourth-grade) was .85. Further, the authors indicate that content validity evidence was gathered during the development of the instrument.

\section{Data Analysis}

Statistics included both descriptive statistics and inferential statistics. Descriptive statistics included means, standard deviations, frequencies, and correlations. Inferential statistics included $F$ tests. Directional hypotheses were used, to increase power. As the research design was quasi-experimental with a non-randomized control group, the groups could not be assumed to be equivalent on the pretest. As a result, the pretest scores were used, as a covariate, to adjust the posttest scores. SPSS (21) was used to conduct the analysis. The results were declared significant if $p \leq .05$.

A two-way Analysis of Variance (ANOVA) was conducted to test the inter-rater reliability of the scores of the independent evaluators assigned to assess the quality of the students' writing based on their writing samples for the overall writing score, the score for ideas and the score for conventions.

Research hypotheses 1, 2, 3, were tested using univariate analysis of covariance (ANCOVA), based on the three relevant score areas of Spandel's (2013) Teacher Six- 
Point Writing Guide: the total score, ideas, and conventions. Like the other four scores: organization, voice, sentence structure, and word choice are essential to the total score they were also examined as points of interest. The pretest scores served as covariates. The independent variable was the writing condition or group: participation in the Writers' Club, the At Home Writing Group or the group with no extra writing. The dependent variable was the aspect of writing under scrutiny.

Research Hypothesis 4 was also tested using univariate ANCOVA. An ANCOVA was performed on the score of the Writing Attitude Survey. Again the pretest score served as the covariate, and the independent variable was the writing condition or group: participation in the Writers' Club, the At Home Writing Group or the group with no extra writing. SPSS (21) was used to conduct the ANCOVA.

\section{Summary}

A quasi-experimental, pretest-posttest, non-equivalent group design was used. The treatment methods comprised, participation in Writers' Club, the At Home Writing Group, or a group with no extra writing. The goal was to determine if participation in one of the groups had an effect on fourth-grade, Hispanic students' writing expertise, overall, in respect of their inclusion of details (ideas), and their use of the conventions of customary English. The fourth-grade, Hispanic students were divided into thirds approximately and participated in one of the three conditions, or groups. They provided two writing samples and completed two Writing Attitude Surveys, one prior to the intervention and one post the intervention that were analyzed to determine the effect of the intervention. 


\section{CHAPTER 4}

\section{RESULTS}

The primary focus of the current study was to examine the effect of participation in Writers' Club on the writing of fourth-grade, Hispanic students in a South Florida public school, with particular attention to their overall writing, their ability to incorporate details (ideas) and their adherence to the conventions of customary English. As a secondary area of focus, the study also examined the effect of participation in Writers' Club on fourth-grade, Hispanic students' attitude towards writing. The study examined whether writing skills and attitudes changed through extra writing based on participation in Writers' Club, the At Home Writing Group, and No Extra Writing. All students received regular classroom instruction and homework. Quantitative methods were used for data analysis to measure the effect of participation in Writers' Club on fourth-grade, Hispanic students' writing samples and responses to a Writing Attitude Survey.

\section{Overall Sample Characteristics}

Sixty, fourth-grade, Hispanic students provided writing samples and responded to a Writing Attitude Survey before and after the intervention. The students participated in one of three groups for the duration of the study: Writers' Club, the At Home Writing Group or the No Extra Writing Group. All students received regular writing instruction and homework.

Of the 60 fourth-grade students included in the study, 59 (98\%) were Hispanic and $1(2 \%)$ was Asian; 39 (65\%) were boys and 21 (35\%) were girls. All $60(100 \%)$ students were of low socio economic status, based on free and reduced lunch eligibility. The composition of the groups is detailed in Table 11. 
Table 11

Group Composition $(N=60)$

\begin{tabular}{clll}
\hline Demographic & \multicolumn{2}{c}{ Group } \\
\cline { 2 - 4 } & Writers' Club & $\begin{array}{l}\text { At Home Writing } \\
\text { Group }\end{array}$ & No Extra Writing \\
\hline Participants & 22 & 18 & 20 \\
& $(36.67 \%)$ & $(30 \%)$ & $(33.33 \%)$ \\
Race/Ethnicity & & 17 & 20 \\
Hispanic & 22 & $(94.4 \%)$ & $(100 \%)$ \\
Asian & $(100 \%)$ & 1 & 0 \\
Sex & 0 & $(5.6 \%)$ & $(0 \%)$ \\
Boys & $(0 \%)$ & 10 & 16 \\
Girls & 13 & $(55.5 \%)$ & $(80 \%)$ \\
& $(59.1 \%)$ & 8 & 4 \\
\hline
\end{tabular}

Scoring Procedures

\section{Writing Samples}

The writing samples were distributed to the independent evaluators in two batches, each evaluator received eight or nine samples to evaluate per batch. Once the study had begun, and the independent evaluators had attended the professional development workshop to learn how to use Spandel's (2013) Teacher Six-Point Writing Guide, the researcher distributed packages of pretest writing samples to the evaluators, together with copies of the Teacher Six-Point Writing Guide. Evaluators examined each writing sample and then scored it according to the 6 Traits - Ideas, Organization, Voice, Word Choice, Sentence Fluency and Conventions/Presentation. Each trait earned a score ranging from 1-6 with the possibility of two decimal points. Once the scored rubrics were returned to the researcher, the math was checked and a total score was computed by 
adding the six scores that had been generated by the independent evaluators, to result in an overall writing score. Once the intervention had been completed, the process was repeated with the posttest writing samples.

At the conclusion of the professional development workshop, the independent evaluators each scored two different writing samples for the three aspects of writing of interest that the researcher used to calculate inter-rater reliability. The scores used for determining inter-rater reliability were the scores for ideas, conventions and the overall score. A two-way ANOVA following a random-effects model was used. The independent variable was the six raters and the dependent variable was the six scores generated from the two writing samples (Andrade et al., 2009) examined using Spandel's (2013) Teacher Six-Point Writing Guide. The specific scores under examination were those for ideas, conventions and the overall score for both writing samples. The calculations were manually conducted by the researcher following an algorithm suggested by Downie and Heath (1983). The reliability of all six raters taken together resulted in a correlational coefficient of $r_{t t}=.88$. This indicates that $88 \%$ of the observed variance is due to true score variance or similarity in ratings between coders. The level of agreement falls at the high end of the scale; 0.0-0.2 indicates slight agreement, 0.210.40 indicates fair agreement, 0.41-0.60 indicates moderate agreement, 0.61-0.80 indicates substantial agreement, and 0.81-1.0 indicates almost perfect agreement (Landis \& Koch, 1977, as cited by Hallgren, 2012).

Since the goal of the study was to compare the effect of participation in the Writers' Club on writing skills of fourth-grade, Hispanic students, overall, for ideas and conventions their pretest and posttest writing samples were analyzed to determine 
whether there was a significant difference between their mean scores for these aspects of writing compared to fourth-grade, Hispanic students who did not participate in the Writers' Club but instead participated in the At Home Writing Group or the No Extra Writing group.

The first analysis to be carried out was for the effect of participation in Writers' Club on the overall writing of fourth-grade, Hispanic students; in response to the first research question that was:

- What effect does participation in a writers' club have on fourth-grade, Hispanic students' writing?

Following the general linear model, a univariate ANCOVA was conducted. The overall writing score was the dependent variable, group membership was the independent variable, and the pretest writing scores were the covariate. The unadjusted descriptive statistics for the dependent variable, the posttest writing scores, were: Writers' Club $n=$ 22, $M=22.96, S D=4.89$; At Home Writing Group $n=18, M=23.73, S D=6.28$; No Extra Writing $n=20, M=19.45, S D=6.96$. The descriptive statistics, when data are adjusted for the covariate, are in Table 12.

Table 12

Overall Writing Posttest Mean Scores Adjusted by Pretest Score

\begin{tabular}{llll}
\hline Group & Mean & \multicolumn{2}{c}{$95 \%$ Confidence Interval } \\
\cline { 3 - 4 } & & Lower Bound & Upper Bound \\
\hline Writers' Club & 22.951 & 20.699 & 25.203 \\
At Home Writing Group & 22.744 & 20.213 & 25.275 \\
No Extra Writing & 20.352 & 17.954 & 22.750 \\
\hline
\end{tabular}


The inferential statistics indicated that there was no significant difference for overall writing between the groups based on the posttest writing sample scores when controlled for pretest scores $F(2,56)=1.45, p=.242$. $\mathrm{H}_{1}$ was not supported. The null could not be rejected. As a result, examining the individual differences between the pairs of treatments was moot.

The next analysis to be carried out was in relation to the effect of participation in Writers' Club on fourth-grade, Hispanic students' incorporation of ideas, in response to the second research question that was:

- What effect does participation in a writers' club have on fourth-grade, Hispanic students' incorporation of ideas in their writing?

Following the general linear model, a univariate ANCOVA was conducted. The posttest score for ideas was the dependent variable, group membership was the independent variable, and the pretest score for ideas was the covariate. The unadjusted descriptive statistics for the dependent variable, the writing sample posttest ideas, were: Writers' Club $n=22, M=4.16, S D=0.91$; At Home Writing Group $n=18, M=4.05, S D=1.20$; and No Extra Writing $n=20, M=3.55, S D=1.35$. The descriptive statistics, when data are adjusted for the covariate, are in Table 13. 
Table 13

Ideas Posttest Mean Scores Adjusted by Pretest Score

\begin{tabular}{llll}
\hline Group & Mean & \multicolumn{2}{c}{$95 \%$ Confidence Interval } \\
\cline { 3 - 4 } & & Lower Bound & Upper Bound \\
\hline Writers' Club & 4.158 & 3.679 & 4.638 \\
At Home Writing Group & 3.961 & 3.424 & 4.497 \\
No Extra Writing & 3.636 & 3.127 & 4.145 \\
\hline
\end{tabular}

The inferential statistics indicated that there was no significant difference for the incorporation of ideas in writing between the groups based on the posttest writing sample scores for ideas when controlled for pretest writing scores for ideas; $F(2,56)=1.123, p=$ .332. $\mathrm{H}_{2}$ was not supported. The null could not be rejected. As a result, examining the individual differences between the pairs of treatments was moot.

The last analysis for the students' writing related to the effect of participation in Writers' Club on fourth-grade, Hispanic students use of conventions of customary English, in response to the third research question:

- What effect does participation in a writers' club have on fourth-grade, Hispanic students' use of appropriate conventions of customary English?

Following the general linear model, a univariate ANCOVA was conducted. The posttest score for conventions was the dependent variable, group membership was the independent variable, and the pretest score for conventions was the covariate. The unadjusted descriptive statistics for the dependent variable, the writing sample posttest conventions, were: Writers' Club $n=22, M=4.02, S D=0.59$; At Home Writing Group $n$ 
$=18, M=4.2, S D=1.03$; and No Extra Writing $n=20, M=3.39, S D=1.09$. The adjusted descriptive statistics are found in Table 14 .

Table 14

Conventions Posttest Mean Scores Adjusted by Pretest Score

\begin{tabular}{llll}
\hline Group & Mean & \multicolumn{2}{c}{$95 \%$ Confidence Interval } \\
\cline { 3 - 4 } & & Lower Bound & Upper Bound \\
\hline Writers' Club & 4.057 & 3.734 & 4.380 \\
At Home Writing Group & 3.984 & 3.618 & 4.350 \\
No Extra Writing & 3.539 & 3.196 & 3.882 \\
\hline
\end{tabular}

The inferential statistics indicated that there was no significant difference for the use of appropriate conventions of customary English in writing between the groups based on the posttest writing sample scores for conventions when controlled for pretest writing scores for conventions; $F(2,56)=2.72, p=.075 . \mathrm{H}_{3}$ was not supported. The null could not be rejected. As a result, examining the individual differences between the pairs of treatments was moot.

\section{Writing Attitude Survey}

The Writing Attitude Survey was administered by the researcher. Once the Writing Attitude Survey was administered, the researcher gathered them from the students. Each of the 28 questions on the survey offered the students four options based on "Garfield" expressions. The expressions indicated the students' feelings regarding the question posed; the responses ranged from very sad or angry, to very happy. A response of very sad or angry resulted in a score of 1 , somewhat sad or angry resulted in a score of 2 , somewhat happy resulted in a score of 3 and very happy resulted in a score of 4 . This 
applied to all the questions except the last one that was negatively phrased, resulting in a reverse score. The possible score for responding to all the questions in the most positive manner was 112. The researcher examined each question and assigned the appropriate score. The scores for each question on a page were combined, and then the scores for each page were added to result in a total score. This procedure was followed for both the pretest and the posttest.

A secondary goal of the study was to measure the effect of participation in Writers' Club on fourth-grade, Hispanic students' attitude towards writing. Their pretest and posttest responses to the Writing Attitude Survey were analyzed to determine whether there was a difference in attitude compared to fourth-grade, Hispanic students who did not participate in the Writers' Club but instead participated in the At Home Writing Group or the No Extra Writing group. The fourth research question addressed this aspect of the study.

- What effect does participation in a writers' club have on fourth-grade, Hispanic students' attitude towards writing?

Following the general linear model, a univariate ANCOVA was conducted with the posttest Writing Attitude Survey scores being the dependent variable, the group being the independent variable, and the pretest Writing Attitude Survey scores as the covariate. The unadjusted descriptive statistics for the dependent variable, the responses to the posttest Writing Attitude survey, were: Writers' Club $n=22, M=90.73, S D=12.00$; At Home Writing Group $n=18, M=88.94, S D=7.68$; and No Extra Writing $n=20, M=$ $82.45, S D=14.23$. The descriptive statistics, when data are adjusted for the covariate, are in Table 15. 
Table 15

Writing Attitude Survey Posttest Mean Scores Adjusted by Pretest Score

\begin{tabular}{llll}
\hline Group & Mean & \multicolumn{2}{c}{ 95\% Confidence Interval } \\
\cline { 3 - 4 } & & Lower Bound & Upper Bound \\
\hline Writers' Club & 89.155 & 85.023 & 93.286 \\
At Home Writing Group & 86.358 & 81.737 & 90.980 \\
No Extra Writing & 86.507 & 81.966 & 91.049 \\
\hline
\end{tabular}

The inferential statistics indicated that there was no significant difference for attitude towards writing between the groups based on the posttest Writing Attitude Survey scores when controlled for pretest Writing Attitude Survey scores; $F(2,56)=.550, p=.580 . \mathrm{H}_{4}$ was not supported. The null could not be rejected. As a result, examining the individual differences between the pairs of treatments was moot.

\section{Summary}

This chapter detailed the results of the pretest and posttest data, following statistical analysis. First the overall characteristics of the participants was examined, covering the make-up of the groups based on number of participants in each group and the internal make-up of the groups based on race/ethnicity and sex. There was no need to include socio-economic status (SES) since all the students were determined to be of low SES based on eligibility for either free or reduced lunches. The scoring procedures and statistical analysis of the writing sample scores for the writing component of the study were presented and indicated that there was no statistical difference between the groups for any of the three areas of writing under scrutiny. Finally, the scoring procedures and statistical analysis of the students' responses to the Writing Attitude Survey were 
examined and indicated that there was no statistical difference between the groups based on attitude to writing. 


\section{CHAPTER 5}

\section{CONCLUSIONS, IMPLICATIONS AND DISCUSSION}

The purpose of the current study was to examine the effect of participation in Writers' Club on fourth-grade, Hispanic students' overall writing skill, their incorporation of ideas in their writing and their use of the conventions of customary English in their writing. It also examined the effect of participation in Writers Club on fourth-grade, Hispanic students' attitude towards writing. The study employed two methods of extra writing, the Writers' Club and the At Home Writing Group, each group engaged in 90 minutes of extra writing per week for eight weeks, under different conditions. The remaining participants engaged in no extra writing. All the students received regular writing instruction and homework.

This chapter will, initially, briefly summarize the study restating the problem and the design and procedures. This will be followed by the conclusions highlighting the findings and relating them to the research hypotheses. Then the implications will be stated. Finally, the implication of the findings will be discussed and suggestions provided as to what further research needs to be done.

\section{Summary of the Study}

\section{Restatement of the Problem}

Fourth-grade students have limited proficiency with writing at the national, state and local level, over $75 \%$ of students performing at the basic or below basic level (National Center for Education Statistics, 20120a; FDOE, 2005-2013c). Their attitude towards writing as they progress through the grades (Kear et al, 2000: Knudsen, 1991, 1992, 1993) also declines. Additionally, Hispanic students perform less well than their 
White counterparts (FDOE, 2005-2013b). Therefore, it is important to examine ways in that writing instruction can be targeted to address these students' needs. Furthermore, the Florida Department of Education made the standards for the inclusion of details and the adherence to the conventions of customary English more stringent in 2012 (Geisinger et al., 2012; FDOE, 2005-2013a) making it necessary to specifically address these aspects of writing. The current study addressed a method of instruction that had the potential to facilitate improvement in students' writing skills. It examined the effect of extra writing under two different conditions, in a Writers' Club and an At Home Writing Group, on fourth-grade, Hispanic students' writing skills and attitude towards writing,

\section{Restatement of the Design and Procedures}

The current study followed a quantitative, quasi-experimental, pre-posttest, nonequivalent group design, for examining fourth-grade, Hispanic students' writing skills and attitude toward writing under various instructional conditions.

Sixty, fourth-grade, Hispanic students enrolled in a Miami-Dade county public school, volunteered to participate in one of three writing conditions; the Writers' Club, the At Home Writing Group or No Extra Writing. The study was conducted over an 8week period. All the students received regular classroom writing instruction and homework.

Prior to the start of the interventions, the students all provided a pretest writing sample, on the topic of My Family. They also completed the pretest Writing Attitude Survey. On completion of the intervention, the students all provided a posttest writing sample on the same topic. They also completed a posttest Writing Attitude Survey. The students who were members of the Writers' Club made up the experimental group, those 
in the At Home Writing Group and the No Extra Writing group made up the comparison groups.

The members of the Writers' Club attended three, 30 minute, meetings per week. These were held in the media center at the school. The students received instruction from the researcher-guide in letter writing and essay writing. This instruction focused on the inclusion of details (ideas) in their writing and the adherence to the conventions of customary English. Specific instruction regarding the inclusions of details (ideas) included conducting research, the use of graphic organizers and discussion with peers and the researcher-guide. Instruction directed towards the adherence to the conventions of customary English included correcting unpunctuated sentences that focused on particular conventions. This was done primarily through discussion with peers and the researcherguide.

The students in the At Home Writing Group, received no instruction but, were provided, each week, with folders containing seven different writing activities. These activities included an item related to conventions, two or three writing projects, two or three writing prompts, and a Free Choice option. These students were permitted to use their discretion regarding which and how many activities to complete, and how to break up the 90 minute time frame. Each week there was a Writing Log to be completed by the student indicating how much time had been spent on each activity; this had to be verified by a parent, who initialed each entry made by the student. Students in the No Extra Writing group completed no additional writing. All students participated in classroom writing instruction and homework. 


\section{Conclusion}

The conclusions of the study were that there were no significant differences between participation in Writers' Club and participation in either the At Home Writing Group or the no extra writing group on fourth-grade, Hispanic students writing; overall, or for the inclusion of details (ideas), or for the adherence to the conventions of customary English. It was further concluded that there were no significant differences between participation in Writers' Club and participation in either the At Home Writing Group or the no extra writing group on fourth-grade, Hispanic students attitude towards writing.

\section{Implications}

The implication is that the study, as conducted, showed that extra writing time made no difference. It might be replicated with slightly different conditions. These are discussed below.

\section{Discussion}

Despite the findings indicating that there were no significant effects by group (Writers' Club, At Home Writing Group or No Extra Writing) on students' writing, for any of the three aspects under consideration (overall, incorporation of details [ideas] and adherence to the conventions of customary English); or on fourth-grade, Hispanic students' attitude towards writing, there were a number of serious limitations to the study.

It was originally proposed to conduct the study in the fall-semester as an afterschool activity. However, delays in the receipt of the necessary approvals resulted in the deferral of the study to the spring-semester. When the original information letters were sent out, the oft repeated response by the students' parents was that the students were 
already enrolled in after-school activities and could not be part of the Writers' Club. It was then determined that by rearranging the daily schedule, the Writers' Club could be conducted during the school day. Based upon the issues which resulted from conducting the study during the school day (these will be discussed next), it is recommended that any replication of the study be conducted, as originally proposed, during the fall-semester as an after-school activity.

The meetings were disrupted as a fairly common occurrence. The Writers' Club meetings were disrupted by the Spelling Bee, beginning during the second week. While the Spelling Bee was conducted some of the furniture was removed from the meeting space. There were insufficient tables and chairs for the students to work in comfortable conditions (Meeting $4 \& 5$ ). The Writers' Club was again disrupted for the next week by the Book Fair (Meetings 6, 7, \& 8). This was going on within the media center where the Writers' Cub meetings were held. The noise level made it difficult for members of the Writers' Club to hear instruction, or to concentrate on their writing. Seating was also restricted. The Writers' Club was further disrupted on a number of occasions by classroom related activities such as the celebration of the Chinese New Year (Meeting 17), a story reading (Meeting 19), and an ice cream celebration for a classroom achievement (Meeting 22). One meeting of the Writers' Club was cut short because the meeting space was needed for testing (Meeting 19).

Perhaps the most important limitation was the tardy arrival of nine students, who regularly arrived at Writers' Club meetings late. As the intervention progressed, these same nine students arrived progressively later. Finally, The Writing Log included in the 
At Home Writing Group folders was not always completed, nor did some parents reliably initial their students' entries.

The disruption which resulted from the Spelling Bee causing cramped conditions (Meetings 4 \& 5) resulted in reduced concentration and off task behavior. This disruption also contravened the establishment of the space and the routines within the space, which according to Cambourne (2000) are essential elements to learning.

The Book Fair disruption was severe. The media space was co-occupied by the Book Fair for three consecutive meetings (Meetings 6, 7, \& 8). While students visited the Book Fair, usually 20-30 students at a time, the noise level precluded any instruction being provided. The members of the Writers' Club were unable to hear the researcherguide. The noise level was also very disturbing to the students, resulting in them being off task for some, or all, of the time. Again the conditions contravened Cambourne's (2000) conditions regarding space and routines within the space. In addition, the disturbance impeded the students' immersion in the activities, hindered any demonstration and precluded engagement, which Cambourne $(1995,2001)$ argued is the key to learning.

These two disruptions covered five consecutive meetings, and occurred at the beginning of the study, when initial instruction was being given. They disturbed almost the whole of the letter writing section of the study, which formed the basis of the essay portion. They had the potential to impede students' internalization of the concepts being addressed. Being that these early meetings were the foundation upon which further instruction would be built, the effect may have severely affected the students' overall writing, the inclusion of details (ideas) and the adherence to the conventions of customary 
English. The impact could also have hampered the enhancement of their attitude towards writing, possibly through frustration. These two disruptions may have hindered the students' immersion into the Writers' Club. Less than six weeks of the study remained.

The interruptions related to the celebration of the Chinese New Year, the story reading, and the ice cream party, involved other students entering the Writers' Club space, and making announcements that distracted students who were already engaged in Writers' Club activities. The end of the meeting involving the story reading was cut short by an assistant principal. She entered the media center abruptly and informed everyone that the space was needed for testing and must be vacated quickly.

The interruption regarding the celebration of the Chinese New Year (Meeting 17) resulted in a foreshortened meeting. The researcher-guide was advised, approximately 30 minutes prior to the Writers' Club meeting, that Chinese food had been ordered, but had not yet arrived. The students, when asked, decided that they did not want to cancel Writers' Club altogether. Therefore, the researcher-guide agreed to meet immediately, but the meeting did not run for its full 30 minutes. It was cut short when the food arrived, impeding instruction and reducing writing time.

Whilst only one student decided to leave the meeting for the story reading (Meeting 19), the other students determined that they could catch up on the reading on their own. The discussion related to the story reading was off topic, reducing the time on task. This meeting was also foreshortened by between five and ten minutes because the room was needed for testing. The students' concentration was interrupted and they had to pack up very quickly. Overall, this meeting was barely a meeting at all. 
The interruption related to the ice cream celebration (Meeting 22) resulted in a mass exodus of the students in that class. This not only resulted in those students missing instruction, and writing time, but distracted the rest of the members of the Writers' Club, who were not included.

Although these interruptions were not on consecutive meetings they had the potential to have compromised the students' internalization of concepts. They each breached Cambourne's $(1995,2000,2001)$ conditions of learning both in regard to those relating to the space, and in relation to the other conditions. The level and degree of the interruptions caused by classroom issues had the potential to have limited the students' improvement in their writing skills, overall, for the inclusion of details (ideas), and their adherence to the conventions of customary English. They also had the potential to have an effect on their attitude towards writing.

The study consisted of 24 meetings; eight of which were disrupted to a greater or lesser extent. These meetings constituted one third of the total number of meetings, which when added to the two logistical meetings meant that 10 meetings failed to offer consistent on-task writing experiences following Cambourne's conditions for learning. This could be interpreted to indicate that a considerable proportion of the study was compromised on its objectives to provide extra writing in a social setting, following Cambourne's $(1995,2000,2001)$ conditions for learning.

The issue of repeated tardiness is possibly the most telling of the limitations. One segment of the Writers' Club membership gradually arrived later and later. The students were all in the same class. It was not established if they were dilatory about leaving their classroom and walking to the media center or if their teacher was not releasing them 
promptly. At the start of the Writers' Club, an agreement was entered into with the teachers. The students would be released from their classrooms five minutes before the Writers' Club meeting was scheduled to start, and they would be released promptly after 30 minutes so they could be back in their classrooms five minutes later. This arrangement worked well for the majority of the students, who arrived promptly more often than not. On at least one occasion, they arrived after the conventions exercise had been completed, missing it altogether. Nine students were involved, over $40 \%$ of the whole group. These students were not only impacted by their tardiness but also by all the disruptions and interruptions. They missed instruction more than writing time, but this certainly impacted their exposure to demonstration, at least by the researcher-guide. There is also a subliminal message being sent, if they were delayed by their teacher, that the Writers' Club was not important, that might possibly impact their attitude towards writing. The tardiness of these nine students has the potential to have impacted their posttest writing samples adversely and their attitude towards writing.

The combination of these limitations could realistically have depressed the scores sufficiently to render the posttest writing scores non-significant, for the various aspects of writing, when they might have been without them. They could have also severely impacted the significance of the posttest attitude towards writing scores. The implication of this set of circumstances is that it would be advisable to replicate the study and reexamine the effect of extra writing on fourth-grade, Hispanic students' writing, and attitude to writing under the same three conditions: membership of Writers' Club, participation in the At Home Writing Group and No Extra Writing, following Cambourne's $(1995,2000,2001)$ conditions of learning. However, serious consideration 
would need to be given to reverting to the originally proposed conditions; that is holding the Writers' Club meetings in an after-school setting, preferably in the fall-semester. This would reduce, if not eliminate, the effects of classroom issues bleeding over the study, even if the meetings were to remain at 30 minutes duration rather than the originally proposed 90 minutes.

The final limitation related to the At Home Writing Group rather than the Writers' Club and so will be dealt with separately. Some of the At Home Writing Group students, on occasion, either failed to complete the Writing Log or failed to have a parent initial to confirm that the work had been completed as recorded. Overall, after the researcher had examined the work that had been turned in, it was determined that the students had completed an amount of work that could reasonably be deemed to have taken the allocated 90 minutes. Even though sometimes the quantity of work may have appeared inadequate, there is no accounting for the amount of time spent thinking about what to write, deliberately selecting ideas, organizing them and building upon them to produce written work (Arapoff, 1967; Graves, 1983). It was determined that whilst the Writing Log was a tool to hold the students responsible for adhering to the 90 minute requirement, if there was sufficient evidence to support a belief that this had been done, the Writing Log per se was not a critical component of the study.

Based on this conclusion there remains the question of why the At Home Writing Group did not show significantly different scores on the posttest writing samples and the posttest attitude towards writing than the no extra writing group. This group had been determined to have experienced the requisite 90 minutes per week of extra writing experiences. Nevertheless, the study was based upon the premise that the components of 
the study were extra writing, a social setting and adherence to Cambourne's (1995, 200, 2001) conditions for learning. The conditions under which the At Home Writing Group completed their writing tasks is unknown. It could be posited that extra writing is insufficient to effect a significant difference between fourth-grade Hispanic students writing, and attitude towards writing. They also need the social setting and the conditions for learning for extra writing to be effective. It must be pointed out that this is speculation; there is no empirical evidence to support it.

Based on the limitations of the study, the posttest scores for the Writers' Club writing samples may have been depressed owing to a variety of circumstances. The time limit for the Writers' Club meeting, 30 minutes, was very short, thus interruptions had an impact on both instruction and writing time. These interruptions resulted in off-task activities (Datta, 1982), potentially hampering achievement.

As a worst case scenario, it could be argued that the severity of the limitations rendered the value of both the Writers' Club and the At Home Writing Group as insignificant, to the point of being no better than participation in the No Extra Writing group. This could account for there being no statistically significant difference in the posttest mean scores of the three groups.

Lavy (2009), in his study exploring the effect of instructional time on achievement, argued that a single hour of extra instruction per week had the potential to enhance skills. Whilst the Writers' Club provided 90 minutes of extra time per week it was for a period of eight weeks only and the time was broken up into 30 minute meetings. It is reasonable to speculate that the effect of extra writing by means of a Writers' Club on fourth-grade, Hispanic students' writing skills might be effective if 
conducted for a period lasting longer than eight weeks, and/or if the meetings were of at least an hour, rather than 30 minutes. Inevitably, there is reduced coherence when starting and stopping times are taken into consideration. Further research is called for to examine whether providing instruction in the form of a Writers' Club may prove to be a viable means for enhancing writing skills and attitude towards writing.

\section{Summary}

The current study examined the effect of extra writing on fourth-grade, Hispanic students' writing and their attitude towards writing. Whilst no significance was found for either the aspects of writing under study or for any change in the students' attitude towards writing, there were limitations that could have impacted the results of the study. Therefore, reexamining the effect of extra writing following the basic framework of the current study may provide insight into ways writing instruction could be made more effective. The major change that would need to be made would be to conduct the Writers' Club out of school hours to reduce, or eliminate, as many disruptions as possible to students' full participation in the Writers' Club experience. 


\section{REFERENCES}

Afflerbach, P. (2011). Formative assessment: Knowing where students stand in relation to learning goals. Reading Today, 29(1), 22

Andrade, H., Buff, C., Terry, J., Erano, M., \& Paolino, S. (2009). Assessment-driven improvements in middle school students' writing. Middle School Journal, 40(4), 4-12

Applebee, A. N. (1986). Problems in process approaches: Toward a reconceptualization of process instruction. In A. R. Petrosky and D. Bartholomea (Eds.), The teaching of writing: Eighty-fifth yearbook of the National Society for the Study of Education, part II (pp. 95-113). Chicago, IL: University of Chicago Press

Applebee, A. (2000). Alternative models of writing development. In R. Indrisano \& J. Squire (Eds.), Perspectives on writing: Research, theory, and practice (pp. 90110). Newark, DE: International Reading Association

Arapoff, N. (1967). Writing: A thinking process. TESOL Quarterly. 1(2), 33-39

Arter, J.A., Spandel, V., Culham, R., \& Pollard, J. (1994 April). The impact of training students to be self-assessors of writing. Paper presented at the meeting of the American Education Research Association, New Orleans, LA.

Atwell, N. (1998). In the middle: New understandings about writing, reading and learning. Portsmouth, NH: Heinemann

Barletta, L. (2008). “Asi se escribe 'ira": Culture and collaborative writing among Mexican American fourth grade students. (Doctoral Dissertation). Retrieved from ProQuest Information and Learning Company. (UMI Microform 3315809)

Barnard, I. (2002). Whole -class workshops: The transformation of students into writers. Writing, 12(2), 124-143

Beaufort, A. (2008). Writing in the professions. In C. Bazerman (Ed.), Handbook of research on writing: History, society, school, individual, text (pp. 221-235)

Mahwah, NJ: Lawrence Erlbaum Assoc. Inc.

Bellamy (n.d.). Research on writing with the $6+1$ traits. Retrieved from http://educationnorthwest.org/webfm send/143

Berliner, D \& Rosenshine, B. (1976). The acquisition of knowledge in the classroom. Beginning Teacher Evaluation Study. Technical Report IV-1. Retrieved from http://files.eric.ed.gov/fulltext/ED146158.pdf 
Bezbatchenko, A., (n.d.). Writing at the college level: Ways to improve your writing skills for the classes ahead. Retrieved from http://www.collegeview.com/articles/article/writing-at-the-college-level

Bromley, K. (2007). Best practices in teaching writing. In L. B. Gambrell, L. M. Morrow \& M. Pressley (Eds.), Best practices in literacy instruction (pp. 243-263). New York, NY: Guilford Press

Bruffee, K. (1984). Collaborative learning and the "Conversation of Mankind". College English, 46(7), 635-652

Bruner, J. (1986). Actual minds, possible worlds. Cambridge, MA: Harvard University Press

Calfee, R. \& Miller, R. (2007). Best practices in writing assessment. In S. Graham, C. A. MacArthur \& J. Fitzgerald (Eds.), Best practices in writing instruction (pp. 265286). New York, NY: Guilford Press

Calkins, L. (1994). The art of teaching writing. Portsmouth, NH: Heinemann

Cambourne, B. (1995). Toward and educationally relevant theory of literacy learning: Twenty years of inquiry. The Reading Teacher, 49(3), 182-190

Cambourne, B. (2000). Observing literacy learning in elementary classrooms: Nine years of classroom anthropology. The Reading Teacher, 53(6), 512-515

Cambourne, B. (2001). Turning learning theory into classroom instruction: A minicase study. The Reading Teacher, 54(4), 414-417

Carmichael, S. B., Martino, G., Porter-Magee, K., \& Silson, W. S. (2010). The state of state standards- and the Common Core- in 2010. Washington, DC: Thomas B. Fordham Institute

Carvalho, A. (2012). State release of results for the spring 2012 Florida Comprehensive Assessment Test (FCAT) writing grades 4, 8, and 10. Memorandum. Retrieved from http://oada.dadeschools.net/fcat/M1044StateReleaseofResultsfortheSpring2012FC $\underline{\text { AT.pdf }}$

Coe, M, Hanita, M., Nishioka, V. \& Smiley, R. (2011). An investigation of the impact of the $6+1$ Trait Writing model on grade 5 student writing achievement. (NCEE 2012-4010). Washington, DC: National Center for Education Evaluation and Regional Assistance, Institute of Educational Sciences, U. S. Department of Education 
College Entrance Examination Board (2003). The neglected " $R$ " the need for a writing revolution. Retrieved from http://www.collegeboard.com/prod_downloads/writingcom/neglectedr.pdf

Common Core State Standards Initiative (2014a). English and language arts standards $>>$ writing $>>$ grade 4 . Retrieved from http://www.corestandards.org/ELALiteracy/W/4/

Common Core State Standards Initiative (2014b). Standards in your state. Retrieved from http://www.corestandards.org/standards-in-your-state/

Conboy, M. (2008). Writing and journalism: Politics, social movements, and the public sphere. In C. Bazerman (Ed.), Handbook of research on writing: History, society, school, individual, text (pp. 205-220). Mahwah, NJ: Lawrence Erlbaum Assoc. Inc.

Corden, R. (2007). Developing reading-writing connections: the impact of explicit instruction of literary devices on the quality of students' narrative writing. Journal of Research in Childhood Education, 21(3), 269-289

Culham, R. (2003). 6+1 Traits of writing: The complete guide grades 3 and up. New York, NY: Scholastic

Datta, L. (1982). Employment-related basic skills. In H. F. Silberman (Ed.). The $81^{\text {st }}$ yearbook of The National Society for the Study of Education: Part II - Education and Work (pp 140-168). Chicago, IL: The National Society for the Study of Education

Diederich, P. B. (1974). Measuring growth in English. Urbana, IL: National Council of Teachers of English

Downie, N. M. \& Heath, R. W. (1983). Basic statistical methods. New York, NY: Harper \& Rowe

Ede, L. (1989). Writing as a social process: A theoretical foundation for writing centers? Retrieved from http://casebuilder.rhet.ualr.edu/wcrp/publications/wcj/wcj9.2/WCJ9.2_Ede.pdf

Elsenbrioch, C. \& Gilbert, N. (2014). Modeling Norms. New York, NY: Springer Dordrecht Heidelberg

Emig, J. (1971). The composing process of twelfth graders. Urbana, IL: National Council of Teachers of English 
Farbman, D. \& Kaplan, C. (2005). Time for a change: the promise of extended-time schools promoting student achievement. Boston, MA: Massachusetts 2020

Fin, D. E. \& Petrilli, M. J. (2010). Forward - The state of state standards- and the Common Core- in 2010. Washington, D.C.: Thomas B. Fordham Institute

Florida Department of Education. (2005-2013a). Common Core State Standards. Retrieved from https://www.fldoe.org/schools/ccc.asp

Florida Department of Education. (2005-2013b). FCAT 2.0 Student performance results: State writing demographic report. Retrieved from http://app1.fldoe.org/FCATDemographics/Selections.aspx?reportTypeID=8\&leve $\underline{1=\text { State } \& \text { subj }=\text { Writing }}$

Florida Department of Education (2005-2013c). FCAT Writing. Retrieved from http://fcat.fldoe.org/fwinfopg.asp

Florida Department of Education. (2005-2013d). Florida Standards. Retrieved from http://www.fldoe.org/bii/curriculum/sss/

Florida Department of Education. (2005-2013e). LAFS: Language Arts Florida Standards. Retrieved from http://www.fldoe.org/pdf/lafs.pdf

Furr, D. (2003). Struggling readers get hooked on writing. The Reading Teacher, 56(6), 518-525

Ganz, A. (2003). Stories of a growing community: A teacher-researcher in a third grade writing workshop. (Doctoral dissertation). Retrieved from ProQuest Dissertations and Theses. (UMI Number 3086908)

Gardner, N. S. \& Powell, R. (2013). The Common Core is a change for the better. Phi Delta Kappan, 95(4), 49-53.

Geisinger, K., Romhild, A. \& Chin, T. Y. (2012). Report on the scoring of the FCAT writing assessment. Retrieved from https://www.fldoe.org/arm/pdf/2012BurosReportFCATWritingAssessment.pdf

Gibney, T. (2012). Teaching memoir in the elementary school classroom. The Reading Teacher, 66(3), 243-253

Graham, S., Harris, K. \& Olinghouse, N. (2007). Addressing executive function problems in writing: An example from the self-regulated strategy development model. In L. Meltzer (Ed.), Executive function in education: From theory to practice (pp. 216236) New York, NY: The Guildford Press 
Graham, S. \& Perin, D. (2007). A meta-analysis of writing instruction for adolescent students. Journal of Educational Psychology, 99(3), 445-476

Graham, S., Berninger, V., \& Fan, W. (2007). The structural relationship between writing attitude and writing achievement in first and third grade students. Contemporary educational psychology, 32, 516-536.

Graham, S., Harris, K., \& Hebert, M. A. (2011). Informing writing: The benefits of formative assessment. A Carnegie Corporation time to act report. Washington, D.C.: Alliance for Excellent Education

Graves, D. (1983). Writing teachers and students work. Portsmouth, NH: Heinemann

Graves, D. (1994). A fresh look at writing. Portsmouth, NH: Heinemann

Graves, D. (2002). Testing is not teaching: What should count in education. Portsmouth, NH: Heinemann

Hain, B. (2011). PARCC Consortium - A five component assessment model. Reading Today, 29(1), 24.

Hallgren, K. (2012). Computing inter-rater reliability for observational Data: An overview and tutorial. Retrieved from http://www.ncbi.nlm.nih.gov/pmc/articles/PMC3402032/

Heller, M. (2006). Telling stories and talking facts: First graders' engagements in a nonfiction book club. The Reading Teacher, 60(4), 358-369

Kear, D. Coffman, G., McKenna, M., \& Ambrosio, A. (2000). Measuring attitude toward writing: A new tool for teachers. The Reading Teacher, 54(1), 10-23.

Kesler, T. (2012). Writing with voice. The Reading Teacher, 66(1), 25-29

Knudson, R. E. (1991). Development and application of a writing attitude survey in grades 4 and 8. Psychological Reports, 68, 807-816

Knudson, R. E. (1992). Development and use of a writing attitude survey for grades 1 to 3. Psychological Reports, 70, 711-720

Knudson, R. E. (1993). Development of a writing attitude survey for grades 9 to 12: Effects of gender, grade and ethnicity. Psychological Reports, 73, 587-594

Kong, A. \& Fitch, E. (2002). Using book club to engage culturally and linguistically diverse learners in reading, writing, and talking about books. The Reading Teacher, 56(4), 352-362 
Kozlow, M. \& Bellamy, P. (2004). Experimental study on the impact of the $6+1$ Trait ${ }^{\circledR}$ Writing Model on student achievement in writing. Portland, OR: Northwest Regional Education Laboratory

Kumar, L. \& Eyck, R. (2008). Using assessment for instruction. Rexford, NY: International Center for Leadership in Education

Lavy, V. (2009). The effect of time on math, science and reading: Evidence from developed and developing countries. Retrieved from http://cep.lse.ac.uk/seminarpapers/08-12-09-LAV.pdf

Long, R. (2011). Common Core State Standards: Approaching the assessment issue. Reading Today, 29(1), 23-24

McCarry, B. \& Greenwood, S. (2009). Practice what you teach: Writers' Lunch Club in first grade. Young Children, 64(1), 37-41

McGrory, K. (2013). Renaming "Common Core" standards does little to end Florida's education debate. Tampa Bay Times. January 19, 2013

Miami Herald (n.d.). The changing demographics of Miami-Dade schools. Retrieved from http://www.miamiherald.com/projects/2014/school-demographics/

Michael, K. (2003). Fifth grade students' use of genre in a collaborative writing workshop. (Doctoral Dissertation). Retrieved from ProQuest Information and Learning Company. (UMI Microform 3099184)

Montelongo J. A, \& Hernandez, A. C. (2007). Reinforcing expository reading and writing skills: A more versatile sentence completion task. The Reading Teacher, 60(6), 538-546

Murray, D. M. (1982). Learning by teaching. Portsmouth, NH: Boynton/Cook

National Center for Education Statistics (2006). Digest of Education Statistics. Retrieved from http://nces.ed.gov/programs/digest/d06/tables/dt06 089.asp

National Center for Education Statistics. (2012a). NAEP Assessment Schedule 19692017. Retrieved from http://nces.ed.gov/nationsreportcard/about/assessmentsched.aspx

National Center for Education Statistics (2012b). The Nation's Report Card: Writing 2011 (NCES 2012-470). Institute of Education Sciences, U.S. Department of Education, Washington, D.C. 
National Center for Education Statistics (n.d.). Achievement levels. Retrieved from http://nces.ed.gov/nationsreportcard/NDEHelp/WebHelp/achievement levels.htm

National Commission on Writing. (2003). The neglected " $R$ " the need for a writing revolution. The College Board Retrieved from http://www.collegeboard.com/prod downloads/writingcom/neglectedr.pdf

National Commission on Writing. (2005). Writing: A powerful message from state government. The College Board. Retrieved from http://www.collegeboard.com/prod downloads/writingcom/powerful-messagefrom-state.pdf

National Commission on Writing (2006). Writing and school reform. The College Board. Retrieved from http://www.collegeboard.com/prod_downloads/writingcom/writing-schoolreform-natl-comm-writing.pdf

National Governors Association Center for Best Practices, Council of Chief State School Officers. (2010). Common Core State Standards. Washington, D.C.: National Governors Association Center for Best Practices, Council of Chief State School Officers Retrieved from http://www.corestandards.org/resources/key-points-inenglish-language-arts

National Governors Association Center for Best Practices, Council of Chief State School Officers. (2010). Common Core State Standards English and language arts. Washington, D.C.: National Governors Association Center for Best Practices, Council of Chief State School Officers Retrieved from http://www.corestandards.org/ELA-Literacy/W/3

National Writing Project (2012). National Writing Project offers high-quality writing assessment services. Retrieved from http://www.nwp.org/cs/public/print/resource/3776

Newell, G. E. (2006). Writing to learn: How alternative theories of school writing account for student performance. In C. MacArthur, S. Graham \& J. Fitzgerald (Eds.), Handbook of writing research. (pp. 235-247). New York, NY: Guilford Press

O’Connor, J. (2014, April 29). In Morning Edition: Washington: DC: National Public Radio

Paquette, K. (2008). Study of elementary students' attitude to writing after a cross-age tutoring experience. Reading Improvement, 48(4), 181-191 
Partnership for $21^{\text {st }}$ Century Skills. (2011). Framework for $21^{\text {st }}$ century learning. Retrieved from http://www.p21.org/overview

Peha, S. (n.d.) Writing across the curriculum. Retrieved from http://www.ttms.org/PDFs/06\%20Writing\%20Across $\% 20$ the $\% 20$ Curriculum $\% 20$ v001\%20\%28Full $\% 29 . \mathrm{pdf}$

Persky,H. R., Daane, M.C. \& Jin, Y. (2003). The Nation’s Report Card: Writing 2002, Washington, D.C.: U.S. Department of Education. Institute of Education Sciences. National Center for Education Statistics NCES 2003-529

Polleck, J. N. (2010). Creating transformational spaces: High school book clubs with inner-city adolescent females. The High School Journal, January/February, 50-68

Porter, A., McMaken, J., Hwang, J. \& Yang, R. (2011). Common Core Standards: The new U.S. intended curriculum. Educational Researcher, 40(3), 103-116

Purves, A. (1992). Reflections on research and assessment in written composition. Research in the Teaching of English, 26, 108-122.

Raphael, T. E. \& McMahon, S. I. (1994). Book club: An alternative framework for reading instruction. The Reading Teacher, 48(2), 102-116

Raphael, T. E., Florio-Ruane, S. \& George, M. (2001). Book club plus: A conceptual framework to organize literacy instruction. Language Arts, 79(2), p 159-168

Raphael, T. E. (2001). Book club workshop: Learning about language and literacy through culture. Retrieved from: http://www.ciera.org/library/archive/199904/art-online-99-04.html

Read, S. \& Landon-Hays, Melanie M. (2013). The knowing/doing gap: Challenges of effective writing instruction in high school. Teaching/Writing: The Journal of Writing Teacher Education, 2(2), 6-15

Reif, L., (2007). Writing: Commonsense matters. In K. Beers, R. E. Probst, \& L. Reif (Eds.), Adolescent literacy turning promise into practice (pp. 189-208). Portsmouth, NH: Heinemann

Romero, M. \& Barbera, E. (2011). Quality of E-Learners' time and learning performance beyond quantitative time-on-task. The International Review of Research in Open and distance Learning, 12(5), 125-137. Retrieved from http://www.irrodl.org/index.php/irrodl/article/view/999/1870 
Smith, C. B., Ed. (2003). Successful use of the six traits in writing. ERIC Topical Bibliography and Commentary. Bloomington, IN: ERIC Clearinghouse on Reading, English and Communication

Spandel, V. (2013). Creating writers: 6 traits, process, workshop and literature. Upper Saddle River, NJ: Pearson

Temple, C., Ogle, D., Crawford, A., \& Freppon, P. (2011). All students read: Teaching for literacy in today's diverse classrooms. Boston, MA: Pearson Education

Tiersma, P., (2008). Writing, text and the law. In C. Bazerman (Ed.), Handbook of research on writing: History, society, school, individual, text (pp. 129-141). Mahwah, NJ: Lawrence Erlbaum Assoc. Inc.

Tompkins, G. E. (2008). Teaching writing: balancing process and product. Upper Saddle River, NJ: Pearson

U.S. Census Bureau (2014). State and county quick facts. Retrieved from http://quickfacts.census.gov/qfd/states/12/12086.html

Vygotsky, L. (1978). Mind and society. Cambridge, MA: Harvard University Press

Vygotsky, L. (1997). Interaction between learning and development. Retrieved from http://www.colorado.edu/physics/phys4810/phys 4810 fa08/4810 readings/vygot chap6.pdf

Wall, H. (2000). How do authors do it?: Using literature in a writers' workshop. The New Advocate, 13(2), 157-170

Williams, J. M. \& McEnerney, L. (n.d.). Writing in college: Some crucial differences between high school and college writing. Retrieved from http://writingprogram.uchicago.edu/resources/collegewriting/high_school v college.htm\# Toc $\underline{431538571}$

Wood, B. (2014, April 7). Florida to pay Utah $\$ 5.4 \mathrm{M}$ for Common Core test rental. Deseret News Retrieved from http://www.deseretnews.com/article/865600442/Florida-to-pay-Utah-54M-forCommon-Core-test-rental.html?.pg=all 


\section{APPENDICES}

\section{APPENDIX A}

\section{Description of Grade 4 Writing Scores}

6.0: The writing focuses on the topic, is logically organized, and includes ample development of supporting ideas or examples. It demonstrates a mature command of language, including precision in word choice. Sentences vary in structure. Conventions are generally correct.

5.0: The writing focuses on the topic with adequate development of supporting ideas or examples. It has an organizational pattern, but lapses may occur. Word choice is adequate. Sentences vary in structure. Punctuation, capitalization, and spelling are generally correct.

4.0: The writing generally focuses on the topic, but it may contain extraneous information. An organizational pattern is evident, but lapses may occur. Some supporting ideas contain specifics and details, but others are not developed. Word choice is adequate. Sentences vary somewhat in structure, though many are simple. Knowledge of conventions is demonstrated, and commonly used words are usually spelled correctly.

3.0: The writing generally focuses on the topic, but it may contain extraneous information. An organizational pattern has been attempted, but lapses may occur. Some of the supporting ideas or examples may not be developed. Word choice is adequate but limited. Sentences vary somewhat in structure, though many are simple. Knowledge of conventions is demonstrated, and commonly used words are usually spelled correctly.

2.0: The writing may be slightly related to the topic or offer little relevant information and few supporting ideas or examples. There is little evidence of an organizational pattern. Word choice may be limited or immature. Sentences may be limited to simple constructions. Frequent errors may occur in punctuation, capitalization, and spelling.

1.0: The writing may only minimally address the topic because there is little or no development of supporting ideas or examples. Unrelated information may be included. No organizational pattern is evident. Ideas are usually provided through lists, and word choice is limited or immature. Frequent errors in punctuation, capitalization, spelling, and sentence structure may impede communication.

$\mathrm{U}$ : The writing is unrelated to the assigned topic or cannot be read

\section{$\underline{\text { http://fcat.fldoe.org/mediapacket/2011/pdf/STComparisonWriting.pdf }}$}




\section{APPENDIX B \\ Teacher Meeting Agenda}

\section{WRITERS' CLUB: THE EFFECT OF EXTRA WRITING ON FOURTH-GRADE, HISPANIC STUDENTS' WRITING AND THEIR ATTITUDE TOWARDS WRITING \\ Meeting with Teachers \\ (approximately 15-20 minutes)}

Agenda

1. Introductions

2. Explain what the study comprises

a. Writers' Club (25 students - ESOL 3 or above)

i. Volunteer students will participate in an after-school club, three days a week

ii. Parents MUST sign consent forms before student can participate

iii. Child assent MUST be obtained

b. At Home Writing Group (21 students - ESOL 3 or above)

i. Volunteer students will participate in writing activities at home

ii. Parents MUST sign consent form before student can participate

iii. Child assent MUST be obtained

c. Comparison group (remaining students)

i. All non-participant students

3. Explain involvement of teachers

a. Collection of a writing samples from all students

i. Pre-test - before the study begins in earnest - date to be determined

ii. Post-test - after completion of the study - date to be determined

1. Materials will be provided

2. Topic will be assigned

b. Administration of Writing Attitude Survey (if the teachers agree to administer the survey)

i. Writing Attitude Surveys will be provided to the teachers

ii. Demonstration of how to administer the survey

iii. Date for administration will be determined

iv. Completed surveys will be collected by the researcher

c. Administration of Writing Attitude Survey (if the teachers are unwilling to administer the survey)

i. Agree a date and time for the researcher to administer the Writing Attitude Survey

d. Distribution and collection of At Home Writing Group folders

i. Each student will receive a folder with a number of writing activities each week

ii. At the end of the week the completed folder will be handed in by the student

iii. Teacher will check to see that the activity log is completed

iv. Each week, the researcher will provide the teacher with the week's folders for distribution and will collect completed folders

v. Determine a day and time for distribution and collection of folders

4. Any questions/concerns

5. Thank teachers for their cooperation 


\section{APPENDIX C \\ Parent Information Letter and Consent Form (English and Spanish)

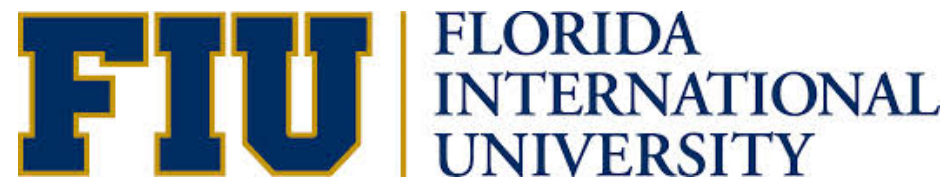

\section{WRITERS' CLUB: THE EFFECT OF EXTRA WRITING ON FOURTH-GRADE, HISPANIC STUDENTS' WRITING AND THEIR ATTITUDE TOWARDS WRITING}

\section{Dear Fourth-Grade Parents,}

My name is Helen Barnes, I am a student at Florida International University (FIU) in the College of Education. I am working on earning my doctoral degree. As part of my studies, I must conduct research and I would like to study the effect of extra writing activities on students' writing skills. Dr. Tercilla has given her approval for me to conduct my study at Greenglade Elementary School. I will be conducting two types of extra writing.

\section{The Writers' Club}

The Writers' Club will take place during regular school hours three days a week, for eight weeks. Each meeting will last for $\mathbf{3 0}$ minutes and be held in the media center. During the Writers' Club the children will receive instruction in writing. They will be able to work alone, with a buddy or in groups. The children will have conferences with the teacher and will be able to share their writing with the teacher and each other. You will not have to pay to join the club or for any materials.

\section{At Home Writing Group}

The At Home Writing Group will involve the children in extra writing activities, like homework. Each week the children will be given a folder that will have a selection of writing activities for them to choose from. The children will be expected to spend 90 minutes each week doing the activities. There will be a work log that will need to be completed each week confirming that 90 minutes of work has been done during the week. The work log needs to be signed by an adult in the house. It will not be necessary for all the activities to be completed just so long as the child has worked for 90 minutes on writing. You will not have to pay for any materials.

You may choose that group your child would like to be part of, The Writers' Club or the At Home Writing Group, or you may choose not to have your child join either group. There will be only 25 places in each group and children will be accepted on a first come, first served basis. There will be no payment for joining either group.

All the children will write an essay at the beginning of the study and again at the end of the study, during regular class time. These essays will be evaluated to see if joining either of the groups helps children improve their writing skills. In addition, all the children will complete an attitude survey, during class time. This will also be done twice, at the beginning of the study and at the 
end. I would also ask to be given some personal information: age, sex, free and reduced lunch status, race/ethnicity.

All personal information would be kept private, only the other participants and the children's teachers would know they are participating. All data will be stored securely on a USB drive and/or in a locked box in my home.

Feel free to contact me either by phone at (786) --- ---- or by email at Helen.Barnes@,fiu.edu. Should you have any questions you may contact my advisor Dr. Joyce Fine at (305) 3486152.

Yours sincerely,

Helen Barnes, M.S., Ed.S.

Please complete and return the bottom part of this page to your child's teacher as soon as possible. THANK YOU VERY MUCH

\section{FIU}

WRITERS' CLUB: THE EFFECT OF EXTRA WRITING ON FOURTH-GRADE, HISPANIC STUDENTS' WRITING AND THEIR ATTITUDE TOWARDS WRITING

I have read this information letter and agree to allow my child to participate in this study

Yes

No

First Choice:

Second Choice:

We will try to make sure that your child is included in your first choice. All children will receive their regular classroom instruction and homework. If you do not wish your child to participate in either the Writers' Club or the At Home Writing Group your child will only provide two writing samples and complete two writing attitude surveys, both will be done during class time, unless you specifically ask that your child not be included.

Signature of Parent/Guardian

Printed Name of Child Participant

Signature of Person Obtaining Consent $\overline{\text { Printed Name of Parent/Guardian }}$

Date

Date 


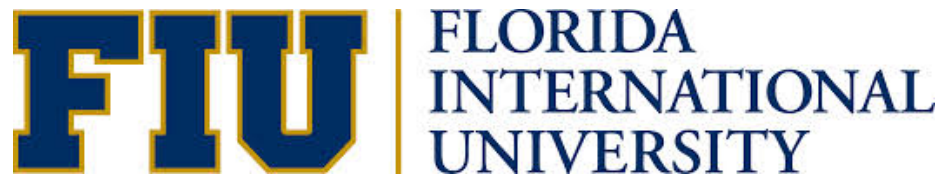

\section{CLUB DE ESCRITORES: EL RESULTADO DE LA ESCRITURA EXTRA EN LA ACTITUD Y ESCRITURA EN ESTUDIANTES HISPANOS DE CUARTO GRADO}

Estimados padres de cuarto grado,

Mi nombre es Helen Barnes, soy estudiante de la Universidad Internacional de la Florida (FIU) en la facultad de educación y en camino a obtener mi doctorado. Como parte de mis estudios, debo realizar una investigación. Me gustaría hacerlo sobre el resultado de las actividades adicionales y habilidades de escritura de los estudiantes. Dr. Tercilla ha dado su aprobación para que yo realice mis estudios en la Escuela Primaria Greenglade. Yo llevaré a cabo dos tipos de escritura extra.

1. Club de Escritores,

El club de escritores tendrá lugar durante el horario regular de clases, tres días a la semana, durante ocho semanas. Cada reunión tendrá una duración de 30 minutos y se llevará a cabo en el salón de comunicación.

Durante el Club de Escritores los niños recibirán instrucción por escrito. Ellos podrán trabajar solos, con un compañero o en grupo. Los niños se reunirán con el maestro y podrán compartir sus escritos con el maestro y con los demás alumnos. No hay costo alguno para pertenecer al club o por cualquier material.

\section{El "At Home" Grupo de Redacción;}

El Club de Grupo de Redacción en casa, involucrará a los niños en actividades adicionales de escritura, además de sus deberes. Cada semana se les dará una carpeta a todos los niños que incluirá una selección de actividades de escritura para que puedan elegir.

Se requiere que los niños dediquen 90 minutos a la semana haciendo estas actividades. Habrá una agenda y lista de trabajo que deberá ser completada semanalmente confirmando que se ha trabajado por 90 minutos durante la semana. Esta lista necesita ser firmada por un adulto en la casa. No es necesario completar todas las actividades siempre y cuando el niño haya trabajado durante 90 minutos en la escritura. Usted no tendrá que pagar por materiales.

Usted puede elegir el grupo al cual su hijo(a) le gustaría ser parte de: Club de Escritores o el At Home Grupo de Redacción, o puede optar por no tener a su hijo(a) en ningún grupo.

Habrá sólo 25 espacios en cada grupo y los niños serán aceptados de acuerdo al espacio disponible. No habrá pago por unirse a cualquiera de los grupos.

Todos los niños escribirán un ensayo al comienzo y nuevamente al final del estudio, durante el tiempo de clase regular. Estos ensayos serán evaluados para ver si el unirse a los grupos le ayudó a mejorar sus habilidades de escritura. Además, todos los niños van a completar una encuesta de 
comportamiento, durante clase. Esto se hará dos veces, al inicio y al final del estudio. También se les pediría algunos datos personales: edad, sexo, estado de almuerzo gratis o precio reducido, raza y etnia. La información personal se mantendrá privada, sólo los niños participantes y sus profesores sabrán quien estará participando. Todos los datos se guardaran de forma segura en una unidad USB y confidencial.

Si tiene alguna pregunta no dude en ponerse en contacto conmigo por teléfono al (786) --- ---- o por correo electrónico a helen.barnes@fiu.edu Y si desea hacer otras preguntas puede llamar a mi consejera Dra. Joyce Fine al (305) 348-6152.

Atentamente

Helen Barnes, M.S., Ed.S.

Por favor complete y devuelva la parte inferior de esta página con el maestro de su hijo(a) lo más pronto posible. Muchas gracias

\section{FIU}

\section{CLUB DE ESCRITORES: EL RESULTADO DE LA ESCRITURA EXTRA EN LA ACTITUD Y ESCRITURA EN ESTUDIANTES HISPANOS DE CUARTO GRADO}

He leído esta carta de información y estoy de acuerdo con permitir que mi hijo(a) participe en este estudio

Sí__ No___ Primer Opción: Segunda Opción:

Trataremos de asegurar de que su hijo(a) este incluido en su primera opción. Todos los niños participantes recibirán sus clases y deberes en su aula regular.

Si usted no desea que su hijo(a) participe en ninguno de los grupos; su hijo(a) tendrá que proporcionar solamente dos muestras de escritura y dos encuestas sobre su actitud escrita, Las cuales se completaran durante la clase, a menos que Usted específicamente pida que su niño no participe.

Firma del Padre / Tutor

Nombre del niño participante

Firma de la persona que otorga el consentimiento
Nombre del Padre/ Tutor (letra de molde)

\section{Fecha}

Fecha 


\section{APPENDIX D \\ Student Meeting Agenda}

\section{WRITERS' CLUB: THE EFFECT OF EXTRA WRITING ON FOURTH-GRADE, HISPANIC STUDENTS' WRITING AND THEIR ATTITUDE TOWARDS WRITING \\ Classroom visit - Meeting with Students \\ (approximately 15 minutes)}

Agenda

1. Introductions

2. Explain study

a. Writers' Club

i. A club that will meet three times a week during school time to write about things that interest them, it will involve reading books, using the computer, writing in a journal, sharing with their friends and lots of discussion. They will not need to buy anything, everything will be provided.

ii. Parental permission MUST be obtained

iii. Children will have to sign an agreement to join the club

iv. It is important to attend every meeting if possible

v. There will be no grades

vi. They will produce a writing sample as part of regular classroom activity

vii. They will complete the Writing Attitude Survey as part of regular classroom activity

b. At Home Writers Group

i. A group of students who will receive writing activities to complete at home. They can share what they are doing with family members and have help if necessary. They will need to complete the activity log every time they do some of the work and have it signed. There will be a choice of activities but they must complete $1 \frac{1}{2}$ hours of work each week.

ii. Each week they will be provided with a new folder with a selection of activities for them to choose from.

iii. Each week they will hand in the old folder with all their work inside it, along with the completed activity log showing that they have done $1 \frac{1}{2}$ hours of work.

iv. There will be no grades

v. They will produce a writing sample as part of regular classroom activity

vi. They will complete the Writing Attitude Survey as part of regular classroom activity

c. Comparison Group

i. Students will receive regular classroom instruction without any additional writing

ii. They will produce a writing sample as part of regular classroom activity

iii. They will complete the Writing Attitude Survey as part of regular classroom activity

3. Hand out
a. Invitations to Parent Meeting
b. Parent permission slips
c. Child assent forms

4. Questions/concerns

5. Thank students for listening 


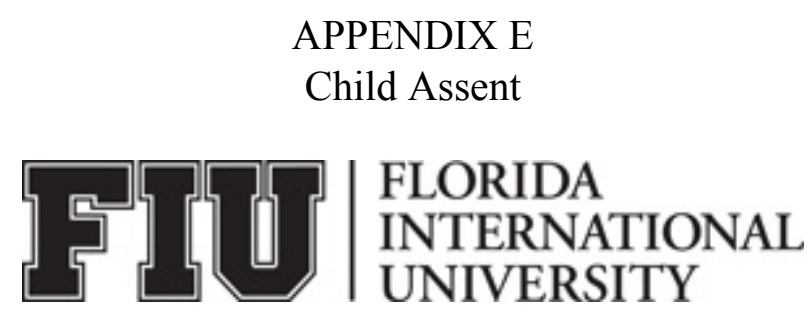

\section{WRITERS' CLUB: THE EFFECT OF EXTRA WRITING ON FOURTH-GRADE, HISPANIC STUDENTS' WRITING AND THEIR ATTITUDE TOWARDS WRITING}

My name is Helen Barnes. I am a student at FIU. I would like you to help me with the research I have to do to earn my degree. I would like to find out more about how to help children write well.

I would like you to join either the Writers' Club or the At Home Writing Group.

\section{Writers' Club}

The Writers' Club will take place during school three days a week, for eight weeks. Each meeting will last for 30 minutes and be held in the media center. During the Writers' Club you will receive instruction in writing. You will be able to work alone, with a buddy or in groups. You will have conferences with the teacher and will be able to share your writing with the teacher and other members of the club. You will not have to pay to join the club or for any materials.

\section{At Home Writing Group}

The At Home Writing Group will involve you in extra writing activities, like homework. Each week you will be given a folder that will have a selection of writing activities for you to choose from. You will be expected to spend 90 minutes each week doing the activities. There will be a work log that will need to be completed each week confirming that 90 minutes of work has been done during the week. The work log needs to be signed by an adult in your home. It will not be necessary for all the activities to be completed just so long as you have worked for 90 minutes on writing. You will not have to pay for any materials.

I would like to help you with your research and be a part of the study YES $\mathrm{NO}$

My first choice is

My second choice is
Writers' Club
Writers' Club
At Home Writing Group

At Home Writing Group
Print your name

Person obtaining child's assent
Sign your name

\section{Date}




\section{APPENDIX F \\ Parent Meeting Agenda}

\section{WRITERS' CLUB: THE EFFECT OF EXTRA WRITING ON FOURTH-GRADE, HISPANIC STUDENTS' WRITING AND THEIR ATTITUDE TOWARDS WRITING \\ Parent Meeting \\ (approximately 30-45 minutes) \\ Agenda}

1. Introductions

2. Explain study

a. Writers' Club (Limits - ESOL level 3 or above, 25 students)

i. An after-school club that will meet three times a week to write about things that interest the students, it will involve reading books, using the computer, writing in a journal, sharing with their friends and lots of discussion. They will not need to buy anything everything will be provided.

ii. Parental permission MUST be obtained (forms are available in English and Spanish)

iii. Students will have to sign an agreement to join the club (forms will be available in English)

iv. It is important for the students to attend every meeting, if possible

v. There will be no grades

vi. The students will receive regular classroom instruction

vii. The students will produce two writing samples as part of regular classroom activity

viii. The students will complete the Writing Attitude Survey as part of regular classroom activity

b. At Home Writers Group (Limits - ESOL level 3 or above, 25 students)

i. A group of students who will receive writing activities to complete at home. They can share what they are doing with family members and have help if necessary. The student will need to complete the activity log every time he/she does some of the work and have it signed. There will be a choice of activities but 90 minutes of work must be completed each week.

ii. Each week the students will be provided with a new folder with a selection of activities for them to choose from.

iii. Each week the students will hand in the completed folder with all their work inside it, along with the completed activity log showing that they have done 90 minutes of work.

iv. There will be no grades

v. The students will produce a writing sample as part of regular classroom activity

vi. They will complete the Writing Attitude Survey as part of regular classroom activity

c. Comparison Group

i. Students will receive regular classroom instruction without any additional writing

ii. They will produce a writing sample as part of regular classroom activity

iii. They will complete the Writing Attitude Survey as part of regular classroom activity

3. Hand out

a. Parent permission slips (English and Spanish)

4. Questions/concerns

5. Thank parents for attending 
APPENDIX G

Lesson Plans and Reflections

Week 1

Lesson Plan

Meeting 1

\begin{tabular}{|c|c|c|c|c|c|c|}
\hline Time & Activity & Objective & Teachers Actions & Children's Actions & Materials & $\begin{array}{c}\text { Cambourne's } \\
\text { Constructs }\end{array}$ \\
\hline $12: 30$ & Attendance & & Call roll. & Respond to name & $\begin{array}{l}\text { Attendance } \\
\log \end{array}$ & $\begin{array}{l}\text { Routines within the } \\
\text { space }\end{array}$ \\
\hline $\begin{array}{l}12: 32 \\
- \\
12: 45\end{array}$ & $\begin{array}{l}\text { Introduction } \\
\text { Explanation } \\
\text { of Writers' } \\
\text { Club. }\end{array}$ & & $\begin{array}{l}\text { I will introduce myself. Ask if the students } \\
\text { all know each other. Explain the details of } \\
\text { the writers' club and show the students a } \\
\text { small bell that will be placed in the } \\
\text { classroom. This is to be rung by anyone } \\
\text { wanting the attention of the whole class. It } \\
\text { is to be rung very gently and quickly. When } \\
\text { anyone hears the bell it is time to be silent } \\
\text { and once everyone is silent the person } \\
\text { ringing the bell will make whatever } \\
\text { announcement is needed. This will be } \\
\text { demonstrated. }\end{array}$ & $\begin{array}{l}\text { Listen, introduce } \\
\text { themselves to any } \\
\text { student they do not } \\
\text { know, test the bell. }\end{array}$ & & $\begin{array}{l}\text { Routines within the } \\
\text { space - Learning } \\
\text { activities within the } \\
\text { timeframe }\end{array}$ \\
\hline $\begin{array}{l}12: 45 \\
- \\
12: 55\end{array}$ & $\begin{array}{l}\text { Books, Bell } \\
\& \text { Tidy up }\end{array}$ & $\begin{array}{l}\text { Provide children } \\
\text { with notebooks } \\
\text { and pencils } \\
\text { Classroom } \\
\text { management }\end{array}$ & $\begin{array}{l}\text { Each child will select a composition book } \\
\text { and pencil, they will write their names in } \\
\text { the books. The books and pencils will be } \\
\text { put away in the crate. }\end{array}$ & $\begin{array}{l}\text { The children will select } \\
\text { a book and pencil for } \\
\text { themselves and will } \\
\text { write their names in } \\
\text { their books. } \\
\text { Then they will check } \\
\text { the whole room to } \\
\text { ensure that it is tidy and } \\
\text { ready for use. }\end{array}$ & $\begin{array}{l}\text { Books, } \\
\text { bell, crate }\end{array}$ & $\begin{array}{l}\text { Behaviors within the } \\
\text { space - conduct and } \\
\text { actions } \\
\text { Routines within the } \\
\text { space - Learning } \\
\text { activities within the } \\
\text { timeframe }\end{array}$ \\
\hline $\begin{array}{l}12: 55 \\
-1: 00\end{array}$ & Rules & & $\begin{array}{l}\text { The children will be informed that all Clubs } \\
\text { have rules and asked to think of appropriate } \\
\text { rules for the Writers' Club }\end{array}$ & Listen & & $\begin{array}{l}\text { Behaviors within the } \\
\text { space }\end{array}$ \\
\hline
\end{tabular}


I visited the classrooms to distribute the At Home Writing Group folders. I explained that they would have seven activities each week; that they could choose any of them; that if they wanted to they could do Free Write repeatedly; that the only stipulation was that they write for 30 minutes three times per week and that they have their parents sign the Writing Log.

In anticipation of the Writers' Club, 30 composition books, with a variety of covers, and colorful pencils were purchased. Each student had a choice of pencil and composition book. All the pencils were prepared with an area scraped down to the wood so each student's name could be written on his/her pencil for easy identification during meetings. Prior to the students' arrival, I laid out all the books and pencils on a table. I wrote each students' name on a Post It note and stuck it face down on the table so the order in which the books were chosen would be random and I couldn't be accused of favoritism Physical space - Location and environment

The students arrived promptly and sat down. I asked them to attempt to enter and take their places quietly Behaviors within the space - Conduct and actions. I called attendance. I asked if all the students knew each other, they all did. I reintroduced myself, I had visited the classroom before the first meeting to explain the study and on a different date to administer the Writing Attitude Survey so they were familiar with me. I briefly explained the Writers' Club. Telling the students time would be spent working on punctuation, there would be reading and writing during every meeting Routines within the space - Learning activities within the timeframe. The first two meetings were set aside for logistics. The students were very excited by the sight of all the books and pencils so I decided to let them select their books before explaining about the bell.

I selected a student to choose a book and pencil. Once this was done the student pulled up one of the Post It notes and read the name of the next student who would choose his/her book and pencil. This continued until all the students had a book and pencil. Then each student wrote his/her name in a book, placed the pencil inside the book and closed it.

I then explained the use of the bell. It was available to everyone but must be used appropriately. I demonstrated ringing it quietly and said when it was rung everyone should stop talking immediately and freeze. Some of the students wanted to try it, this was allowed as they left the room. Behaviors within the space - Conduct and actions

I explained that all clubs have rules and asked the students to think about what rules they might like for their Writers' Club and to come to the next meeting ready to share those ideas. Behaviors within the space - Conduct and actions

The meeting closed.

Two students were absent 
Week 1

Lesson Plan

Meeting 2

\begin{tabular}{|c|c|c|c|c|c|c|}
\hline Time & Activity & Objective & Teachers Actions & Children's Actions & Materials & $\begin{array}{c}\text { Cambourne's } \\
\text { Constructs }\end{array}$ \\
\hline $12: 30$ & Attendance & & Call roll. & $\begin{array}{l}\text { Respond to name, } \\
\text { collect book and pencil }\end{array}$ & $\begin{array}{l}\text { Attendance } \\
\text { log, books } \\
\text { and pencils }\end{array}$ & $\begin{array}{l}\text { Routines within the } \\
\text { space }\end{array}$ \\
\hline $\begin{array}{l}12: 32 \\
-1: 00\end{array}$ & Club Rules & $\begin{array}{l}\text { LAFS.4.SL.1.1 } \\
\text { Follow agreed- } \\
\text { upon rules for } \\
\text { discussions and } \\
\text { carry out } \\
\text { assigned roles. } \\
\text { LAFS.4.SL.1.1 } \\
\text { Engage in } \\
\text { discussion } \\
\text { LAFS.4.L.2.3 - } \\
\text { Use appropriate } \\
\text { conventions } \\
\text { when speaking }\end{array}$ & $\begin{array}{l}\text { The students write down, in their } \\
\text { notebooks, the ideas they have for rules for } \\
\text { the club. Ideas will be shared with the } \\
\text { whole group. All rules must be phrased } \\
\text { from a positive perspective. Discussion of } \\
\text { the wording of the rules. The end result is } \\
\text { likely to be that there will be three } \\
\text { overriding rules "Respect yourself, Respect } \\
\text { others and Respect the materials" there may } \\
\text { be specifics that the children want to } \\
\text { include. I will explain how having the rules } \\
\text { written down makes it easy to remember } \\
\text { them and to refer to them. I will explain } \\
\text { that this is one way writing helps us in our } \\
\text { everyday lives. }\end{array}$ & $\begin{array}{l}\text { They will write down in } \\
\text { their notebooks the date } \\
\text { followed by up to } 3 \\
\text { rules they think are } \\
\text { important for a club. } \\
\text { The children will } \\
\text { discuss behaviors that } \\
\text { are acceptable and } \\
\text { those that are not and } \\
\text { most particularly how } \\
\text { we treat each other. }\end{array}$ & $\begin{array}{l}\text { Note } \\
\text { books, } \\
\text { pencils, } \\
\text { markers }\end{array}$ & $\begin{array}{l}\text { Behaviors within the } \\
\text { space } \\
\text { Responsibility - } \\
\text { Making decisions } \\
\text { and choices about } \\
\text { learning }\end{array}$ \\
\hline $\begin{array}{l}12: 50 \\
-1: 00\end{array}$ & $\begin{array}{l}\text { Write a brief } \\
\text { paragraph }\end{array}$ & $\begin{array}{l}\text { LAFS.4.L.1.1 } \\
\text { Demonstrate } \\
\text { command of the } \\
\text { conventions of } \\
\text { standard English }\end{array}$ & $\begin{array}{l}\text { I will ask the children to write a paragraph } \\
\text { on a topic of their choice. Each paragraph } \\
\text { will be examined for use of conventions to } \\
\text { assess what needs to be addressed. }\end{array}$ & $\begin{array}{l}\text { The children will write } \\
\text { in their notebooks. }\end{array}$ & $\begin{array}{l}\text { Books, } \\
\text { pencils }\end{array}$ & $\begin{array}{l}\text { Immersion - writing } \\
\text { experiences } \\
\text { Behaviors within the } \\
\text { space }\end{array}$ \\
\hline & $\begin{array}{l}\text { Read aloud } \\
6 \text { mins }\end{array}$ & Read aloud & $\begin{array}{l}\text { Goldilocks and the Three Bears retold by } \\
\text { Vera Southgate, }\end{array}$ & $\begin{array}{l}\text { The children will sit } \\
\text { and listen. }\end{array}$ & Book & \\
\hline
\end{tabular}


The students entered the Media Center promptly. They were attentive to being quiet Behaviors within the space. I called attendance. There was a new student, she was given the opportunity to select a book and pencil from those still available.

The students were asked if they had thought of rules they would like to include for their Writers' Club. Most of them replied in the affirmative. They were asked to open their books and write down their ideas. They were assured there were no right or wrong responses, but that all ideas would be discussed Behaviors within the space. This took longer than expected by 3 or 4 minutes. A white board had been set up prior to the start of class, once the students were ready they shared their ideas and, on the white board, I wrote down the rules they suggested. Gradually, they internalized that everything they had suggested refined to respect, one child suddenly exclaimed, "This all relates to respect." I agreed and identified that most of their ideas related to respecting others. Another child shared that, "We need to respect our ideas; we need to respect our work." Finally one student said they should respect their book and pencil. I agreed with them and the rules were decided upon - respect yourself, respect others and respect materials.

This took longer than anticipated so they did not have time to write a paragraph and I certainly did not have time to read to them. These activities will be moved forward to the next meeting.

They did not have time to create their poster of the rules I informed them that I would do that over the weekend, ready for our next meeting.

There was no third meeting in the first week. On Friday there was no school for a teacher work day.

Three students were absent 
Week 2

Lesson Plan

Meeting 3

\begin{tabular}{|c|c|c|c|c|c|c|}
\hline Time & Activity & Objective & Teachers Actions & Children's Actions & Materials & $\begin{array}{c}\text { Cambourne's } \\
\text { Constructs }\end{array}$ \\
\hline $12: 30$ & Attendance & & Call roll. & $\begin{array}{l}\text { Respond to name, } \\
\text { collect book and pencil }\end{array}$ & $\begin{array}{l}\text { Attendance } \\
\text { log, books } \\
\text { and pencils }\end{array}$ & $\begin{array}{l}\text { Routines within the } \\
\text { space }\end{array}$ \\
\hline $\begin{array}{c}12: 32 \\
- \\
12: 42\end{array}$ & $\begin{array}{l}\text { Write a brief } \\
\text { paragraph }\end{array}$ & $\begin{array}{l}\text { LAFS.4.W.2.4 } \\
\text { Produce writing } \\
\text { in that the } \\
\text { development } \\
\text { and organization } \\
\text { are appropriate } \\
\text { to task, purpose, } \\
\text { and audience } \\
\text { LAFS.4.L.1.1 } \\
\text { Demonstrate } \\
\text { command of the } \\
\text { conventions of } \\
\text { standard English }\end{array}$ & $\begin{array}{l}\text { I will ask the children to write a paragraph } \\
\text { on a topic of their choice. I will tell them I } \\
\text { will focus on their punctuation } \\
\text { (conventions) and what ideas they include. }\end{array}$ & $\begin{array}{l}\text { The children will write } \\
\text { in their notebooks. }\end{array}$ & $\begin{array}{l}\text { Books and } \\
\text { pencils }\end{array}$ & $\begin{array}{l}\text { Immersion - writing } \\
\text { experiences } \\
\text { Behaviors within the } \\
\text { space }\end{array}$ \\
\hline $\begin{array}{c}12: 42 \\
- \\
12: 52\end{array}$ & $\begin{array}{l}\text { Examine } \\
\text { poorly } \\
\text { punctuated } \\
\text { sentences. } \\
\text { Correct } \\
\text { them. Write } \\
\text { corrected } \\
\text { sentence in } \\
\text { notebook }\end{array}$ & $\begin{array}{l}\text { LAFS.4.SL.1.1 } \\
\text { Engage in } \\
\text { discussion } \\
\text { LAFS.4.L.1.1 } \\
\text { Demonstrate } \\
\text { command of the } \\
\text { conventions of } \\
\text { standard English } \\
\text { LAFS.4.L.1.2.a } \\
\text { Use correct } \\
\text { capitalization. }\end{array}$ & $\begin{array}{l}\text { Sentences will be written on the white } \\
\text { board disregarding capitalization and } \\
\text { sentence endings. Ask the students to } \\
\text { orally correct the sentence. Make the } \\
\text { corrections as they are discussed. } \\
\text { Observe students as they write the sentence } \\
\text { following correct rules of punctuation in } \\
\text { their notebooks }\end{array}$ & $\begin{array}{l}\text { Discuss what needs to } \\
\text { be done to the sentences } \\
\text { to correct them. } \\
\text { Writing sentence using } \\
\text { correct punctuation in } \\
\text { their books. }\end{array}$ & $\begin{array}{l}\text { Books and } \\
\text { pencils. }\end{array}$ & $\begin{array}{l}\text { Immersion - writing } \\
\text { experiences } \\
\text { Demonstration - } \\
\text { Experiencing } \\
\text { multifaceted } \\
\text { exposure to text }\end{array}$ \\
\hline $\begin{array}{l}12: 52 \\
-1: 00\end{array}$ & $\begin{array}{l}\text { Read aloud } \\
6 \text { mins }\end{array}$ & Read aloud & $\begin{array}{l}\text { Goldilocks and the Three Bears retold by } \\
\text { Vera Southgate }\end{array}$ & $\begin{array}{l}\text { The children will sit } \\
\text { and listen. }\end{array}$ & Book & \\
\hline
\end{tabular}


I collected and distributed the At Home Writing Group folders. Many students greeted me by name. Many Writers' Club students were excited that they would meet with me shortly.

Prior to the start of the meeting, I placed the rules in a clearly visible place. I wrote the sentences for correction on the white board. The students were pleased with how the rules had come out Behaviors within the space. Most of the students came in quietly. A small group were late. I started promptly at 12:30.

I informed them that they had 10 minutes to write a brief paragraph about a topic of their choice. They quickly opened their notebooks. I wrote my own paragraph and then observed how they were progressing. One student, who had been absent for the previous two meetings, was having a problem getting started. I posed stimulating questions Immersion - The state of being steeped in stimuli. He eventually wrote two sentences about liking baseball. Some of the others were talking to their friends and wrote very little. Other students wrote quickly and fairly prolifically. Two students said they were finished before time was up. I encouraged them to continue writing, choosing another topic if they liked. Attendance was taken by observation. The timer went off and I asked them to stop. After the paragraph, I began correcting the incorrect sentences, on the board Demonstration Experiencing multifaceted exposure to text. They identified all the punctuation needed, during discussion. The sentences were:

All sentences begin with a capital letter. All sentences have a sentence ending.

Thank you for attending today's meeting. Did you have a pleasant weekend? That is a very pretty dress!

The only two punctuation marks that offered any challenge were the apostrophe in "today's" and the exclamation mark at the end. This leads me to think they know the basics. I asked them to write down the corrected sentences. Then I read aloud to them. Some of the students completed copying the corrected sentences while I read. All of the students professed to be familiar with the story Goldilocks and the three bears. I explained before dismissal that they would be taking a point of view and writing a letter, during the next meeting.

After the meeting, I examined all the students' writing and found that most of them had a reasonable grasp of basic punctuation - capitals at the start of sentences and appropriate sentence endings. A few were still using capital letters randomly throughout their work. Based on the little evidence available, they need reinforcement regarding the capitalization of proper nouns. The use of apostrophes was somewhat random, In discussion, at least one student was able to articulate that apostrophes are used for possession, no mention was made of contractions. The use of grammar followed normal speech with the exception of one student who left out the pronoun "I" throughout his (JS) piece. This can be dealt with on an individual basis, as can the use of "gonna" instead of "going to" in two students' JR(a) and VM writing samples. All students received written feedback through their notebooks. Response - meaningful response from significant others in regards to goals; Expectations - Messages for success communicated by significant others

One student was absent 
Week 2

Lesson Plan

Meeting 4

\begin{tabular}{|c|c|c|c|c|c|c|}
\hline Time & Activity & Objective & Teachers Actions & Children's Actions & Materials & $\begin{array}{l}\text { Cambourne's } \\
\text { Constructs }\end{array}$ \\
\hline $12: 30$ & Attendance & & Call roll. & $\begin{array}{l}\text { Respond to name, } \\
\text { collect book and pencil }\end{array}$ & $\begin{array}{l}\text { Attendance } \\
\log ,\end{array}$ & $\begin{array}{l}\text { Routines within the } \\
\text { space }\end{array}$ \\
\hline $\begin{array}{c}12.32 \\
- \\
12.42\end{array}$ & Discussion & $\begin{array}{l}\text { LAFS.4.SL.1.1 } \\
\text { Engage in } \\
\text { discussion } \\
\text { expressing point } \\
\text { of view } \\
\text { LAFS.4.L.2.3 } \\
\text { Use appropriate } \\
\text { conventions } \\
\text { when speaking }\end{array}$ & $\begin{array}{l}\text { Using questioning strategy ask children } \\
\text { how bears might feel. What might they like } \\
\text { to say to Goldilocks? If they knew her } \\
\text { address they could write her a letter telling } \\
\text { her how they feel. Is there anything } \\
\text { Goldilocks might be able to say to the } \\
\text { bears? She knows where they live and } \\
\text { could write them a letter. If you were either } \\
\text { one of the bears or Goldilocks what would } \\
\text { you say? Why do people write letters to } \\
\text { each other? Have you ever written a letter } \\
\text { to someone else? }\end{array}$ & $\begin{array}{l}\text { The children will } \\
\text { respond to the } \\
\text { questions, imagining } \\
\text { they are either } \\
\text { Goldilocks or one of } \\
\text { the three bears. } \\
\text { They will share their } \\
\text { experiences of letter } \\
\text { writing. }\end{array}$ & & $\begin{array}{l}\text { Engagement - } \\
\text { Intentional active } \\
\text { participation }\end{array}$ \\
\hline $\begin{array}{c}12.42 \\
- \\
12: 57\end{array}$ & Writing time & $\begin{array}{l}\text { LAFS.4.W.1.1 } \\
\text { Write opinion } \\
\text { pieces on topics } \\
\text { or texts, } \\
\text { supporting a } \\
\text { point of view } \\
\text { with reasons and } \\
\text { information. }\end{array}$ & $\begin{array}{l}\text { Please open your books. Once you have } \\
\text { decided that character you would like to be, } \\
\text { write what you would like to say to the } \\
\text { other character, in your book. Would you } \\
\text { like to work on your own, with a partner or } \\
\text { form a small group (4)? It is OK to talk } \\
\text { together about what you might like to say. } \\
\text { It is important not only to put down what } \\
\text { you might want to say but to include why } \\
\text { you feel that way. I will write in my own } \\
\text { book. } \\
\text { I will circulate observing/supporting the } \\
\text { children. Conference with any who need } \\
\text { one-to-one support. }\end{array}$ & $\begin{array}{l}\text { Children will decide } \\
\text { whether to work alone, } \\
\text { with a partner or in a } \\
\text { small group (4). They } \\
\text { will use their books to } \\
\text { first write the date then } \\
\text { to write what they } \\
\text { would like to say as } \\
\text { either a bear or as } \\
\text { goldilocks. If they are } \\
\text { working with a partner } \\
\text { or in a small group they } \\
\text { all write down what } \\
\text { they decide to say. }\end{array}$ & $\begin{array}{l}\text { Books, } \\
\text { pencils. }\end{array}$ & $\begin{array}{l}\text { Engagement - } \\
\text { ntentional active } \\
\text { participation } \\
\text { Immersion - writing } \\
\text { experiences } \\
\text { Behaviors within the } \\
\text { space } \\
\text { Use - Opportunities } \\
\text { to practice }\end{array}$ \\
\hline 12.57 & Letter format & $\begin{array}{l}\text { LAFS.4.W.2.4 } \\
\text { Produce } \\
\text { appropriately } \\
\text { organized } \\
\text { writing } \\
\end{array}$ & $\begin{array}{l}\text { Eexample of letter format written on the } \\
\text { white board and Messages in the mailbox: } \\
\text { How to write a letter by Loreen Leedy } \\
\text { available for students to look at. }\end{array}$ & Listen & & $\begin{array}{l}\text { Immersion - writing } \\
\text { experiences }\end{array}$ \\
\hline
\end{tabular}


Our meeting area has been disrupted. The large table has been removed. There are insufficient places for all the students. I rearranged the tables, converting from four to six students to a table. This makes the space cramped but, if they are courteous and respectful, it can work. I was advised that the Spelling Bee was taking place in the hall and that the table would be needed for the rest of the week. Physical space; Behaviors within the space

Everyone came in more quietly. I explained that we would have be very considerate of each other with the restricted spacing. Everyone agreed that we could manage. Physical space

A lively discussion of point of view was held. They all determined that Goldilocks needed to apologize. One of the boys wanted to know if boys could be Goldilocks. I said, "Yes, being a boy or girl is not important for this task. An apology is universal." They had a variety of ideas about what could be said by each of the three bears. At least one student took each character. They discussed their own character selection and paired up with other students taking the same point of view. They discussed what they could say and took notes.

Three of the girls JR(a), VM, \& AD went directly into letter format, based on the layout on the white board Demonstration - Experiencing multifaceted exposure to text. I explained that at this point they were only gathering ideas and not formatting it per se. One student, JR(a), wants to get everything done, rather than think about what needs to be done and gradually build up ideas. Another student, AM, wrote nothing until I spoke to him.

Once they had time to write down ideas and the meeting was about to close I pointed out the letter format on the white board and told them we would go over it in detail later.

Conferences - $\quad$ JR(a) and VM "gonna" is slang and in written work needs to be "going to" (1 minute)

(Expectations; JS use of pronoun I, gave examples and asked him to say the sentence aloud to check if I needed to be Response) written (2 minutes)

One student was absent. 
Week 2

Lesson Plan

Meeting 5

\begin{tabular}{|c|c|c|c|c|c|c|}
\hline Time & Activity & Objective & Teachers Actions & Children's Actions & Materials & $\begin{array}{c}\text { Cambourne's } \\
\text { Constructs }\end{array}$ \\
\hline $12: 30$ & Attendance & & Call roll. & $\begin{array}{l}\text { Respond to name, } \\
\text { collect book and pencil }\end{array}$ & $\begin{array}{l}\text { Attendance } \\
\log ,\end{array}$ & $\begin{array}{l}\text { Routines within the } \\
\text { space }\end{array}$ \\
\hline $\begin{array}{l}12.32- \\
12.40\end{array}$ & Conventions & $\begin{array}{l}\text { LAFS.4.L.1.2.a } \\
\text { Use correct } \\
\text { capitalization. }\end{array}$ & $\begin{array}{l}\text { Unpunctuated sentence already on board, } \\
\text { focus will be caps and sentence endings. } \\
\text { Discussion of corrections needed. }\end{array}$ & $\begin{array}{l}\text { Students will discuss } \\
\text { corrections and then } \\
\text { write corrected version } \\
\text { in their books. }\end{array}$ & $\begin{array}{l}\text { Books and } \\
\text { pencils }\end{array}$ & $\begin{array}{l}\text { Immersion - } \\
\text { Engagement - }\end{array}$ \\
\hline $\begin{array}{l}12: 40- \\
12: 43\end{array}$ & Review & $\begin{array}{l}\text { LAFS.4.W.2.4 } \\
\text { Produce writing } \\
\text { in that the } \\
\text { development } \\
\text { and organization } \\
\text { are appropriate } \\
\text { to task, purpose, } \\
\text { and audience }\end{array}$ & $\begin{array}{l}\text { Review letter format example on board } \\
\text { make Messages in the Mailbox by Loreen } \\
\text { Leedy available. }\end{array}$ & $\begin{array}{l}\text { Students will recall } \\
\text { format }\end{array}$ & $\begin{array}{l}\text { Letter } \\
\text { format on } \\
\text { white } \\
\text { board and } \\
\text { in book }\end{array}$ & $\begin{array}{l}\text { Immersion - writing } \\
\text { experiences }\end{array}$ \\
\hline $\begin{array}{l}12.43- \\
1: 00\end{array}$ & Writing time & $\begin{array}{l}\text { LAFS.4.W.2.5 } \\
\text { With guidance } \\
\text { and support } \\
\text { from peers } \\
\text { revise and edit } \\
\text { LAFS.4.W.1.1 } \\
\text { Write opinion } \\
\text { pieces on topics } \\
\text { or texts, } \\
\text { supporting a } \\
\text { point of view } \\
\text { with reasons and } \\
\text { information. }\end{array}$ & $\begin{array}{l}\text { I will encourage students to share what they } \\
\text { already have and what they need to do next. } \\
\text { I will explain that it is Ok to "borrow" ideas } \\
\text { from each other. } \\
\text { I will direct the children to continuing their } \\
\text { work on letters to/from Goldilocks or the } \\
\text { three bears. } \\
\text { I will circulate observing/supporting the } \\
\text { children. Conference with any who need } \\
\text { one-to-one support. }\end{array}$ & $\begin{array}{l}\text { Students listen and } \\
\text { share what they already } \\
\text { have and where they } \\
\text { might go next with their } \\
\text { writing. } \\
\text { Students will continue } \\
\text { with their letters } \\
\text { focusing on point of } \\
\text { view and conventions, } \\
\text { including supporting } \\
\text { ideas. }\end{array}$ & $\begin{array}{l}\text { Books, } \\
\text { pencils. }\end{array}$ & $\begin{array}{l}\text { Engagement - } \\
\text { Intentional active } \\
\text { participation } \\
\text { Approximation - } \\
\text { Measured steps } \\
\text { towards learning } \\
\text { goals } \\
\text { Immersion - writing } \\
\text { experiences } \\
\text { Behaviors within the } \\
\text { space }\end{array}$ \\
\hline
\end{tabular}


The meeting space was even more chaotic than yesterday. Not only was the large table missing but two of the smaller tables had been removed. I managed to retrieve one of them. Seating capacity was limited, I had 20 seats for 22 students. Physical space; Routines within the space; Behaviors within the space.

I wrote sentences on the white board for development of conventions - the use of capital letters for proper nouns:

Proper nouns are the names of people, places and things. Proper nouns have capital letters.

Sue went to New York.

Dr. Brown went to the hospital.

Mars is called the red planet.

The prompt arrivals came in fairly quietly and quickly found seats. We began discussing the sentences and what needed to be done with them. The arrival of the tardy students was disruptive. Some students wanted to change places. Two students AN \& JB were in conflict. I asked what the problem was and was told they didn't get along. One of the students, LP, volunteered to sit at a side table to make room for the two to be separated. As a result, the time allocated to conventions development had doubled from 10 minutes to 20 minutes. The students' writing time had been severely curtailed. On the spot, I decided to read a letter taken from Dear Peter Rabbit by Alma Flor Ada. It is written by Baby Bear to Goldilocks and provided an example of the detail that could be included. At the same time it eased the tension in the room, caused by the difference of opinion that had taken place Demonstration - Experiencing multifaceted exposure to text.

I wished them all a good weekend and promised that writing time would be the priority for next meeting.

Conferences: (Expectations; Response)

Two students were absent. 
Week 3

Lesson Plan

Meeting 6

\begin{tabular}{|c|c|c|c|c|c|c|}
\hline Time & Activity & Objective & Teachers Actions & Children's Actions & Materials & $\begin{array}{l}\text { Cambourne's } \\
\text { Constructs }\end{array}$ \\
\hline $12: 30$ & Attendance & & Call roll. & $\begin{array}{l}\text { Respond to name, } \\
\text { collect book and pencil }\end{array}$ & $\begin{array}{l}\text { Attendance } \\
\text { log, books } \\
\text { and pencils }\end{array}$ & $\begin{array}{l}\text { Routines within the } \\
\text { space }\end{array}$ \\
\hline $\begin{array}{c}12.32 \\
- \\
12: 38\end{array}$ & Letter format & $\begin{array}{l}\text { LAFS.4.W.2.4 } \\
\text { Produce writing } \\
\text { in that the } \\
\text { development } \\
\text { and organization } \\
\text { are appropriate } \\
\text { to task, purpose, } \\
\text { and audience }\end{array}$ & $\begin{array}{l}\text { I will have an example of letter format } \\
\text { written on the white board and Messages in } \\
\text { the mailbox: How to write a letter by } \\
\text { Loreen Leedy available for students to look } \\
\text { at. }\end{array}$ & Listen, any questions & & $\begin{array}{l}\text { Immersion - writing } \\
\text { experiences }\end{array}$ \\
\hline $\begin{array}{c}12: 38 \\
- \\
12: 58\end{array}$ & $\begin{array}{l}\text { Writing } \\
\text { Time }\end{array}$ & $\begin{array}{l}\text { LAFS.4.W.2.4 } \\
\text { writing } \\
\text { appropriate to } \\
\text { task, purpose, } \\
\text { and audience } \\
\text { LAFS.4.W.2.5 } \\
\text { With guidance } \\
\text { and support } \\
\text { from peers } \\
\text { revise and edit } \\
\text { LAFS.4.W.1.1 } \\
\text { Write opinion } \\
\text { pieces on topics } \\
\text { supporting a } \\
\text { point of view } \\
\text { with reasons and } \\
\text { information. } \\
\text { LAFS.4.W.4.10 } \\
\text { Write over } \\
\text { extended time } \\
\text { frames }\end{array}$ & $\begin{array}{l}\text { Explanation to students that they are going } \\
\text { to turn what their ideas for what they would } \\
\text { like to say into letters. Ask, would you like } \\
\text { to work on your own, with a partner or } \\
\text { form a small group (4)? It is OK to talk } \\
\text { together about what you might like to say. I } \\
\text { will write in my own book. I will circulate } \\
\text { observing/supporting students. Conference } \\
\text { with at least } 3 \text { students about their writing. }\end{array}$ & $\begin{array}{l}\text { Children will decide to } \\
\text { work alone, with a } \\
\text { partner or in a small } \\
\text { group. They will date } \\
\text { their work and begin } \\
\text { turning their ideas into } \\
\text { a letter. If they are } \\
\text { working with a partner } \\
\text { or in a small group they } \\
\text { all write down what } \\
\text { they decide to say. }\end{array}$ & $\begin{array}{l}\text { Note } \\
\text { books, } \\
\text { pencils }\end{array}$ & $\begin{array}{l}\text { Engagement - } \\
\text { Intentional active } \\
\text { participation } \\
\text { Approximation - } \\
\text { Measured steps } \\
\text { towards learning } \\
\text { goals } \\
\text { Immersion - writing } \\
\text { experiences } \\
\text { Use-Opportunities } \\
\text { to practice } \\
\text { Behaviors within the } \\
\text { space }\end{array}$ \\
\hline
\end{tabular}


I collected and distributed the At Home Writing Group folders. The students are very friendly at this point.

The Book Fair is taking place in the Media Center today, and for the rest of the week. The tables have been commandeered and we have insufficient seating spaces, with desks, for everyone. Despite student cooperation, the noise in the background makes it difficult to be heard and to concentrate. Physical space; Routines within the space; Behaviors within the space Attendance taken.

Letter format on white board Demonstration. All students familiar by now. Group discussion of what the addresses for the characters could be, bearing in mind the setting of the book. Explained that each aspect of the story would benefit from a single paragraph - porridge, broken chair, sleeping in beds. Some students had grouped everything together. Over the weekend, I provided one to one written feedback to each student via their notebooks. Some students were given a sample paragraph based on their notes and supplemented by my ideas to get them started. These students spoke to me about whether it was acceptable to copy what I had provided. I agreed and they all said they could carry on now. Expectations; Response. Students wrote in their books or asked to move on to final copies, as they saw fit Approximation - Measured steps towards learning goals. I provided those who wished to move on with copy paper, a line guide and a binder clip. I explained the use of the line guide. Clip it behind the blank paper and write on the lines. When the line guide was removed they would have excellent copy. This was a new concept. They liked the idea.

$\mathrm{AN}$ and JB chose to sit next to each other, this surprised me after last meeting. However, I said nothing but observed them closely. Their behavior was exemplary. At the end of the meeting, I spoke to them saying that I thought they didn't get on but... AN interrupted me and said, "But you said we were too good." I said I wanted to compliment them on the way they had behaved during the meeting, Expectations - Messages for success communicated by significant others they both smiled broadly and a large number of the other students spontaneously applauded the two of them. This surprised me but it is evidence of their support for one another. AN told me he is really enjoying the Writers' Club.

Conferences: $\quad$ AN - conventions capital and lower case Pp. Needs to check spelling in copied work (2 minutes).

(Expectations;

Response)

GR - absent for 3 meetings owing to virus. Explained what we had been doing, he is familiar with

Goldilocks and the Three Bears he would like to take his book home overnight, to catch up. I allowed this. He asked about taking a point of view, I explained that he could choose that character and orally provided a sample of what might be said. He appeared to understand (6 minutes).

LP - Excellent notes, he is ready to transfer to letter format ( 2 minutes).

$\mathrm{BT}$ - conversion of notes to draft (2 minutes)

All the students were provided with individual feedback, through their notebooks Expectations; Response

All students present. 
Week 3

Lesson Plan

Meeting 7

\begin{tabular}{|c|c|c|c|c|c|c|}
\hline Time & Activity & Objective & Teachers Actions & Children's Actions & Materials & $\begin{array}{l}\text { Cambourne's } \\
\text { Constructs }\end{array}$ \\
\hline $12: 30$ & Attendance & & Call roll. & $\begin{array}{l}\text { Respond to name, } \\
\text { collect book and pencil }\end{array}$ & $\begin{array}{l}\text { Attendance } \\
\text { log, books } \\
\text { and pencils }\end{array}$ & $\begin{array}{l}\text { Routines within the } \\
\text { space }\end{array}$ \\
\hline $\begin{array}{c}12: 32 \\
- \\
12: 52\end{array}$ & $\begin{array}{l}\text { Writing } \\
\text { Time }\end{array}$ & $\begin{array}{l}\text { LAFS.4.W.2.4 } \\
\text { writing } \\
\text { appropriate to } \\
\text { task, purpose, } \\
\text { and audience } \\
\text { LAFS.4.W.1.1 } \\
\text { Write opinion } \\
\text { pieces } \\
\text { LAFS.4.W.4.10 } \\
\text { Write over } \\
\text { extended time } \\
\text { frames } \\
\text { LAFS.4.W.1.3 } \\
\text { develop } \\
\text { experiences } \\
\text { using descriptive } \\
\text { details and clear } \\
\text { event sequences }\end{array}$ & $\begin{array}{l}\text { Complete writing the letter in its final } \\
\text { format, using plain paper with a line guide } \\
\text { to create a professional piece of work. }\end{array}$ & $\begin{array}{l}\text { Children will decide to } \\
\text { work alone, with a } \\
\text { partner or in a small } \\
\text { group. They will date } \\
\text { their work and begin } \\
\text { turning their ideas into } \\
\text { a letter. If they are } \\
\text { working with a partner } \\
\text { or in a small group they } \\
\text { all write down what } \\
\text { they decide to say. }\end{array}$ & $\begin{array}{l}\text { Note } \\
\text { books, } \\
\text { pencils }\end{array}$ & $\begin{array}{l}\text { Engagement- } \\
\text { Intentional active } \\
\text { participation } \\
\text { Immersion - writing } \\
\text { experiences } \\
\text { Use-Opportunities } \\
\text { to practice } \\
\text { Behaviors within the } \\
\text { space }\end{array}$ \\
\hline $\begin{array}{l}12: 53 \\
-1: 00\end{array}$ & $\begin{array}{l}\text { Being an } \\
\text { audience }\end{array}$ & $\begin{array}{l}\text { LAFS.4.SL.1.1.a } \\
\text { Come to } \\
\text { discussion } \\
\text { prepared. } \\
\text { b. follow agreed } \\
\text { upon rules for } \\
\text { discussion and } \\
\text { carry out } \\
\text { assigned roles. }\end{array}$ & $\begin{array}{l}\text { We will discuss how to listen to someone } \\
\text { sharing their work. Being a good listener. } \\
\text { Thinking about what the other person has } \\
\text { written. Thinking of ways to improve their } \\
\text { writing and thinking about ways to say } \\
\text { what we think without hurting their } \\
\text { feelings. }\end{array}$ & $\begin{array}{l}\text { Participate in } \\
\text { discussion }\end{array}$ & & $\begin{array}{l}\text { Routines within the } \\
\text { space }\end{array}$ \\
\hline
\end{tabular}


The Book Fair is still going on but four desks had been placed in the space and the large table had been returned. I had space for all my students to sit down. The noise level improved, with fewer children at the Book Fair Physical space. Called attendance.

Copy paper, a line guide and a binder clip were provided. I arranged seating so students working from the same point of view were working together Physical space. I wanted them to support each other in the final push to a completed assignment Behaviors within the space. Initially, there was some resistance, but when I explained why I had done it and that it would only be for this meeting, they settled down to work cooperatively. One pair was a gender mix that caused long faces. I shared that each of them had a specific benefit to offer the other, and they complied. Later in the meeting I talked to them, and found that they agreed they had both been helped by the other. One student (AG) worked alone. NL said he now understands what to do to include ideas.

I wrote some of my own letter, those students around me looked over my shoulder periodically but went back to their own work Demonstration - Experiencing multifaceted exposure to text.

We discussed how to be an audience Behaviors within the space - points made included: listen $(\mathrm{CH})$, be respectful when someone is reading (AN), be polite when making comments (GG), sit quietly (LP), pay attention (BT), wait your turn (AG).

I prepared them that we would start with sentences for correction that will be done independently in their notebooks, then move on to sharing Routines within the space - Learning activities within the timeframe.

Conferences: $\quad$ LP - development of excellent notes into a letter (2 minutes)

(Expectations; $\quad$ JB - getting started on the letter, using the line guide (repeated encouragement)

Response)

EA - confirming that she was doing what was required (1 minute)

JA - help with how to order ideas (2 minutes)

$\mathrm{AM}$ - how to transfer notes to letter format (2 minutes)

GR - he missed some of the earlier meetings but had taken his work home to develop, he has produced

excellent ideas, needed help with letter format ( 3 minutes)

$\mathrm{DC}$ - conversion of notes into letter, wording from one character to the other (2 minutes)

NL and JR(a) - value to each other, shared that they are both strong students and have much to offer each other, if they can get over the gender difference ( 2 minutes)

AT - issues with JB, his partner, I believed AT would be able to support JB but this didn't work out, I advised AT to focus on his own work and I would help JB (1 minute)

Two students absent. 
Week 3

\begin{tabular}{|c|c|c|c|c|c|c|}
\hline Time & Activity & Objective & Teachers Actions & Children's Actions & Materials & $\begin{array}{l}\text { Cambourne's } \\
\text { Constructs }\end{array}$ \\
\hline $12: 30$ & Attendance & & Call roll. & $\begin{array}{l}\text { Respond to name, } \\
\text { collect book and pencil }\end{array}$ & $\begin{array}{l}\text { Attendance } \\
\log ,\end{array}$ & $\begin{array}{l}\text { Routines within the } \\
\text { space }\end{array}$ \\
\hline $\begin{array}{c}12: 32 \\
- \\
12: 37\end{array}$ & $\begin{array}{l}\text { Write } \\
\text { corrected } \\
\text { sentence in } \\
\text { notebook }\end{array}$ & $\begin{array}{l}\text { LAFS.4.L.1.1 } \\
\text { Demonstrate } \\
\text { command of the } \\
\text { conventions of } \\
\text { standard English } \\
\text { LAFS.4.L.1.2.a } \\
\text { capitalization }\end{array}$ & $\begin{array}{l}\text { Unpunctuated sentence already on board, } \\
\text { focus will be caps and sentence endings. } \\
\text { Observe students as they correct the } \\
\text { sentence following correct rules of } \\
\text { punctuation in their notebooks }\end{array}$ & $\begin{array}{l}\text { Writing sentence using } \\
\text { correct punctuation in } \\
\text { their books. }\end{array}$ & $\begin{array}{l}\text { Note } \\
\text { books. }\end{array}$ & $\begin{array}{l}\text { Immersion - } \\
\text { Engagement - }\end{array}$ \\
\hline $\begin{array}{c}12: 37 \\
- \\
12: 40\end{array}$ & $\begin{array}{l}\text { Review } \\
\text { being an } \\
\text { audience }\end{array}$ & $\begin{array}{l}\text { LAFS.4.SL.1.1.a } \\
\text { Prepared for } \\
\text { discussion } \\
\text { b. follow agreed } \\
\text { discussion rules } \\
\text { and carry out } \\
\text { assigned roles. }\end{array}$ & $\begin{array}{l}\text { We will gather as a whole group to discuss } \\
\text { how to listen to someone sharing their } \\
\text { work. Being a good listener. Thinking } \\
\text { about what the other person has written. } \\
\text { Thinking of ways to improve their writing } \\
\text { and thinking about ways to say what we } \\
\text { think without hurting their feelings. }\end{array}$ & $\begin{array}{l}\text { Participate in } \\
\text { discussion }\end{array}$ & & $\begin{array}{l}\text { Routines within the } \\
\text { space }\end{array}$ \\
\hline $\begin{array}{c}12: 40 \\
- \\
12: 58\end{array}$ & $\begin{array}{l}\text { Sharing } \\
\text { Time }\end{array}$ & $\begin{array}{l}\text { LAFS.4.SL.1.1.a } \\
\text { Come to } \\
\text { discussion } \\
\text { prepared. } \\
\text { b. follow agreed } \\
\text { upon rules for } \\
\text { discussion and } \\
\text { carry out } \\
\text { assigned roles. }\end{array}$ & $\begin{array}{l}\text { Authors' Circle - observe as students share } \\
\text { their work aloud. Asked for volunteers to } \\
\text { read aloud to their classmates. Any student } \\
\text { who does not wish to participate is free to } \\
\text { abstain. }\end{array}$ & $\begin{array}{l}\text { Students will read } \\
\text { aloud. Students will } \\
\text { listen to classmates. } \\
\text { Students will offer } \\
\text { constructive } \\
\text { suggestions. Students } \\
\text { will offer praise. }\end{array}$ & Note books & $\begin{array}{l}\text { Engagement - } \\
\text { Intentional active } \\
\text { participation } \\
\text { Behaviors within the } \\
\text { space }\end{array}$ \\
\hline $\begin{array}{c}12: 58 \\
- \\
1: 00\end{array}$ & $\begin{array}{l}\text { Prepare to } \\
\text { change topic }\end{array}$ & & $\begin{array}{l}\text { Next week we will begin studying the } \\
\text { Everglades and writing essays }\end{array}$ & Students listen & & $\begin{array}{l}\text { Routines within the } \\
\text { space }\end{array}$ \\
\hline
\end{tabular}


The Book Fair is still going on but there were sufficient spaces. However, the noise level was high again Physical space. Called attendance - one student absent.

The sentences for correction were already on the board, so as the students entered the space I reminded them to copy and correct them independently Approximation - Measured steps towards learning goals. A few students came in late. We went quickly over the corrections. The students are becoming adept at this, missing only a comma and an apostrophe, that one student, AN, said he knew was needed but he couldn't remember what it was called Routines within the space.

Capital letters are used at the beginning of sentences and for proper nouns.

Will you be coming to Writers' Club on Wednesday?

Yes, I will, and on Thursday and Friday too.

Ms. Helen will be there on all three days.

Quickly, the behaviors of an audience were reviewed. Some of the students were very keen to begin sharing, wanting to read aloud to their classmates. I had set up an Author's Chair (there is a rocking chair in the Media Center and it was available) Physical space. The students had to read loudly because of the noise being made by the students at the Book Fair. About $66 \%$ of the students chose to read loud, some choosing to use the Authors' Chair and some opting to read from where they were seated. The other students were respectful and made little noise to distract the reader. Positive comments were offered but clapping was discouraged because of the shortage of time Expectations - Messages for success communicated by significant others; Response Meaningful response from significant others in regards to goals; Behaviors within the space. All the students got into character to a greater or lesser degree - one student, AM, became Papa Bear to the extent he referred to "my wife" and "my son" in his letter to Goldilocks. Only one student, DC, took the role of Mama Bear. She read last; her position surprised the other students, she expressed that point of view well. JR(a), EA, DC, VM and CH said they had enjoyed writing their letters.

While the first students read, a few of the others completed their letters and asked to read when everyone else had finished; I acquiesced. Everyone who wanted to, read. Demonstration - Experiencing multifaceted exposure to text; Engagement - Intentional active participation.

During the final two minutes, I informed the students we would start writing essays about the Everglades. I would be reading about the manatee but they could choose any Everglades' topic and research it to write about. They were excited.

One student absent.

I received feedback from one of the classroom teachers that the students are enjoying being part of the Writers' Club. She informed me that other students, who did not sign up, are regretting not joining. 
Week 4

Lesson Plan

Meeting 9

\begin{tabular}{|c|c|c|c|c|c|c|}
\hline Time & Activity & Objective & Teachers Actions & Children's Actions & Materials & $\begin{array}{c}\text { Cambourne's } \\
\text { Constructs } \\
\end{array}$ \\
\hline $12: 30$ & Attendance & & Call roll. & $\begin{array}{l}\text { Respond to name, } \\
\text { collect book and pencil }\end{array}$ & $\begin{array}{l}\text { Attendance } \\
\text { log, books } \\
\text { and pencils }\end{array}$ & $\begin{array}{l}\text { Routines within the } \\
\text { space }\end{array}$ \\
\hline $\begin{array}{c}12: 32 \\
- \\
12: 42\end{array}$ & Conventions & $\begin{array}{l}\text { LAFS.4.L.1.1 } \\
\text { Demonstrate } \\
\text { command of the } \\
\text { conventions of } \\
\text { standard English }\end{array}$ & $\begin{array}{l}\text { Unpunctuated sentence already on board, } \\
\text { review caps, sentence endings and focus on } \\
\text { commas after transitions and in lists. } \\
\text { Observe students as they correct the } \\
\text { sentences following correct rules of } \\
\text { punctuation in their notebooks }\end{array}$ & $\begin{array}{l}\text { Correct and copy } \\
\text { sentences }\end{array}$ & Note books & $\begin{array}{l}\text { Immersion - } \\
\text { Engagement - } \\
\text { Demonstration - }\end{array}$ \\
\hline $\begin{array}{c}12: 42 \\
- \\
12: 47\end{array}$ & $\begin{array}{l}\text { Introduce the } \\
\text { Everglades }\end{array}$ & $\begin{array}{l}\text { LAFS.4.RI.1.1 } \\
\text { Refer to details } \\
\text { and examples in } \\
\text { a text } \\
\text { LAFS.4.RI.1.2 } \\
\text { determine main } \\
\text { idea and explain } \\
\text { how it is } \\
\text { supported by } \\
\text { key details, }\end{array}$ & $\begin{array}{l}\text { Share the picture book Everglades National } \\
\text { Park by Tom and Terisa Stack with the } \\
\text { students, showing pictures and talking } \\
\text { about them. } \\
\text { Switch from fiction to non-fiction, from } \\
\text { narrative to information text using pictures } \\
\text { to make the transition }\end{array}$ & $\begin{array}{l}\text { Listen and make } \\
\text { comments }\end{array}$ & Text & $\begin{array}{l}\text { Immersion - } \\
\text { Engagement - } \\
\text { Demonstration - } \\
\text { Routines within the } \\
\text { space }\end{array}$ \\
\hline $\begin{array}{c}12: 47 \\
- \\
12: 52 \\
\end{array}$ & $\begin{array}{l}\text { Read aloud } \\
(5 \text { minutes })\end{array}$ & Read aloud & $\begin{array}{l}\text { Manatees by Patricia A Fink Martin. I will } \\
\text { read to page } 25 \text {. Covering appearance, } \\
\text { habitat and food. }\end{array}$ & The children will listen. & Book & $\begin{array}{l}\text { Immersion - } \\
\text { Demonstration - }\end{array}$ \\
\hline $\begin{array}{l}12: 52 \\
-1: 00\end{array}$ & $\begin{array}{l}\text { Discussion } \\
\text { of } \\
\text { organization } \\
\text { of expository } \\
\text { text }\end{array}$ & $\begin{array}{l}\text { LAFS.4.SL.1.1. } \\
\text { bfollows agreed } \\
\text { discussion rules } \\
\text { LAFS.4.L. } 2.3 \\
\text { Use appropriate } \\
\text { conventions } \\
\text { when speaking }\end{array}$ & $\begin{array}{l}\text { Draw students into discussion of the topics } \\
\text { covered by the first part of the book. Using } \\
\text { questioning strategy enquire why the author } \\
\text { might have chosen to address appearance } \\
\text { followed by habitat and food. Ask students } \\
\text { if they have selected a topic they would like } \\
\text { to research and write about relating to the } \\
\text { Everglades. }\end{array}$ & $\begin{array}{l}\text { Participate in } \\
\text { discussion. Share what } \\
\text { they would like to write } \\
\text { about. They may } \\
\text { choose to follow my } \\
\text { lead and work on } \\
\text { manatees. }\end{array}$ & & $\begin{array}{l}\text { Immersion - } \\
\text { Engagement - } \\
\text { Behaviors within the } \\
\text { space }\end{array}$ \\
\hline
\end{tabular}


Over the weekend, I provided one to one written feedback about the letters to each student, via their notebooks. Expectations - Messages for success communicated by significant others, Response - Meaningful response from significant others in regards to goals.

I collected and distributed the At Home Writing Group folders.

Most of the students came in promptly. They started the sentences on the board with little reminding or encouragement Responsibility - Making decisions and choices about learning. A timer to keep them focused was effective. They are in transition from having me correct the sentences, based on their suggestions, and taking it over for themselves while I observe

Approximation. A student (GR) asked if he could make the changes, I handed him the marker. Quickly it changed hands - each student doing one or two corrections before handing the marker over. This is exactly what I want for them, confidence and proactivity. Responsibility - Making decisions and choices about learning. About 6 students arrived after the sentences were done. The sentences follow:

Commas are used in lists and after transitions.

Jose likes red, green, and blue. However, he sometimes chooses yellow. Whereas, Maria likes purple and brown stripes.

At the beginning of meetings, they want to engage in chatter (the students are in three different classes; they do not all interact with each daily). The proposed time frame would have provided time for this important community building activity.

They were excited with the Everglades book. The major problem was them wanting to share anecdotes about the various birds and animals. They were obviously stimulated by all the different animals they could choose from, for their writing. Often saying, "I never thought of that." Some of the students expressed that they thought writing about the Everglades would be fun. I read Manatees to p.25. They listened relatively quietly. I put into place a strategy of stopping reading and waiting silently for them to quieten down. This works well.

The discussion of the structure of the writing. AM was particularly adept at identifying what the author was doing appearance, followed by habitat and then food. They commented on the details given on the various topics. EA gave a clear retelling of the opening of the book - demonstrating focus and strong recall.

Conferences: $\quad$ JD - corrections of sentence (2 minutes)

(Expectations; JB - getting started on the sentences (repeated encouragement)

Response) $\quad$ EA \& JB - writing on table

Two students were absent. 
Week 4

Lesson Plan

Meeting 10

\begin{tabular}{|c|c|c|c|c|c|c|}
\hline Time & Activity & Objective & Teachers Actions & Children's Actions & Materials & $\begin{array}{l}\text { Cambourne's } \\
\text { Constructs }\end{array}$ \\
\hline $12: 30$ & Attendance & & Call roll. & $\begin{array}{l}\text { Respond to name, } \\
\text { collect book and pencil }\end{array}$ & $\begin{array}{l}\text { Attendance } \\
\text { log, books } \\
\text { and pencils }\end{array}$ & $\begin{array}{l}\text { Routines within the } \\
\text { space }\end{array}$ \\
\hline $\begin{array}{c}12: 32 \\
- \\
12: 37\end{array}$ & $\begin{array}{l}\text { Read aloud } \\
\text { (5 minutes) }\end{array}$ & Read aloud & $\begin{array}{l}\text { Manatees by Patricia A Fink Martin. I } \\
\text { will read from page } 25 \text { to the end. } \\
\text { Covering migration, reproduction and } \\
\text { endangerment. }\end{array}$ & The children will listen. & Text & $\begin{array}{l}\text { Immersion - } \\
\text { Demonstration - }\end{array}$ \\
\hline $\begin{array}{l}12: 37 \\
- \\
12: 47\end{array}$ & $\begin{array}{l}\text { Discuss } \\
\text { organization } \\
\text { of expository } \\
\text { text }\end{array}$ & $\begin{array}{l}\text { LAFS.4.SL.1.1. } \\
\text { bfollow agreed } \\
\text { upon rules for } \\
\text { discussion and } \\
\text { carry out } \\
\text { assigned roles } \\
\text { LAFS.4.L.2.3 } \\
\text { Use appropriate } \\
\text { conventions } \\
\text { when speaking }\end{array}$ & $\begin{array}{l}\text { Draw students into discussion of the } \\
\text { topics covered by the second part of the } \\
\text { book. Using questioning strategy enquire } \\
\text { why the author might have chosen to } \\
\text { address migration, gestation and } \\
\text { endangerment next. Ask students if they } \\
\text { have selected a topic they would like to } \\
\text { research and write about relating to the } \\
\text { Everglades. }\end{array}$ & $\begin{array}{l}\text { Participate in } \\
\text { discussion. Share what } \\
\text { they would like to write } \\
\text { about. They may } \\
\text { choose to follow my } \\
\text { lead and work on } \\
\text { manatees. }\end{array}$ & & $\begin{array}{l}\text { Immersion - } \\
\text { Engagement - } \\
\text { Behaviors within the } \\
\text { space }\end{array}$ \\
\hline $\begin{array}{l}12: 48 \\
-1: 00\end{array}$ & $\begin{array}{l}\text { Writing time } \\
\text { Notes - } \\
\text { graphic } \\
\text { organizer }\end{array}$ & $\begin{array}{l}\text { LAFS.4.W.2.4 } \\
\text { writing } \\
\text { appropriate to } \\
\text { task, purpose, } \\
\text { and audience } \\
\text { LAFS.4.RI.1.1 } \\
\text { Refer to details } \\
\text { and examples in } \\
\text { a text when } \\
\text { explaining what } \\
\text { the text says } \\
\text { explicitly }\end{array}$ & $\begin{array}{l}\text { Demonstrate writing notes, using a } \\
\text { graphic organizer to order my thoughts. } \\
\text { Evaluate what the important points are, } \\
\text { taken from the research. Determine what } \\
\text { I wish to include. Examine if I still have } \\
\text { any questions that will require further } \\
\text { research. Determine how I will conduct } \\
\text { my research. }\end{array}$ & $\begin{array}{l}\text { Read informational } \\
\text { texts } \\
\text { Students will have } \\
\text { access to graphic } \\
\text { organizers and will be } \\
\text { encouraged to emulate } \\
\text { my work, using their } \\
\text { own research and topic. }\end{array}$ & $\begin{array}{l}\text { Notebook } \\
\text { and } \\
\text { pencils, } \\
\text { graphic } \\
\text { organizer }\end{array}$ & $\begin{array}{l}\text { Immersion - } \\
\text { Engagement - }\end{array}$ \\
\hline
\end{tabular}


The students are very excited about starting the new project. They quickly collected their books and pencils and selected books from the array laid out Routines within space. It was difficult to settle them down to listen to the final section of Manatees. I read aloud while they listened, somewhat inattentively. Their excitement about writing on self-selected topics was palpable.

Comments included, "We can write about any animal we like," and "I love panthers, I am going to write about them."

The "bubbles" graphic organizer was demonstrated, using the board. The students quickly titled the six bubbles appearance, habitat, food, migration, reproduction and endangerment. These designations were taken from the book Manatees by Patricia Fink that I had read aloud. We began filling in some details for appearance, using both Manatees and Sam the Sea Cow that one of the students had selected. I explained that good researchers use more than one source. I asked them to do some research out of meeting time to find more information on the topic they had chosen. One student GR observed that the "bubbles" organizer made it easy to add more details.

Then they broke away to look at the books and make decisions on what they would like to write about Responsibility Making decisions and choices about learning. Once they decided, I invited them to group up based on their topics. I reminded them to do further research on their own, before we broke up for the day.

Three students (LP, JR, JB) had to be moved, temporarily, to single person desks because they were talking persistently while I was reading aloud. As soon as I finished, they were released back to their chosen seats. They apologized.

Conferences:

(Expectations;

Response)

All students present.
JB - Having trouble deciding what he wants to study. We looked through the book Alligators by Monica Kulling. I pointed out different animals and birds in the book suggesting each one would make a good topic. He is still suffering from the consequences of the incident with writing on the table. He talked about his grandmother being unwell. (5 minutes) 
Week 4

Lesson Plan

Meeting 11

\begin{tabular}{|c|c|c|c|c|c|c|}
\hline Time & Activity & Objective & Teachers Actions & Children's Actions & Materials & $\begin{array}{l}\text { Cambourne's } \\
\text { Constructs }\end{array}$ \\
\hline $12: 30$ & Attendance & & Call roll. & $\begin{array}{l}\text { Respond to name, } \\
\text { collect book and pencil }\end{array}$ & $\begin{array}{l}\text { Attendance } \\
\text { log, books } \\
\text { and pencils }\end{array}$ & $\begin{array}{l}\text { Routines within the } \\
\text { space }\end{array}$ \\
\hline $\begin{array}{c}12: 32 \\
- \\
12: 40\end{array}$ & Conventions & $\begin{array}{l}\text { LAFS.4.L.1.1 } \\
\text { Demonstrate } \\
\text { command of the } \\
\text { conventions of } \\
\text { standard English } \\
\text { LAFS.4.L.1.2.a } \\
\text { Use correct } \\
\text { capitalization } \\
\text { LAFS.4.SL.1.1.a } \\
\text { Come to } \\
\text { discussion } \\
\text { prepared. } \\
\text { b. follow agreed } \\
\text { upon rules for } \\
\text { discussion and } \\
\text { carry out } \\
\text { assigned roles. }\end{array}$ & $\begin{array}{l}\text { Unpunctuated sentence already on board, } \\
\text { review caps, sentence endings and focus on } \\
\text { commas after transitions and in lists. } \\
\text { Observe students as they correct the } \\
\text { sentences following correct rules of } \\
\text { punctuation in their notebooks }\end{array}$ & $\begin{array}{l}\text { Correct and copy } \\
\text { sentences }\end{array}$ & Note books & $\begin{array}{l}\text { Immersion - } \\
\text { Engagement - } \\
\text { Demonstration - }\end{array}$ \\
\hline $\begin{array}{l}12: 40 \\
-1: 00\end{array}$ & Writing time & $\begin{array}{l}\text { LAFS.4.RI.1.2 } \\
\text { determine main } \\
\text { idea and explain } \\
\text { how it is } \\
\text { supported by } \\
\text { key details } \\
\text { LAFS.4.RI.4.10 } \\
\text { read and } \\
\text { comprehend } \\
\text { informational } \\
\text { text }\end{array}$ & $\begin{array}{l}\text { Explain how to begin writing notes and } \\
\text { filling in graphic organizer, using research } \\
\text { material. } \\
\text { Lay out a variety of graphic organizers for } \\
\text { the students to choose from for note taking. } \\
\text { All graphic organizers were sourced from } \\
\text { Florida Center for Reading Research. }\end{array}$ & $\begin{array}{l}\text { Read books, and/or } \\
\text { other material } \\
\text { (computers) to gather } \\
\text { information for writing } \\
\text { about topic of choice. } \\
\text { Taking notes on graphic } \\
\text { organizer. }\end{array}$ & $\begin{array}{l}\text { Notebooks, } \\
\text { pencils, } \\
\text { graphic } \\
\text { organizers, } \\
\text { research } \\
\text { books. }\end{array}$ & $\begin{array}{l}\text { Demonstration - } \\
\text { Immersion - } \\
\text { Engagement - } \\
\text { Approximation - } \\
\text { Use - }\end{array}$ \\
\hline
\end{tabular}


Excitement about the Everglades project is still running high. I used a timer to focus the students on completing the poorly punctuated sentence. Most of them quickly settled to writing it down and correcting it so they could get to their writing

Responsibility - Making decisions and choices about learning. They took control of making the corrections while I looked on. As a group, they can make all the corrections, though they do not necessarily do them in the right order. The sentences were:

In the Everglades there are many animal species.

Herons, hawks, and egrets are all birds.

Alligators, turtles and snakes are all reptiles.

Panthers, raccoons, and deer are all mammals.

Shortly after starting to work on their topics, theyasked if they could use the computers, I agreed. Next session I need to go over some appropriate behaviors in regards to using them, Behaviors within the space - Conduct and actions.

Conferences: $\quad \mathrm{NL}$ - Using computer to add to research, explained expectations (2 minutes).

(Expectations; $\quad \mathrm{CH}$ - wanted help with graphic organizer deciding that idea to put where, I explained it didn't matter she

Response) could decide order later (2 minutes).

$\mathrm{LM}$ - topic difficulties

EA - wants to do flowers rather than an animal - no problem (2 minutes)

$\mathrm{AM}$ - noise level, he is distracting other students, I directed his attention to the rules - Respect Others (2 minutes)

JB came in very late he had been held up by the counselor. He was somewhat distressed so I sat with him while he completed his sentences and then talked quickly to him about his topic. He is still undecided, but he told me he likes Writers' Club. Over the weekend, each student was given individual, written feedback, in their notebooks Expectations, Response. I noted that I needed to review some of the punctuation in the sentences. There are very few of the students incorporating all the corrections in their work Approximation. This may be a function of too little time, they are hurrying so they can get to their writing, or they are not confident about what needs to be done.

One student absent. 
Week 5

Lesson Plan

Meeting 12

\begin{tabular}{|c|c|c|c|c|c|c|}
\hline Time & Activity & Objective & Teachers Actions & Children's Actions & Materials & $\begin{array}{l}\text { Cambourne's } \\
\text { Constructs }\end{array}$ \\
\hline $12: 30$ & Attendance & & Call roll. & $\begin{array}{l}\text { Respond to name, } \\
\text { collect book and pencil }\end{array}$ & $\begin{array}{l}\text { Attendance } \\
\text { log, books } \\
\text { and pencils }\end{array}$ & $\begin{array}{l}\text { Routines within the } \\
\text { space }\end{array}$ \\
\hline $\begin{array}{c}12: 32 \\
- \\
12: 40\end{array}$ & Conventions & $\begin{array}{l}\text { LAFS.4.L.1.1 } \\
\text { Demonstrate } \\
\text { command of the } \\
\text { conventions of } \\
\text { standard English } \\
\text { LAFS.4.L.1.2.a } \\
\text { Use correct } \\
\text { capitalization } \\
\text { LAFS.4.SL.1.1.a } \\
\text { \& b. }\end{array}$ & $\begin{array}{l}\text { Review specific sentences that have been } \\
\text { done previously, particularly the use of } \\
\text { commas. Observe students as they correct } \\
\text { the sentences following rules of } \\
\text { punctuation in their notebooks }\end{array}$ & $\begin{array}{l}\text { Correct and copy } \\
\text { sentences }\end{array}$ & Note books & $\begin{array}{l}\text { Immersion - } \\
\text { Engagement - } \\
\text { Demonstration - }\end{array}$ \\
\hline $\begin{array}{c}12 ; 40 \\
- \\
12: 45\end{array}$ & $\begin{array}{l}\text { Rules for } \\
\text { computers }\end{array}$ & $\begin{array}{l}\text { LAFS.4.SL.1.1.a } \\
\& b .\end{array}$ & $\begin{array}{l}\text { Discuss appropriate behaviors for using the } \\
\text { computers. }\end{array}$ & $\begin{array}{l}\text { Participate in } \\
\text { discussion }\end{array}$ & & $\begin{array}{l}\text { Behaviors within the } \\
\text { space }\end{array}$ \\
\hline $\begin{array}{l}12: 40 \\
-1: 00\end{array}$ & Writing time & $\begin{array}{l}\text { LAFS.4.RI.1.1 } \\
\text { Refer to details } \\
\text { and examples in } \\
\text { a text } \\
\text { LAFS.4.RI.1.2 } \\
\text { determine main } \\
\text { idea and explain } \\
\text { how it is } \\
\text { supported by } \\
\text { key details } \\
\text { LAFS.4.RI.4.10 } \\
\text { read and } \\
\text { comprehend } \\
\text { informational } \\
\text { text }\end{array}$ & $\begin{array}{l}\text { Lay out a variety of graphic organizers for } \\
\text { the students to choose from for note taking. } \\
\text { All graphic organizers were sourced from } \\
\text { Florida Center for Reading Research. } \\
\text { Encourage them to write notes about the } \\
\text { topic. They may work in teams producing a } \\
\text { single graphic organizer, but they all must } \\
\text { produce a piece of work. }\end{array}$ & $\begin{array}{l}\text { Read books, and/or } \\
\text { other material } \\
\text { (computers) to gather } \\
\text { information for writing } \\
\text { about topic of choice. } \\
\text { Taking notes on graphic } \\
\text { organizer. }\end{array}$ & $\begin{array}{l}\text { Notebooks, } \\
\text { pencils, } \\
\text { graphic } \\
\text { organizers, } \\
\text { research } \\
\text { books. }\end{array}$ & $\begin{array}{l}\text { Demonstration - } \\
\text { Immersion - } \\
\text { Engagement - } \\
\text { Approximation - } \\
\text { Use }\end{array}$ \\
\hline
\end{tabular}


I collected and distributed the At Home Writing Group's folders. I let them know we are half way through the program and that I appreciated their hard work. I spoke to two students about the quantity of work they were completing. It seemed too little for the amount of time. They both admitted to family problems, when I reminded them that it wasn't about how much work they did just that they worked for the appropriate amount of time over the course of a week. I said they could work for 15 minutes six times a week if that would be easier. They both thought they could bring their work up to scratch. One of the AHWG students approached me to let me know his mom couldn't help him. I told him that was fine and asked if he could still work on his own. He confirmed that he could, he was worried that if he did too little work it wouldn't be enough for me. I explain the premise of the study and he left me content. Expectations; Response

Based on my examination of their work, over the weekend, I determined that more work needed to be done on the conventions. We reviewed the exercise we had done during meeting 9 Use-Opportunities to practice. I asked them to find it in their books, or if they had not written it down last week to write it down now. We discussed the nature of the assignment. The first sentence provides instruction and the following sentences provide practice. They demonstrated a less than clear understanding of transitions. We went over what a transition was and then searched through the exercise to see if we could find them. Both were identified. All the other punctuation marks were discussed. Two students wanted to use a semi colon after blue; I told them it was acceptable. Many students couldn't recall what it was called, one helped everyone else out. Nearly everyone employed it. One student had to be reminded why Maria needed a capital letter Expectations; Response; Approximation.

The discussion of behavior when using the computer was brief, it needs to be reviewed again tomorrow Behaviors. The students were excited to get back to their projects. Most of them appear to have an idea of what to work on Engagement; Responsibility. There are some clearly defined groups producing interesting work on a defined, manageable topic. Some students are using the computers appropriately; while others are still over-excited. JR(b) - Studying the lobster closely. Isolated himself from other students and read without interruption, I complimented him on his diligence Expectations; Response.

Conferences: $\quad \mathrm{CH}-$ too loud while at the computer, needs to moderate voice (1 minute).

(Expectations; $\quad \mathrm{AM}$ - repeated comments on noise level, he is distracting other students, I directed his attention to the rules - Response) Respect Others (2 minutes)

LM - topic difficulties

EA wants to do flowers rather than an animal - no problem (2 minutes)

I provided one-to-one feedback to each student via their notebooks, including comments and encouragement Expectations;

Response

One student absent. 
Week 5

Lesson Plan

Meeting 13

\begin{tabular}{|c|c|c|c|c|c|c|}
\hline Time & Activity & Objective & Teachers Actions & Children's Actions & Materials & $\begin{array}{l}\text { Cambourne's } \\
\text { Constructs }\end{array}$ \\
\hline $12: 30$ & Attendance & & Call roll. & $\begin{array}{l}\text { Respond to name, } \\
\text { collect book and pencil }\end{array}$ & $\begin{array}{l}\text { Attendance } \\
\text { log, books } \\
\text { and pencils }\end{array}$ & $\begin{array}{l}\text { Routines within the } \\
\text { space }\end{array}$ \\
\hline $\begin{array}{c}12: 32 \\
- \\
12: 40\end{array}$ & Conventions & $\begin{array}{l}\text { LAFS.4.L.1.1 } \\
\text { Demonstrate } \\
\text { command of the } \\
\text { conventions of } \\
\text { standard English } \\
\text { LAFS.4.L.1.2.a } \\
\text { Use correct } \\
\text { capitalization } \\
\text { LAFS.4.SL.1.1.a } \\
\& \text { b. }\end{array}$ & $\begin{array}{l}\text { Review specific sentences that have been } \\
\text { done previously, particularly the use of } \\
\text { commas in lists. Observe students as they } \\
\text { correct the sentences following rules of } \\
\text { punctuation in their notebooks }\end{array}$ & $\begin{array}{l}\text { Correct and copy } \\
\text { sentences }\end{array}$ & Note books & $\begin{array}{l}\text { Immersion - } \\
\text { Engagement - } \\
\text { Demonstration - } \\
\text { Approximation - }\end{array}$ \\
\hline $\begin{array}{c}12 ; 40 \\
- \\
12: 45\end{array}$ & $\begin{array}{l}\text { Rules for } \\
\text { computers }\end{array}$ & $\begin{array}{l}\text { LAFS.4.SL.1.1.a } \\
\& b .\end{array}$ & $\begin{array}{l}\text { Discuss appropriate behaviors for using the } \\
\text { computers. }\end{array}$ & $\begin{array}{l}\text { Participate in } \\
\text { discussion }\end{array}$ & & $\begin{array}{l}\text { Behaviors within the } \\
\text { space }\end{array}$ \\
\hline $\begin{array}{l}12: 40 \\
-1: 00\end{array}$ & Writing time & $\begin{array}{l}\text { LAFS.4.W.2.4 } \\
\text { writing } \\
\text { appropriate to } \\
\text { task, purpose, } \\
\text { and audience } \\
\text { LAFS.4.RI.1.1 } \\
\text { Refer to details } \\
\text { and examples in } \\
\text { a text } \\
\text { LAFS.4.RI.1.2 } \\
\text { determine main } \\
\text { idea and key } \\
\text { details }\end{array}$ & $\begin{array}{l}\text { Encourage them to continue writing notes } \\
\text { about the topic, with or without graphic } \\
\text { organizers provided. They may work in } \\
\text { teams producing a single graphic organizer, } \\
\text { but they all must produce a piece of work. } \\
\text { Help them identify who their audience } \\
\text { might be. Are they writing to explain, } \\
\text { express an opinion, or take a stand? Who } \\
\text { are they as writer - journalist, scientist, or } \\
\text { advertiser? Can they "become" a manatee } \\
\text { and write from an "I" perspective? }\end{array}$ & $\begin{array}{l}\text { Read books, and/or } \\
\text { other material to gather } \\
\text { information for writing } \\
\text { about topic of choice. } \\
\text { Taking notes on graphic } \\
\text { organizer or in } \\
\text { notebook. Think about } \\
\text { starting rough draft }\end{array}$ & $\begin{array}{l}\text { Notebooks, } \\
\text { pencils, } \\
\text { graphic } \\
\text { organizers, } \\
\text { research } \\
\text { books. }\end{array}$ & $\begin{array}{l}\text { Demonstration - } \\
\text { Immersion - } \\
\text { Engagement - } \\
\text { Approximation - } \\
\text { Use }\end{array}$ \\
\hline
\end{tabular}


Prior to the arrival of the students, I placed their books on the tables according to topic. Physical space There are groups studying American Alligators (6), manatees (3), panthers (3), dolphins (2), lobsters (1), pelicans (1), turtles(1), octopi (1), coral reef fish (1), herons (1), skinks (1) and plants (1). There was little comment about my having organized their seating.

A review of the use of commas was conducted using the sentences from meeting 10. This time nearly all the students participated actively in the placement of the commas. This exercise was easier because they only had to employ them in lists, a single degree of difficulty. I had made an error in judgment, believing they could address two uses in one exercise. Next week, I will address commas after transitions. Use - Opportunities to practice

There was a brief discussion about the use of computers and the appropriate behaviors. They responded well. Moving to the computers in their groups and using them appropriately. I believe these are instilled behaviors and, perhaps, the excitement of what they were doing yesterday resulted in chaos. Behaviors

The students almost all produced completed graphic organizers, either commercially produced versions (all taken from FCRR) or their own design. Some first drafts are underway Approximation. The alligators group consists of students with very disparate abilities; despite this, efforts are being made by them all to work together harmoniously. LP is particularly generous with his help. MG and JA work somewhat exclusively but are willing to share information. They were the original alligator pair. There are a limited number of books available and they all need to use all the books for good research. AT is easily frustrated by JB but is working to suppress his irritation. JB has yet to write anything down, but is beginning to contribute more constructively to discussion. EA is copying from her research.

Conferences: Response)

Two students absent.
VM - using Post Its to take notes, ideally she would like to highlight (1 minute)

Alligator group - transition from graphic organizers to rough draft, whilst they have been allowed to develop graphic organizers as a group, everyone must write their own rough draft and final copy (3 minutes) GR - compliment - benefits to concentration when an appropriate partner is chosen, he is working well alongside JR(b), they are working on different topics - skinks and lobsters respectively (1 minute) $\mathrm{JR}(\mathrm{b})$ - detailed research, lots of reading but must get to rough draft, he may not need to complete a graphic organizer, he is able to talk authoritatively about his topic (2 minutes)

FC - using Post Its in similar manner to VM (30 seconds)

$\mathrm{JR}(\mathrm{b})$ has become reluctant to leave when the meeting is over. He expressed that he is enjoying Writer's Club and would rather stay than go to P.E. I have to be firm that Writers' Club is over. Other students have expressed that they are having a good time and wish it could be longer - AN, LP, GR, and JA 
Week 5

Lesson Plan

Meeting 14

\begin{tabular}{|c|c|c|c|c|c|c|}
\hline Time & Activity & Objective & Teachers Actions & Children's Actions & Materials & $\begin{array}{l}\text { Cambourne's } \\
\text { Constructs }\end{array}$ \\
\hline $12: 30$ & Attendance & & Call roll. & $\begin{array}{l}\text { Respond to name, } \\
\text { collect book and pencil }\end{array}$ & $\begin{array}{l}\text { Attendance } \\
\text { log, books } \\
\text { and pencils }\end{array}$ & $\begin{array}{l}\text { Routines within the } \\
\text { space }\end{array}$ \\
\hline $\begin{array}{l}12: 32 \\
-1: 00\end{array}$ & Writing time & $\begin{array}{l}\text { LAFS.4.W.1.1.a. } \\
\text { Introduce a topic } \\
\text { clearly, create an } \\
\text { organizational } \\
\text { structure } \\
\text { b. support with } \\
\text { facts and details } \\
\text { LAFS.4.W.2.4 } \\
\text { writing } \\
\text { appropriate to } \\
\text { task, purpose, } \\
\text { and audience }\end{array}$ & $\begin{array}{l}\text { Lead discussion to identify who the } \\
\text { audience might be. Are they writing to } \\
\text { explain, express an opinion, or take a } \\
\text { stand? Who are they as writer - journalist, } \\
\text { scientist, or advertiser? Can they "become" } \\
\text { a manatee and write from an "I" } \\
\text { perspective? } \\
\text { Direct them to write rough draft, using } \\
\text { alternate lines to allow space for editing. } \\
\text { Students may work with each other in their } \\
\text { groups or with a partner who is not writing } \\
\text { on the same topic. }\end{array}$ & $\begin{array}{l}\text { Taking notes on graphic } \\
\text { organizer or in } \\
\text { notebook, writing rough } \\
\text { draft. }\end{array}$ & $\begin{array}{l}\text { Notebooks, } \\
\text { pencils, } \\
\text { graphic } \\
\text { organizers, }\end{array}$ & $\begin{array}{l}\text { Demonstration - } \\
\text { Immersion - } \\
\text { Engagement - } \\
\text { Approximation - } \\
\text { Use - } \\
\text { Responsibility - }\end{array}$ \\
\hline
\end{tabular}


Today's meeting was focused entirely on writing, developing the graphic organizers to be ready for first draft or starting first draft. The students were shown the benefits of writing on alternate lines; leaves room for editing. Some of the students required me to put dots on the lines they were to write on. Most of them understood the concept and readily complied. The alligator group continues to become more cohesive. JB has yet to write anything but he is being cooperative and participating. GR is excited about how his skink project is developing. He stopped me to ask questions about what to include in appearance, were length and weight included Response. He told me, "This is the best writing class ever."

Further discussion regarding the audience was held, the following stances were covered: descriptive, being a scientist, a reporter and writing from the "I" perspective; being the animal and telling a life story (some of the books were written following that format). It is necessary to decide who the paper is being written for and why. AN wanted to be a reporter but, though he could think of a title for his work, he was unsure how to include his research in the article Approximation.

I am becoming quite frustrated by the brevity of the meetings. I rarely get time to write myself, thus providing a model of a writer. My plan to have a writing sample for them to see me editing is not panning out as I had planned. I will have to create a sample at home, that they will not see in its development. I am managing conferences, these are brief but targeted.

Conferences:

(Expectations;

Response)

\author{
AN - writer's stance, audience (3 minutes) \\ $\mathrm{AD}, \mathrm{AD}, \mathrm{AN}$ - panthers, endangered by man's incursion on their territory and many are killed on the roads \\ (3 minutes) \\ JR(a) - compliment - producing excellent notes on graphic organizer, helped AM, he was absent previous \\ day ( 2 minutes) \\ JS - working quickly on computer to gather information on Coral Reef fish (2 minutes), he was absent twice
}

Eight students came in late. Two were absent, EA was one of them. 
Week 6

Lesson Plan

Meeting 15

\begin{tabular}{|c|c|c|c|c|c|c|}
\hline Time & Activity & Objective & Teachers Actions & Children's Actions & Materials & $\begin{array}{l}\text { Cambourne's } \\
\text { Constructs }\end{array}$ \\
\hline $12: 30$ & Attendance & & Call roll. & $\begin{array}{l}\text { Respond to name, } \\
\text { collect book and pencil }\end{array}$ & $\begin{array}{l}\text { Attendance } \\
\text { log, books } \\
\text { and pencils }\end{array}$ & $\begin{array}{l}\text { Routines within the } \\
\text { space }\end{array}$ \\
\hline $\begin{array}{l}12: 32 \\
-1: 00\end{array}$ & $\begin{array}{l}\text { Writing } \\
\text { time }\end{array}$ & $\begin{array}{l}\text { LAFS.4.W.1.2.a. } \\
\text { Introduce a topic } \\
\text { clearly, group } \\
\text { related } \\
\text { information in } \\
\text { paragraphs and } \\
\text { sections } \\
\text { b. develop topic } \\
\text { with facts, } \\
\text { definitions, etc. } \\
\text { c. link ideas d. } \\
\text { use domain } \\
\text { specific } \\
\text { vocabulary } \\
\text { e. provide a } \\
\text { concluding } \\
\text { statement }\end{array}$ & $\begin{array}{l}\text { Provide support to students on an as need } \\
\text { basis. }\end{array}$ & $\begin{array}{l}\text { Complete rough draft, } \\
\text { edit and decide what } \\
\text { paper to use for final } \\
\text { draft. }\end{array}$ & $\begin{array}{l}\text { Notebooks, } \\
\text { pencils, } \\
\text { paper }\end{array}$ & $\begin{array}{l}\text { Demonstration - } \\
\text { Immersion - } \\
\text { Engagement - } \\
\text { Approximation - } \\
\text { Use - } \\
\text { Responsibility - }\end{array}$ \\
\hline
\end{tabular}


I collected and distributed the At Home Writing Group's folders. Three students were absent. JG shared that he had been visiting a friend over the long weekend and had left his folder at home. He asked to do double work to make up. He will give me both folders next week. I notice his parent is not initialing the Writing Log but the quantity and quality of his work indicates that he is complying with the requirement to complete 90 minutes per week.

I am noticing a trend, the students are coming in in groups with one group joining us somewhat tardily each meeting. They are all from the same classroom. Ten students were tardy.

Students continued with their rough drafts. One student, MG, decided he was ready to begin his final copy with copy paper and a line guide. Needed help to center title and author. One or two are procrastinating. I was advised EA was quitting. I spoke to her. She shared she is facing emotional issues, her grandfather was a writer and he died recently. She finds this is bringing up difficult memories. I suggested that she drop the project and write about how she feels; and that she sit on a comfy sofa, a little separated from the rest of the group. She liked this idea, she sat on the sofa with her notebook and wrote for most of the rest of the session, producing more than she has since we began meeting. I told her to decide if she wants to come back tomorrow.

Conferences:

(Expectations;

Response)
AT - having difficulty concentrating, sit at single person desk (1 minute)

$\mathrm{CH}, \mathrm{BT}, \mathrm{DC}$ - misunderstood, they worked together to produce a graphic organizers and are now helping each other to produce a single final copy. I explained that the goal had been to produce individual final writing samples, we compromised by agreeing that they would each write it out in full (3 minutes) $\mathrm{FC}$ - following similar format to manatee group, sitting at same table. Original work preferred. (1 minute) JR(a) - working on final draft - using informational bullet format, each section titled.

GR - very excitable, deeply interested in his topic (skinks), wants to share every detail as he writes it down - disruptive (2 minutes)

JR(b) - did excellent research, reading diligently, having more difficulty writing down what he has learned, talks authoritatively about topic (lobsters), break topic down, start with changing appearance ( 2 minutes) $\mathrm{NL}$ - converting graphic organizer to draft, wants to know where to begin, appearance works, followed by habitat (turtles) (2 minutes)

AG - graphic organizer, transfer to draft, develop complete sentences from his notes and reorganize (2 minutes)

MG, JA - proof read, check for spelling and punctuation errors, then swap and check each other's (2 minutes) 
Students were reminded to proof read for conventions, particularly capitals and commas. I suggested they reviewed their conventions exercises and ask another student to swap drafts and help each other. Proof reading is very important if a good final copy is to be the result. Tomorrow we will write again, working on final drafts ready to share on Friday.

I provided each student with feedback using their notebooks. 
Week 6

Lesson Plan

Meeting 16

\begin{tabular}{|c|c|c|c|c|c|c|}
\hline Time & Activity & Objective & Teachers Actions & Children's Actions & Materials & $\begin{array}{l}\text { Cambourne's } \\
\text { Constructs }\end{array}$ \\
\hline $12: 30$ & Attendance & & Call roll. & $\begin{array}{l}\text { Respond to name, } \\
\text { collect book and pencil }\end{array}$ & $\begin{array}{l}\text { Attendance } \\
\text { log, books } \\
\text { and pencils }\end{array}$ & $\begin{array}{l}\text { Routines within the } \\
\text { space }\end{array}$ \\
\hline $\begin{array}{c}12: 32 \\
- \\
12: 37\end{array}$ & $\begin{array}{l}\text { Write } \\
\text { corrected } \\
\text { sentence in } \\
\text { notebook }\end{array}$ & $\begin{array}{l}\text { LAFS.4.L.1.1 } \\
\text { Demonstrate } \\
\text { command of the } \\
\text { conventions of } \\
\text { standard English } \\
\text { LAFS.4.L.1.2.a } \\
\text { Use correct } \\
\text { capitalization }\end{array}$ & $\begin{array}{l}\text { Unpunctuated sentence already on board, } \\
\text { focus will be commas after transitions. } \\
\text { Observe students as they correct the } \\
\text { sentence following correct rules of } \\
\text { punctuation in their notebooks }\end{array}$ & $\begin{array}{l}\text { Writing sentence using } \\
\text { correct punctuation in } \\
\text { their books. }\end{array}$ & $\begin{array}{l}\text { Note } \\
\text { books. }\end{array}$ & $\begin{array}{l}\text { Immersion - } \\
\text { Engagement - } \\
\text { Use - }\end{array}$ \\
\hline $\begin{array}{c}12: 32 \\
-1: 00\end{array}$ & Writing time & $\begin{array}{l}\text { LAFS.4.W.1.2.a. } \\
\text { Introduce a topic } \\
\text { clearly, group } \\
\text { related } \\
\text { information in } \\
\text { paragraphs and } \\
\text { sections } \\
\text { b. develop topic } \\
\text { with facts, } \\
\text { definitions, etc. } \\
\text { c. link ideas d. } \\
\text { use domain } \\
\text { specific } \\
\text { vocabulary } \\
\text { e. provide a } \\
\text { concluding } \\
\text { statement }\end{array}$ & $\begin{array}{l}\text { Support them as they complete their final } \\
\text { draft ready to share tomorrow. }\end{array}$ & $\begin{array}{l}\text { Decide that sort of } \\
\text { paper they want to use. } \\
\text { Complete final draft. }\end{array}$ & $\begin{array}{l}\text { Notebooks, } \\
\text { pencils, } \\
\text { paper }\end{array}$ & $\begin{array}{l}\text { Demonstration - } \\
\text { Immersion - } \\
\text { Engagement - } \\
\text { Approximation - } \\
\text { Use - } \\
\text { Responsibility - }\end{array}$ \\
\hline
\end{tabular}


One of the At Home Writing Group's absent students returned today and we exchanged folders. The other two students are expected to be absent for the rest of the week.

EA returned. She has decided to continue. I offered her Spoonbill Swamp by Brenda Gulberson to read, I thought she would enjoy it. I told her once she had read it she could write about it. This she did and over the course of the meeting wrote first about her emotional response to the book and then about the content.

Although I planned to do a conventions exercise, I didn't. The students were enthusiastic to start on their final drafts, in anticipation of sharing them tomorrow. I believed more benefit would accrue to their writing skills by cashing in on their enthusiasm than by doing conventions. Comments included: "I want to just write." "Can't we write all the time?" "I have to finish so I can read it." "Meetings are too short." The group, as a whole, was working on the final draft - Immersion; Engagement; Use. MG finished his early and asked if he could help anyone else. I suggested he work with JB, they are both doing alligators. He willingly complied and JB seemed to like the attention. By the end of the session JB had written more than he has before and MG was proud of himself, especially when I complimented him on being a good teacher. I encouraged JB to continue with his good work - Expectations; Response.

Conferences: $\quad \mathrm{MG}$ - providing peer support (more capable other) to JB, demonstrating the use of the graphic organizers,

(Expectations;

Response)

All present.
$\mathrm{MG}$ - providing peer support (more capable other) to JB, demonstrating
developed as a group, to write final copy. JB did not do a rough draft. (30 seconds)

JR(a) - sudden loss of confidence regarding her format, when she realized what other students were doing. I supported her in her choice ( 2 minutes)

$\mathrm{NL}$ - needs to address completing his rough draft so he can move on to a final copy, he appears to have "frozen" (writers' block) (2 minutes)

AM - playing rather than working, did the same thing when writing letters and caught up at the last minute, procrastination (1 minute)

LP - excellent notes, needed support to convert into fluid writing for a rough draft followed by a final copy (2 minutes)

JS - hindered by earlier absences, crisis of confidence about sharing tomorrow (1 minute)

GR - use of supporting details, he has a lot of information - appearance includes weight and length (2 minutes)

AT - disinclined to finish because does not want to share, I said he needn't share but his work needed to finished for me to read privately (1 minute) 
Week 6

Lesson Plan

Meeting 17

\begin{tabular}{|c|c|c|c|c|c|c|}
\hline Time & Activity & Objective & Teachers Actions & Children's Actions & Materials & $\begin{array}{c}\text { Cambourne's } \\
\text { Constructs }\end{array}$ \\
\hline $12: 30$ & Attendance & & Call roll. & $\begin{array}{l}\text { Respond to name, } \\
\text { collect book and pencil }\end{array}$ & $\begin{array}{l}\text { Attendance } \\
\text { log, books } \\
\text { and pencils }\end{array}$ & $\begin{array}{l}\text { Routines within the } \\
\text { space }\end{array}$ \\
\hline $\begin{array}{c}12: 32 \\
- \\
12: 37\end{array}$ & $\begin{array}{l}\text { Review } \\
\text { being an } \\
\text { audience }\end{array}$ & $\begin{array}{l}\text { LAFS.4.SL.1.1.a } \\
\text { Come to } \\
\text { discussion } \\
\text { prepared. } \\
\text { b. follow agreed } \\
\text { upon rules for } \\
\text { discussion and } \\
\text { carry out } \\
\text { assigned roles. }\end{array}$ & $\begin{array}{l}\text { We will gather as a whole group to discuss } \\
\text { how to listen to someone sharing their } \\
\text { work. Being a good listener. Thinking } \\
\text { about what the other person has written. } \\
\text { Thinking of ways to improve their writing } \\
\text { and thinking about ways to say what we } \\
\text { think without hurting their feelings. }\end{array}$ & $\begin{array}{l}\text { Participate in } \\
\text { discussion }\end{array}$ & & $\begin{array}{l}\text { Routines within the } \\
\text { space }\end{array}$ \\
\hline $\begin{array}{c}12: 37 \\
- \\
12: 58\end{array}$ & $\begin{array}{l}\text { Sharing } \\
\text { Time }\end{array}$ & $\begin{array}{l}\text { LAFS.4.SL.1.1.a } \\
\text { Come to } \\
\text { discussion } \\
\text { prepared. } \\
\text { b. follow agreed } \\
\text { upon rules for } \\
\text { discussion and } \\
\text { carry out } \\
\text { assigned roles. }\end{array}$ & $\begin{array}{l}\text { Authors' Circle - observe as students share } \\
\text { their work aloud. Asked for volunteers to } \\
\text { read aloud to their classmates. Any student } \\
\text { who does not wish to participate is free to } \\
\text { abstain. }\end{array}$ & $\begin{array}{l}\text { Students will read } \\
\text { aloud. Students will } \\
\text { listen to classmates. } \\
\text { Students will offer } \\
\text { constructive } \\
\text { suggestions. Students } \\
\text { will offer praise. }\end{array}$ & Note books & $\begin{array}{l}\text { Engagement - } \\
\text { Intentional active } \\
\text { participation } \\
\text { Behaviors within the } \\
\text { space }\end{array}$ \\
\hline $\begin{array}{c}12: 58 \\
- \\
1: 00\end{array}$ & $\begin{array}{l}\text { Prepare to } \\
\text { change topic }\end{array}$ & & Next week we will select topics of interest & Students listen & & $\begin{array}{l}\text { Routines within the } \\
\text { space }\end{array}$ \\
\hline
\end{tabular}


Total chaos! The classes were celebrating Chinese New Year by eating Chinese food. It had been ordered, but had not arrived. Could I wait until 1:30? No. The students were offered a choice: have Writers' Club immediately, a little early, and eat Chinese food afterwards, or stay to eat Chinese food. With one exception, JS, they wanted to attend Writers' Club.

The students quickly got organized. If they were ready to share, they sat on the rug, if they still had work to complete they sat at the desks. Before joining us to share his work, MG wanted to help anyone who needed it, especially JB. He gradually moved from JB, who joined the sharing group, to AM and finally NL. All completed acceptable products with his assistance. DC finished her work and wanted to assume this role, so she helped AM when MG had moved on to NL. EA absent, grandmother is in hospital. JS decided to remain in classroom.

Sharing: $\quad$ GR - skinks appearance, very narrow topic, but lots of detail

JA - alligators, more comprehensive, excellent lead, good details, weaker conclusion

LP - alligators, strong lead, excellent details, minimal sentence fluency, and conclusion needs help

$\mathrm{CH} \& \mathrm{BT}$ - manatees, reading paragraphs alternately, real lead sentence was three in, closure needs help.

AN - panthers, excellent lead and voice, some interesting detail, focused on endangerment, acceptable conclusion

JR(a) - dolphins, well organized, different format - well presented

JB - alligators, good detail, very proud of his accomplishment

GG - apprehensive about sharing, alligators, excellent details, good lead but conclusion needs support

MG and DC were ready to share but too busy helping other students. AG completed his assignment just as the messenger arrived to say the food was ready, disrupting the sharing session completely. Some students asked to leave immediately and others wanted to carry on. Five students remained and the others left. DC was helping AM, MG was helping NL and GG wanted to help me tidy up. Both AM and NL completed their assignments by the time they left. They had some concern that their teacher might "change their cards" I said not to worry, I would escort them back to class at the usual time and let her know how well they had been behaving.

This project has taken up 8 meetings. The students have refined a topic of their choice, from a larger topic, within an overall subject area. They have addressed the skills involved in writing over an extended time frame - conducted research, taken notes, organized their material, shared/worked with peers, developed a rough draft and produced a final copy. After reflection, I decided the students need some relief so we will play some "quick write" games, next week. I told the students that we have two full weeks and one meeting left, but that I will come for one extra day to make up for lost time. They asked if we could meet for an hour rather than 30 minutes, I will speak to the principle to see if this is possible.

Four students absent. 
Week 7

Lesson Plan

Meeting 18

\begin{tabular}{|c|c|c|c|c|c|c|}
\hline Time & Activity & Objective & Teachers Actions & Children's Actions & Materials & $\begin{array}{l}\text { Cambourne's } \\
\text { Constructs }\end{array}$ \\
\hline $12: 30$ & Attendance & & Call roll. & $\begin{array}{l}\text { Respond to name, } \\
\text { collect book and } \\
\text { pencil }\end{array}$ & $\begin{array}{l}\text { Attendance } \\
\text { log, books } \\
\text { and pencils }\end{array}$ & $\begin{array}{l}\text { Routines within the } \\
\text { space }\end{array}$ \\
\hline $\begin{array}{c}12: 32 \\
- \\
12: 37\end{array}$ & $\begin{array}{l}\text { Write } \\
\text { corrected } \\
\text { sentence in } \\
\text { notebook }\end{array}$ & $\begin{array}{l}\text { LAFS.4.L.1.1 } \\
\text { Demonstrate } \\
\text { command of the } \\
\text { conventions of } \\
\text { standard English } \\
\text { LAFS.4.L.1.2.a } \\
\text { Use correct } \\
\text { capitalization }\end{array}$ & $\begin{array}{l}\text { Unpunctuated sentence already on board, } \\
\text { focus will be commas after transitions. } \\
\text { Observe students as they correct the } \\
\text { sentence following correct rules of } \\
\text { punctuation in their notebooks }\end{array}$ & $\begin{array}{l}\text { Writing sentence } \\
\text { using correct } \\
\text { punctuation in their } \\
\text { books. }\end{array}$ & $\begin{array}{l}\text { Note } \\
\text { books. }\end{array}$ & $\begin{array}{l}\text { Immersion - } \\
\text { Engagement - } \\
\text { Use - }\end{array}$ \\
\hline $\begin{array}{l}12: 32 \\
-1: 00\end{array}$ & Writing time & $\begin{array}{l}\text { LAFS.4.W.1.2.a. } \\
\text { Introduce a topic } \\
\text { clearly, group } \\
\text { related } \\
\text { information in } \\
\text { paragraphs and } \\
\text { sections } \\
\text { b. develop topic } \\
\text { with facts, } \\
\text { definitions, etc. } \\
\text { c. link ideas d. } \\
\text { use domain } \\
\text { specific } \\
\text { vocabulary } \\
\text { e. provide a } \\
\text { concluding } \\
\text { statement }\end{array}$ & $\begin{array}{l}\text { Explain that we will play some quick write } \\
\text { games. } \\
\text { The first game is to write as many words as } \\
\text { possible in } 1 \text { minute. Then the children } \\
\text { will share how many words they wrote and } \\
\text { we will do it again, to see if they can write } \\
\text { more the next time. It is not a competition } \\
\text { against another student just one against } \\
\text { oneself. } \\
\text { Then explain that they will write on a topic } \\
\text { of their choice for } 10 \text { minutes. } \\
\text { Explain that the piece can be narrative, a } \\
\text { story, or informational. } \\
\text { Tell students to think of a topic they would } \\
\text { like to write about tomorrow for a little } \\
\text { longer - } 15-20 \text { minutes. They will share } \\
\text { what they have written }\end{array}$ & $\begin{array}{l}\text { Write for one minute } \\
\text { against the timer, } \\
\text { count the words, do it } \\
\text { again, check if the } \\
\text { number of words had } \\
\text { increased. } \\
\text { Listen } \\
\text { Write for } 10 \text { minutes } \\
\text { on a topic of their } \\
\text { choice. They shared } \\
\text { what their topic was. }\end{array}$ & $\begin{array}{l}\text { Notebooks, } \\
\text { pencils, } \\
\text { paper }\end{array}$ & $\begin{array}{l}\text { Immersion - } \\
\text { Engagement - } \\
\text { Responsibility - }\end{array}$ \\
\hline
\end{tabular}


I collected and distributed the At Home Writing Group folderss. One student had lost his folder and the two students who were sick last week did not hand in a folder.

The same group of students continue to arrive a little late, however, all the students entered the room in a very much more controlled manner; they are internalizing the behaviors in the space. I asked them to write down the sentences on the board. I suggested that they try to do the corrections as they go along. Some students finished quickly, I asked them to pair up and see if they agreed about the corrections and to come to agreement if there were discrepancies. We then went over the sentences:

Today, we will play a game. We will do "quick writes." First, Ms. Helen will set the timer.

Next, we will write for one minute. Then, we will count the number of words.

While completing the Everglades project, the students have been working hard so they were excited to play. They were rather noisy and, unfortunately, a test was going on in the adjoining classroom. An administrator came in and admonished them to be quiet. I would have been gentler, they were not out of hand, just excited. After that, we whispered. They completed the One Minute Writes and enjoyed seeing how many words they could do. One student, LP, wrote "do" repeatedly, I explained he had to write different words. They all enjoyed doing this. Then I asked them to think of a topic they knew a lot about. Various ideas came out, and they settled down to write for 10 minutes. I wrote alongside them. Once they finished they wanted to read their work aloud, but there wasn't time. I told them tomorrow they would be able to write for a little longer and that I would allow time for sharing. I was asked if they could choose the same topic, I said, "Yes."

Conferences: $\quad$ JB - complimented him on his effort. He has probably made more progress than any other student in the (Expectations; $\quad$ group. He started out not writing anything. Today he did the conventions exercise and wrote half a page, Response) followed by a drawing of himself shooting hoops.

EA - Thanked me for my support last week. I encouraged her to continue writing about her grief as a way of acknowledging it and coming to terms with the loss of her grandfather. She shared that her mother had said the same thing.

AG - wants to share his report from last week. I said, "Tomorrow."

All the students were provided with individual feedback, through their notebooks Expectations; Response

Two students absent. 
Week 7

Lesson Plan

Meeting 19

\begin{tabular}{|c|c|c|c|c|c|c|}
\hline Time & Activity & Objective & Teachers Actions & Children's Actions & Materials & $\begin{array}{l}\text { Cambourne's } \\
\text { Constructs }\end{array}$ \\
\hline $12: 30$ & Attendance & & Call roll. & $\begin{array}{l}\text { Respond to name, } \\
\text { collect book and pencil }\end{array}$ & $\begin{array}{l}\text { Attendance } \\
\text { log, books } \\
\text { and pencils }\end{array}$ & $\begin{array}{l}\text { Routines within the } \\
\text { space }\end{array}$ \\
\hline $\begin{array}{c}12: 32 \\
- \\
12: 50\end{array}$ & Writing time & $\begin{array}{l}\text { LAFS.4.W.1.2.a. } \\
\text { Introduce a topic } \\
\text { clearly, group } \\
\text { related } \\
\text { information in } \\
\text { paragraphs and } \\
\text { sections } \\
\text { b. develop topic } \\
\text { with facts, } \\
\text { definitions, etc. } \\
\text { c. link ideas d. } \\
\text { use domain } \\
\text { specific } \\
\text { vocabulary } \\
\text { e. provide a } \\
\text { concluding } \\
\text { statement }\end{array}$ & $\begin{array}{l}\text { Explain that there will be free selection of } \\
\text { topic to write about. } \\
\text { Explain that the piece can be narrative, a } \\
\text { story, or informational. If an informational } \\
\text { topic is selected it will be necessary to } \\
\text { determine what form it will take - } \\
\text { compare/contrast, persuasive, etc. } \\
\text { Provide a selection of graphic organizers } \\
\text { for both narrative and informational (all } \\
\text { taken from FCRR) }\end{array}$ & $\begin{array}{l}\text { Decide on topic, } \\
\text { prepare and begin } \\
\text { writing. }\end{array}$ & $\begin{array}{l}\text { Notebooks, } \\
\text { pencils, } \\
\text { paper }\end{array}$ & $\begin{array}{l}\text { Immersion - } \\
\text { Engagement - } \\
\text { Responsibility - }\end{array}$ \\
\hline $\begin{array}{l}12: 50 \\
-1: 00\end{array}$ & $\begin{array}{l}\text { Sharing } \\
\text { Time }\end{array}$ & $\begin{array}{l}\text { LAFS.4.SL.1.1.a } \\
\text { Come to } \\
\text { discussion } \\
\text { prepared. } \\
\text { b. follow agreed } \\
\text { upon rules for } \\
\text { discussion and } \\
\text { carry out } \\
\text { assigned roles. }\end{array}$ & $\begin{array}{l}\text { Authors' Circle- observe as students share } \\
\text { their work aloud. Asked for volunteers to } \\
\text { read aloud to their classmates. Any student } \\
\text { who does not wish to participate is free to } \\
\text { abstain. }\end{array}$ & $\begin{array}{l}\text { Students will read } \\
\text { aloud. Students will } \\
\text { listen to classmates. } \\
\text { Students will offer } \\
\text { constructive } \\
\text { suggestions. Students } \\
\text { will offer praise. }\end{array}$ & Note books & $\begin{array}{l}\text { Engagement - } \\
\text { Intentional active } \\
\text { participation } \\
\text { Behaviors within the } \\
\text { space }\end{array}$ \\
\hline
\end{tabular}


The students were excited that they would get to write and then share. The majority had ideas. Four students asked to be excused since their teacher was reading aloud to them and they didn't want to miss the next part of the book. I said they must choose for themselves, but that there were only two meetings before the statewide test. Three of the four decided they could read the book for themselves at home, and stayed.

Some of the students took graphic organizers Responsibility, Some worked alone, some chose to work with a buddy. I set the timer for 16 minutes. I observed, just until I could see they were all engaged; then, I took out my notebook and began writing. I stopped after five minutes and circled the room, reminding those who were still working on the graphic organizer they had 10 minutes left of writing time. I returned to my seat and continued writing. Within two or three minutes, the room went almost completely silent Engagement, Use. As students completed their work, one or two wanted to interrupt me to share, but were admonished by their peers, to read over their work and let me continue with mine. I was thrilled. Just as the timer went off I stood up and asked them to move quickly and quietly to the carpet so we could share our work. Two students asked if they could remain at the tables to finish what they were doing. I agreed and asked them to join us when they were finished. They did.

One student, $\mathrm{CH}$, was first into the Author's Chair (a rocking chair that is kept in the library and that I had set out on one side of the carpet). The rest of the students sat down with minimal fuss Behaviors. I asked one student, AM, to sit beside me. Each of the students read their work aloud and quickly vacated the chair so the next person could take a turn. In total 14 students were able to share their work, two were absent, and three refused the opportunity. Three were not offered the option to read because the meeting ended abruptly. The room was needed for a test and the assistant principal entered and demanded that we restore the desks to where they were prior to the meeting. Two students helped her and the rest very quickly placed their books in the box and left.

There were no conferences, only quick comments were made at the conclusion of each reading.

Two students absent. 


\begin{tabular}{|c|c|c|c|c|c|c|}
\hline Time & Activity & Objective & Teachers Actions & Children's Actions & Materials & $\begin{array}{l}\text { Cambourne's } \\
\text { Constructs }\end{array}$ \\
\hline $12: 30$ & Attendance & & Call roll. & $\begin{array}{l}\text { Respond to name, } \\
\text { collect book and pencil }\end{array}$ & $\begin{array}{l}\text { Attendance } \\
\log , \text { books } \\
\text { and pencils }\end{array}$ & $\begin{array}{l}\text { Routines within the } \\
\text { space }\end{array}$ \\
\hline $\begin{array}{c}12: 32 \\
- \\
12: 45\end{array}$ & $\begin{array}{l}\text { Write } \\
\text { corrected } \\
\text { sentence in } \\
\text { notebook }\end{array}$ & $\begin{array}{l}\text { LAFS.4.L.1.1 } \\
\text { Demonstrate } \\
\text { command of the } \\
\text { conventions of } \\
\text { standard English } \\
\text { LAFS.4.L.1.2.a } \\
\text { Use correct } \\
\text { capitalization }\end{array}$ & $\begin{array}{l}\text { Unpunctuated sentence already on board, } \\
\text { focus will be everything we have gone over } \\
\text { so far - capital letters to start a sentence } \\
\text { and for proper nouns, commas in a list and } \\
\text { after transitions words. Observe students as } \\
\text { they correct the sentence in their notebooks, } \\
\text { following correct rules of punctuation }\end{array}$ & $\begin{array}{l}\text { Writing sentence using } \\
\text { correct punctuation in } \\
\text { their books. }\end{array}$ & $\begin{array}{l}\text { Note } \\
\text { books, } \\
\text { pencils. }\end{array}$ & $\begin{array}{l}\text { Immersion - } \\
\text { Engagement - } \\
\text { Use - }\end{array}$ \\
\hline $\begin{array}{l}12: 45 \\
-1: 00\end{array}$ & $\begin{array}{l}\text { Discussion } \\
\text { "What have I } \\
\text { learned from } \\
\text { being in } \\
\text { Writers' } \\
\text { Club" and } \\
\text { "What do I } \\
\text { need to } \\
\text { remember } \\
\text { for the test" }\end{array}$ & $\begin{array}{l}\text { LAFS.4.SL.1.1.a } \\
\text { Come to } \\
\text { discussion } \\
\text { prepared. } \\
\text { b. follow agreed } \\
\text { upon rules for } \\
\text { discussion and } \\
\text { carry out } \\
\text { assigned roles. }\end{array}$ & $\begin{array}{l}\text { The statewide test will be given before the } \\
\text { next meeting. Discuss what they have } \\
\text { learned. Bring to the forefront of their } \\
\text { minds important steps to take - read the } \\
\text { prompt at least twice, stop and think, write } \\
\text { some notes before beginning to write, draw } \\
\text { a graphic organizer if it will help, include } \\
\text { lots of details in their writing, proof read } \\
\text { their work to check for conventions, } \\
\text { particularly capital letters and commas. Be } \\
\text { attentive to spelling but do not hold back on } \\
\text { using strong words because of spelling. }\end{array}$ & $\begin{array}{l}\text { Listen, contribute to the } \\
\text { discussion sharing what } \\
\text { they have learned. }\end{array}$ & & $\begin{array}{l}\text { Immersion - } \\
\text { Engagement - } \\
\text { Responsibility - }\end{array}$ \\
\hline
\end{tabular}


The students have got into the habit of coming in quickly, collecting their materials and checking if there are sentences on the board Responsibility. If there are, they begin to write. Some of them are correcting as they go, and some write the whole exercise and then go over it making corrections; either is acceptable. Once they have made corrections, they team up with a classmate, who has also finished, to see if they agree on what needed to be done. I circle the room until I see everyone has finished and then we go over it. They are working almost independently on this task Routines and Behaviors in the space; Responsibility. The sentences were:

The Everglades is a unique ecosystem. Everglades National Park contains the Anhinga Trail, to the south. In the north, it is possible to visit Shark Valley and Big Cyprus, where the panthers are.

Since the sentences are corrected by the time I look at them, after the meeting, I am not fully aware of how well each individual student is internalizing the rules. This is outweighed by the building of a cooperative community through allowing them to tell me what corrections need to be made. Everyone then checks to see if they got them right, or if they need to make changes Expectations; Response. When I examine the notebooks I do find some errors are still evident.

The discussion about what they had learned during Writer's Club was productive and the students made many comments; examples follow: "I now know when to put commas after transition words and phrases." "I learned how to do writing in stages." "I liked using the graphic organizers, particularly choosing my own." "Taking notes is hard." "I learned a lot working in my group." "I know to think about adding more information." "Remembering all the punctuations is easier if you read your work when you are finished." "I liked doing the Everglades." Once they had made their comments, I went over what it is important to remember. I told them test writing is done in steps: read the prompt, then, re-read it; make notes of some ideas, create a graphic organizer, if it helps; start writing and include as many details as they can think of; when they are finished proof read for errors, particularly the capital letters and commas they have been learning about; check the spelling of any words they are not sure about; if there is time left over, it is time to write some more, even if they think it is finished. Adding more information or ideas is a good thing. Then I wished them a happy weekend and good luck with the test. I assured them they could all write an excellent essay if they followed the steps and thought about all the things they had learned Expectations; Response. One of the students said that their teachers had told them that.

There were no conferences today, it was a whole-group support.

Three students absent. 


\begin{tabular}{|c|c|c|c|c|c|c|}
\hline Time & Activity & Objective & Teachers Actions & Children's Actions & Materials & $\begin{array}{l}\text { Cambourne's } \\
\text { Constructs }\end{array}$ \\
\hline $12: 30$ & Attendance & & Call roll. & $\begin{array}{l}\text { Respond to name, } \\
\text { collect book and pencil }\end{array}$ & $\begin{array}{l}\text { Attendance } \\
\text { log, books } \\
\text { and pencils }\end{array}$ & $\begin{array}{l}\text { Routines within the } \\
\text { space }\end{array}$ \\
\hline $\begin{array}{c}12: 32 \\
- \\
12: 50\end{array}$ & $\begin{array}{l}\text { Write } \\
\text { corrected } \\
\text { sentence in } \\
\text { notebook }\end{array}$ & $\begin{array}{l}\text { LAFS.4.L.1.1 } \\
\text { Demonstrate } \\
\text { command of the } \\
\text { conventions of } \\
\text { standard English } \\
\text { LAFS.4.L.1.2.a } \\
\text { Use correct } \\
\text { capitalization }\end{array}$ & $\begin{array}{l}\text { Unpunctuated sentence already on board, } \\
\text { focus will be quotation marks to indicate } \\
\text { speech. Observe students as they correct } \\
\text { the sentence in their notebooks, following } \\
\text { correct rules of punctuation. }\end{array}$ & $\begin{array}{l}\text { Writing sentence using } \\
\text { correct punctuation in } \\
\text { their books. }\end{array}$ & $\begin{array}{l}\text { Note } \\
\text { books, } \\
\text { pencils. }\end{array}$ & $\begin{array}{l}\text { Immersion - } \\
\text { Engagement - } \\
\text { Use - } \\
\text { Approximation - }\end{array}$ \\
\hline $\begin{array}{l}12: 50 \\
-1: 00\end{array}$ & $\begin{array}{l}\text { Discussion } \\
\text { "How did the } \\
\text { test go" }\end{array}$ & $\begin{array}{l}\text { LAFS.4.SL.1.1.a } \\
\text { Come to } \\
\text { discussion } \\
\text { prepared. } \\
\text { b. follow agreed } \\
\text { upon rules for } \\
\text { discussion and } \\
\text { carry out } \\
\text { assigned roles. }\end{array}$ & $\begin{array}{l}\text { The statewide test was given since the last } \\
\text { meeting. Discuss what they did and how } \\
\text { they approached completing the task. Ask } \\
\text { if the Writers' Club activities had helped } \\
\text { them in any way. }\end{array}$ & $\begin{array}{l}\text { Listen, contribute to the } \\
\text { discussion sharing what } \\
\text { they have learned. }\end{array}$ & & $\begin{array}{l}\text { Immersion - } \\
\text { Engagement - } \\
\text { Responsibility - }\end{array}$ \\
\hline
\end{tabular}


I collected and distributed the At Home Writing Group's folders. Some students were confused about the due date, they thought I was collecting on Thursday, not Wednesday. I explained that that would be the case next week. I agreed to visit the classroom to collect missing folders. I appraised them that this is the last week of the study.

Eight students arrived promptly for the meeting. I told them we would focus on the use of quotation marks and that they could write down the sentences and see if they could punctuate them while we awaited the other students Approximation, Use. Gradually, the others trickled in. As each group appeared they became more rowdy. They all wrote down the sentences that were:

Quotation marks indicate speech.

Jensi said, "Good morning, Ms. Helen."

"It is hot, today." said Leo.

Then we addressed a very difficult sentence: "Maikel," said Vanessa, "is going to the zoo." The punctuation is critical. Revise it, and it changes who is going to the zoo. Maikel said, "Vanessa is going to the zoo." Demonstration. The students were intrigued by this sentence Approximation. We discussed it and various volunteers began to read the two different punctuations expressively all but one of the students understood what was happening Engagement, Immersion, Use. I was able to demonstrate how important punctuation is. One student, JA, said, "Now I get why it is so important." This exercise took up the bulk of the meeting. One student, NL, indicated he was finished so I allowed him to return to class. I attempted to ask them how the writing test had gone on Monday, but someone called out, "Can't we just write." So I said, "Yes," and for the final five to ten minutes of the meeting they wrote about whatever they wished Engagement, Immersion; Responsibility.

Conferences: $\quad$ Four students (JB, FC, AN and JD) had 1 minute conferences with me saying that they couldn't think of (Expectations; $\quad$ anything, I told each of them if they started with, "Today, I got out of bed and ..." they would be able to get Response) started. They all did, three of the four students wrote about something completely different once they put their pencils to the paper.

Time was quickly up. I told them their writing would be their ticket out the door. The students each brought their books, open at their work, for me to see. Some had written quite prolifically, considering the impromptu nature of the task. They placed their books in the box and deposited their pencils in the jar, before leaving Responsibility, Routines.

All present. 


\begin{tabular}{|c|c|c|c|c|c|c|}
\hline Time & Activity & Objective & Teachers Actions & Children's Actions & Materials & $\begin{array}{c}\text { Cambourne's } \\
\text { Constructs }\end{array}$ \\
\hline $12: 30$ & Attendance & & Call roll. & $\begin{array}{l}\text { Respond to name, } \\
\text { collect book and pencil }\end{array}$ & $\begin{array}{l}\text { Attendance } \\
\text { log, books } \\
\text { and pencils }\end{array}$ & $\begin{array}{l}\text { Routines within the } \\
\text { space }\end{array}$ \\
\hline $\begin{array}{c}12: 32 \\
- \\
12: 37\end{array}$ & $\begin{array}{l}\text { Write } \\
\text { corrected } \\
\text { sentence in } \\
\text { notebook }\end{array}$ & $\begin{array}{l}\text { LAFS.4.L.1.1 } \\
\text { Demonstrate } \\
\text { command of the } \\
\text { conventions of } \\
\text { standard English } \\
\text { LAFS.4.L.1.2.a } \\
\text { Use correct } \\
\text { capitalization }\end{array}$ & $\begin{array}{l}\text { Unpunctuated sentence already on board, } \\
\text { focus will be commas after transitions. } \\
\text { Observe students as they correct the } \\
\text { sentence following correct rules of } \\
\text { punctuation in their notebooks }\end{array}$ & $\begin{array}{l}\text { Writing sentence using } \\
\text { correct punctuation in } \\
\text { their books. }\end{array}$ & $\begin{array}{l}\text { Note } \\
\text { books. }\end{array}$ & $\begin{array}{l}\text { Immersion - } \\
\text { Engagement - } \\
\text { Use - }\end{array}$ \\
\hline $\begin{array}{l}12: 32 \\
-1: 00\end{array}$ & Writing time & $\begin{array}{l}\text { LAFS.4.W.1.2.a. } \\
\text { Introduce a topic } \\
\text { clearly, group } \\
\text { related } \\
\text { information in } \\
\text { paragraphs and } \\
\text { sections } \\
\text { b. develop topic } \\
\text { with facts, } \\
\text { definitions, etc. } \\
\text { c. link ideas d. } \\
\text { use domain } \\
\text { specific } \\
\text { vocabulary } \\
\text { e. provide a } \\
\text { concluding } \\
\text { statement }\end{array}$ & $\begin{array}{l}\text { Explain that they will write on a topic of } \\
\text { their choice for } 10 \text { minutes. } \\
\text { Explain that the piece can be narrative, a } \\
\text { story, or informational. } \\
\text { Tell students to think of a topic they would } \\
\text { like to write about tomorrow for a little } \\
\text { longer - } 15-20 \text { minutes. They will share } \\
\text { what they have written }\end{array}$ & $\begin{array}{l}\text { Write for } 10 \text { minutes on } \\
\text { a topic of their choice. } \\
\text { They shared what their } \\
\text { topic was. }\end{array}$ & $\begin{array}{l}\text { Notebooks, } \\
\text { pencils, } \\
\text { paper }\end{array}$ & $\begin{array}{l}\text { Immersion - } \\
\text { Engagement - } \\
\text { Responsibility - }\end{array}$ \\
\hline
\end{tabular}


Eight students arrived promptly, these students are all in the same class. The next group straggled in but before meeting is scheduled to begin. The final group of students was late. That has become par for the course. Before the meeting had got properly under way, two students came in and announced that their class had won a competition and there was a celebration in the classroom. They needed FC, AD, GR, JR(b), and JS. I asked the students what they wished to do. Once ice cream was mentioned, they all left.

I had written sentences involving dialogue on the board. As the students arrived, they found seats and started writing them down Routines, Responsibility, Immersion, Engagement. Some of the early arrivals had finished before the tardy students started. When they were ready, the students found partners to compare Approximation. It became obvious that the slower students were not going to catch up. As a result, I asked those who had finished, and checked the exercise, to start writing about a topic of their choice. One late arrival, AM, was being particularly dilatory. Once everyone had completed the exercise, I asked for their attention and began to go over the sentences. I had discussed the first two punctuation marks when JB stood up and rapidly went over the whole exercise. We were all dumbfounded. He has grown so much since the beginning of the Writers' Club. I

complimented all the other students for their respect while JB did this. I then complimented him because, although he had not identified all the punctuation marks, everything he had mentioned was correct. He puffed up like a peacock with pride. We then went over each correction and everyone corrected their books as necessary. They have become adept at this exercise and are taking it more as a game than an exercise. There is the potential for them to become rather rowdy but they are all on task so I do little to scotch their enthusiasm. The sentences were:

"Hello, how are you?" Arturo said. "I'm well." Melissa replied.

"Where is the library?" she asked. He responded, "Across the hall."

The interruption had reduced the time considerably, so to finish off we played One Minute Writes. There were no conferences.

The next activity will involve writing over a short time frame - two meetings. The focus will be on including many details by answering who, what, where, why, when, and how questions about a refined topic, my suggestion will be to write about their best friend. They will be given graphic organizers.

Five students absent, those who went to the celebration. 
Week 8

Lesson Plan

\begin{tabular}{|c|c|c|c|c|c|c|}
\hline Time & Activity & Objective & Teachers Actions & Children's Actions & Materials & $\begin{array}{c}\text { Cambourne's } \\
\text { Constructs }\end{array}$ \\
\hline $12: 30$ & Attendance & & Call roll. & $\begin{array}{l}\text { Respond to name, } \\
\text { collect book and pencil }\end{array}$ & $\begin{array}{l}\text { Attendance } \\
\text { log, books } \\
\text { and pencils }\end{array}$ & $\begin{array}{l}\text { Routines within the } \\
\text { space }\end{array}$ \\
\hline $\begin{array}{c}12: 32 \\
- \\
12: 50\end{array}$ & Writing time & $\begin{array}{l}\text { LAFS.4.W.1.2.a. } \\
\text { Introduce a topic } \\
\text { clearly, group } \\
\text { related } \\
\text { information in } \\
\text { paragraphs and } \\
\text { sections } \\
\text { b. develop topic } \\
\text { with facts, } \\
\text { definitions, etc. } \\
\text { c. link ideas d. } \\
\text { use domain } \\
\text { specific } \\
\text { vocabulary } \\
\text { e. provide a } \\
\text { concluding } \\
\text { statement }\end{array}$ & $\begin{array}{l}\text { Explain that for the last two meetings they } \\
\text { will be completing an essay. Explain that } \\
\text { there will be free selection of topic to write } \\
\text { about, but I will suggest writing about My } \\
\text { Best Friend. } \\
\text { Explain that the piece can be narrative, a } \\
\text { story, or informational. If an informational } \\
\text { topic is selected it will be necessary to } \\
\text { determine what form it will take - } \\
\text { compare/contrast, persuasive, etc. } \\
\text { Provide a selection of graphic organizers } \\
\text { for both narrative and informational (all } \\
\text { taken from FCRR) }\end{array}$ & $\begin{array}{l}\text { Decide on topic, } \\
\text { prepare and begin } \\
\text { writing. }\end{array}$ & $\begin{array}{l}\text { Notebooks, } \\
\text { pencils, } \\
\text { paper }\end{array}$ & $\begin{array}{l}\text { Immersion - } \\
\text { Engagement - } \\
\text { Responsibility - } \\
\text { Approximation - } \\
\text { Use - }\end{array}$ \\
\hline
\end{tabular}


The same students were tardy. I promised them the opportunity to focus on writing. I suggested the topic, My Best Friend. Graphic organizers focusing on character (sourced from FCRR), were provided. Some of the members of the Writers' Club are best friends so they asked if they could sit together while they wrote about each other. Other students chose partners, or not, as they liked. One small group developed. They had the idea of writing about each other, even though they were not best friends. This group of girls has been sitting together regularly during Writers' Club, and formed a mini-community within the larger community (CH, FC, DC, BT), supporting each other in their writing and holding discussions about the "how tos" of writing. I believe their friendship has deepened because of the experience. They decided to each write about the person on their left. When asked why they chose to do this, they told me that they had heard me talking to the best friends, saying to ask questions of each other to elaborate on the details and thought this was a good idea Responsibility, Approximation, Immersion, Engagement, Use. Many of the best friends spent most of today's time interviewing each other to find more details that they included on a variety of graphic organizers Engagement, Use.

AM did not want to write about his best friend so he chose to write about a sports personality. He is very knowledgeable about baseball. Whenever he has had the opportunity to do shorter writing tasks and self-select the topic, he picks a player and writes, quite extensively, about him. He told me he is going to miss being able to do this when Writers' Club is over. Many of the members have shared with me that they wish Writers' club could continue. One student even said, "Next year, when we have Writers' Club in the afternoon, for two hours, we will be able to do lots of things." I told her she would have to wait and see if Writers' Club was offered next year.

Conferences:

(Expectations; Response)

JR, EA, VM - Small group, best friends, using character (FCRR - C.001.SS1) graphic organizer and discussing each section, hung up on "What others say about character" I told them to ask each other (1 minute)

CH, DC, BT, FC - using a variety of graphic organizers, (FCRR - C.001.SS2, FCRR - C001.SS3, FCRR C002.SS1 [2]), discussing how graphic organizers make writing more manageable.

Conferences were more generalized and addressed to small groups rather than individuals.

They were reminded that next meeting was the last for the study, but that there would be the final "celebration" meeting. They groaned and made comments like, "I wish Writers" Club could go on forever." "Writing is more fun when we do it in Writers' Club." I told them they could continue thinking about what they wanted to say in their essays over the weekend. Next meeting there would be time to write a final draft and to edit it with a friend. We would start reading them aloud but could save any we didn't get to until the "celebration" meeting.

One student was absent. 


\begin{tabular}{|c|c|c|c|c|c|c|}
\hline Time & Activity & Objective & Teachers Actions & Children's Actions & Materials & $\begin{array}{c}\text { Cambourne's } \\
\text { Constructs }\end{array}$ \\
\hline $12: 30$ & Attendance & & Call roll. & $\begin{array}{l}\text { Respond to name, } \\
\text { collect book and pencil }\end{array}$ & $\begin{array}{l}\text { Attendance } \\
\text { log, books } \\
\text { and pencils }\end{array}$ & $\begin{array}{l}\text { Routines within the } \\
\text { space }\end{array}$ \\
\hline $\begin{array}{c}12: 32 \\
- \\
12: 50\end{array}$ & Writing time & $\begin{array}{l}\text { LAFS.4.W.1.2.a. } \\
\text { Introduce a topic } \\
\text { clearly, group } \\
\text { related } \\
\text { information in } \\
\text { paragraphs and } \\
\text { sections } \\
\text { b. develop topic } \\
\text { with facts, } \\
\text { definitions, etc. } \\
\text { c. link ideas d. } \\
\text { use domain } \\
\text { specific } \\
\text { vocabulary } \\
\text { e. provide a } \\
\text { concluding } \\
\text { statement }\end{array}$ & $\begin{array}{l}\text { Offer students support with the topic they } \\
\text { have selected. } \\
\text { Answer any questions. }\end{array}$ & $\begin{array}{l}\text { Continue with topic, } \\
\text { complete preparation } \\
\text { and write final draft. } \\
\text { Edit with a friend. }\end{array}$ & $\begin{array}{l}\text { Notebooks, } \\
\text { pencils, } \\
\text { paper }\end{array}$ & $\begin{array}{l}\text { Immersion - } \\
\text { Engagement - } \\
\text { Responsibility - } \\
\text { Use - }\end{array}$ \\
\hline $\begin{array}{l}12: 50 \\
-1: 00\end{array}$ & $\begin{array}{l}\text { Sharing } \\
\text { Time }\end{array}$ & $\begin{array}{l}\text { LAFS.4.SL.1.1.a } \\
\text { Come to } \\
\text { discussion } \\
\text { prepared. } \\
\text { b. follow agreed } \\
\text { upon rules for } \\
\text { discussion and } \\
\text { carry out } \\
\text { assigned roles. }\end{array}$ & $\begin{array}{l}\text { Authors' Circle - observe as students share } \\
\text { their work aloud. Asked for volunteers to } \\
\text { read aloud to their classmates. Any student } \\
\text { who does not wish to participate is free to } \\
\text { abstain. }\end{array}$ & $\begin{array}{l}\text { Students will read } \\
\text { aloud. Students will } \\
\text { listen to classmates. } \\
\text { Students will offer } \\
\text { constructive } \\
\text { suggestions. Students } \\
\text { will offer praise. }\end{array}$ & Note books & $\begin{array}{l}\text { Engagement - } \\
\text { Intentional active } \\
\text { participation } \\
\text { Behaviors within the } \\
\text { space }\end{array}$ \\
\hline
\end{tabular}


There is a definite atmosphere of closure. The students are vocal about not wanting the Writers' club to end. Comments like: "Can't you go on doing Writers" Club." "We like writing in Writers" Club." "You need to visit us once a week after Writers' Club is over, so we can show you our writing." "Why can't we carry on after Spring Break?"

Students carried on with their writing about a person project. The existing groups and pairs supported each other to complete the assignment. Many students swapped their work with each other for editing help. MG told me he wished they could do it in class because it helped to get it right. He also loves to help other people, as do DC and JA. They are always willing to look over a classmates work and offer suggestions Engagement, Approximation, Use. They are also happy to have a classmate look over their work.

AM took himself off to a desk separated from the rest of the room and worked on his sports personality. He wrote a final product covering over two pages. It contained interesting details about his personality, some of that were insightful and enlightening to his reader.

When it was time to share, some of the students were not finished with their work. They asked to remain at the desks to finish Immersion, Engagement, Use. Those who were ready to share, moved over to the rocking chair and rug. $\mathrm{CH}$ was quick to take her seat, but was willing to give it up when LP asked if he could go first. I did not get involved in the exchange, just observed the personal progress that has been achieved over the past 8 weeks.

Sharing:

LP - Good description, best friend is a girl, who remains unnamed (perhaps he is embarrassed to have a girl for a best friend. GR - very voluble when sharing, his best friend was JR(b), his partner when working on the Everglades project (a new best friend), he had described him from observation, gathered all his favorite things - food, places to go, animal, and included details about his family.

$\mathrm{BT}$ - wrote about $\mathrm{CH}$ but included her best friend in the piece, one of the other students in her class.

JD - wrote about his favorite sport - soccer, he included some details.

$\mathrm{AD}$ - wrote about FC, good description, family, foods, activities, quotes - no paragraphs but lots of detail.

JS - best friend, this was his longest and most detailed piece produced so far!

$\mathrm{CH}-$ started writing about a member of the group but switched to her real best friend, animated, really shared her feelings

Time ran out. The post test will be administered before the "celebration" meeting, tomorrow. The rest of the students who want to share will do so then.

All present. 


\section{APPENDIX H}

\section{List of Books}

(provided by the researcher-guide to the students for research or reference)

\begin{tabular}{|c|c|c|c|c|}
\hline \multicolumn{5}{|c|}{ Writers' Club - Model Texts } \\
\hline Item & Title & Genre & Use and Summary & Focus of Instruction \\
\hline \multicolumn{5}{|c|}{ Books read aloud to students (whole or part) } \\
\hline 1 & $\begin{array}{l}\text { Goldilocks } \\
\text { and the } \\
\text { Three Bears } \\
\text { retold by } \\
\text { Vera } \\
\text { Southgate }\end{array}$ & Fairytale & $\begin{array}{l}\text { Read aloud in its entirety. } \\
\text { Three bears go for a walk while waiting } \\
\text { for their breakfast to cool down. } \\
\text { Goldilocks, a little girl, enters the empty } \\
\text { house and tries the three bowls of } \\
\text { porridge, then tries three chairs and finally } \\
\text { tests three beds. She falls asleep in the last } \\
\text { one. The bears return to find the porridge } \\
\text { tasted, the chairs sat upon and the beds } \\
\text { mussed up. They discover Goldilocks and } \\
\text { in fright she leapt from the window and } \\
\text { ran home. The bears never saw her again. }\end{array}$ & $\begin{array}{l}\text { - Introductory story to encourage student } \\
\text { to see multiple points of view. } \\
\text { LAFS.4.W.1.1 - write, supporting point } \\
\text { of view with reasons } \\
\text { - encourage discussion of what each might } \\
\text { say to the other. } \\
\text { LAFS.4.L. } 2.3 \text { - Use appropriate } \\
\text { conventions when speaking - informal } \\
\text { language in group discussion } \\
\text { LAFS.4.RL.1.1 - refer to details and } \\
\text { examples in text when explaining what } \\
\text { the text says explicitly and drawing } \\
\text { inferences from the text. }\end{array}$ \\
\hline 2 & $\begin{array}{l}\text { Dear Peter } \\
\text { Rabbit by } \\
\text { Alma Flor } \\
\text { Ada }\end{array}$ & $\begin{array}{l}\text { Story } \\
\text { demonstrating } \\
\text { letter format }\end{array}$ & $\begin{array}{l}\text { Single letter read aloud; otherwise } \\
\text { available as resource. } \\
\text { A series of letters written between a } \\
\text { number of story book characters including } \\
\text { Goldilocks, Peter Rabbit, the three little } \\
\text { pigs, and little Red Riding Hood. }\end{array}$ & $\begin{array}{l}\text { - Model text - follow accepted letter } \\
\text { format } \\
\text { LAFS.4.W.2.4 - Produce clear, coherent } \\
\text { writing in that the development and } \\
\text { organization are appropriate to task. } \\
\text { LAFS.4.L. } 2.3 \text { - Use knowledge of } \\
\text { language and its conventions when } \\
\text { writing. } \\
\text { a. choose words and phrases to convey } \\
\text { ideas precisely. } \\
\text { b. choose punctuation for effect }\end{array}$ \\
\hline
\end{tabular}




\begin{tabular}{|c|c|c|c|c|}
\hline \multicolumn{5}{|c|}{ Books made available to students as resources } \\
\hline 3 & $\begin{array}{l}\text { The Jolly } \\
\text { Christmas } \\
\text { Postman by } \\
\text { Janet \& } \\
\text { Allan } \\
\text { Ahlberg }\end{array}$ & Letters & $\begin{array}{l}\text { Resource available for students. } \\
\text { Interactive book includes card, game, } \\
\text { puzzle, etc. related to Christmas }\end{array}$ & $\begin{array}{l}\text { - Model text -examples of different kinds } \\
\text { of letters included in previous text. } \\
\text { LAFS.4.W.2.4 - Produce clear, coherent } \\
\text { writing in that the development and } \\
\text { organization are appropriate to task. }\end{array}$ \\
\hline 4 & $\begin{array}{l}\text { The Jolly } \\
\text { Postman by } \\
\text { Janet \& } \\
\text { Allan } \\
\text { Ahlberg }\end{array}$ & Letters & $\begin{array}{l}\text { Resource available for students. } \\
\text { Interactive book of letters sent between } \\
\text { story book characters, that includes } \\
\text { advertising material, a post card, a } \\
\text { business letter, a birthday card, etc. It } \\
\text { concludes with Goldilocks birthday party. }\end{array}$ & $\begin{array}{l}\text { - Model text -examples of different kinds } \\
\text { of letters included in previous text. } \\
\text { LAFS.4.W.2.4 - Produce clear, coherent } \\
\text { writing in that the development and } \\
\text { organization are appropriate to task. }\end{array}$ \\
\hline 5 & $\begin{array}{l}\text { Dear Annie } \\
\text { by Judith } \\
\text { Caseley }\end{array}$ & Story & $\begin{array}{l}\text { Resource available for students to } \\
\text { examine. } \\
\text { Grandpa starts writing letters to Annie } \\
\text { from the day she is born. To begin with } \\
\text { her mother replies but gradually as she } \\
\text { grows up Annie takes over writing weekly } \\
\text { to her Grandpa. She takes her letters in to } \\
\text { "show and tell" at school and all the } \\
\text { children decided they would like to have } \\
\text { pen pals too. }\end{array}$ & $\begin{array}{l}\text { - Book to show the value of writing and } \\
\text { its impact on everyday life. }\end{array}$ \\
\hline 6 & $\begin{array}{l}\text { Messages in } \\
\text { the Mailbox } \\
\text { by Loreen } \\
\text { Leedy }\end{array}$ & Instructions & $\begin{array}{l}\text { Letters shown to students as samples. } \\
\text { Using an alligator as the guide, text } \\
\text { provides instructions on writing letters, } \\
\text { the format, why write letters, addressing } \\
\text { envelopes, writing postcards, invitations, }\end{array}$ & $\begin{array}{l}\text { - Follow accepted format for letter } \\
\text { writing. } \\
\text { LAFS.4.W. } 2.4 \text { - Produce clear, coherent } \\
\text { writing in that the development and } \\
\text { organization are appropriate to task. }\end{array}$ \\
\hline
\end{tabular}




\begin{tabular}{|c|c|c|c|c|}
\hline & & & $\begin{array}{l}\text { thank-you notes, get-well letters, love } \\
\text { letters, sympathy letters, notes of apology, } \\
\text { congratulations, form letters, fan letters, } \\
\text { business letter - requests, complaints, } \\
\text { protests, and letters to the editor. }\end{array}$ & $\begin{array}{l}\text { LAFS.4.W.1.3 - write narratives to } \\
\text { develop real or imagined experiences } \\
\text { using descriptive details and clear event } \\
\text { sequences }\end{array}$ \\
\hline 7 & $\begin{array}{l}\text { Dear Mr. } \\
\text { Blueberry } \\
\text { by Simon } \\
\text { James }\end{array}$ & Letters & $\begin{array}{l}\text { Resource available for students to } \\
\text { examine. } \\
\text { Letters between Emily and Mr. Blueberry } \\
\text { regarding Emily's experiences with a } \\
\text { whale. }\end{array}$ & $\begin{array}{l}\text { - Model text -examples of different kinds } \\
\text { of letters included in previous text. } \\
\text { LAFS.4.W. } 2.4 \text { - Produce clear, coherent } \\
\text { writing in that the development and } \\
\text { organization are appropriate to task. }\end{array}$ \\
\hline \multicolumn{5}{|c|}{ Books read aloud to students (whole or part) } \\
\hline 8 & $\begin{array}{l}\text { Everglades } \\
\text { National } \\
\text { Park by } \\
\text { Tom and } \\
\text { Terisa Stack }\end{array}$ & $\begin{array}{l}\text { Informational } \\
\text { picture book }\end{array}$ & $\begin{array}{l}\text { Shared in its entirety. } \\
\text { Book of photographs with captions. All } \\
\text { photographs relate to the unique } \\
\text { Everglades environment showing vistas, } \\
\text { and a variety of indigenous flora and } \\
\text { fauna. }\end{array}$ & $\begin{array}{l}\text { Switch from fiction to non-fiction, from } \\
\text { narrative to information text using } \\
\text { pictures to make the transition. } \\
\text { - LAFS.4.RI.1.1 - Refer to details and } \\
\text { examples in a text when explaining what } \\
\text { the text says explicitly and when drawing } \\
\text { inferences from the text. } \\
\text { - LAFS.4.RI.1.2 - determine main idea } \\
\text { and explain how it is supported by key } \\
\text { details, summarize the text. }\end{array}$ \\
\hline 9 & $\begin{array}{l}\text { Manatees by } \\
\text { Patricia A. } \\
\text { Fink }\end{array}$ & $\begin{array}{l}\text { Informational } \\
\text { text }\end{array}$ & $\begin{array}{l}\text { Read aloud in its entirety. } \\
\text { A book about manatees, including } \\
\text { description, habitat, food source, } \\
\text { migration, reproduction, endangerment, } \\
\text { and what can be done. }\end{array}$ & $\begin{array}{l}\text { Informational text, from a different } \\
\text { perspective, the objective outside } \\
\text { observer. } \\
\text { - SC.4.L.17.In.4 - Interdependence: A. } \\
\text { animals, including humans, interact with } \\
\text { and depend upon each other and their } \\
\text { environments to satisfy their basic needs. }\end{array}$ \\
\hline
\end{tabular}




\begin{tabular}{|c|c|c|c|c|}
\hline & & & $\begin{array}{l}\text { Sources of further information are } \\
\text { provided. }\end{array}$ & $\begin{array}{l}\text { B. human activities can have major } \\
\text { impacts on the environment } \\
\text { Brainstorm ideas for what to write about } \\
\text { and who to write to (audience) } \\
\text { Brainstorm ideas on what perspective to } \\
\text { take when writing, creating narrative or } \\
\text { informational text and following the } \\
\text { appropriate genre specific structure } \\
\text { - LAFS.4.W.2.5 -With guidance and } \\
\text { support from peers and adults, develop } \\
\text { and strengthen writing by planning } \\
\text { - LAFS.4.SL.1.1 - engage in collaborative } \\
\text { discussions building on others' ideas and } \\
\text { expressing their own clearly. B. follow } \\
\text { agreed upon rules for discussion. D. } \\
\text { review key ideas expressed and explain } \\
\text { their own and understanding in light of } \\
\text { discussion } \\
\text { - LAFS.4.RL.3.9 - compare and contrast } \\
\text { the treatment of similar themes and topics } \\
\text { - LAFS.4.RI.2.6 - compare and contrast } \\
\text { firsthand and secondhand account } \\
\text { Gain experience with science vocabulary } \\
\text { and incorporate it in written work } \\
\text { - LAFS.4.RI.2.4 - determine the meaning } \\
\text { of general academic and domain specific } \\
\text { words or phrases in a text }\end{array}$ \\
\hline \multicolumn{5}{|c|}{ Books made available to students as resources } \\
\hline 10 & $\begin{array}{l}\text { Coral Reef: } \\
\text { A DK } 24 \\
\text { hours book }\end{array}$ & Informational & $\begin{array}{l}\text { Text presenting } 24 \text { hours on a coral reef. } \\
\text { Beginning at day break - 6:00 a.m. when } \\
\text { certain fish species begin their day. It }\end{array}$ & $\begin{array}{l}\text { A resource text for use with research } \\
\text { and/or to brainstorm ideas of what to write } \\
\text { about. }\end{array}$ \\
\hline
\end{tabular}




\begin{tabular}{|c|c|c|c|c|}
\hline & $\begin{array}{l}\text { by Caroline } \\
\text { Bingham }\end{array}$ & & $\begin{array}{l}\text { progresses hour by hour addressing } \\
\text { plankton, corals, fish disguises, predators } \\
\text { and prey, parrot fish, turtles, rays, } \\
\text { cleaning fish, sharks, etc. At 4:00 p.m. the } \\
\text { books takes a peek above the water and } \\
\text { introduces, herons, lizards, crabs, bats and } \\
\text { some birds. At 5:00 p.m. it returns } \\
\text { underwater and explains sea slugs. As day } \\
\text { transitions into night the nocturnal species } \\
\text { are presented: mandarin fish, reef crabs, } \\
\text { cone shells, bigeyes and worms, sharks } \\
\text { and squid and eels. }\end{array}$ & $\begin{array}{l}\text { - LAFS.4.W.3.9 - draw evidence from } \\
\text { informational text to support research } \\
\text { - LAFS.4.W.3.7 - conduct short research } \\
\text { projects that build knowledge } \\
\text { - LAFS.4.W.3.8 - gather relevant } \\
\text { information from print and digital sources } \\
\text { - LAFS.4.W.2.5 - With guidance and } \\
\text { support from peers and adults, develop } \\
\text { and strengthen writing by planning }\end{array}$ \\
\hline 11 & $\begin{array}{l}\text { Alligators } \\
\text { and } \\
\text { Crocodiles } \\
\text { by Deborah } \\
\text { Dennard }\end{array}$ & Informational & $\begin{array}{l}\text { Describes the characteristics, habitat and } \\
\text { behavior of a variety of alligators and } \\
\text { crocodiles from around the world. } \\
\text { Alligators and crocodiles are compared } \\
\text { and contrasted for characteristics. } \\
\text { Text includes illustrations, photographs, } \\
\text { diagrams captions, and Fun Facts } \\
\text { Sources of further information are } \\
\text { provided. }\end{array}$ & $\begin{array}{l}\text { Alligators are at the top of the food chain } \\
\text { in the Everglades, although this text } \\
\text { provides information about crocodilians } \\
\text { from all over the world there is a section } \\
\text { on American alligators and specific } \\
\text { reference is made to the American } \\
\text { crocodile that is only found on the } \\
\text { southernmost tip of Florida. } \\
\text { - SC.4.L.17.Su. } 2 \text { - recognize that animals } \\
\text { eat plants and other animals for their food } \\
\text { - SC.4.L.16.In.3 - identify similarities in } \\
\text { the major stages in the life cycles of } \\
\text { common Florida animals. } \\
\text { Discuss how the structure of informational } \\
\text { text differs (compare and contrast, } \\
\text { description, cause and effect) } \\
\text { Revise written work. } \\
\text { Work on one piece of writing for a period } \\
\text { of time. }\end{array}$ \\
\hline
\end{tabular}




\begin{tabular}{|c|c|c|c|c|}
\hline & & & & $\begin{array}{l}\text { - LAFS.4.RI.2.5 - describe the overall } \\
\text { structure of events, ideas, concepts or } \\
\text { information in a text } \\
\text { - LAFS.4.W.1.1 - write opinion pieces on } \\
\text { topics of texts, supporting point of view } \\
\text { with reasons and information } \\
\text { - LAFS.4.W.1.2 - write informational text } \\
\text { to examine a topic and convey ideas or } \\
\text { information. A. introduce a topic clearly, } \\
\text { group related information in paragraphs. } \\
\text { B. develop the topic with facts, definitions } \\
\text { and concrete details. D. use precise } \\
\text { language and domain specific vocabulary } \\
\text { Gain experience with science vocabulary } \\
\text { and incorporate it in written work } \\
\text { - LAFS.4.RI.2.4 - determine the meaning } \\
\text { of general academic and domain specific } \\
\text { words or phrases in a text }\end{array}$ \\
\hline 12 & $\begin{array}{l}\text { Turtles by } \\
\text { Deborah } \\
\text { Dennard }\end{array}$ & Informational & $\begin{array}{l}\text { Describes the characteristics, habitat and } \\
\text { behavior of a variety of turtles from } \\
\text { around the world. } \\
\text { Text includes illustrations, photographs, } \\
\text { diagrams captions, and Fun Facts } \\
\text { Sources of further information are } \\
\text { provided. }\end{array}$ & $\begin{array}{l}\text { Identify the major characteristics of } \\
\text { turtles. Compare and contrast adaptations } \\
\text { of turtles depending on their habitat. } \\
\text { - SC.4L.16.Su. } 2 \text { - recognize behaviors of } \\
\text { common animals } \\
\text { - SC.4.L.16.In. } 3 \text { - identify the similarities } \\
\text { in the major stages in the life cycles of } \\
\text { common Florida animals } \\
\text { Plan, revise and edit written work } \\
\text { - LAFS.4.W.1.2 - Write } \\
\text { information/explanatory text to examine a } \\
\text { topic and convey ideas and information } \\
\text { clearly. }\end{array}$ \\
\hline
\end{tabular}




\begin{tabular}{|c|c|c|c|c|}
\hline & & & & $\begin{array}{l}\text { - LAFS.4.W.2.5 - With guidance and } \\
\text { support from peers and adults, develop } \\
\text { and strengthen writing by planning, } \\
\text { revising and editing }\end{array}$ \\
\hline 13 & $\begin{array}{l}\text { Iguanas as a } \\
\text { Hobby by } \\
\text { Shelly K. } \\
\text { Ferrel }\end{array}$ & Informational & $\begin{array}{l}\text { Description of iguanas, where they come } \\
\text { from, and how to keep them in captivity. } \\
\text { This text was provided at the specific } \\
\text { request of one student who wanted to } \\
\text { know more about lizards. }\end{array}$ & $\begin{array}{l}\text { Iguanas are a non-native species that has } \\
\text { been popular as a pet in Florida } \\
\text { - SC.4L.16.Su. } 2 \text { - recognize behaviors of } \\
\text { common animals } \\
\text { Plan, revise and edit written work } \\
\text { - LAFS.4.W.1.2 - Write } \\
\text { information/explanatory text to examine a } \\
\text { topic and convey ideas and information } \\
\text { clearly. } \\
\text { - LAFS.4.W. } 2.5 \text { - With guidance and } \\
\text { support from peers and adults, develop } \\
\text { and strengthen writing by planning, } \\
\text { revising and editing }\end{array}$ \\
\hline 14 & $\begin{array}{l}\text { Florida's } \\
\text { Fabulous } \\
\text { Mammals } \\
\text { by Jerry L. } \\
\text { Gingerich }\end{array}$ & Informational & $\begin{array}{l}\text { Text covers animals with pouches, } \\
\text { armored animals, insect eaters, flying } \\
\text { mammals, rodents, rabbits, meat-eaters } \\
\text { (cats, dogs and others) hooved animals, } \\
\text { marine mammals and other exotic species. }\end{array}$ & $\begin{array}{l}\text { A resource text for use with research } \\
\text { and/or to brainstorm ideas of what to write } \\
\text { about. } \\
\text { - LAFS.4.W.3.9 - draw evidence from } \\
\text { informational text to support research } \\
\text { - LAFS.4.W.3.7 - conduct short research } \\
\text { projects that build knowledge } \\
\text { - LAFS.4.W.3.8 - gather relevant } \\
\text { information from print and digital sources } \\
\text { - LAFS.4.W.2.5 - With guidance and } \\
\text { support from peers and adults, develop } \\
\text { and strengthen writing by planning }\end{array}$ \\
\hline 15 & $\begin{array}{l}\text { Spoonbill } \\
\text { Swamp }\end{array}$ & Informational & $\begin{array}{l}\text { Compares and contrasts how the spoonbill } \\
\text { and alligator solves the problem (problem }\end{array}$ & $\begin{array}{l}\text { Discuss how two different animals take } \\
\text { care of their young. }\end{array}$ \\
\hline
\end{tabular}




\begin{tabular}{|c|c|c|c|c|}
\hline & $\begin{array}{l}\text { By Brenda } \\
\text { Z. } \\
\text { Gulberson }\end{array}$ & & $\begin{array}{l}\text { and solution) of how to feed their babies } \\
\text { during the course of a single day. }\end{array}$ & $\begin{array}{l}\text { - SC.4.L.16.Su. } 2 \text { - recognize the } \\
\text { behaviors of common animals } \\
\text { - SC.4.L.16.Pa.3 - match offspring of } \\
\text { animals with parents } \\
\text { - SC.4.L.17.in. } 2 \text { - recognize that animals } \\
\text { must eat plants or other animals to survive } \\
\text { Examine two styles of informational } \\
\text { writing (compare and contrast; problem } \\
\text { and solution) identify relevant academic } \\
\text { words that indicate a genre } \\
\text { - LAFS.4.RI.2.5 - describe the overall } \\
\text { structure of events, ideas, concepts or } \\
\text { information in a text } \\
\text { - LAFS.4.RI.1.1 - refer to details and } \\
\text { examples in text when explaining what } \\
\text { the text says } \\
\text { - LAFS.4.RI.1.2 - determine the main } \\
\text { idea of a text and explain how it is support } \\
\text { by key details }\end{array}$ \\
\hline 16 & $\begin{array}{l}\text { Little Skin's } \\
\text { Tail by } \\
\text { Janet } \\
\text { Halfmann }\end{array}$ & $\begin{array}{l}\text { Fact-based } \\
\text { fiction }\end{array}$ & $\begin{array}{l}\text { The little skink lost her tail to a hungry } \\
\text { crow, while it grows back she imagines } \\
\text { what it would be like to have the tail of a } \\
\text { variety of other animals. } \\
\text { The book includes activities relating to the } \\
\text { different features of a variety of animals, } \\
\text { footprints and tails. There is also a math } \\
\text { activity involving "over and up" location. }\end{array}$ & $\begin{array}{l}\text { Animals have physical characteristics that } \\
\text { adapt them for their own protection and } \\
\text { animals eat each other to survive } \\
\text { - SC.4.L.17.Su. } 2 \text { - recognize that animals } \\
\text { eat other animals for their food } \\
\text { Identify a main idea and its supporting } \\
\text { details } \\
\text { - LAFS.4.RI.1.2 - Determine the main } \\
\text { idea of text and explain how it is } \\
\text { supported by key details }\end{array}$ \\
\hline
\end{tabular}




\begin{tabular}{|c|c|c|c|c|}
\hline & & & & $\begin{array}{l}\text { Revise written work in collaboration with } \\
\text { peers in small groups and one-to-one } \\
\text { conferences } \\
\text { - LAFS.4.W.2.5 -With guidance and } \\
\text { support from peers and adults, develop } \\
\text { and strengthen writing by revising } \\
\text { - LAFS.4.SL.1.1 - engage in collaborative } \\
\text { discussions building on others' ideas and } \\
\text { expressing their own clearly. B. follow } \\
\text { agreed upon rules for discussion. D. } \\
\text { review key ideas expressed and explain } \\
\text { their own and understanding in light of } \\
\text { discussion }\end{array}$ \\
\hline 17 & $\begin{array}{l}\text { Sam the Sea } \\
\text { Cow by } \\
\text { Francine } \\
\text { Jacobs }\end{array}$ & $\begin{array}{l}\text { Fact-based } \\
\text { fiction }\end{array}$ & $\begin{array}{l}\text { A chapter story about manatees told from } \\
\text { the perspective of Sam. The story opens } \\
\text { with Sam as a new-born calf. It identifies } \\
\text { the role his mother plays in his survival. It } \\
\text { identifies his characteristics as a mammal. } \\
\text { He is hit by the propeller of a boat but } \\
\text { heals. He gets trapped in a drain and has } \\
\text { to be rescued. He is transported to } \\
\text { Seaquarium where he recovers from his } \\
\text { injuries. He does not adapt to life in } \\
\text { captivity so, after a time, he is returned to } \\
\text { the river where he meets other manatees } \\
\text { and resumes his life in his natural habitat. } \\
\text { The book is based on a true story and } \\
\text { closes with facts about manatees. } \\
\text { Resources for further research are } \\
\text { provided. }\end{array}$ & $\begin{array}{l}\text { Introduce the students to another } \\
\text { endangered Florida animal. A text } \\
\text { offering a transition between fiction and } \\
\text { fact. } \\
\text { - SC.4.L.17.In.4 - Interdependence: A. } \\
\text { animals, including humans, interact with } \\
\text { and depend upon each other and their } \\
\text { environments to satisfy their basic needs. } \\
\text { B. human activities can have major } \\
\text { impacts on the environment } \\
\text { Brainstorm ideas for what to write about } \\
\text { and who to write to (audience) } \\
\text { - LAFS.4.W.2.5 -With guidance and } \\
\text { support from peers and adults, develop } \\
\text { and strengthen writing by planning } \\
\text { - LAFS.4.SL.1.1 - engage in collaborative } \\
\text { discussions building on others' ideas and } \\
\text { expressing their own clearly. B. follow }\end{array}$ \\
\hline
\end{tabular}




\begin{tabular}{|c|c|c|c|c|}
\hline & & & & $\begin{array}{l}\text { agreed upon rules for discussion. D. } \\
\text { review key ideas expressed and explain } \\
\text { their own and understanding in light of } \\
\text { discussion }\end{array}$ \\
\hline 18 & $\begin{array}{l}\text { Alligators: } \\
\text { Life in the } \\
\text { Wild by } \\
\text { Monica } \\
\text { Kulling }\end{array}$ & Informational & $\begin{array}{l}\text { This book opens with an alligator catching } \\
\text { a heron. It covers the history of alligators, } \\
\text { where they are found, feeding habits, } \\
\text { habitat, reproduction, care of young, } \\
\text { habitat and its destruction. }\end{array}$ & $\begin{array}{l}\text { A third grade reading level (for struggling } \\
\text { readers) text providing basic information } \\
\text { about an animal success story (alligators } \\
\text { were on the endangered list but are now } \\
\text { becoming more prolific). } \\
\text { - SC.4.L.17.In.4 - B. human activities can } \\
\text { have major impacts on the environment } \\
\text { - SC.4.L.17.Su.2 - recognize that animals } \\
\text { eat other animals for their food } \\
\text { Brainstorm ideas for what to write about } \\
\text { and who to write to (audience) } \\
\text { - LAFS.4.W.2.5 -With guidance and } \\
\text { support from peers and adults, develop } \\
\text { and strengthen writing by planning } \\
\text { - LAFS.4.SL.1.1 - engage in collaborative } \\
\text { discussions building on others' ideas and } \\
\text { expressing their own clearly. B. follow } \\
\text { agreed upon rules for discussion. D. } \\
\text { review key ideas expressed and explain } \\
\text { their own and understanding in light of } \\
\text { discussion }\end{array}$ \\
\hline 19 & $\begin{array}{l}\text { Henry the } \\
\text { Impatient } \\
\text { Heron by } \\
\text { Donna Love }\end{array}$ & $\begin{array}{l}\text { Fact-based } \\
\text { fiction }\end{array}$ & $\begin{array}{l}\text { Henry the heron couldn't stand still. He } \\
\text { was always moving, and it drove everyone } \\
\text { crazy. All herons have to stand still to } \\
\text { catch their food, so how would Henry } \\
\text { ever be able to eat on his own? When he } \\
\text { became distracted he flew off to satisfy }\end{array}$ & $\begin{array}{l}\text { The heron needs to stand still to catch its } \\
\text { prey. It hunts a variety of other animals } \\
\text { for its food. } \\
\text { - SC.4.L.17.In. } 2 \text { - recognize that animals } \\
\text { cannot make their own food and they must } \\
\text { eat other animals to survive }\end{array}$ \\
\hline
\end{tabular}




\begin{tabular}{|c|c|c|c|c|}
\hline & & & $\begin{array}{l}\text { his curiosity. In the process he was } \\
\text { separated from his mother and had to be } \\
\text { independent. He attempted to catch a } \\
\text { variety of prey animals but was } \\
\text { unsuccessful. He met a Great Blue Heron } \\
\text { and as given good advice about standing } \\
\text { still. He put it into practice and caught his } \\
\text { first meal. } \\
\text { The book offers a range of activities } \\
\text { including Great Blue Heron facts, the } \\
\text { hunting traits of herons, facts about } \\
\text { wetlands, and heron life cycle. }\end{array}$ & $\begin{array}{l}\text { Revision and editing are essential to } \\
\text { producing a quality writing product. } \\
\text { - LAFS. } 4 \text {. W. } 2.5 \text { - With guidance and } \\
\text { support from peers and adults develop and } \\
\text { strengthen writing by planning and } \\
\text { editing. }\end{array}$ \\
\hline 20 & $\begin{array}{l}\text { Dolphin by } \\
\text { Robert A. } \\
\text { Morris }\end{array}$ & Informational & $\begin{array}{l}\text { The book opens with the birth of a calf, } \\
\text { and continues with facts about dolphins. } \\
\text { The dolphins come into contact with a } \\
\text { ship, sharks, whales, a school of mackerel } \\
\text { and closes with how dolphins work } \\
\text { together to deal with predators. }\end{array}$ & $\begin{array}{l}\text { Brainstorm ideas for what to write about } \\
\text { and who to write to (audience) } \\
\text { - LAFS.4.W.2.5 -With guidance and } \\
\text { support from peers and adults, develop } \\
\text { and strengthen writing by planning } \\
\text { - LAFS.4.SL.1.1 - engage in collaborative } \\
\text { discussions building on others' ideas and } \\
\text { expressing their own clearly. B. follow } \\
\text { agreed upon rules for discussion. D. } \\
\text { review key ideas expressed and explain } \\
\text { their own and understanding in light of } \\
\text { discussion }\end{array}$ \\
\hline 21 & $\begin{array}{l}\text { Leroy the } \\
\text { Lobster by } \\
\text { Katherine } \\
\text { Orr }\end{array}$ & $\begin{array}{l}\text { Fact-based } \\
\text { fiction }\end{array}$ & $\begin{array}{l}\text { Leroy, a lobster, tells his life story from } \\
\text { birth to reproduction, including predators } \\
\text { prey, moulting, etc. }\end{array}$ & $\begin{array}{l}\text { Life cycle of lobster } \\
\text { - SC.4.L.16 - a. offspring of pants and } \\
\text { animals are similar to, but not exactly like, } \\
\text { their parents or each other; b. life cycles } \\
\text { vary among organisms, but reproduction }\end{array}$ \\
\hline
\end{tabular}




\begin{tabular}{|c|c|c|c|c|}
\hline & & & & $\begin{array}{l}\text { is a major stage in the life cycle of all } \\
\text { organisms } \\
\text { A resource text for use with research } \\
\text { and/or to brainstorm ideas of what to write } \\
\text { about. } \\
\text { - LAFS.4.W.3.9 - draw evidence from } \\
\text { informational text to support research }\end{array}$ \\
\hline 22 & $\begin{array}{l}\text { Shelley by } \\
\text { Katherine } \\
\text { Orr }\end{array}$ & Informational & Text follows the life cycle of a conch & $\begin{array}{l}\text { Life cycle of conch } \\
\text { - SC.4.L.16-a. offspring of pants and } \\
\text { animals are similar to, but not exactly like, } \\
\text { their parents or each other; b. life cycles } \\
\text { vary among organisms, but reproduction } \\
\text { is a major stage in the life cycle of all } \\
\text { organisms } \\
\text { A resource text for use with research } \\
\text { and/or to brainstorm ideas of what to write } \\
\text { about. } \\
\text { - LAFS.4.W.3.9- draw evidence from } \\
\text { informational text to support research }\end{array}$ \\
\hline 23 & $\begin{array}{l}\text { An } \\
\text { Adventure } \\
\text { with Oscar } \\
\text { the Otter by } \\
\text { Maurice } \\
\text { Pledger }\end{array}$ & $\begin{array}{l}\text { Fact-based } \\
\text { fiction }\end{array}$ & $\begin{array}{l}\text { Oscar the Otter searches through his } \\
\text { environment to find a gold fish. Along } \\
\text { the way he meets many other animals } \\
\text { found in his environment, a newt, a water } \\
\text { vole, a kingfisher, a beaver, a salmon, a } \\
\text { turtle, and finally a gold fish. } \\
\text { This is a pop-up book designed to whet } \\
\text { the appetite of a young reader. }\end{array}$ & $\begin{array}{l}\text { Plan, revise and edit written work } \\
\text { - LAFS.4.W. } 2.5 \text { - with the support of } \\
\text { peers and adults develop written texts by } \\
\text { planning } \\
\text { - LAFS.4.W.3.7 - conduct short research } \\
\text { projects that build knowledge through } \\
\text { investigation of different aspects of a } \\
\text { topic } \\
\text { - LAFS .4.W. gather relevant information } \\
\text { from print and digital sources; take notes } \\
\text { and categorize information and provide a } \\
\text { list of sources }\end{array}$ \\
\hline
\end{tabular}




\begin{tabular}{|c|c|c|c|c|}
\hline & & & $\begin{array}{l}\text { It was included at the express request of a } \\
\text { student, who went on to conduct online } \\
\text { research into otters in the Everglades. }\end{array}$ & \\
\hline 24 & $\begin{array}{l}\text { One Small } \\
\text { Square: } \\
\text { Coral Reef } \\
\text { by Donald } \\
\text { M. silver }\end{array}$ & Informational & $\begin{array}{l}\text { Description of coral reef conditions. The } \\
\text { text describes the flora and fauna of the } \\
\text { coral reef. It presents reefs in squares } \\
\text { (cubes) identifying what might be seen by } \\
\text { day and by night. The Great Barrier Reef } \\
\text { of Australia is included but the second } \\
\text { largest reef in the world is found just off } \\
\text { the coast of Florida. Reproduction of fish } \\
\text { and coral polyps is explained; it a seasonal } \\
\text { activity. } \\
\text { Text includes illustrations, diagrams, } \\
\text { maps, captions and asides. } \\
\text { Activities are provided in the form of mix } \\
\text { and match outlines of the various plants } \\
\text { and animals. } \\
\text { Sources of further information are } \\
\text { provided }\end{array}$ & $\begin{array}{l}\text { Seasonal nature of coral polyp } \\
\text { reproduction. } \\
\text { - SC.4.L.17.In.1 identify seasonal changes } \\
\text { in Florida plants and animals } \\
\text { - SC.4.L.17.Su.2 - recognize that animals } \\
\text { eat plants and other animals for their food } \\
\text { Recognize different genres within } \\
\text { informational text - compare and contrast, } \\
\text { cause and effect } \\
\text { Select topics to employ one of the } \\
\text { explored writing genres, conduct research } \\
\text { to support written product } \\
\text { - LAFS.4.RI.2.5 - describe the overall } \\
\text { structure of events, etc. } \\
\text { - LAFS.4.W.3.9 - draw evidence from } \\
\text { informational text to support research } \\
\text { - LAFS.4.W.3.7 - conduct short research } \\
\text { projects that build knowledge } \\
\text { - LAFS.4.W.3.8 - gather relevant } \\
\text { information from print and digital sources }\end{array}$ \\
\hline 25 & $\begin{array}{l}\text { One Small } \\
\text { Square: } \\
\text { Swamp } \\
\text { By Donald } \\
\text { M. Silver }\end{array}$ & Informational & $\begin{array}{l}\text { Description of swamp conditions. The } \\
\text { introduction provides the historical } \\
\text { background to the modern-day swamp. } \\
\text { The text describes the flora and fauna of } \\
\text { the swamp. It presents swamps in squares } \\
\text { (cubes) identifying what might be seen } \\
\text { above and below the water level. Cyprus } \\
\text { and mangrove swamps are included - }\end{array}$ & $\begin{array}{l}\text { Informational text covering a plethora of } \\
\text { plants and animals and including life } \\
\text { cycles, ecosystems, endangerment, } \\
\text { reproduction and predation. } \\
\text { - SC.4.L.16 - a. offspring of pants and } \\
\text { animals are similar to, but not exactly like, } \\
\text { their parents or each other; b. life cycles } \\
\text { vary among organisms, but reproduction }\end{array}$ \\
\hline
\end{tabular}




\begin{tabular}{|c|c|c|c|c|}
\hline & & & $\begin{array}{l}\text { both of that form part of the Everglades } \\
\text { ecosystem. } \\
\text { Activities are provided in the form of mix } \\
\text { and match outlines of the various plants } \\
\text { and animals. } \\
\text { Sources of further information are } \\
\text { provided. }\end{array}$ & $\begin{array}{l}\text { is a major stage in the life cycle of all } \\
\text { organisms } \\
\text { Brainstorm what aspects of the Everglades } \\
\text { (Florida) might be of interest to study } \\
\text { further and write about. Potential } \\
\text { audiences for written products. } \\
\text { - LAFS.4.W.2.5 - with the support of } \\
\text { peers and adults develop written texts by } \\
\text { planning } \\
\text { - LAFS.4.W.3.7 - conduct short research } \\
\text { projects that build knowledge through } \\
\text { investigation of different aspects of a } \\
\text { topic } \\
\text { - LAFS .4.W. gather relevant information } \\
\text { from print and digital sources; take notes } \\
\text { and categorize information and provide a } \\
\text { list of sources }\end{array}$ \\
\hline 26 & $\begin{array}{l}\text { Izzie Lizzie } \\
\text { Alligator by } \\
\text { Suzanne } \\
\text { Tate }\end{array}$ & $\begin{array}{l}\text { Fact-based } \\
\text { fiction }\end{array}$ & $\begin{array}{l}\text { Izzie Lizzie is a female alligator. The text } \\
\text { describes her and then transitions to her } \\
\text { laying eggs and their hatching. Too few } \\
\text { of her clutch hatch and she wonders what } \\
\text { the problem is. She expresses her need of } \\
\text { "HELPFUL HUMANS." The text then } \\
\text { addresses what animals prey upon young } \\
\text { alligators and her need for food. The } \\
\text { humans discover the soft shelled eggs and } \\
\text { identify a chemical spill as the cause. The } \\
\text { text returns to the alligator and her care of } \\
\text { her young. It follows the cycle to the next } \\
\text { year and her meeting with a bull alligator. }\end{array}$ & $\begin{array}{l}\text { Informational text covering reproduction, } \\
\text { ecosystems, endangerment, and predation } \\
\text { - SC.4.L.16 - a. offspring of pants and } \\
\text { animals are similar to, but not exactly like, } \\
\text { their parents or each other; b. life cycles } \\
\text { vary among organisms, but reproduction } \\
\text { is a major stage in the life cycle of all } \\
\text { organisms } \\
\text { - SC.4.L.17.Su. } 2 \text { - recognize that animals } \\
\text { eat plants and other animals for their food } \\
\text { - SC.4.L.17.In.4 - B. human activities can } \\
\text { have major impacts on the environment } \\
\text { Plan, develop, revise, edit written work }\end{array}$ \\
\hline
\end{tabular}




\begin{tabular}{|c|c|c|c|c|}
\hline & & & & $\begin{array}{l}\text { - LAFS. } 4 . \text { W. } 2.5 \text { - with the support of } \\
\text { peers and adults develop written texts by } \\
\text { planning } \\
\text { - LAFS.4.W.3.7 - conduct short research } \\
\text { projects that build knowledge through } \\
\text { investigation of different aspects of a } \\
\text { topic }\end{array}$ \\
\hline 27 & $\begin{array}{l}\text { Oozey } \\
\text { Octopus: A } \\
\text { Tale of a } \\
\text { Clever } \\
\text { Critter by } \\
\text { Suzanne } \\
\text { Tate }\end{array}$ & $\begin{array}{l}\text { Fact-based } \\
\text { fiction }\end{array}$ & $\begin{array}{l}\text { The text provides a description of the } \\
\text { octopus, its prey and defense against } \\
\text { predators, its habitat and the role of } \\
\text { humans. }\end{array}$ & $\begin{array}{l}\text { Informational text covering reproduction, } \\
\text { ecosystems, endangerment, and predation } \\
\text { - SC.4.L.16 - a. offspring of pants and } \\
\text { animals are similar to, but not exactly like, } \\
\text { their parents or each other; b. life cycles } \\
\text { vary among organisms, but reproduction } \\
\text { is a major stage in the life cycle of all } \\
\text { organisms } \\
\text { - SC.4.L.17.Su. } 2 \text { - recognize that animals } \\
\text { eat plants and other animals for their food } \\
\text { - SC.4.L.17.In.4 - B. human activities can } \\
\text { have major impacts on the environment } \\
\text { Plan, develop, revise, edit written work } \\
\text { - LAFS.4.W.2.5 - with the support of } \\
\text { peers and adults develop written texts by } \\
\text { planning } \\
\text { - LAFS.4.W.3.7 - conduct short research } \\
\text { projects that build knowledge through } \\
\text { investigation of different aspects of a } \\
\text { topic }\end{array}$ \\
\hline 28 & $\begin{array}{l}\text { Perky } \\
\text { Pelican by } \\
\text { Suzanne } \\
\text { Tate }\end{array}$ & $\begin{array}{l}\text { Fact-based } \\
\text { fiction }\end{array}$ & $\begin{array}{l}\text { The text provides a description of the } \\
\text { pelican, its prey and defense against } \\
\text { predators, its habitat and the role of } \\
\text { humans. }\end{array}$ & $\begin{array}{l}\text { Informational text covering reproduction, } \\
\text { ecosystems, endangerment, and predation } \\
\text { - SC.4.L.16 - a. offspring of pants and } \\
\text { animals are similar to, but not exactly like, }\end{array}$ \\
\hline
\end{tabular}




\begin{tabular}{|c|c|c|c|c|}
\hline & & & & $\begin{array}{l}\text { their parents or each other; b. life cycles } \\
\text { vary among organisms, but reproduction } \\
\text { is a major stage in the life cycle of all } \\
\text { organisms } \\
\text { - SC.4.L.17.Su. } 2 \text { - recognize that animals } \\
\text { eat plants and other animals for their food } \\
\text { - SC.4.L.17.In.4 - B. human activities can } \\
\text { have major impacts on the environment } \\
\text { Plan, develop, revise, edit written work } \\
\text { - LAFS.4.W.2.5 - with the support of } \\
\text { peers and adults develop written texts by } \\
\text { planning } \\
\text { - LAFS.4.W.3.7 - conduct short research } \\
\text { projects that build knowledge through } \\
\text { investigation of different aspects of a } \\
\text { topic }\end{array}$ \\
\hline 29 & $\begin{array}{l}\text { Bottlenose } \\
\text { Dolphins by } \\
\text { Paul } \\
\text { Thompson } \\
\text { \& Ben } \\
\text { Wilson }\end{array}$ & Informational & $\begin{array}{l}\text { This is a sophisticated text that first } \\
\text { introduces the dolphin and goes on to } \\
\text { discuss their place as a mammal of the } \\
\text { sea. The search for food and life } \\
\text { threatening situations are covered. } \\
\text { Dolphin conservation and the politics } \\
\text { surrounding it are addressed as how the } \\
\text { reader can get involved. The book closes } \\
\text { with basic facts about dolphins. } \\
\text { Sources for further research are provided. }\end{array}$ & $\begin{array}{l}\text { A middle school level text providing good } \\
\text { research into dolphins } \\
\text { - SC.4.L.17.In.4 - Interdependence: A. } \\
\text { animals, including humans, interact with } \\
\text { and depend upon each other and their } \\
\text { environments to satisfy their basic needs. } \\
\text { B. human activities can have major } \\
\text { impacts on the environment } \\
\text { Brainstorm ideas for what to write about } \\
\text { and who to write to (audience) } \\
\text { - LAFS.4.W.2.5 - With guidance and } \\
\text { support from peers and adults, develop } \\
\text { and strengthen writing by planning } \\
\text { - LAFS.4.SL.1.1 - engage in collaborative } \\
\text { discussions building on others' ideas and }\end{array}$ \\
\hline
\end{tabular}




\begin{tabular}{|c|c|c|c|c|}
\hline & & & & $\begin{array}{l}\text { expressing their own clearly. B. follow } \\
\text { agreed upon rules for discussion. D. } \\
\text { review key ideas expressed and explain } \\
\text { their own and understanding in light of } \\
\text { discussion }\end{array}$ \\
\hline 30 & $\begin{array}{l}\text { Hiding in } \\
\text { the Sea by } \\
\text { Mary } \\
\text { Velsco }\end{array}$ & Informational & $\begin{array}{l}\text { Brief descriptions of a variety of sea } \\
\text { creatures and how they camouflage } \\
\text { themselves - squid, red fish, stone fish, } \\
\text { crabs, sea urchins, etc. }\end{array}$ & $\begin{array}{l}\text { A } 2^{\text {nd }} \text { grade text included to provide a } \\
\text { starting point for further research } \\
\text { Brainstorming } \\
\text { - LAFS.4.W.3.7 - conduct short research } \\
\text { projects that build knowledge through } \\
\text { investigation of different aspects of a } \\
\text { topic }\end{array}$ \\
\hline 31 & $\begin{array}{l}\text { Florida's } \\
\text { Fabulous } \\
\text { Flowers by } \\
\text { Winston } \\
\text { Williams }\end{array}$ & Informational & $\begin{array}{l}\text { Text covers flowering vines, flowering } \\
\text { plants, foliage plants, succulent plants, } \\
\text { beach plants, gingers, heliconias, } \\
\text { bromeliads, ferns, bulbous plants and } \\
\text { collectors specialty plants }\end{array}$ & $\begin{array}{l}\text { A middle school level text. A resource } \\
\text { text for use with research and/or to } \\
\text { brainstorm ideas of what to write about. } \\
\text { - LAFS.4.W.3.9 - draw evidence from } \\
\text { informational text to support research } \\
\text { - LAFS.4.W.3.7 - conduct short research } \\
\text { projects that build knowledge } \\
\text { - LAFS.4.W.3.8 - gather relevant } \\
\text { information from print and digital sources } \\
\text { - LAFS.4.W.2.5 -With guidance and } \\
\text { support from peers and adults, develop } \\
\text { and strengthen writing by planning }\end{array}$ \\
\hline 32 & $\begin{array}{l}\text { Florida's } \\
\text { Fabulous } \\
\text { Waterbirds } \\
\text { by Winston } \\
\text { Williams }\end{array}$ & Informational & $\begin{array}{l}\text { A text taking individual species of water } \\
\text { birds and providing between one and four } \\
\text { pages of information including - anhinga, } \\
\text { cormorants, egrets, flamingos, gulls, } \\
\text { gallinules, herons (many varieties) osprey, } \\
\text { pelicans, etc. }\end{array}$ & $\begin{array}{l}\text { A middle school level text. A resource } \\
\text { text for use with research and/or to } \\
\text { brainstorm ideas of what to write about. } \\
\text { - LAFS.4.W.3.9 - draw evidence from } \\
\text { informational text to support research } \\
\text { - LAFS.4.W.3.7 - conduct short research } \\
\text { projects that build knowledge }\end{array}$ \\
\hline
\end{tabular}




\begin{tabular}{|c|c|c|c|c|}
\hline & & & & $\begin{array}{l}\text { - LAFS.4.W.3.8 - gather relevant } \\
\text { information from print and digital sources } \\
\text { - LAFS.4.W.2.5 -With guidance and } \\
\text { support from peers and adults, develop } \\
\text { and strengthen writing by planning }\end{array}$ \\
\hline 33 & $\begin{array}{l}\text { Felina's } \\
\text { New Home } \\
\text { by Loran } \\
\text { Wlodarski }\end{array}$ & $\begin{array}{l}\text { Fact-based } \\
\text { fiction }\end{array}$ & $\begin{array}{l}\text { Felina the Florida panther loved growing } \\
\text { up in her Everglades home until she } \\
\text { realized that her environment was } \\
\text { beginning to shrink. She and the other } \\
\text { animals are affected by human impact on } \\
\text { their environment. After Felina becomes } \\
\text { ill she is caught by humans, healed and } \\
\text { returned to the wild. } \\
\text { The book offers activities for children } \\
\text { relating to the Florida panther life cycle, } \\
\text { endangered and threatened animals and } \\
\text { other native species facts. }\end{array}$ & $\begin{array}{l}\text { Mix of fact and fiction to engage the } \\
\text { students' interest in the Everglades } \\
\text { wildlife, particularly the endangered } \\
\text { Florida panther, and the ways human } \\
\text { activities have an effect. Told from the } \\
\text { perspective of the panther. } \\
\text { - SC.4.L.17.In.4 - Interdependence: A. } \\
\text { animals, including humans, interact with } \\
\text { and depend upon each other and their } \\
\text { environments to satisfy their basic needs. } \\
\text { B. human activities can have major } \\
\text { impacts on the environment } \\
\text { Brainstorm ideas for what to write about } \\
\text { and who to write to (audience) } \\
\text { - LAFS.4.W.2.5 - With guidance and } \\
\text { support from peers and adults, develop } \\
\text { and strengthen writing by planning } \\
\text { LAFS.4.SL.1.1 - engage in collaborative } \\
\text { discussions building on others' ideas and } \\
\text { expressing their own clearly. B. follow } \\
\text { agreed upon rules for discussion. D. } \\
\text { review key ideas expressed and explain } \\
\text { their own and understanding in light of } \\
\text { discussion }\end{array}$ \\
\hline
\end{tabular}




\section{APPENDIX I \\ Writing Log \\ At Home Writers' Group Writing Log}

Dear Parents,

Please feel free to work with your child as he/she completes the activities. Make sure that your child spends $\mathbf{3 0}$ minutes $\mathbf{3}$ times a week. The time can be broken up into more sessions if necessary, so the child does not become over-tired. It is not necessary for your child to complete all the enclosed activities just to work for at least an hour and a half during the week. If there is an activity that your child would like to save until next week please keep it for the next folder.

Ask your child to complete the log below and please initial that the work has been done and that the time recorded is accurate.

Thank you for your help.

\begin{tabular}{|l|l|l|l|l|l|}
\hline Date & Activity Selected & Started & Finished & $\begin{array}{l}\text { Total } \\
\text { Time }\end{array}$ & $\begin{array}{l}\text { Parent } \\
\text { Initials }\end{array}$ \\
\hline & & & & & \\
\hline & & & & & \\
\hline & & & & & \\
\hline & & & & & \\
\hline & & & & & \\
\hline & & & & & \\
\hline & & & & & \\
\hline & & & & & \\
\hline & & & & & \\
\hline & & & & & \\
\hline & & & & & \\
\hline
\end{tabular}

\section{Parent Signature}

Date: 
APPENDIX J

Weekly Writing Activities Developed by the Researcher Week 1

\section{Dr. Martin Luther King Jr.}

Include his date of birth, where he was born, who his parents were and what they did, add some information about his family. Where did he go to school or college? What did he do? Was he married? Did he have any children? What were his achievements? When did he die? 


\section{ME}

If I could choose one word to describe myself, it would be

Pick one word to describe yourself. It can be any word - it does not have to be a descriptive word, it can be a noun or verb. Write it down in the space above. Then explain why you chose that word.

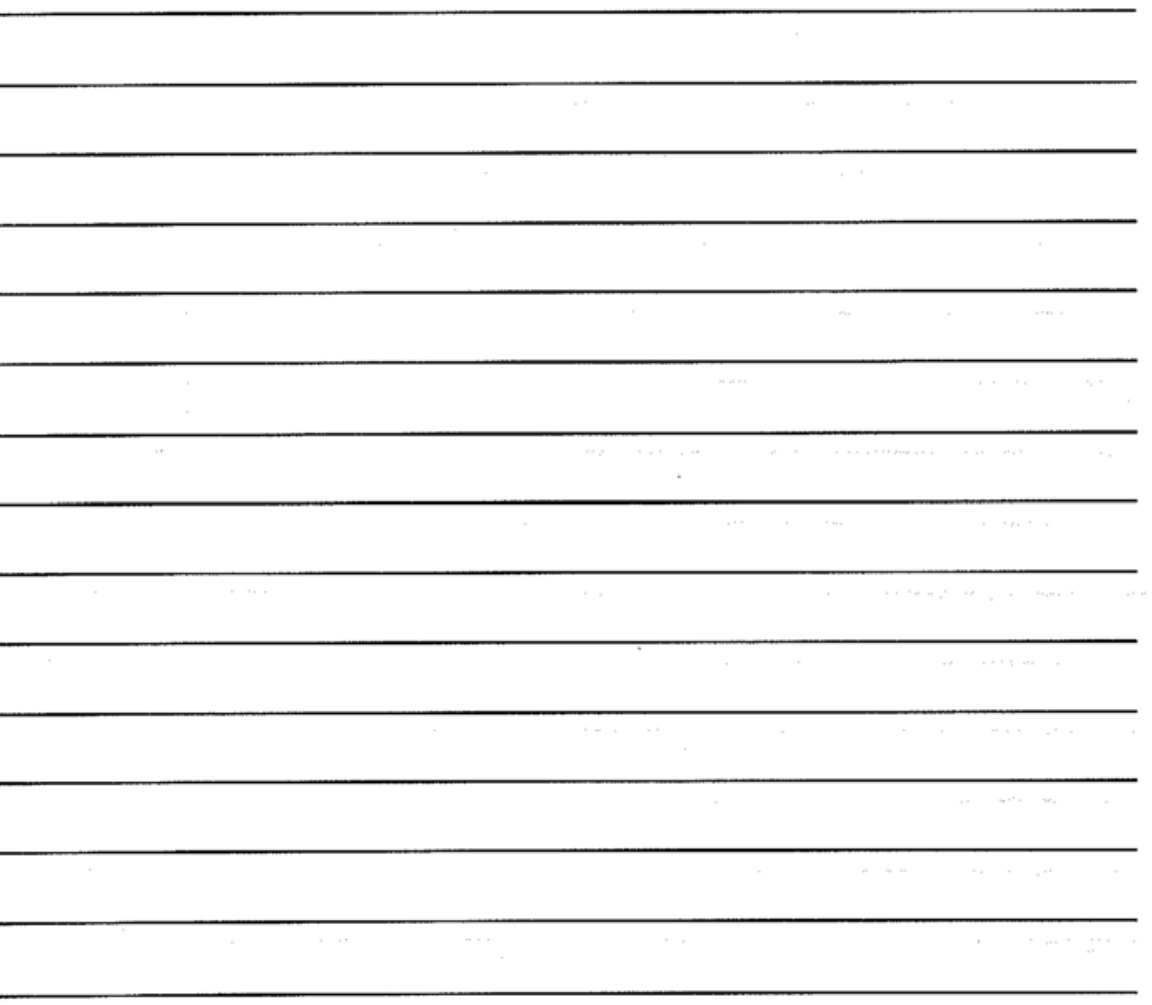




\section{FREE CHOICE}

Write about anything that you like. Choose your own topic and share your thoughts. 
Week 2

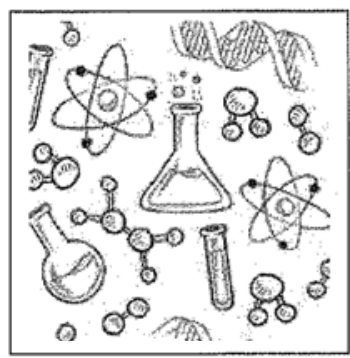

Imagine you are a scientist and you have created a new potion. Write about what your potion does. Describe its powers and how you can use it to help the world.

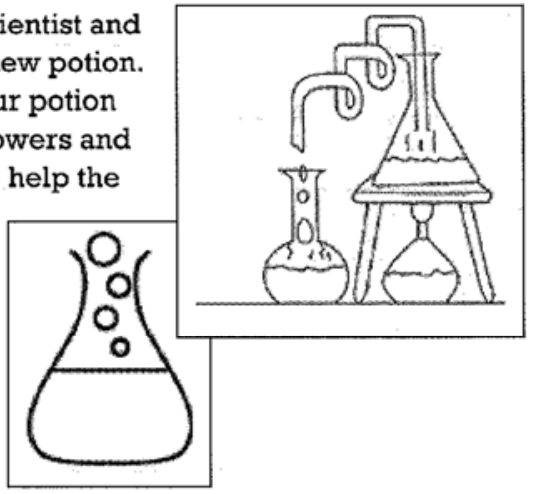




\section{Compare and Contrast}

An alligator

A panda

A piranha

A zebra

A cat with

with

with

with

with

OR an ostrich

a koala

a shark

a tiger

a dog

Any other combination you would like to compare and contrast - say what is alike and what is different about each. 


\section{FREE CHOICE}

Write about anything that you like. Choose your own topic and share your thoughts. 
Week 3

Holidays

What is your favorite holiday? Why do you like that holiday particularly? How do you celebrate that holiday? What does that holiday mean? 
Imagine you are the lead singer in a music band!

What kind of music would you play? What is the name of your band? What is the name of your best song? Write describing how you set up your band, who are be the other members of your band, and where and when you play your music.

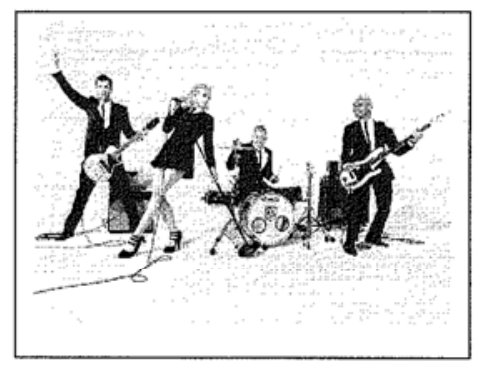




\section{FREE CHOICE}

Write about anything that you like. Choose your own topic and share your thoughts. 
Week 4

\section{FREE CHOICE}

Write about anything that you like. Choose your own topic and share your thoughts. 


\section{Week 5}

\section{Writing an Acrostic and a Report}

An acrostic is a poem form which uses the first letter(s) of your topic as the base.

Manatees are mammals

Amazon River, Florida and parts of Africa are habitats where manatees live

Nostrils are often the only visible part of a manatee

A submerged manatee can remain under water for up to 15 minutes

There are three species of manatee

Endangered species

Eats one tenth of its own weight in 24 hours.

Manatee information found at

http://animals.nationalgeographic.com/animals/mammals/manatee/

Think of a topic you would like to create an acrostic about, do some research to find some reliable information about your topic and write your acrostic.

Go to the following web site: http:/www.readwritethink.org/files/resources/interactives/acrostic/ Follow the directions and create your own acrostic, remember to print it out.

Once you have finished your acrostic poem you have the basic information you will need to write a report on your topic. You may need to do some more research before you can finish your report. You will almost certainly have to re-organize your information so your report makes sense.

Write a report on your topic. 


\section{PRESIDENT?}

Pick a president of the United States of America. Do some research about him.

Include his date of birth, where he was born, who his parents were and what they did, add some information about his family. Where did he go to school or college? What did he do before he became president? Was he married? Did he have any children? When did he become president? How long was he president for? What were his achievements while he was president? Is he dead, if so when did he die? 


\section{FREE CHOICE}

Write about anything that you like. Choose your own topic and share your thoughts. 


\section{Week 6}

\section{Bio-poem Poetry Page}

Write a bio-poem. Select a family member, an important person in the news or in history and follow the steps below.

Bio-poem poetry is a poem about someone that describes that person in 11 lines. The first line is the person's first name followed by a dash. The second line consists of four adjectives describing the person it's written about. On the third line, it states brother of, or sister of and then the name(s) of any siblings. Lover of followed by three different things that the person loves.

So on and so forth.

(First name)-

(Four adjectives)

(Brother of or Sister of)

Lover of (three different things that the person loves)

Who feels (three different feelings and when or where they are felt)

Who gives (three different things the person gives)

Who fears (three different fears the person has)

Who would like to see (three different things the person would like to see)

Who lives (a brief description of where the person lives)

-(last name) 
Pick a topic that is important to you. It can be about anything. Write about it so your reader can understand how you feel.

Your family. Your pets. An animal you like. Something that makes you mad. Something that makes you sad. Something that you think is funny. How you feel about something taking a bath, doing homework, taking a walk, earning an $\bar{A}$.

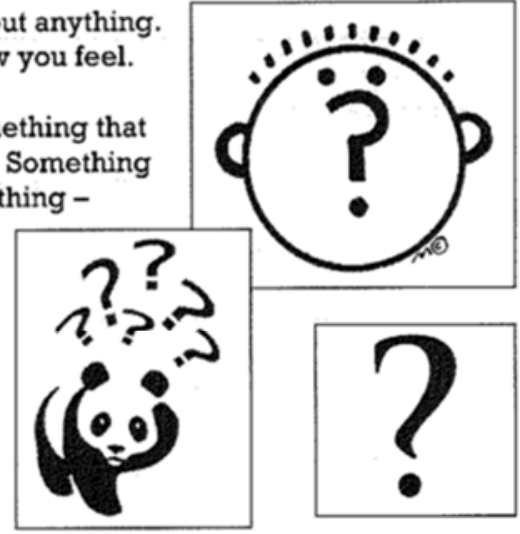




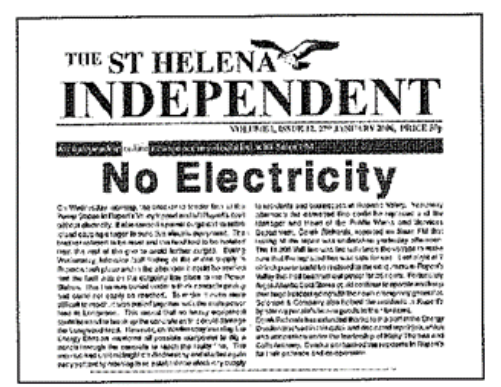

What if the electricity went off permanently? How would you do ordinary things? What would you do for fun?

Write how having no electricity could make your life better.

Describe how it could affect your life now. 


\section{FREE CHOICE}

Write about anything that you like. Choose your own topic and share your thoughts. 
Week 7

\section{Special Powers}

If you could have one special power, what would it be? How would you use it, for good or evil?

Some ideas for special powers: become invisible, read minds, run as fast as a cheetah, climb like a monkey, be telepathic, never need to eat, or invent your own. 


\section{FREE CHOICE}

Write about anything that you like. Choose your own topic and share your thoughts. 


\section{Week 8}

\section{My Birthday}

When is your birthday? How old will you be? How do you like to celebrate your birthday? What was your best birthday present ever? Who do you like to celebrate your birthday with? Describe the best party you could have to celebrate your birthday.

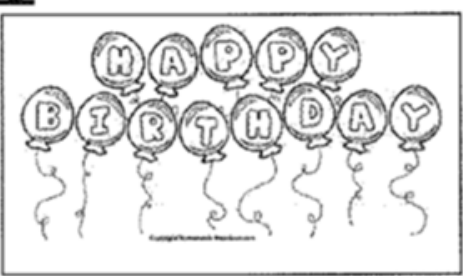




\section{No Phone}

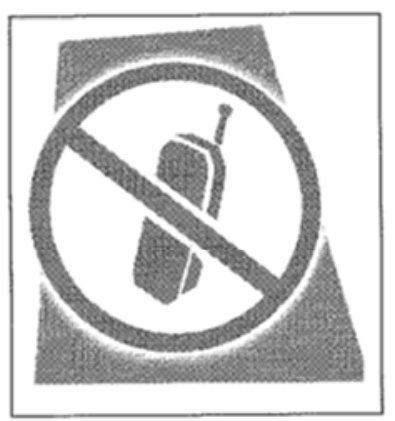

Imagine you lived before the phone had been invented. How would not having a phone change your life? How would you manage to communicate with other people? 


\section{Imagine you are the lead singer in a music band!}

What kind of music would you play? What is the name of your band? What is the name of your best song? Write to persuade your reader to attend your first concert.

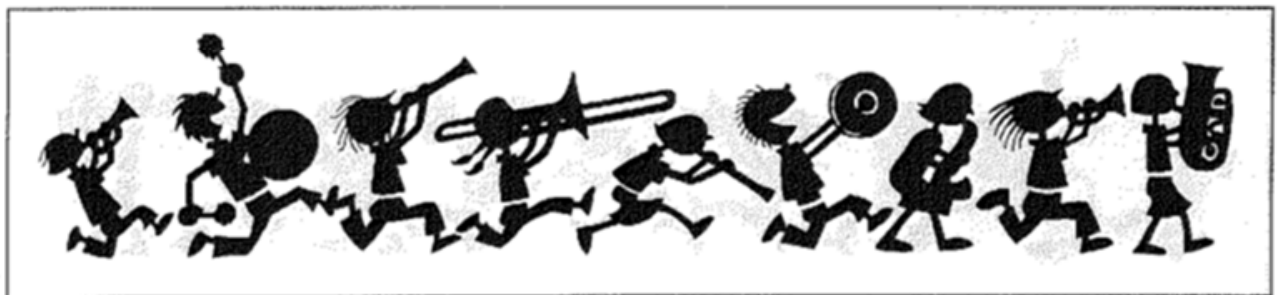




\section{FREE CHOICE}

Write about anything that you like. Choose your own topic and share your thoughts. 
APPENDIX K

PowerPoint Presentation for Independent Evaluators

Slide 1

\section{Creating Writers: 6 Traits,} Process, Workshop, and

Literature

- Vicki Spandel

PowerPoint by Helen Barnes

Slide 2

\section{What are the Six Traits?}

- Ideas

- Organization

- Voice

- Word Choice

- Sentence Fluency

- Conventions and Presentation 
Slide 3

\section{Look at}

- The Redwoods

- Mouse Alert

Slide 4

\section{The Redwoods}

- What are the strongest - and the weakest - traits, in your opinion?

- Is the writer male or female?

- How old is the writer?

- What writing assignment prompted this piece? 


\section{Mouse Alert}

-What are the strongest - and the weakest - traits, in your opinion?

- Is the writer male or female?

- How old is the writer?

- What writing assignment prompted this piece?

- Could you make a movie out of this?

Slide 6

\section{Ideas}

Definition: Ideas are the heart of the writer's message - the main thing the writer has to say - plus all the details (facts, explanations, anecdotes, observations) that clarify or expand the message. The strength of the writer's ideas depends on knowledge of the topic, observation skills (especially the ability to notice what others miss), and a knack for choosing details that make the message both clear and interesting. Hallmarks of good ideas include clarity, focus, thoroughness, insight, authenticity, and originality. 


\section{Ideas}

- Narrow, manageable topic

- Clear main message (point, thesis, storyline), easy to understand

- Rich, intriguing, vivid details expand the message

- Insight, makes the reader think

- Knowledge from experience, research

- Compelling, holds the readers attention, believable, authentic

From the ideas the other traits flow

Slide 8

\section{Evaluation}

Questions to ask yourself, as an evaluator:

- Is the topic obvious? Does the title fit? If it is untitled could the reader assign a title, easily?

- Does the writer pay attention to the little things, the details, has the writer looked closely at the topic? Is the reader left with questions?

- Do the details which are included add to and support the main idea? 
Slide 9

\section{Evaluation}

- Is the message focused and manageable? Is the reader interested; is the writer on track?

- Does the writer use his senses; so the reader can mentally see, hear, feel, smell, touch the topic?

- If it is an informational piece, does it teach you anything? Could you write a multiple choice test based upon it?

Slide 10

\section{Look at and evaluate for Ideas}

- Baseball

- Making Decisions 


\section{Conventions}

Definition: Conventions are a reflection of what is currently acceptable in print. Written conventions encompass spelling, punctuation, grammar, usage, capitalization, and paragraphing; anything about which a copyeditor might say, "This is acceptable - this is not." It also includes little nuances such as use of italics, dashes or ellipses - things that affect voice as well as meaning. Because conventions are forever changing we must rely on what is currently acceptable and effective.

Slide 12

\section{Conventions}

Conventions is not the easiest trait to assess because there is a lack of agreement on what is conventionally correct - (e.g. commas in a series, capitalization, numbers, beginning a sentence with a conjunction, etc.). It is important to remember the purpose behind conventions - helping readers interpret text.

Conventions create readability. Strong papers are those in which conventions enhance meaning and voice. 
Slide 13

\section{Evaluation}

Questions to ask yourself?

- Did I understand it easily? Was I having to stop to mentally edit, as I read through the paper?

- Was spelling an issue? Were simple words spelled incorrectly, or was it only sophisticated words?

- Was the piece over punctuated? Exclamation points everywhere! Or exclamation points repeated after a comment!!!!

Slide 14

\section{Evaluation}

Were capital letters used appropriately? (beginning of sentences, proper nouns, I [these are critical], shock words - Wow, Boom, etc. Using all caps in a word may be acceptable if it expresses strong feeling and enhances voice.)

- Were commas in place? (words in a series, after transition words or phrases, round a parenthetical element [a phrase which would not change the meaning of the sentence if it were removed]) 


\section{Evaluation}

- Were apostrophes used for possession and contractions? (Susan's dog, the dog's lead, dont, cant, etc.)

- Were quotation marks used appropriately?

- Was there noun/verb agreement? (I is going.., the doors was open, etc.)

- Did sentences make grammatical sense?

- Were paragraphs included, if appropriate?

- Was more sophisticated punctuation attempted? (; - () :)

Slide 16

\section{Look at and evaluate for Conventions}

- Baseball

- Making Decisions 


\section{Organization}

Definition: Good writing has an underlying structure. Avoid first, second, etc. this distracts from the message. We want to know that the writer has a clear direction and is guiding us through the discussion or story. Organization should be clear but flexible allowing for surprises. It is not formulaic and may be complex, especially in longer pieces.

Slide 18

\section{Organization}

- The arrangement of the ideas, the "framework" of the piece

- Enticing lead, hook pulls the reader in

- Clear design guides readers, enhances understanding, flow of the piece, logical sequencing

- Strong transitions tie the ideas together

- Good pacing - time spent where it counts

- Ending wraps up discussion 


\section{Evaluation}

\section{Questions:}

- Is there a good lead to entice the reader? Does the conclusion indicate the writer learned something and hopes you did too?

- Is the writing easy to follow? Does it flow from one point to the next with strong transitions?

- Does the design fit the message? (compare/contrast, description, problem/solution, etc.)

Slide 20

\section{Look at and evaluate for Organization}

- Baseball

- Making Decisions 


\section{Voice}

Definition: The imprint of the writer on the page. The writer is speaking to us. Voice is the connection between the writer and the reader. It is the human touch that makes readers tune in and believe what is said. Writing voices shift and change just as our speaking voices do, dependent upon the situation or circumstances. The writing needs to be defined by the unique voice of the writer.

Slide 22

\section{Voice}

Voice builds the bridge from writer to reader, it shows the personality, enthusiasm, and engagement of the writer

- Individual, distinctive

- A "read aloud" piece, it talks to you

- Passionate, energetic

- Speaks to readers

- Confident, self-assured

Writer is present on page 


\section{Evaluation}

Questions:

- Is the writing individual, distinctive? Does the writers' personality come across?

- Can I hear the writer speaking?

- Do I feel an emotional response to the paper? (anger, ahhh, oh dear, I'm sorry)

- Is the piece authentic?

- Does the writer know the topic well; is it personal experience?

Do I feel I "know" the writer?

Slide 24

\section{Look at and evaluate for Voice}

- Baseball

- Making Decisions 


\section{Word Choice}

Definition: Words, phrases or expressions writers use to create images, share ideas or explain concepts. Word choice demonstrates searching for the right word. Careful word choice creates clarity, ensuring understanding and making pictures in the reader's mind. Word choice is part of voice, voice without strong words is hard to achieve.

Slide 26

\section{Word Choice}

The bridge from message to voice

- Clear, aids the reader's understanding

- Original, memorable

- Concise, to the point

- Natural, unforced

- Filled with strong verbs

- Avoid modifier overload Paints word pictures 


\section{Word Choice}

Questions:

- Has the writer stretched to find the right word, even if he can't spell it?

- Is the writing concise - the right word in the right place - punchy?

- Do the words sound natural?

- Are there strong verbs? (Verbs are more effective than adjectives)

- Do want to quote the text?

- Is the phrasing original?

Slide 28

\section{Look at and evaluate for Word Choice}

- Baseball

- Making Decisions 


\section{Sentence Fluency}

Definition: Fluency makes the writing dance. Writing fluency is achieved by reading aloud. The writing is easy to read, it could be read aloud with little practice, expressively and with voice. Well placed fragments, use of alliteration, assonance, purposeful repetition are all marks of sentence fluency when used well. Fluency is genre specific. Readability is the key.

Slide 30

\section{Sentence Fluency}

- Easy to read

- Enhances voice

- Variety in length and structure

- Easy-on-the-ear rhythm, cadence, flow

- Natural dialogue, if present

- Fragments, used for "punch", flavor

- Repetition, only for emphasis 


\section{Evaluation}

Questions:

- Could I read this aloud with ease? Would it sound fluent when read aloud? Could I do it without practice? Is it rhythmic?

- Is there variety of length and structure present?

- Has the writer added variety by using questions, exclamations, monologues or dialogues

- Is there sentence to sentence flow? Do the sentences have purposeful beginnings?

Slide 32

\section{Look at and evaluate for the Sentence Fluency}

- Baseball

- Making Decisions 
Slide 33

\section{Practice Evaluations}

- A Strange Visitor

- Baseball

- Computing Batting Averages

- Going Veggie

- Japan

- Making Decisions

- Some Cartoons are Violent

- Zeena 


\section{APPENDIX L}

Writing Sample Prompt and Lined Paper

WRITERS' CLUB: THE EFFECT OF EXTRA WRITING ON FOURTH-GRADE, HISPANIC STUDENTS' WRITING AND THEIR ATTITUDE TOWARDS WRITING

WRITING SAMPLE

Student's Name

\section{MY FAMILY}

There are lots of different types of families. Some children live with their parents and brothers and sisters, some children live with their grandparents or uncles and aunts, and other children live with adults who are not related to them. Whatever sort of family we have those people are important to us. Write about your family.

Use the back of this page if you want to make notes before you begin writing. 


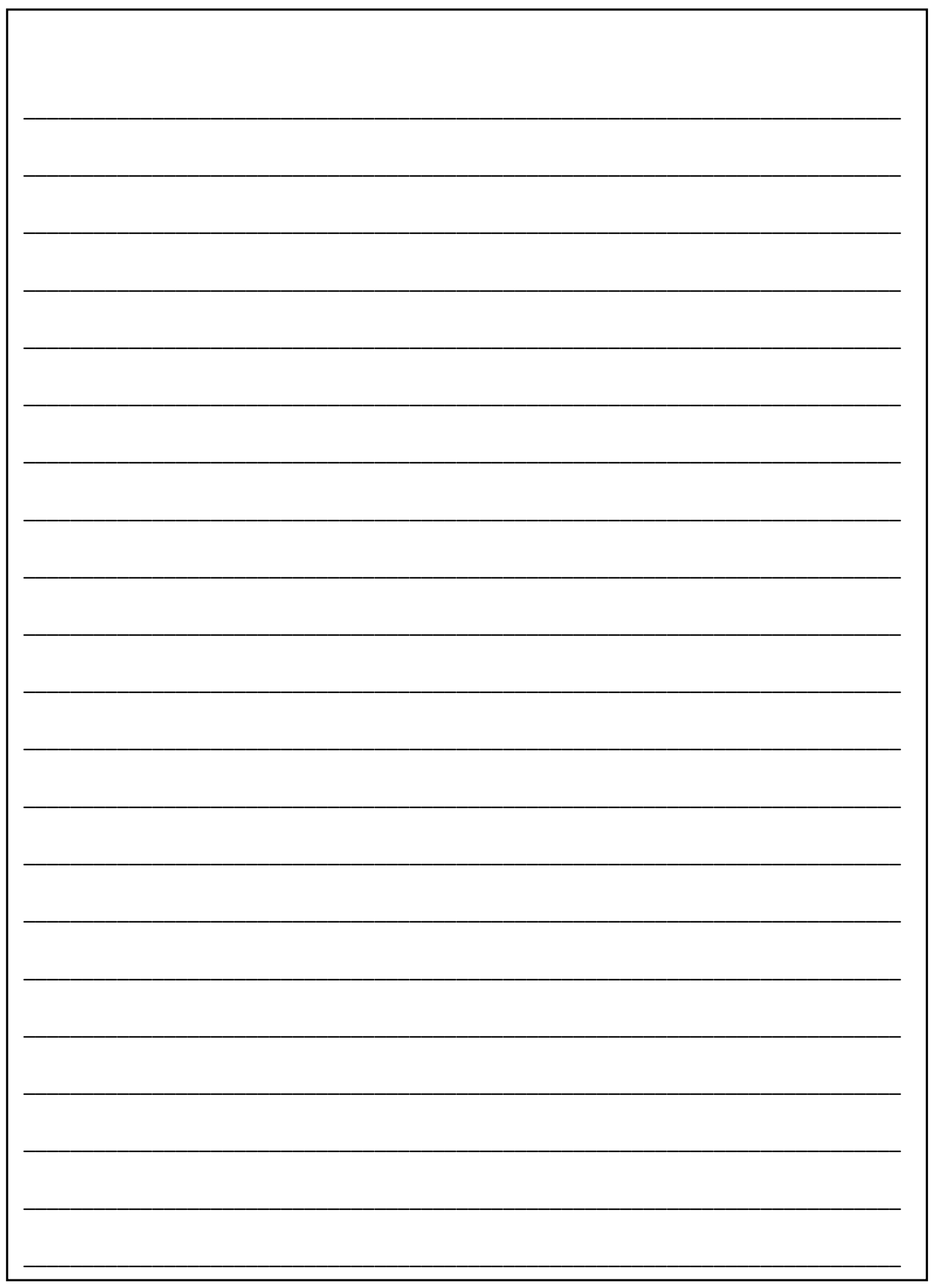




\title{
APPENDIX M
}

Administration of Writing Sample Pretest and Posttest Teacher Instructions

\section{WRITERS' CLUB: THE EFFECT OF EXTRA WRITING ON FOURTH-GRADE,} HISPANIC STUDENTS' WRITING AND THEIR ATTITUDE TOWARDS WRITING

\begin{abstract}
ADMINISTRATION OF THE PRETEST
Tell the students that they will be providing a writing sample that will not be for a grade. Distribute the materials, ensuring that all the students have a copy.

Ask the students to write their names on the line provided on the front page. Ask them to write their names only in this space.

Read the prompt aloud to the students. Tell them they may do any planning on the back of the cover sheet.
\end{abstract}

Allow the students 45 minutes to write.

Collect all the writing samples. They will be collected by the researcher for evaluation. 
WRITERS' CLUB: THE EFFECT OF EXTRA WRITING ON FOURTH-GRADE, HISPANIC STUDENTS' WRITING AND THEIR ATTITUDE TOWARDS WRITING

\section{ADMINISTRATION OF THE POSTTEST}

Tell the students that they will be providing a writing sample that will not be for a grade. Distribute the materials, ensuring that all the students have a copy.

Ask the students to write their names on the line provided on the front page. Ask them to write their names only in this space.

Read the prompt aloud to the students. Tell them they may do any planning on the back of the cover sheet.

Allow the students 45 minutes to write.

Collect all the writing samples. They will be collected by the researcher for evaluation. 


\section{APPENDIX N}

Enlarged "Garfield" Expressions with Explanation

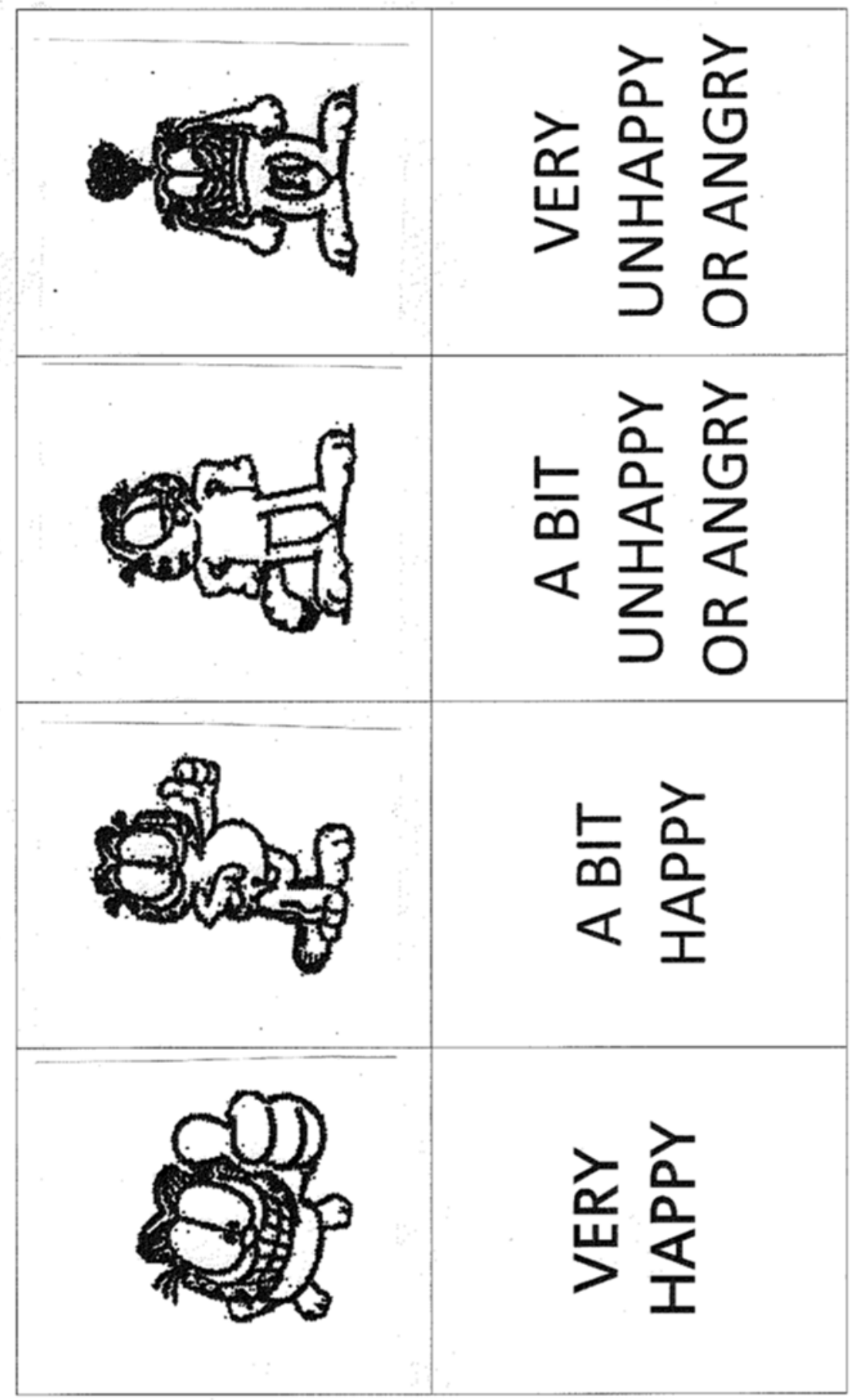


VITA

\title{
HELEN FELICITY ANGELA BARNES
}

\author{
Born, Birmingham, UK
}

1980

Associate of the Chartered Building Society Institute (Bachelors in Banking equivalent)

1992

American Montessori Society

Elementary Certification

2007

M.S. Reading Education

Florida International University

Miami, Florida

2013

Education Specialist

Florida International University

Miami, Florida

1974-1982 Banking Positions,

United Kingdom

1982-1985

Banking Positions

Miami, Florida

1990-2008

Classroom Teaching

Montessori classrooms

Miami, Florida

$2008-2010$

Adjunct Professor

Florida International University

Miami, Florida

2010

Graduate Assistant

Florida International University

Miami, Florida

2010-2015 Adjunct Professor

Florida International University

Miami, Florida 


\section{PUBLICATIONS AND PRESENTATIONS}

Barnes, H. \& Fine, J. (in process). The effect of teachers' writing - purpose and frequency and writing experience on their attitudes towards writing.

Barnes, H. (2014, July). The effect of attitude and experience with writing on teachers' engagement with writing - purpose and frequency. Paper presented at the annual meeting of the United Kingdom Literacy Association, Brighton, U.K.

Barnes, H. (2013, December). The effect of teachers' writing - purpose and frequency and writing experience on their attitudes towards writing. Paper presented at the annual meeting of the American Reading Forum, Sanibel Island, FL.

Barnes, H. \& Fine, J. (2012). Teachers' perception of parental engagement in their children's school-based writing development. American Reading Forum: Yearbook. Vol. 32

Barnes, H. (2012, February). Montessori teachers' perceptions of parents' engagement in children's school-based writing. Paper presented at the annual meeting of the Florida International University Graduate Student Scholarly Forum, Miami, FL.

Barnes, H. (2011, December). Teachers' perceptions of parents' engagement in children's writing development. Paper presented at the annual meeting of the American Reading Forum, Sanibel Island, FL. 